Florida International University

FIU Digital Commons

6-25-2013

\title{
Effect of the Supplemental Nutrition Assistance Program (SNAP) and Nutrition Education on Nutrition and Health Outcomes of HIV+ Individuals
}

Irene Hatsu

Florida International University, ihats001@fiu.edu

Follow this and additional works at: https://digitalcommons.fiu.edu/etd

Part of the International and Community Nutrition Commons

\section{Recommended Citation}

Hatsu, Irene, "Effect of the Supplemental Nutrition Assistance Program (SNAP) and Nutrition Education on Nutrition and Health Outcomes of HIV+ Individuals" (2013). FIU Electronic Theses and Dissertations. 924.

https://digitalcommons.fiu.edu/etd/924

This work is brought to you for free and open access by the University Graduate School at FIU Digital Commons. It has been accepted for inclusion in FIU Electronic Theses and Dissertations by an authorized administrator of FIU Digital Commons. For more information, please contact dcc@fiu.edu. 


\title{
FLORIDA INTERNATIONAL UNIVERSITY \\ Miami, Florida
}

\section{EFFECT OF THE SUPPLEMENTAL NUTRITION ASSISTANCE PROGRAM (SNAP) AND NUTRITION EDUCATION ON NUTRITION AND HEALTH OUTCOMES OF HIV+ INDIVIDUALS}

\author{
A dissertation submitted in partial fulfillment of \\ the requirements for the degree of \\ DOCTOR OF PHILOSOPHY \\ in \\ DIETETICS AND NUTRITION \\ by \\ Irene E. Hatsu
}


To: Dean Michele Ciccazzo

R.Stempel College of Public Health and Social Work

This dissertation, written by Irene E. Hatsu, and entitled Effect of the Supplemental Nutrition Assistance Program (SNAP) and Nutrition Education on Nutrition and Health Outcomes of HIV+ Individuals, having been approved in respect to style and intellectual content, is referred to you for judgment.

We have read this dissertation and recommend that it be approved.

Marianna Baum

Fatma Huffman

Barbara Thomlison

Paulette Johnson

Adriana Campa, Major Professor

Date of Defense: June 25, 2013

The dissertation of Irene E. Hatsu is approved.

Dean Michele Ciccazzo R.Stempel College of Public Health and Social Work

Dean Lakshmi N. Reddi University Graduate School

Florida International University, 2013 
(C) Copyright 2013 by Irene E. Hatsu

All rights reserved. 


\section{DEDICATION}

I dedicate this dissertation to God for His grace and provision throughout my life and for seeing me through my doctoral education.

I also dedicate this work to my family in Ghana and my "adopted" family in California, without whose encouragement and support I will not have made it this far. Thank you for being there, and for believing in me. 


\section{ACKNOWLEDGMENTS}

This dissertation would not have been completed without the excellent guidance of my committee members. I would like to express my deepest gratitude to my Major Professor Dr. Campa for being the model mentor. Her patience, encouragement and guidance during this period of doctoral studies and research were needed and tremendously appreciated. In addition, I extend my gratitude to Dr. Huffman for mentoring and supporting me throughout my years at Florida International University. She believed in me during times when I didn't believe in myself and constantly found ways to financially support me so I could focus on my research. Without her help, getting a doctoral degree would have remained a dream. Dr. Baum, your ideas and perspectives greatly shaped and enhanced my research, making it what it is right now. Thank you. Dr. Thomlison, thank you for always making time to read, gently critique and provide feedback for my work. I would also like to thank Dr. Johnson for making statistics and data analysis meaningful and an enjoyable process.

Dr. Dixon, you made the dissertation journey a pleasant one by opening your doors, giving me your insight, and praying. I am equally indebted to Shawn Williams, Shakira Barr, and the Baum/Campa Research Group. Without their valuable input, data collection for my research would have been very challenging. I would also like to send my love to all my friends and church family for their prayers and support.

Finally, I would like to acknowledge the University Graduate School for granting me the Data and Evidence Acquisition Fellowship to support me during the data collection process for my dissertation. 


\section{ABSTRACT OF THE DISSERTATION \\ EFFECT OF THE SUPPLEMENTAL NUTRITION ASSISTANCE PROGRAM (SNAP) AND NUTRITION EDUCATION ON NUTRITION AND HEALTH OUTCOMES OF HIV+ INDIVIDUALS}

by

Irene E. Hatsu

Florida International University, 2013

Miami, Florida

Professor Adriana Campa, Major Professor

Factors associated with and barriers to participation in Supplemental Nutrition Assistance Program (SNAP) and the effect participation has on food security, nutrition status, disease status and quality of life was investigated in a cross-sectional study including 175 HIV infected individuals. In addition, the effect of a targeted nutrition education on nutrition knowledge, readiness to dietary behavior change, nutrition status, disease status and quality of life was also investigated among a subset of the population $(\mathrm{N}=45)$ in a randomized clinical control trial.

SNAP participation rate was $70.3 \%$, similar to the State of Florida and national participation rates. SNAP participation was positively and independently associated with being born in the US $(P<0.001)$, having monthly income less than $\$ 1000(P=0.006)$, and receiving antiretroviral treatment $(P<0.001)$. Participation barriers include denial of participation by program, recent incarceration, living in a shelter where participation is not allowed and unawareness of eligibility status. In regression analyses, SNAP participation was not significantly associated with improved food security, nutrition 
status, disease status and health related quality of life (HRQOL). Over half (56\%) of the population experienced food insecurity and had inadequate intakes of half of the nutrients assessed. Illicit drug, alcohol and cigarette use were high in this population $(31 \%, 55 \%$ and $63 \%$ respectively), and affected food security, nutrients intake, disease status and HRQOL. The nutrition education intervention resulted in a trend towards improvements nutrition knowledge, self-efficacy, and readiness to change without impacting nutrition status, disease state and quality of life.

Food insecurity and other nutrition related issues, with implications for treatment, management and cost of HIV disease, continue to plague infected individuals living in poverty. More resources, including food and nutrition programs, specifically targeted towards this population are needed to address these issues. 


\section{TABLE OF CONTENTS}

CHAPTER

PAGE

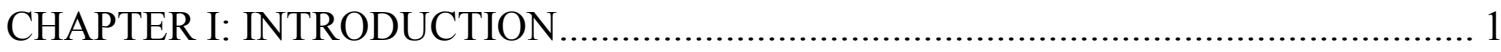

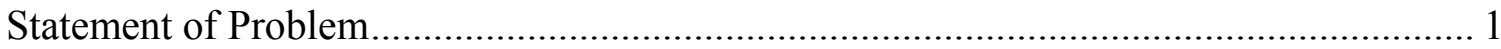

Specific Aims and Hypotheses ................................................................................. 4

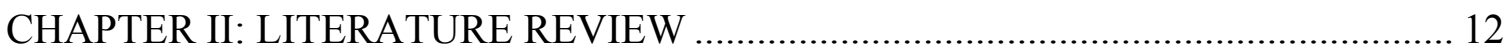

Epidemiology of HIV/AIDS in the US, Florida and Miami-Dade County ...................... 12

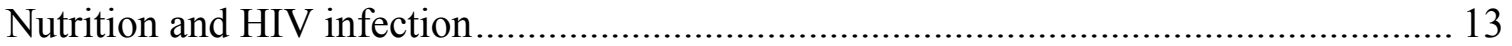

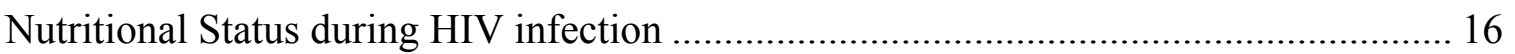

Food Insecurity among HIV Infected Persons................................................................. 20

The Food Stamp/Supplemental Nutrition Assistance Program .......................................... 25

Effects and Benefits of Food Stamp Program................................................................ 27

Barriers to Participation in the Supplemental Nutrition Assistance Program (SNAP).... 30

Food Assistance and Nutrition and Health Outcome in HIV infected............................... 32

Knowledge Attitude and Self-Efficacy in Nutrition Education ......................................... 34

Nutrition Education among Low Income and Food Assistance Users ............................. 35

Nutrition Education among HIV Infected Individuals.................................................... 37

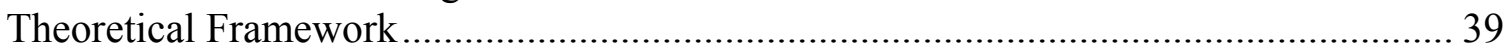

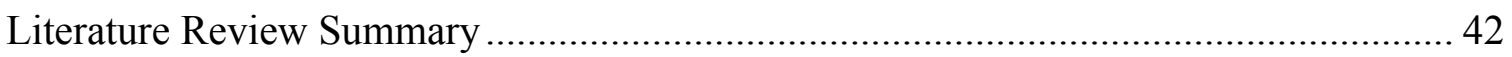

CHAPTER III: SUPPLEMENTAL NUTRITION ASSISTANCE PROGRAM (SNAP) AND THE HIV INFECTED POPULATION IN MIAMI: WHO PARTICIPATES, WHO DOESN'T AND WHY........................................................................................ 71

CHAPTER IV: ASSOCIATION OF SUPPLEMENTAL NUTRITION ASSISTANCE PROGRAM (SNAP), WITH FOOD SECURITY AND NUTRITIONAL STATUS OF

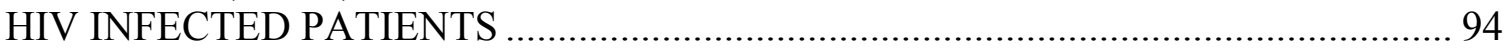

CHAPTER V: ASSOCIATION OF SUPPLEMENTAL NUTRITION ASSISTANCE PROGRAM (SNAP) WITH HEALTH RELATED QUALITY OF LIFE AND DISEASE STATE OF HIV INFECTED PATIENTS ............................................................. 128

CHAPTER VI: NUTRITION EDUCATION PROGRAM FOR LOW INCOME HIV

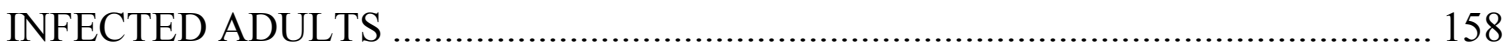

CHAPTER VII: SUMMARY AND CONCLUSIONS …………………………........ 185

CHAPTER VIII: STRENGTHS AND LIMITATIONS ................................................ 193

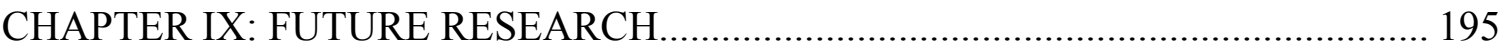




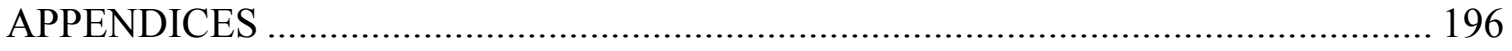

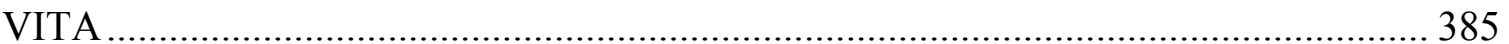




\section{LIST OF TABLES}

TABLE

PAGE

\section{CHAPTER II}

Table 1: Summary of nutrition education intervention strategy 41

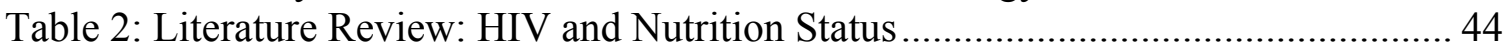

Table 3: Literature Review: HIV and Food Insecurity ................................................ 46

Table 4: Literature Review: HIV, Nutrition Programs and Impact on Health Outcomes 48

Table 5: Literature Review: Nutrition Education in HIV infected Individuals

\section{CHAPTER III}

Table 1: Demographic characteristics of HIV infected by SNAP participant status ........ 86

Table 2 Health related characteristics of HIV infected by SNAP participation status .... 87

Table 3: Food security status of HIV infected by SNAP participation status .................. 87

Table 4: Quality of Life (QOL) of HIV infected by SNAP participation status............... 88

Table 5: Pathological symptoms of HIV infected by SNAP participation status ............. 88

Table 6: Factors associated with SNAP participation among HIV infected adults ..........89

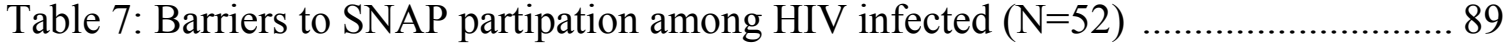

\section{CHAPTER IV}

Table 1: Demographic characteristics by SNAP participation status among HIV infected adults

Table 2: Lifestyle related characteristics by SNAP participation status among HIV infected adults

Table 3: Food security status by SNAP participation status among HIV infected adults

Table 4: Logistic regression of food security on SNAP participation status among HIV infected adults

Table 5: Logistic regression of food security on demographic and health characteristics among HIV infected adults

Table 6: Mean nutrient intake by SNAP participation status among HIV infected adults

Table 7: Percentages with nutrients intake below Estimated Average Requirements (EAR) by SNAP participation status among HIV infected adults

Table 8: Logistic regression of adequacy of nutrient intakes on SNAP participation status among HIV infected adults

Table 9: Mean values for body composition and biochemical indicators by SNAP participation statusamong HIV infected adults

Table 10: Multiple linear regression for body composition and biochemical indicators on

SNAP participation status among HIV infected adults.

\section{CHAPTER V}

Table 1: Sociodemographic characteristics by SNAP participation status 143

Table 2: Health and behavior related characteristics by SNAP participation status....... 144 
Table 3: Standard and T scores for HIV infected cohort in Miami compared to the general

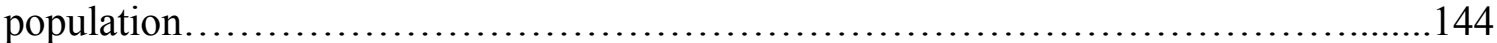

Table 4: T scores by SNAP participation status compared to the general population.... 145

Table 5: Immunologic and virologic parameters by SNAP participation status ............ 145

Table 6: Pearson's correlation of disease status parameters and quality of life domains with SNAP participation status 146

Table 7a: Regression of Physical Component Summary (PCS) on SNAP participation status 146

Table 7b: Regression of Mental Component Summary (MCS) on SNAP participation status

Table 7c: Regression of Physical Functioning Score (PF) on SNAP participation status

Table 7d: Regression of Role Physical Score (RP) on SNAP participation status ......... 148

Table 7e: Regression of Bodily Pain Score (BP) on SNAP participation status ............. 148

Table 7f: Regression of General Health Score (GH) on SNAP participation status ...... 149

Table 7g: Regression of Vitality Score (VT) on SNAP participation status .................. 149

Table 7h: Regression of Social Functioning Score (SF) on SNAP participation status. 150

Table 7i: Regression of Role Emotional Score (RE) on SNAP participation status ...... 150

Table 7j: Regression of Mental Health Score (MH) on SNAP participation status ....... 151

Table 8a: Regression of CD4 cell count on SNAP participation status........................... 151

Table 8b: Regression of viral load on SNAP participation status .................................. 152

CHAPTER VI

Table 1: Baseline sociodemographic characteristics by group ....................................... 175

Table 2: Health and behavior related characteristics by group....................................... 176

Table 3: Nutrition knowledge scores across the three assessment periods by group ..... 176 Table 4: Diet and shopping self-efficacy scores across the three assessment periods by

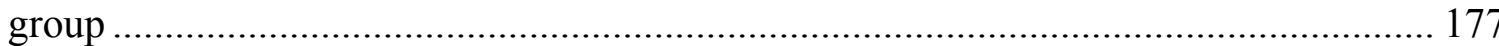

Table 5:Dietary stages of change across the three assessment periods by group........... 178

Table 6: Dietary intake across the three assessment periods by group........................... 179

Table 7: Nutrition status indicators across the three assessment periods by group ........ 179 Table 8: Disease State and Quality of Life indicators across the three assessment periods by group 


\section{CHAPTER I: INTRODUCTION}

\section{Statement of Problem}

Human Immunodeficiency Virus (HIV) infection, as other infections, creates metabolic conditions that may lead to reduced nutrient intake and absorption, as well as increased nutrient requirement and utilization. ${ }^{1-3}$ These metabolic alterations may hasten disease progression and reduce adherence and response to treatment, making adequate nutritional status at the onset and during the course of the disease critical for individuals infected with HIV. ${ }^{2,4}$

In addition to the health impact of the disease, low income individuals infected with HIV experience food insecurity (defined as availability of nutritionally adequate and uncontaminated foods) which could also affect the natural course of the disease progression and its management. ${ }^{5-8}$ The extent of reported food insecurity among households of individuals infected with HIV is significantly higher than that reported in the general public. ${ }^{5-8}$ Interventions of food assistance for such individuals, especially in resource-limited settings, successfully reversed food insecurity conditions, and improved nutrition and disease status. ${ }^{9-12}$ In the United States, the Food Stamp Program (FSP), currently known as the Supplemental Nutrition Assistance Program (SNAP) is the largest of the food assistance programs for low income households and individuals. The aim of the program is "to alleviate hunger and malnutrition ... by increasing food purchasing power for all eligible households who apply for participation" as stated in the Food Stamp Act, amended in 2008 (P.L. 108-269). ${ }^{13}$ Among some low income populations, several studies have demonstrated nutrition and health benefits from participation in the SNAP program, ${ }^{14-16}$ although these results were not consistent for all studies. ${ }^{17,18}$ Other 
studies have shown the benefit of nutrition education programs in improving nutrient

intake through increases in nutrition knowledge and self-efficacy. ${ }^{19,20}$ In this study, we proposed that the provision of food assistance would alleviate food insecurity, improve nutrient intakes and affect HIV disease management for low income people living with the infection. Furthermore, we proposed that nutrition education will also improve the nutrition and health parameters listed above.

There is lack of information in the literature about the utilization and barriers to utilization of the supplemental nutrition assistance program by low income HIV infected adults, and the benefits of this program to this population at high nutritional risk. As such, the study's first aim was to characterize factors associated with, as well as barriers to program participation, among low income HIV infected SNAP participants and eligible non-participants. Another aim was to assess the association of the supplemental nutrition assistance program with nutritional status, food insecurity, disease stage, and quality of life of low income HIV infected adults. Thirdly, it assessed the effectiveness of a nutrition education intervention to increase nutrition knowledge, readiness for dietary behavior change, and self-efficacy of HIV infected adults in making choices to eat healthy. Additionally, it also determined the effectiveness of the nutritional education intervention to increase nutrient intake and improve nutritional status, disease stage and health-related quality of life.

\section{Significance of Study}

The study was particularly relevant for several reasons. First, it aimed to determine the effect that SNAP has on food security, nutritional, and health status of HIV infected adults. In general, low income individuals are a disempowered population with 
regards to adequate nutrition. This study helped to identify barriers to SNAP participation among HIV infected adults who are eligible but not participating in this program. The information obtained is useful for program administrators in identifying and targeting those in need of outreach efforts, thus maximizing SNAP participation, and improving nutritional services and their benefits to people living with HIV.

These studies also aimed at empowering and engaging low income HIV infected individuals to improve dietary practices with the ultimate goal of achieving adequate nutritional status to maintain health. Improving nutrition may translate into better HIV management, ${ }^{2}$ which could lead to reduction in the cost of healthcare for the individual and the community. By providing nutrition education to this vulnerable population in this study, we not only contributed to broadening information about types of effective interventions for managing HIV, but also determined the degree to which such interventions can enhance the health and quality of life of HIV infected adults. Though similar studies investigating the effects of SNAP on nutrition and health have been conducted in several other non-HIV populations, ${ }^{14-16}$ to the best of our knowledge, this is the first such study being conducted in the HIV infected population. The information obtained by this study will contribute practical and valuable information for policy decision making to invest limited resources in areas and conditions where they will maximize outcomes. The study utilized both an observational cross-sectional study design and a randomized controlled trial. The results are divided into four chapters, each responding to individualized specific aims and hypotheses. 


\section{Specific Aims and Hypotheses}

\section{A. Observational Cross-Sectional Study}

\section{CHAPTER III: SUPPLEMENTAL NUTRITION ASSISTANCE PROGRAM}

(SNAP) AND THE HIV INFECTED POPULATION IN MIAMI: WHO

\section{PARTICIPATES, WHO DOESN'T AND WHY.}

Specific Aim 1: To identify and characterize factors associated with SNAP participation among HIV infected participants and HIV infected eligible non-participants respectively. Hypothesis 1: Factors associated with participation will differ significantly among HIV infected SNAP participants and HIV infected eligible non-participants.

Specific Aim 2: To identify barriers to SNAP participation among HIV infected eligible non-participants.

Rationale: The barriers to access and utilization of SNAP are not well understood in this cohort due to the marginalization. This low income HIV infected population is mainly comprised of minorities living in poverty, largely plagued by substance abuse and criminalization.

\section{CHAPTER IV: ASSOCIATION OF SUPPLEMENTAL NUTRITION}

\section{ASSISTANCE PROGRAM (SNAP), WITH FOOD SECURITY AND}

NUTRITIONAL STATUS OF HIV INFECTED ADULTS

Specific Aim 1: To determine the association between SNAP participation and food security among HIV infected individuals.

Hypothesis 1: SNAP participation will be significantly and directly associated with food security (as measured by the 6-item food security survey module) in HIV infected adults. 
Specific Aim 2: To determine the association between SNAP participation and nutritional status of HIV infected individuals.

Hypothesis 2: SNAP participation will be significantly and directly associated with nutritional status (as measured by nutrient intake and adequacy of intake, BMI, hemoglobin, hematocrit and albumin) in HIV infected adults.

\section{CHAPTER V: ASSOCIATION OF SUPPLEMENTAL NUTRITION}

\section{ASSISTANCE PROGRAM (SNAP), WITH HEALTH RELATED QUALITY OF LIFE AND DISEASE STATE OF HIV INFECTED ADULTS}

Specific Aim 1: To determine the association between SNAP participation and disease stage of HIV infected individuals.

Hypothesis 1: SNAP participation will be significantly and inversely associated with disease stage (as measured by CD4 and viral load) in HIV infected adults.

Specific Aim 2: To determine the association between SNAP participation and health related quality of life of HIV infected individuals.

Hypothesis 2: SNAP participation will be significantly and directly associated with health-related quality of life (as measured by the SF-36 survey ${ }^{21}$ and Spitzer Quality of life index ${ }^{22}$ ) in HIV infected adults. 


\section{B. Randomized Trial of Nutritional Intervention \\ CHAPTER VI: NUTRITION EDUCATION PROGRAM FOR LOW INCOME HIV INFECTED ADULTS}

Specific Aim 1: Determine the effect of nutrition education on nutrition knowledge of HIV+ adults.

Hypothesis 1a: Nutrition education will significantly increase nutrition knowledge (as measured by a general nutrition knowledge questionnaire for adults) ${ }^{23}$ compared to baseline, among low income HIV infected adults in an intervention group.

Hypothesis 1b: Nutrition education will significantly increase nutrition knowledge in the intervention group compared to the control group of low income HIV infected adults.

Specific Aim 2: Determine the effect of nutrition education on readiness to dietary behavior change (using the stage of change continuum) among HIV infected adults.

Hypothesis 2a: Nutrition education will lead to significant movement along the stage of change continuum (as measured by a validated stage of change questionnaire) ${ }^{24}$ compared to baseline among low income HIV infected adults in an intervention group. Hypothesis 2b: Nutrition education will lead to significant movement along the stage of change continuum in the intervention group compared to the control group of low income HIV infected adults.

Specific Aim 3: Determine the effect of nutrition education on self-efficacy in HIV infected adults.

Hypothesis 3a: Nutrition education will significantly increase self-efficacy (as measured by a validated self-efficacy questionnaire ${ }^{25}$ compared to baseline among low income HIV infected adults in an intervention group. 
Hypothesis 3b: Nutrition education will significantly increase self-efficacy in the intervention group, compared to the control group, of low income HIV infected adults. Specific Aim 4: Determine the effect of nutrition education on nutritional status of HIV infected adults.

Hypothesis 4a: Nutrition education will significantly improve nutritional status (as measured by nutrient intake, BMI, hemoglobin, hematocrit and albumin) compared to baseline among low income HIV infected adults in an intervention group.

Hypothesis 4b: Nutrition education will significantly improve nutritional status in the intervention group, compared to the control group, of low income HIV infected adults. Specific Aim 5: Determine the effect of nutrition education on disease stage of HIV infected adults.

Hypothesis 5a: Recipients of nutrition education will have significantly less advanced disease stage (as measured by CD4 and viral load), compared to baseline, among low income HIV infected adults.

Hypothesis 5b: The intervention group receiving nutrition education will have significantly less advanced disease stage, compared to the control group, of low income HIV infected adults.

Specific Aim 6: Determine the effect of nutrition education on quality of life of HIV infected adults.

Hypothesis 6a: Nutrition education will significantly increase quality of life (as measured by the SF-36 survey ${ }^{21}$ and Spitzer Quality of life index ${ }^{22}$ ) compared to baseline among low income HIV infected adults in an intervention group. 
Hypothesis 6b: Nutrition education will significantly increase quality of life in the intervention group, compared to the control group, of low income HIV infected adults. 


\section{References}

1. Katona P, Katona-Apte J. The Interaction between Nutrition and Infection. Clin Infect Dis. 2008;46(10):1582-1588.

2. Piwoz E, Preble E. HIV / AIDS and nutrition: a review of the literature and recommendations for nutritional care and support in sub-Saharan Africa Washington, DC: Academy for Educational Development [AED], Support for Analysis and Research in Africa Project [SARA]. 2000.

3. McCorkindale C, Dybevik K, Coulston AM, Sucher KP. Nutritional status of HIV-infected patients during the early disease stages. $J$ Am Diet Assoc. 1990;90(9):1236-1241.

4. Semba RD, Tang AM. Micronutrients and the pathogenesis of human immunodeficiency virus infection. Bri J Nutr. 1999;81(03):181-189.

5. Campa A, Zhifang Y, Lai S, et al. HIV-Related Wasting in HIV-Infected Drug Users in the Era of Highly Active Antiretroviral Therapy. Clin Infect Dis. 2005;41(8):1179-1185.

6. Vogenthaler NS, Hadley C, Lewis SJ, Rodriguez AE, Metsch LR, Del Rio C. Food insufficiency among HIV-infected crack-cocaine users in Atlanta and Miami. Public Health Nutr. 2010;15:1-7.

7. Weiser S, Frongillo E, Ragland K, Hogg R, Riley E, Bangsberg D. Food Insecurity is Associated with Incomplete HIV RNA Suppression Among Homeless and Marginally Housed HIV-infected Individuals in San Francisco. $J$ Gen Intern Med. 2009;24(1):14-20.

8. Weiser SD, Tsai AC, Gupta R, et al. Food insecurity is associated with morbidity and patterns of healthcare utilization among HIV-infected individuals in a resource-poor setting. AIDS. 2012;26(1):67-75.

9. Cantrell RA, Sinkala M, Megazinni K, et al. A Pilot Study of Food Supplementation to Improve Adherence to Antiretroviral Therapy Among FoodInsecure Adults in Lusaka, Zambia. J Acquir Immune Defic Syndr. 2008;49(2):190-195. 
10. Koethe JR, Chi BH, Megazzini KM, Heimburger DC, Stringer JS. Macronutrient supplementation for malnourished HIV-infected adults: a review of the evidence in resource-adequate and resource-constrained settings. Clin Infect Dis. 2009;49(5):787-798.

11. Ndekha MJ, Oosterhout JJGv, Zijlstra EE, Manary M, Saloojee H, Manary MJ. Supplementary feeding with either ready-to-use fortified spread or corn-soy blend in wasted adults starting antiretroviral therapy in Malawi: randomised, investigator blinded, controlled trial. BMJ. 2009;338:b1867.

12. Rawat $\mathrm{R}$, Kadiyala $\mathrm{S}, \mathrm{McNamara} \mathrm{PE}$. The impact of food assistance on weight gain and disease progression among HIV-infected individuals accessing AIDS care and treatment services in Uganda. BMC Public Health. 2010;10:316.

13. U.S.C. FOOD AND NUTRITION ACT OF 2008.

14. Allen JE, Gadson KE. Nutrient Consumption Patterns of Low-Income Households: USDA, Economic Research Service. 1983.

15. Devaney B, Moffitt R. Dietary Effects of the Food Stamp Program. Am J Agric Econ. 1991;73(1):202-211.

16. Hama MY, Chern WS. Food Expenditure and Nutrient Availability in Elderly Households. J Consum Affair. 1988;22(1):3-9.

17. Beebout H, Cavin E, Devaney B, . Evaluation of the Nutrition Assistance Program in Puerto Rico: Volume II, Effects on Food Expenditures and Diet Quality. Washington, DC: Mathematica Policy Research, Inc. 1985.

18. Fraker TM, Martini AP, Ohls JC. The Evaluation of the Alabama Food Stamp Cash-out Demonstration: Volume 1, Recipient Impacts. USDA, Food and Nutrition Service. 1992.

19. Cason KL, Cox RH, Wenrich TR, Poole KP, Burney JL. Food Stamp and NonFood Stamp Program Participants Show Similarly Positive Change With Nutrition Education. Top Clin Nutr. 2004;19(2):136-147. 
20. Joy AB, Doisy C. Food Stamp Nutrition Education Program: Assisting Food Stamp Recipients to Become Self-sufficient. J Nutr Edu. 1996;28(2):123-126.

21. Ware JE, Snow KK, Kosinski M, Gandek B. SF-36 health survey: manual and interpretation guide. The Health Institute, New England Medical Center. 1993.

22. Spitzer WO, Dobson AJ, Hall J, et al. Measuring the quality of life of cancer patients: a concise QL-index for use by physicians. J Chronic Dis. 1981;34(12):585-597.

23. Pawlak R, Colby S. Benefits, barriers, self-efficacy and knowledge regarding healthy foods; perception of African Americans living in eastern North Carolina. Nutr Res Pract. 2009;3(1):56-63.

24. Robinson AH, Norman GJ, Sallis JF, Calfas KJ, Rock CL, Patrick K. Validating stage of change measures for physical activity and dietary behaviors for overweight women. Int J Obes. 2008;32(7):1137-1144.

25. Norman GJ, Carlson JA, Sallis JF, Wagner N, Calfas KJ, Patrick K. Reliability and validity of brief psychosocial measures related to dietary behaviors. Int $J$ Behav Nutr Phys Act. 2010;7:56. 


\section{CHAPTER II: LITERATURE REVIEW}

\section{Epidemiology of HIV/AIDS in the US, Florida and Miami-Dade County}

The HIV epidemic continues to be a public health issue in the United states with an estimated 1.2 million people living with the HIV infection. ${ }^{1}$ Although the incidence of the disease has been considered stable in recent years, an estimated 47,129 new cases were diagnosed in 2010 in 46 states. ${ }^{1}$ It is reported that approximately $21 \%$ of individuals infected with HIV are not aware of their status ${ }^{2}$ and hence are major contributors to new infections. ${ }^{3}$ According to the Center for Disease Control and Prevention (CDC), men who have sex with men (MSM) contributed $61 \%$ of new HIV diagnosis in 2009 , although they account for only $2 \%$ of the US population. ${ }^{1}$ Other transmission routes were heterosexual contact (27\%) and injection drug use (9\%). ${ }^{1}$ Among the various ethnic/racial groups, HIV infection continues to burden Blacks/African Americans more than any other group, accounting for $45 \%$ of new diagnoses in 2010 compared to $29 \%$ in Whites and 22\% in Hispanics/Latinos. ${ }^{1}$

The State of Florida has one of the highest number of HIV cases in the United States. ${ }^{4}$ In 2010, it ranked the highest in the number of HIV cases diagnosed in the country, (ahead of California and New York) and third in the number of cases diagnosed with AIDS. ${ }^{4}$ The state reported 5,251 new HIV infections and 3,658 diagnosed AIDS cases in 2010, making the incidence rate of both HIV (27.7 per 100,000) and AIDS (18.4 per 100,000) higher than national averages. ${ }^{4,5}$ In 2011, HIV and AIDS were reported in

all Florida counties except three. ${ }^{4}$ Most cases were from the state's most populous counties, with Miami-Dade ranking first in both HIV and AIDS reported cases. ${ }^{4}$ MiamiDade and Broward counties contributed $39 \%$ of statewide AIDS cases, and by adding the 
cases in Orange County, contributed $50 \%$ of the HIV cases in Florida. ${ }^{4}$ Males account for $76 \%$ and $68 \%$ of Florida's HIV infection and AIDS cases respectively. Similar to nationwide trends, Blacks are over-represented in the epidemic making up 55\% of AIDS cases and $45 \%$ of HIV infection cases, higher than any other ethnic group, even though they account for only $15 \%$ of Florida's population. ${ }^{4}$ The main forms of sexual transmission for HIV in Florida in 2008 were through MSM (43.8\%) and heterosexual contact (30.7\%). ${ }^{6}$ In 2011, there were approximately 25,711 persons living with HIV in Miami-Dade County. ${ }^{7}$ According to the $\mathrm{CDC}$, the county ranked third in the country in 2010 among metropolitan statistical areas in number of AIDS diagnosis. Approximately 1,400 HIV cases and 736 AIDS cases were reported in the county for 2011, with Blacks representing $41 \%$ and $52 \%$ respectively, while Hispanics accounted for $44 \%$ and $39 \%$ respectively. ${ }^{7}$ Cumulatively, however, Blacks represent the highest HIV and AIDS rates in the county $(45 \%$ and $51 \%) .{ }^{7}$ Miami-Dade County also has the third highest disparity of income distribution among large metropolitan areas in the nation. Sixteen percent of the residents of Miami-Dade County live below the federal poverty level. ${ }^{8}$ With high incidence and prevalence rates of HIV/AIDS, and widespread poverty, Miami is an excellent site to study the relationship between HIV infection, participation in nutrition assistance programs and other social and health parameters.

\section{Nutrition and HIV infection}

Infections in general create an environment leading to reduction in nutrient intake and absorption, as well as an increase in the utilization and requirement for nutrients. ${ }^{9,10}$ HIV infection is associated with the destruction of the immune system. As a result, 
maintaining adequate nutritional status in HIV infected individuals is critical. The disease, in combination with underlying or consequent malnutrition, creates a vicious cycle that aggravates disease progression and affects chances of survival. ${ }^{11}$ Poor nutritional status may accelerate disease progression and lead to poor outcomes. On the other hand, HIV infection also impairs nutrient intake, digestion, absorption and utilization, leading to weight loss, nutrient deficiencies, compromised immune function and competence, as well as susceptibility to infections. ${ }^{10,11}$

In people living with HIV, clinical symptoms and treatment side effects such as loss of appetite, nausea and vomiting may lead to reduction in food and nutrient intake. ${ }^{12-}$ ${ }^{14}$ This contributes to weight loss and nutrient deficiency even in asymptomatic patients. ${ }^{12,15}$ Weight loss has been persistent among the HIV infected even in the era of antiretroviral therapy (ART). ${ }^{15}$ In addition to inadequate intake, diarrhea and malabsorption of macronutrients and micronutrients are also common during HIV infection. These conditions are exacerbated by infections from pathogens like Crystosporidia and Cytomegalovirus. When fat malabsorption is present, it may cause decreased bioavailability or deficiency of fat-soluble vitamins. ${ }^{11}$ Even among asymptomatic patients, HIV infection can lead to intestinal defects like permeability and epithelial damage. ${ }^{11,16,17}$ The infection can also alter the body's ability to metabolize and store nutrients such as carbohydrates, ${ }^{12}$ proteins and fats by altering the effect of enzymes and hormones needed for their metabolism. ${ }^{10} \mathrm{HIV}$ infection may impair the production of enzymes and transport proteins in the gastrointestinal track that are needed for nutrient digestion and absorption. Among the essential hormones needed for nutrient utilization and metabolic reactions are insulin, glucagon, cortisol and epinephrine. ${ }^{10}$ 
Poor nutritional status impairs immune function either directly or indirectly. Directly, nutritional deficiency can interfere with the primary activity of the lymphoid system such as during immune cell triggering, interaction and differentiation. Indirectly, it can affect other metabolic and cellular processes needed for immune regulation. ${ }^{18}$ Several micronutrients are necessary for proper immune function. Vitamin A is important for the growth and function of $\mathrm{T}$ and $\mathrm{B}$ cells, antibody responses, as well as for the maintenance of the epithelial integrity of the respiratory and gastrointestinal tract. ${ }^{11}$ Vitamin $\mathrm{E}$ is also essential for the function of T, B, and phagocytic cells. ${ }^{19}$ It also acts as an antioxidant protecting vitamin $\mathrm{A}$ and fats from oxidation. ${ }^{10}$ Zinc and selenium are also important nutrients for the immune system, acting as antioxidants, with involvement in the development of cell mediated and non-specific immunity as well as vitamin A transport. ${ }^{10}$ Several other vitamins and minerals also play a role in immune function; either at the physical barrier (skin/mucosal) level, cellular immunity level, or antibody production level. ${ }^{20}$ Vitamin $\mathrm{B}_{6}, \mathrm{~B}_{12}, \mathrm{C}, \mathrm{D}$, folic acid, iron and copper, all work to enhance the protective activities of immune cells. With the exception of vitamin $\mathrm{C}$ and iron, the rest of the nutrients work to support antibody production. ${ }^{20}$ Nutritional deficiency during HIV infection could result in increased levels of pro-oxidants, leading to oxidative stress, which may hasten HIV replication through nuclear factor $\kappa \mathrm{B}(\mathrm{NF}-\kappa \mathrm{B})$, a transcriptional promoter of proteins involved in HIV transcription. ${ }^{11}$ It can also result in immunosuppression which may affect viral expression and replication and ultimately disease progression and death. Factors that could contribute to poor nutrition include inadequate nutrient intake and absorption, poor appetite, metabolic problems, chronic infection and limited food availability among others. ${ }^{10}$ 
HIV infected individuals are more susceptible to infections because of compromised immunity. Chronic HIV infection also increases the nutritional requirements of those infected above those who are uninfected. ${ }^{11,21,22}$ Antiretroviral therapy (ART) medications can also affect energy expenditure, contributing to higher caloric needs. ${ }^{22} \mathrm{HIV}$ infected individuals, who are asymptomatic, require on average $10 \%$ more energy intake than what is recommended for non-infected healthy individuals, for the same age and gender. ${ }^{21}$ This requirement increases to $20 \%-30 \%$ during the symptomatic phase. Increased energy requirement, among other nutrient needs, makes optimal nutrition critical for managing the HIV disease. ${ }^{23}$

\section{Nutritional Status during HIV infection}

Nutritional status defined by the Mosby's Medical dictionary ( $8^{\text {th }}$ edition) as the "extent to which nutrients are available to meet metabolic needs", ${ }^{24}$ is a good predictor of morbidity and mortality in the course of HIV infection. ${ }^{25,26}$ There are several indicators used in measuring nutritional status such as anthropometric measures (weight, height, body mass index [BMI], and body composition), biochemical measures (such as serum levels of nutrients), clinical measures (such as hemoglobin, hematocrit and serum albumin), and dietary intake of nutrients. The impact that an infection has on nutritional status is dependent on the baseline nutritional status, as well as the nature and level of severity of the infection. ${ }^{27}$ During HIV infection, higher mortality rates are predicted by poor nutritional status, even when treatment is initiated. ${ }^{28,29}$ Again when compared to non-infected individuals, HIV infected patients have lower serum concentration of nutrients and were more susceptible to nutritional deficiencies. ${ }^{30-33}$ 
Early HIV studies reported a severe impact of the disease on nutritional status before the era of antiretroviral therapy (ART). Malnutrition, often associated with low serum levels of micronutrients was common regardless of the socio-economic status of the population infected, and serum nutrient deficiencies were associated with disease progression. ${ }^{11,32,34}$ Review articles that examined the prevalence and impact of micronutrient deficiency in HIV patients in the pre-ART era, reported deficiencies in vitamin $A, C, E, B_{12}$, zinc and selenium. ${ }^{11,35,36}$ Vitamin $B_{6}$, and D deficiencies were also reported in HIV patients prior to ART use. ${ }^{32,37}$ Since the advent of ART use, morbidity and mortality in HIV infected individuals has declined, however, poor nutritional status is still being reported among some populations. ${ }^{29,38}$ Studies conducted in developed countries among HIV patients receiving ART report conflicting results on micronutrient status, even when supplementation was sometimes provided. ${ }^{39-46}$ Some studies found significant differences in serum concentrations of $\alpha$ - tocopherol, $\alpha$ - and $\beta$ - carotene, vitamin $\mathrm{B}_{12}$ and folate between those receiving ART and controls. ${ }^{41,43,46}$ Other crosssectional and longitudinal studies found no differences in vitamins $\mathrm{A}$ and $\mathrm{E},{ }^{42,43} \mathrm{~B}_{6}$ and folate, ${ }^{40}$ selenium, zinc, iron and copper between those receiving ART and controls. ${ }^{39,42}$ One study found those receiving ART to have lower plasma concentration of vitamin A compared to controls. ${ }^{44}$ A recent study reported $77 \%$ of HIV infected study participants to be malnourished. It is unclear, however, whether these individuals were receiving ART treatment or not. ${ }^{47}$ Most studies investigating micronutrient status in HIV infected individuals used serum or plasma measures. ${ }^{11,34}$ These measures have some limitation because (1) they may not be sensitive indicators of micronutrient status ${ }^{11}$ and (2) most of these micronutrients are acute-phase reactants and will vary in body compartments during 
an infection. ${ }^{34} \mathrm{HIV}$ infected individuals are susceptible to opportunistic infections; hence, unless other infections were accounted and controlled for in these studies, the results might have limitations. A consistent body of literature exists that supports a strong relationship between HIV infection and poor nutritional status. ${ }^{34}$ Most evidence supports that this relationship is a reciprocal, vicious and deadly cycle, in which malnutrition and HIV infection advance each other. ${ }^{10,11}$

Weight loss is another indicator of nutritional status and it has been linked to adverse outcomes during HIV infection. ${ }^{48}$ Although ART treatment improved survival rates, weight loss (even as low as 5\%) continued to be an independent predictor of morbidity and mortality in this population up until the mid-2000, when reports of increased overweight/obesity started to emerge among the population. ${ }^{15,49}$ In 2000 , the Nutrition for Healthy Living (NFHL) found 13\% of its 633 participants to have wasting at the time of enrollment to the study. ${ }^{38}$ At follow-up visits, $18 \%$ and $21 \%$ had respectively lost $>10 \%$ and $>5 \%$ of their body weight, with $8 \%$ having a BMI of less than $20 .^{38}$ The weight loss observed in this group occurred in patients successfully treated with ART, in those in whom ART treatment failed and also in ART-naïve patients. ${ }^{38}$ According to another NFHL study, the weight loss prevalence observed in this group is comparable to those observed in the 1990 's. ${ }^{50}$ The weight loss was also found to be a combination of fat and lean body mass loss, depending on initial body weight and etiology of weight loss, ${ }^{51}$ i.e., whether it is was a result of abnormalities in intake or altered metabolism. ${ }^{15}$

The NFHL also reported overweight in its cohort to be between 33\% to $40 \%$ in men and $27 \%$ to $34 \%$ in women. Among this same cohort, obesity rates were $6 \%$ to $13 \%$ 
in men and $21 \%$ to $29 \%$ in women. ${ }^{52,53}$ Other studies have also reported increasing overweight and obesity rates among HIV infected individuals, with several studies reporting higher prevalence of overweight and obesity compared to wasting in the study population ${ }^{54-57}$ It appears that overweight/obesity is being reported at diagnosis, with continued weight gain during the HIV infection. One author suggests this to be a reflection of improved health status in this population, even as the trend mirrors what is being observed in the general public. ${ }^{55}$ With between $46-60 \%$ overweight/obesity rates being reported in certain HIV infected populations, obesity and not weight loss or wasting, seems to be the new nutritional concern for this population, especially when coronary heart disease is on the rise in the ART treated individuals. ${ }^{55,56}$ Lack of access to nutritious foods, metabolic abnormalities, and illicit drug use, all of which can aggravate weight loss and the catabolic nature of the HIV disease are still common; hence, it is important not to completely rule out weight loss as a nutrition concern in this population. ${ }^{58-67}$ The new epidemic of overweight and obesity may be attributed to unhealthy eating habits, excessive caloric and fat intake and treatment related metabolic alterations especially with lipid metabolism. ${ }^{53,68-72}$ On the other hand, two studies by Samaras et al. ${ }^{73}$ and Batterham et al. ${ }^{70}$ found no association between dietary intake and visceral adiposity. Amorosa et al., ${ }^{54}$ however, found positive correlations of BMI with total cholesterol, non-HDL cholesterol as well as triglycerides.

Several studies have reported on issues of dietary and nutrient intake of HIV infected individuals. ${ }^{74-80}$ Caloric and fat over-consumption seems to be a consistent theme in developed areas. ${ }^{74,75,77-79}$ In low income settings, the opposite problem exists, with numerous studies reporting inadequate nutrient intake to be common among HIV infected 
people, especially in those regions where ART is still not widely available. ${ }^{12,81,82}$ In resource adequate areas, low intakes have been reported in HIV infected sociodemographic groups at risk for healthcare disparities and adverse clinical outcomes such as women, drug abusers and minorities. ${ }^{13,81,83}$ On the other hand, adequate nutrient consumption is found in HIV infected men who are educated, high-income earners and supplements users. ${ }^{76,77}$ Two studies found nutrient intake among these economically advantaged HIV infected individuals to be higher than that reported by HIV un-infected populations. ${ }^{76,83}$ Some studies investigating biochemical markers such as hemoglobin, hematocrit and albumin among HIV infected people have consistently reported these parameters as low in this population. ${ }^{47,74,79,80,84-86}$ Most of the studies, however, have been conducted in low resource areas. A multicenter study, conducted among women in North America, reported low albumin levels in those HIV infected and concluded that baseline albumin level independently predicted mortality in this group, with $48 \%$ mortality rate in the lowest serum albumin category compared to $11 \%$ in the highest category. ${ }^{87}$

\section{Food Insecurity among HIV Infected Persons}

Food insecurity has been defined as occurring "whenever the availability of nutritionally adequate and safe foods or the ability to acquire acceptable foods in socially acceptable ways is limited or uncertain. ${ }^{\prime 88}$ Food insecurity embodies one or many of the following characteristics listed: (1) insufficiency in the amount of food, (2) very little diversity in food group choices available, (3) poor food safety, (4) anxiety towards how food is accessed, and (5) acquiring food in socially unacceptable ways. Socially accepted 
ways include not being reliant on emergency food assistance, and not begging, stealing or using any other negative coping mechanism to procuring food during times of shortage. ${ }^{89}$ The USDA measures food security/insecurity levels in the United States at the individual, household and population levels. There are several instruments used in measuring food insecurity, however, the most widely used ones are the US Household Food Security Survey Module, the Household Food Insecurity Access Scale and the Radimer/Cornell Food Security Questionnaire. ${ }^{89}$ The US Household Food Security Survey Module also has 10-item and 6-item short form versions. In 2006, USDA introduced new and revised labels to be used in describing the ranges of food insecurity severity. ${ }^{90}$ They are defined below:

1) High food security: Households reporting no indications of food-access problems or limitations.

2) Marginal food security: Households having one or two reported indications -typically of anxiety over food sufficiency or shortage of food in the house, and having little or no indication of changes in diet or food intake in terms of quality, variety and quantity. 3) Low food security: Household reporting a reduction in the quality, variety, or desirability of diet, with little or no indication of reduction in quantity of food intake. 4) Very low food security: Households reporting multiple indications of disrupted eating patterns and reduced food intake due to lack of money and other resources. Under the old food security description label, both the high food security and marginal food security were described as food security, low food security was categorized as food insecurity without hunger and very low food security was labeled food insecurity with hunger. ${ }^{90}$ 
In 2011, more than 50 million individuals lived in households that experienced food insecurity. ${ }^{90}$ According to the USDA, these included 17.9 million households; 11 million which experienced low food security and 5.7\% experiencing very low food security. ${ }^{90}$ Several studies have evaluated the prevalence of food insecurity among the HIV infected, and their reports suggests that the prevalence is higher than those recorded at the national level, especially in resource adequate settings. Campa et al. ${ }^{49}$ found $81 \%$ of HIV infected drug users surveyed in Miami, who experienced wasting, to be food insecure, while another study conducted in Miami and Atlanta among a similar population reported $34 \%$ food insufficiency. ${ }^{91}$ In British Columbia, $48 \%$ of HIV positive study participants were reported to be food insecure, ${ }^{61}$ while another study conducted in the same province, but among HIV infected injection drug users had a food insecurity prevalence of $64 \% .{ }^{92}$ Among homeless and marginally housed HIV infected individuals in San Francisco, Weiser et al. ${ }^{64}$ estimated $49 \%$ food insecurity among the study population. A study involving HIV infected patients from eight veteran clinics, in the Veteran Aging Cohort Study, reported that $24 \%$ of participants receiving ART treatment were food insecure. ${ }^{93}$

Food insecurity is also prevalent in resource constraint countries. A Kenyan study of patients receiving treatment from 17 HIV care centers estimated that $33.5 \%$ of the population was food insecure. The prevalence of food insecurity was as low as $20 \%$ in some clinics and as high as $50 \%$ in others. ${ }^{94}$ In a recent longitudinal study conducted in Uganda, researchers reported a food insecurity prevalence of $40 \%$ among 458 participants followed for over 2 years. ${ }^{66}$ Earlier studies from Uganda, involving HIV infected women from 144 households, suggest some level of food insecurity with 44\% 
assessing food assistance and 59\% having low diversity in their food intake. ${ }^{95}$ Correlates of food insecurity among HIV infected individuals include gender (being female) having low socioeconomic status (including unemployment, marginal/unstable housing), drug use, recent incarceration and having children in the household. ${ }^{96}$

Food insecurity contributes to HIV transmission, especially among food insecure women responsible for their households. ${ }^{97,98}$ Several studies have found that individuals reporting hunger, or lack in resources to procure food, tend to engage in risky sexual behaviors. ${ }^{97-99}$ A study by Weiser et al., ${ }^{100}$ with over 2000 adults in Botswana and Swaziland, found that among women reporting food insufficiency, $80 \%$ were at increased odds of exchanging sex for money and/or other resources, while 70\% had increased odds of having risky and unprotected sex. These increased odds were still present even after controlling for socioeconomic status. Among HIV positive drug users in Canada, food insecurity was significantly associated with having engaged in unprotected sex in the last 6 months. ${ }^{101}$ Food insecurity also impacts HIV transmission by compromising nutritional status, and consequently, immunological status. ${ }^{102}$ Inadequate nutrient intake may affect the mucosal integrity of the genitalia and gastrointestinal tract, leading to increased risk of HIV transmission. Compromised nutritional status has been associated with mother-tochild transmissions in resource constrained settings. ${ }^{96}$

Though limited in number, some researchers have investigated the effect of food insecurity on accessing HIV related care and services, reporting that even with eligibility and free ART access, food insecure individuals refuse treatment because of lack of food and fear of being able to sustain the consumption of adequate food. ${ }^{103-106} \mathrm{~A}$ recent study found food insecurity to be associated with missed clinic visits, with $17 \%$ of study 
participants having to give up ART treatment, while $30 \%$ and $32 \%$ did not access outpatient and inpatient treatment respectively because of competing demands for food. ${ }^{66}$ HIV infected person who are food insecure, especially those with low socioeconomic status and limited resources, frequently need to choose between receiving HIV related services or food procurement ${ }^{104,106}$

Antiretroviral therapy for HIV infection is most effective when adherence to treatment is $>95 \% .{ }^{107}$ Studies conducted in developed countries and resource-limited settings have identified that food insecure HIV infected individuals are less likely to adhere to treatment, compared to their food secure counterparts. ${ }^{64,108}$ Adherence to treatment, however, increased among those receiving food assistance, stressing the importance of food assistance among low income HIV infected patients. ${ }^{109-111}$

With regards to the impact of food insecurity on disease progression, management and survival, studies have reported associations between food insecurity and decreased CD4 levels, even though the etiology of causality remains unknown. ${ }^{61,63}$ Among participants of the Veterans Aging Cohort Study, those who were food insecure were found to be more likely to have unsuppressed HIV-1 RNA (a situation that could make treatment ineffective) compared to those who were food secure. ${ }^{93}$ In another study involving homeless and marginally housed HIV positive individuals in San Francisco, researchers reported a 77\% lower odd of viral suppression among those with severe food insecurity. ${ }^{64}$ A study by Campa et al., ${ }^{49}$ in Miami among HIV infected drug users, found that food insecurity was an independent predictor of wasting; a condition that was prevalent in this population. In a recent study conducted in Uganda, food insecurity was associated with increased opportunistic infections, hospitalization, and worse physical 
health-related quality of life. ${ }^{66}$ The negative effect of food insecurity on hospitalization has also been reported in developed countries. In a recent study, Weiser et al. ${ }^{112}$ showed that food insecurity among HIV infected individuals was associated with increased health care utilization. To conclude, although mortality had decreased among the HIV infected due to the introduction of ART, a longitudinal study conducted in British Columbia Canada, found that the odds of dying in an eight year follow-up period was two-times more likely among those food insecure and underweight compared to those who had neither characteristics. ${ }^{113}$

\section{The Food Stamp/Supplemental Nutrition Assistance Program}

It is difficult for low income earners, whether chronically ill or not, to access nutritious and safe (uncontaminated) foods with limited resources. The federal government currently funds several food assistance programs targeting such low income households to improve their diets for optimal health. The Food Stamp Program (FSP) is the largest and best known of the food assistance programs. According to the amended Food and Nutrition Act of 2008, the aim of the program is to "permit low income households to obtain a more nutritious diet through normal channels of trade by increasing food purchase power for all eligible households who apply for participation" (P.L. 110-246). ${ }^{114}$ This act also changed the programs' name to Supplemental Nutrition Assistance Program (SNAP), in an effort to address insufficiencies with program participation and benefits ${ }^{114}[$ (Discussions in this literature review pertaining to research/studies associated with the program prior to 2008 will maintain the name Food Stamp Program (FSP)]. 
Established in 1964, the SNAP entitlement program is administered by the United States Department of Agriculture (USDA)'s Food and Nutrition Service Division. Eligibility is based on financial need, having to meet income, assets and employment requirements. ${ }^{115}$ To be income eligible, households must meet three criteria: (1) a gross income test, (2) a net income test and (3) an assets test. A household's gross monthly income must be below $130 \%$ of the Federal Poverty level, which in the fiscal year 2012, translates to $\$ 2,422$ for a household of four. ${ }^{115,116}$ Households that have an elderly or disabled member are exempt from this test, although they must meet the net income limit and have less than $\$ 3,250$ in assets. ${ }^{116}$ To pass the net income test, a household's income must be less than $100 \%$ of the federal poverty level. The net income limit is calculated by standard and itemized deductions to gross income. The assets limit for a household that doesn't have an elderly or disabled member is less than $\$ 2,000 .{ }^{116}$ SNAP participating households are expected to spend $30 \%$ of their resources on food and as a result, the net monthly income of a household is multiplied by 0.3 . The result obtained is then subtracted for the maximum benefit based on household size to determine the final SNAP benefit for that household. The maximum benefit that could be obtained by an individual in 2012 was $\$ 200$ per month. ${ }^{115}$

Application and recertification for SNAP are done at state and county offices. Applying households must provide information to determine eligibility. Recertification for eligibility is periodically assessed at the local offices' discretion and also based on volatility of household income. ${ }^{117}$ In 2011, about 45 million people participated in SNAP with an average of $\$ 134$ being provided per person to over 21 million households per month. The annual cost of SNAP in 2011 was over 70 billion dollars with $72 \%$ 
participation rate for eligible participants. ${ }^{16,118}$ The SNAP program is deemed important because it helps prevent food insecurity, lifts individuals and families out of poverty and is key in supporting families through difficult economic times. ${ }^{116}$

\section{Effects and Benefits of Food Stamp Program}

Food Expenditure: Evidence from the literature suggests that participation in the food stamp program has been beneficial in consistently increasing household food expenditure compared to non-participants. In these studies, food expenditure was measured either as total food expenditure (i.e. foods eaten at home and away from home), or as expenditures of foods used at home. Currently benefits from participation in SNAP are applied towards only foods that are eaten at home. Authors of studies that used "total food expenditure", however, suggest that participation in SNAP allows households to substitute foods eaten at home with those eaten away from home. A study by Hama and Chern, ${ }^{119}$ which investigated the impact of SNAP on food expenditure and nutrient availability in elderly households, found that participation led to an increase in per-capita food expenditure at home. An article by LeBlanc et al. ${ }^{120}$ indicates that the Food Stamp Program or SNAP increases the purchasing power of a low income qualified household, providing about $25 \%$ of their total purchasing power. It is estimated that a dollar of food stamp benefit increases food spending by $\$ 0.17-\$ 0.47 .{ }^{120}$ Unlike other food assistance programs, the SNAP gives participants the opportunity to purchase foods of their choice.

Household Nutrient Availability: Increasing purchasing power and household food expenditure may not necessarily translate into increasing household food energy and nutrient availability. ${ }^{121}$ Households may buy mostly non- nutritious foods because they 
are convenient, palatable, or cheap, in an attempt to stretch their food dollars. Acquiring more expensive forms of similar foods may not result in significant gains in nutrients. ${ }^{121}$ Reports from studies investigating the effect of food stamp participation on these variables have been inconsistent. ${ }^{121}$ Whereas some studies have suggested that participation in food stamp programs can increase nutrient availability and intake, ${ }^{122,123}$ others have found no such association. ${ }^{124,125}$ The contradictions may be due to the differences in the data collection methods, as most of these studies were secondary analyses of large population surveys. ${ }^{121}$ It could also be due to the differences in standards used in assessing dietary and nutrient intake and to the changes undergone by the programs through time. Most of the studies were conducted in the 1970s and 1980s; the results from such studies may not represent current practices in the program. ${ }^{121}$ For example, food choices offered in grocery stores under the current FSP are broader than before and may influence dietary and nutrient intakes. ${ }^{120}$

Studies that found positive nutritional impact indicate that participation in food stamp program increases:

- $\quad$ food energy, ${ }^{122,123,126,127}$ protein, ${ }^{123,126-128}$ and carbohydrates. ${ }^{122}$

- the intake and availability of the following vitamins: $A,{ }^{123} \mathrm{~B}_{6},{ }^{123,129} \mathrm{~B}_{12},{ }^{122}$ $\mathrm{C},{ }^{122,123,127} \mathrm{E},{ }^{129}$ niacin, ${ }^{122}$ riboflavin ${ }^{122,123}$ and thiamin. ${ }^{122,123,128}$

- $\quad$ the availability of iron, magnesium, phosphorus and zinc. ${ }^{119,122,123,127}$

Individual Nutrient Intake: Studies that investigated the effect of food stamp on individual dietary intake, focused on population subgroups, e.g. children and the elderly. ${ }^{129-133}$ Results from these studies are also contradictory and their limitations are similar to those discussed above in relation to the household nutrient availability 
studies. ${ }^{121}$ Among children, one study found that FSP participants consumed more food energy than their non-participating counterparts. ${ }^{130}$ Other studies also found increased energy intake in children, even though the difference in consumption was not significant. ${ }^{131,132,134}$ Moreover, in adults and the elderly, food stamp participation also led to an increase in energy intake, albeit not significant. ${ }^{131,133,135}$ Similarly, Fraker et al. ${ }^{130}$ found that FSP participation had a significant impact on protein intake among children. Other studies, regardless of the type of study population (i.e. children, adults or elderly) did not report significant differences in nutrient intakes between participants and nonparticipants..$^{130,131,135,136} \mathrm{Few}$ studies found significant differences in the individual intake of carbohydrates and fats between FSP participants and non-participants. ${ }^{131,133,136}$ Several studies reported a significant impact of FSP on the intakes of vitamin A, niacin, thiamin, ${ }^{136}$ iron, vitamin $\mathrm{B}_{6},{ }^{132}$ vitamin $\mathrm{B}_{12}$, calcium, zinc, ${ }^{134}$ and folate, ${ }^{131,132}$ among children. Some other studies reported finding no significant impact of participation in FSP on riboflavin, vitamin $\mathrm{C}$ and $\mathrm{E}$ intakes, regardless of the type of population being studied. ${ }^{131,134,136}$ In a review article, Fox et al. ${ }^{121}$ point out that the relationship between household nutrient availability and individual nutrient intake may be weakened because of (1) inequality in nutrient consumption by household members, (2) possible waste of food or consumption by non-family members and (3) consumption of food from other sources other than home.

Health Outcomes: The effect of FSP on biomarkers of nutrition and health outcomes such as hemoglobin, hematocrit, albumin and carotenoids have been reported, ${ }^{137}$ even though results from other studies do not support these findings. ${ }^{138,139}$ Research considering the impact of FSP on general nutrition and health status is limited; however, 
the evidence from such research found no differences between FSP participants and nonparticipants. $^{133}$

Food Security: Several recent surveys have reported the effect of SNAP in reducing food insecurity. The analyses from these studies have been difficult to interpret as individuals who feel food insecure are more likely to participate in the SNAP program, making it seems that program participants are more likely to be food insecure compared to non-participants. ${ }^{121,140}$ Controlling for selection bias, as well as other observable and unobservable differences between SNAP participants and non-participants using modeling and multivariate analysis, have shown mixed results. ${ }^{141-145}$ The most recent of such studies, however, shows that participation in SNAP reduces the probability of food insecurity by $18 \%$ to $33 \%$ in those who are food insecure, and by $20 \%$ to $30 \%$ in those with very low food insecurity. ${ }^{143-145}$ Nord et al., ${ }^{146}$ in a 2011 published study, concluded that SNAP can ameliorate very low food insecurity in the range of $20 \%$ to $50 \%$. In addition, individuals who leave the SNAP program experienced food insecurity when compared to those with continued participation. ${ }^{146,147}$

\section{Barriers to Participation in the Supplemental Nutrition Assistance Program (SNAP)}

Participation in the SNAP program had increased substantially to $72 \%$ in 2009 among eligible individuals after a low of 54\% in 2001 and $2002 .{ }^{116,148}$ The increase in participation has been attributed to changes in the economy, increases in outreach, as well as simplification and less restriction in eligibility requirements. ${ }^{116}$ Participation rates, however, vary among states, with Florida having one of the lowest participation rates in the country at $69 \% .{ }^{149}$ Among subgroups, children have the highest participation rate at 
$92 \%$ while the elderly have the lowest rate at $34 \% .{ }^{116}$ About $33 \%$ of SNAP eligible participants do not participate in the program. ${ }^{150}$ According to a nation-wide survey, 56\% of the households contained an elderly or disabled member. ${ }^{151}$ SNAP participants also tend to be unemployed, have low education, live in female headed households and live with children. ${ }^{117,148,152}$

Participation in the SNAP program may be an essential part of HIV disease management, through improvement of dietary and nutrient intake. There is, however, limited research on the utilization of these programs by HIV-positive persons, and the potential benefits that may be derived from participation. ${ }^{58}$ Surveys conducted among these high risk populations suggest that less than one-third of those eligible are receiving benefits. ${ }^{58}$ Evidence from the literature suggests that among eligible non-participants, the desire for personal independence, stigmatization, lack of awareness about program, confusion about eligibility requirements, homelessness, inadequacy of benefits, length and cost of the application process, as well as previous bad experiences are the barriers to participation in the food stamp program. ${ }^{151-155}$

Among food pantry users in California, homelessness and limited English language skills were the primary barriers to FSP participation. ${ }^{154}$ Seniors listed stigma and misinformation with program rules as participation barriers. ${ }^{156}$ One the findings from the California Women's Health study was that $42 \%$ of eligible non-participants didn't participate in FSP because they "didn't need them". ${ }^{152}$ These women are part of eligible non-participants who perceived that their need for FSP is low because of food sufficiency, or because they were eligible for relatively limited benefits from FSP due to slightly higher income. ${ }^{141,152}$ Ninety six percent of eligible non-participants are aware of 
the FSP program and $66 \%$ will participate if eligibility were certain. ${ }^{151}$ Several strategies are being put in place to increase SNAP participation among eligible non- participants, as the program is not being utilized to its maximum. ${ }^{150}$ It is important to understand what drives the decision to participate in food assistance in eligible HIV positive people, ${ }^{157}$ hence the need to study factors associated with SNAP participation to increase participation rates and the potential benefits derived from participation.

\section{Food Assistance and Nutrition and Health Outcome in HIV infected}

Nutritional interventions through the provision of food assistance have been conducted in several settings among HIV infected individuals. In resource limited settings, relatively few studies have been done; however, these programs have been beneficial in improving nutritional status and adherence to therapy but not immunologic outcomes. ${ }^{109,158-160}$ The food assistance delivered in these settings was either food rations/ food baskets to supplement the local diet or packaged therapeutic diets for nutritional rehabilitation. The supplements mostly used were corn and soy blends, fortified blended foods, high-energy ready-to-use therapeutic foods (RUTF), and a nutrient dense spread suspended in fat. ${ }^{161}$

In a study conducted in Uganda, Rawat et al. ${ }^{160}$ found that giving people living with HIV food assistance resulted in a mean weight gain of $0.36 \mathrm{~kg}$ in 12 months, compared to controls. They also reported that disease progression was slow in the experimental group even though the impact was described as minimal. In another study, $70 \%$ of the experimental group who received food assistance (corn soya blend), achieved $95 \%$ adherence to medication as compared to $48 \%$ in the control group. ${ }^{109}$ A recent study 
conducted in Zambia also reported $>98 \%$ ART adherence rate among HIV adults receiving food assistance. ${ }^{111}$ Among $491 \mathrm{HIV}$ infected adults in Malawi, Ndekha et al. ${ }^{162}$ reported that after 3.5 months of intervention, individuals who received ready- to-use therapeutic spread had a greater increase in BMI compared to those who received cornsoy blend. It is important to note that the populations studied in the resource limited settings were all ART-naïve.

Food assistance interventions conducted in resource adequate settings, like the United States, have mainly provided supplemental formulas and, in some cases, counseling without providing actual foods, or directing those infected towards food assistance programs. ${ }^{163-166}$ Ingredients in these supplemental formulas have included oral formulas of amino acids (whey, glutamine, and arginine), lipids (triglycerides and omega3 fatty acids) and a form of carbohydrate (maltodextrin). ${ }^{163,165,167-170}$ The studies that used formulas supplemented with amino acids were effective in increasing weight. ${ }^{163,169}$ Other trials that gave supplementation formulas, in addition to a normal diet, resulted in elevated energy and protein intake among the supplemented group compared to placebo. ${ }^{168,170}$ Although none of these interventions provided actual foods, some of the interventions were associated with significant changes in nutritional status (gain in weight and BMI) among participants. ${ }^{163,169}$ Like the studies conducted in resource constrained environments, however, these interventions did not result in significant differences in viral load and CD4 counts between treatment and control groups. ${ }^{163,167-169}$ Finally, a study conducted among HIV infected individuals in Haiti reported vast improvements in body composition and food security, but not as much with quality of life, among food assistant recipients compared to non-recipients. ${ }^{171}$ 


\section{Knowledge Attitude and Self-Efficacy in Nutrition Education}

Studies have shown that socioeconomic status (SES) affects dietary intake, with the disadvantaged and the poor adhering less to dietary guidelines, and having poor diet quality. ${ }^{172-174}$ While participation in the SNAP program may be helpful in improving nutritional status, which is important for disease management, food choices made by individuals is determined by more than socioeconomic factors. ${ }^{174}$ Other parameters that affect dietary behavior and food choices include psychosocial factors like knowledge and beliefs about nutrition and health, and the confidence to make and implement dietary changes. ${ }^{174,175}$ Nutrition knowledge is measured either as declarative or procedural knowledge. Procedural knowledge is better related to behavior because it defines the manner in which an action is performed, while declarative knowledge on the other hand, gives factual information about things. ${ }^{176}$ An example of procedural knowledge is how to decrease fat intake in the total diet, while an example of declarative knowledge is to be able to tell the fat content of whole milk. Irrespective of the scales used in measurement, several studies have shown that nutrition knowledge positively affects dietary intake, especially in the presence of a socioeconomic intervention. ${ }^{174,177,178}$ A study by DicksonSpillman and Siegrist ${ }^{176}$ reports that decreased nutrition knowledge is associated with decreased consumption of high quality foods. In their study, individuals with higher nutrition knowledge tended to be female, were younger and had considerably higher education. In addition to knowledge, a positive attitude towards nutrition affects food choices. ${ }^{179,180}$ Dissen et al. ${ }^{180}$ concludes that higher nutrition knowledge is associated with a positive attitude towards nutrition, and hence a healthy dietary habit. Another study, however, found that a positive attitude towards nutrition influences food choices 
greater than nutrition knowledge. ${ }^{181}$ A study conducted by McDermott et al ${ }^{164}$ reported that in HIV infected individuals, nutrition knowledge varied widely irrespective of socioeconomic status. Self-efficacy, defined as the confidence in one's ability to perform a particular behavior is another factor that affects dietary behavior. It is an important aspect of behavioral theories such as the social cognitive theory and uses goalsetting and self-monitoring to effect behavior change. ${ }^{182}$ Among American Indian populations, Gittelsohn et al. found that self-efficacy predicted food acquisition behavior, with the former being predicted by knowledge. ${ }^{175}$ Several other studies have reported on self-efficacy mediating dietary behavior. ${ }^{183}$ Based on the discussion above, it is important to include sessions to improve attitudes towards nutrition and increase nutrition knowledge and self-efficacy in a nutrition education intervention. ${ }^{179,180}$ Identifying nutrition knowledge, needs and concerns of low income HIV infected adults will help tailor education interventions to improve nutrition knowledge, dietary practices and nutrient intake. In a time where the Federal Government is cutting back on assistance programs for HIV infected people due to limited resources, it is crucial to provide evidence of the impact that both, a nutrition assistance program like SNAP and nutrition education, have on the nutritional status and quality of life of low income HIV infected individuals.

\section{Nutrition Education among Low Income and Food Assistance Users}

Nutrition education is defined as "any set of learning experiences designed to facilitate the voluntary adoption of eating and other nutrition related behaviors conducive to wellbeing". ${ }^{184}$ In a review examining the effectiveness of nutrition education 
intervention, Contento and colleagues ${ }^{184}$ concluded that nutrition education is an important aspect of improving dietary practice, if behavior change is established as the goal, and the educational strategy is targeted at this goal. In conducting interventions among low income groups, the one-on-one method of teaching has been proven most effective. Group interventions are also being found effective when combined with additional efforts to maintain adherence. ${ }^{185}$ Nutrition education interventions are also effective among low income groups when they include provision of information, goal setting and barrier identification. ${ }^{185}$ According to evidence from the literature, nutrition education positively influences dietary practices and intakes of low income individuals. ${ }^{186-189}$ In a study designed to improve dietary intake among African-American women in Washington DC, it was found that participants decreased their total caloric and calories from fat intake, although nutrition education did not significantly improve fruit and vegetable intake. ${ }^{188}$ Another study among low income earners in Europe found that nutrition education significantly reduced saturated fat intake but not fruit and vegetable consumption among participants. ${ }^{189}$ In a randomized control trial, Emmons et al. ${ }^{187}$ reported that the percentage of intervention recipients consuming $\geq 5$ fruits and vegetables increased by $3.3 \%$ while that of controls decreased by $3.8 \%$. The SNAP program has an educational component that is optional for States to implement. The United States Department of Agriculture (USDA) provides funding for States that implement the educational component. In settings where these education programs have been implemented, the food buying, meal planning and preparation, as well as food safety practices, have improved among participants. ${ }^{190}$ Where food stamps were provided without nutrition education, researchers report that participants had poor diet quality, 
consuming convenience and fast foods, as well as snacks high in fat and sugar. ${ }^{191}$ Again, populations receiving food stamps without education had increased energy intake especially that from fat. ${ }^{192}$ Cason et al. ${ }^{193}$ showed that food stamp participants and nonparticipants, who received nutrition education, significantly improved their dietary and nutrient intake, as well as food related behaviors. Among women participating in the food stamp program in North Carolina, nutrition education significantly improved nutrition knowledge, self-efficacy, stage of change and dietary behaviors. ${ }^{194}$ The impact of nutrition education has been studied in populations receiving food assistance other than food stamps. The Special Supplemental Nutrition Program for Women, Infant and Children (WIC) participants, who received nutrition education, increased their selfefficacy and scored higher on infant feeding and dietary fat knowledge when compared to controls. ${ }^{195}$ Our study investigated the combined effect of SNAP participation and nutrition education on the nutrition and health outcomes of HIV infected individuals.

\section{Nutrition Education among HIV Infected Individuals}

Nutrition education is recognized as an essential part of HIV care from early diagnosis to end-stage disease, as well as for therapy management for those receiving treatment. ${ }^{196}$ It could stimulate better disease management and quality of life through improved nutrient intake. ${ }^{196,197}$ The needs identified among the HIV infected, for which nutrition education or counseling may be helpful, include immune system strengthening, decreasing disease symptoms and side effect from treatment, lessening the incidence and severity of opportunistic infections and improving quality of life. ${ }^{196,198}$ 
In recognition of the importance of nutrition education in HIV care, the Ryan White program (a program funded by the federal government to provide HIV-related services to low income individuals) has as part of its service categories, a provision for nutrition counseling by a qualified dietitian not withstanding primary care visit. ${ }^{199}$ It is unclear how much HIV infected individuals take advantage of this program and how successful it has been within the context of disease management. The evidence from several studies showed that nutrition education in HIV infected individuals has produced improved nutritional outcomes such as increases in dietary intake, total body weight and fat free mass. ${ }^{164,170,200,201}$ One of the studies investigating the effect of nutrition education on body composition reported a decrease in fat mass among the intervention group with increasing lean body mass. ${ }^{202}$ Other outcomes include adherence to antiretroviral treatment, less side effects from medication, and a better capability to satisfy increased appetite. ${ }^{110}$ In a study conducted in Germany, Schwenk et al. ${ }^{170}$ concluded that nutrition counseling was just as effective as dietary supplementation in increasing fat free mass in 8 weeks of intervention. A study by Van Niekerk et al., ${ }^{201}$ which examined the effect of nutrition education or counseling on body weight in ART naïve patients, found that body weight increased after approximately 4 months of follow up. The increase was greater in the intervention group compared to the control group, with $73 \%$ of the experimental group experiencing stable or increasing weights. The researchers also reported that nutrition counseling was able to offset gastrointestinal tract associated adverse effects, especially in patients with CD4 counts less than $200 .{ }^{201}$ Though there is evidence that nutrition education may improve nutrition health outcomes among HIV infected people, it is uncertain that these improvement are entirely due to the intervention. ${ }^{197}$ In HIV 
infected populations receiving treatment, ART use could play a role in the intervention outcomes. In addition to treatment, socioeconomic status and food insecurity are also possible mediators of nutrition education outcome in this population. ${ }^{197}$ Accounting for these variables in the design of the intervention and using in-depth data analysis will help to understand the effect of nutrition education on health and nutritional status of HIV infected individuals.

\section{Theoretical Framework}

The conceptual model used in the nutrition education intervention for this study is adapted from the StampSmart model, (Figure 1) used by Campbell et al. ${ }^{194}$ This model employs both the Stages-of-Change concept of the Transtheoretical model and the Social Cognitive Theory in its development. ${ }^{194}$ Although the same theoretical framework was used, two features were changed for this study: (1) the content of the education material and (2) the channel used in disseminating intervention materials. The Stage-of-Change theory is widely used in health promotion and has been applied to interventions in several areas including nutrition. ${ }^{203}$ This theory applies the logic that individuals go through different stages of change before developing a new behavior. The stages included in this theory are precontemplation, contemplation, preparation, action, and maintenance. ${ }^{204}$ Components of the educational program were developed to target each stage, focusing on processes involved in each stage. Some of these processes include consciousness raising through information and knowledge provision, self-re-evaluation by discussion with peer role models, self-liberation (belief in ability to change by drawing attention to individuals who have already made commitment to eat healthy), reinforcement management (giving 
praise and recognition) and counter conditioning (using activities to learn how to substitute healthy behaviors for unhealthy ones). ${ }^{205}$

The Social Cognitive Theory integrates an individual with the social environment in which he or she is learning. ${ }^{182}$ It purports that learning is determined by an interrelationship between environmental influences, personal factors, and behavioral attributes. ${ }^{182}$ The focus of this theory is self-efficacy, which is an individual's selfconfidence in performing a particular behavior at a certain competence level. ${ }^{182}$ To be able to perform a behavior, an individual must believe in their ability to do it and this makes self-efficacy an important characteristic to consider in behavior change. This intervention sought to increase self-efficacy through skill development and training to raise individual confidence. The intervention also pointed out and emphasized outcomes (long term benefits to eating healthy) as well as provided incentives that motivated behavior change.

As a modification to the original model, this intervention utilized an interactive and participant centered group seminar/discussion setting instead of multimedia in delivering education materials. In addition, written materials were also provided and these were tailored appropriately for the literacy level of participants. Learning methods applied in the model are lecture, practice and role play, all of which are drawn from the social cognitive theory discussed previously.

This conceptual model requires conducting a needs assessment prior to implementing nutrition education. It is based on the belief that focused nutrition education will increase self-efficacy and progress in stage of change, leading to change in eating behavior. 
Needs Assessment

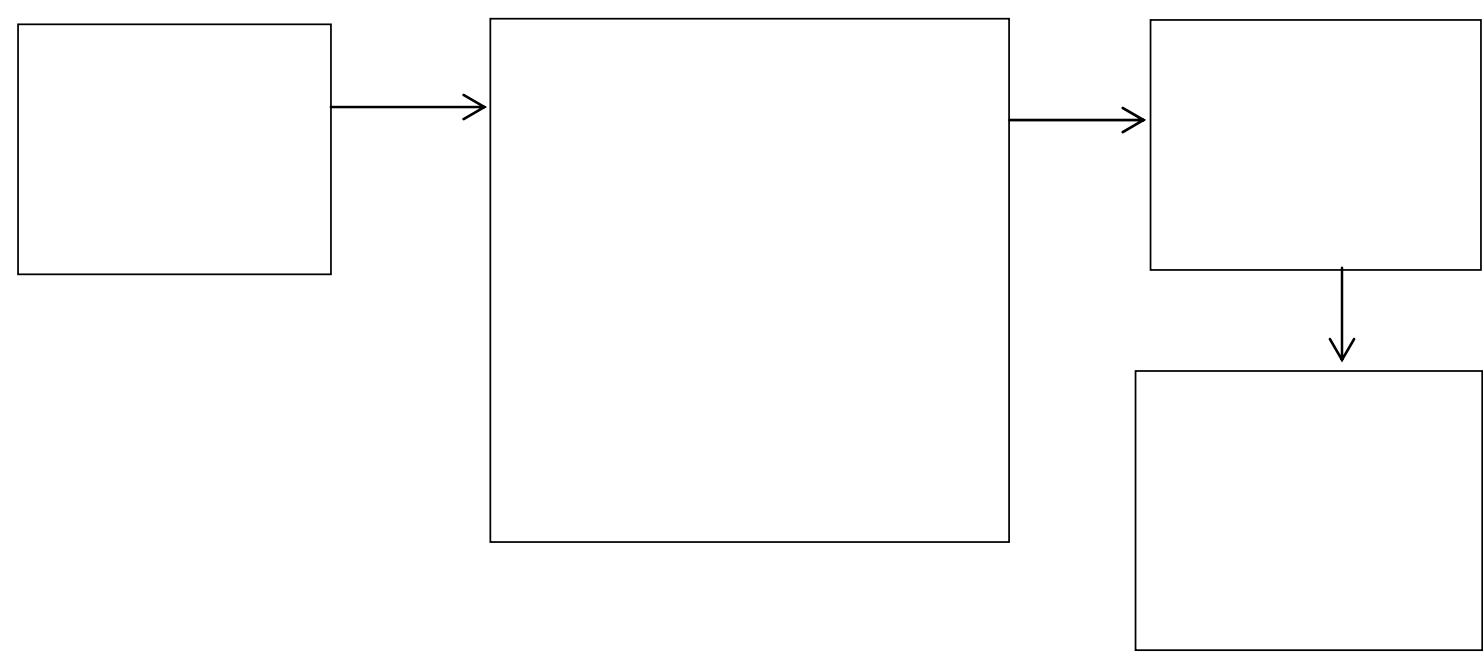

Figure1: Conceptual Model

Adapted from "Stamp Smart Model”, Campbell M K et al. Health Educ. Res. 1999;

$14: 257-26$

Table 1: Summary of nutrition education intervention strategy

\begin{tabular}{|c|c|c|c|c|c|}
\hline $\begin{array}{l}\text { Key Strategies } \\
\text { And Activities }\end{array}$ & $\begin{array}{l}\text { Target } \\
\text { Group }\end{array}$ & $\begin{array}{l}\text { Group } \\
\text { Size }\end{array}$ & $\begin{array}{l}\text { Lead } \\
\text { Staff }\end{array}$ & Frequency & Evaluation \\
\hline $\begin{array}{l}\text { Assessment } \\
\text { Information } \\
\text { dissemination } \\
\text { /Education } \\
\text { - Lecture } \\
\text { - Group } \\
\text { Discussion } \\
\text { - Handouts/ } \\
\text { Posters } \\
\text { - Recipes } \\
\text { Skill training } \\
\text { - Experiential } \\
\text { activities }\end{array}$ & $\begin{array}{l}\text { Low } \\
\text { income } \\
\text { HIV } \\
\text { infected } \\
\text { individuals }\end{array}$ & $\begin{array}{l}15 \text { per } \\
\text { group }\end{array}$ & $\begin{array}{l}\text { A trained } \\
\text { dietitian or } \\
\text { nutritionist }\end{array}$ & $\begin{array}{l}\text { Twice a } \\
\text { month } \\
\text { delivery of } \\
\text { nutrition } \\
\text { education } \\
\text { for } 2 \\
\text { months }\end{array}$ & $\begin{array}{l}\text { Progression in } \\
\text { Stage of Change } \\
\text { Increase in self- } \\
\text { efficacy } \\
\text { Improvement in } \\
\text { dietary practices } \\
\text { Nutritional } \\
\text { Status } \\
\text { Disease Status } \\
\text { Health Status } \\
\text { Quality of Life }\end{array}$ \\
\hline
\end{tabular}




\section{Literature Review Summary}

HIV infection is associated with the destruction of the immune system, a condition that is aggravated by impaired nutritional status. The infection creates a vicious cycle with malnutrition that can exacerbate disease progression and affects chances of survival. ${ }^{10,11}$ Poor nutritional status may hasten the progression of the disease, leading to poor outcomes. ${ }^{11}$ On the other hand, HIV infection is a nutrition-related disease that impairs dietary intake, digestion, absorption and utilization of nutrients, leading to weight loss, nutrient deficiencies, compromised immune function and competence, as well as susceptibility to infection. ${ }^{10}$ Food insecurity is prevalent among the HIV infected individuals, and has been associated with several indicators of low socioeconomic status such as low income, unemployment, homelessness, and poor physical and mental conditions, ${ }^{49,61,64,66,91-94}$ Among the HIV infected, food insecurity has been reported to be associated with HIV disease transmission, progression, management and survival. ${ }^{63,64,97,98}$ Food insecurity increases the probability of poor nutritional status in the HIV infected person $\cdot{ }^{96,102}$ In most cases, provision of food assistance, whether in the case of food insecurity or compromised nutritional status, has ameliorated the effects of the disease. ${ }^{109,158-160,163,167-169}$ Coupling nutrition education with the provision of food assistance may enhance the intervention's outcomes. ${ }^{190-193}$

The Supplemental Nutrition Assistance Program (SNAP) is the largest food assistance program in the United States. ${ }^{116}$ Though the literature presents inconsistent and sometimes contradictory evidence, several studies have demonstrated some nutrition and health benefits of participation in the SNAP in non-HIV infected populations. ${ }^{121-125}$ Few 
studies have evaluated the participation rate for SNAP among HIV infected individuals, and to date, no known study has investigated the impact of this food assistance program on the nutrition and health of the HIV infected people in Miami. This study characterized the utilization of the SNAP program by disadvantaged HIV infected adults in Miami. It also assessed barriers to participation among eligible non-participants, and the impact of program participation on food insecurity, nutritional status, health status, disease stage, and quality of life of low income HIV infected individuals. In addition, this study determined the effectiveness of a nutritional education intervention in improving nutritional status through increasing nutrition knowledge, as well as self-efficacy skills in food selection and nutrient intake. 
Table 2: Literature Review: HIV and Nutritional Status

\begin{tabular}{|c|c|c|c|}
\hline Author/Study design & Study Purpose & Population & Findings \\
\hline $\begin{array}{l}\text { Dusingize JC, } \\
\text { Hoover DR et al. } \\
2012 \\
\text { Observational } \\
\text { study }\end{array}$ & $\begin{array}{l}\text { Determine if and how albumin } \\
\text { can be used as an indication of } \\
\text { malnutrition [Body Mass } \\
\text { Index(BMI), Fat free mass } \\
\text { index (FFMI) or Fat mass index } \\
\text { (FMI)] in HIV infected and } \\
\text { uninfected Africans }\end{array}$ & $\begin{array}{l}710 \text { HIV infected and } \\
226 \text { HIV-uninfected } \\
\text { women }\end{array}$ & $\begin{array}{l}\text { Unadjusted models: In HIV-negative and HIV positive women with } \\
\text { CD4 }>350 \text { cells } / \mu \mathrm{l} \text { : no significant association. In HIV+ women with } \\
\text { CD4 } 200-350 \text { cells } / \mu 1,(\mathrm{p}<0.05) \text { : significant association. In HIV+ } \\
\text { women with CD4 }<200 \text { cells } / \mu \mathrm{l}(\mathrm{P}<0.001) \text { : highly significant } \\
\text { association. Multivariable linear regression: Albumin remained } \\
\text { associated with FFMI in women with CD4 count }<200 \text { cells } / \mu 1(\mathrm{p}<0.01) \\
\text { but not in HIV+ women with CD4 }>200 \text {. Albumin measures end stage } \\
\text { disease and malnutrition in HIV infected individuals. }\end{array}$ \\
\hline $\begin{array}{l}\text { Liu E, Spiegelman } \\
\text { D et al. }{ }^{28} 2011\end{array}$ & $\begin{array}{l}\text { Investigate the associations } \\
\text { between nutritional status, } \\
\text { (body mass index (BMI), } \\
\text { middle upper arm } \\
\text { circumference (MUAC), and } \\
\text { hemoglobin (Hgb) at ART } \\
\text { initiation, and death in the first } \\
3 \text { months of ART. }\end{array}$ & $\begin{array}{l}18,271 \text { HIV infected } \\
\text { Tanzanian adults } \\
\text { initiating antiretroviral } \\
\text { therapy (ART) }\end{array}$ & $\begin{array}{l}\text { Lower BMI, MUAC, and Hgb concentrations were strongly associated } \\
\text { with a higher risk of death within } 3 \text { months of ART initiation. There } \\
\text { was a risk of death associated with weight loss across all levels of } \\
\text { baseline BMI. The highest risk however was observed among patients } \\
\text { with BMI }<17 \mathrm{~kg} / \mathrm{m}^{2}(\mathrm{RR}, 7.9 ; 95 \% \mathrm{CI}, 4.4-14.4) \text {. Poor nutritional } \\
\text { status at ART initiation and in the first } 3 \text { months of ART is strong } \\
\text { independent predictors of mortality. }\end{array}$ \\
\hline $\begin{array}{l}\text { Khalili H, } \\
\text { Soudkakhsh A et } \\
\text { al. }^{47} 2008 \\
\text { Cross-sectional } \\
\text { study }\end{array}$ & $\begin{array}{l}\text { Evaluate the nutritional status } \\
\text { of newly diagnose Iranian HIV } \\
\text { infected individuals and } \\
\text { compare their serum zinc and } \\
\text { selenium levels to uninfected } \\
\text { individuals of the same sex and } \\
\text { age. }\end{array}$ & $\begin{array}{l}100 \text { newly diagnosed } \\
\text { HIV infected Iranians } \\
\text { and } 100 \text { uninfected } \\
\text { controls }\end{array}$ & $\begin{array}{l}\text { Severe, moderate and mild malnutrition were detected in } 15 \%, 38 \% \text { and } \\
24 \% \text { of newly diagnosed HIV }+ \text { individuals respectively. Compared with } \\
\text { uninfected control group, serum zinc and selenium were significantly } \\
\text { lower among HIV infected ( } \mathrm{P}=0.01 \text { and } \mathrm{P}=0.02 \text { respectively). } \\
\text { Malnutrition and low serum zinc and selenium levels were found to be } \\
\text { prevalent in Iranian human immunodeficiency virus infected individuals }\end{array}$ \\
\hline $\begin{array}{l}\text { Hendricks KM, } \\
\text { Mwanburi DM et } \\
\text { al. }^{76} 2008 \\
\text { Longitudinal } \\
\text { cohort study }\end{array}$ & $\begin{array}{l}\text { Assessed the association } \\
\text { between dietary patterns ( } 3 \\
\text { patterns identified: juice and } \\
\text { soda; fast food and fruit drinks; } \\
\text { and fruit, vegetable, and low-fat } \\
\text { dairy and change in body mass } \\
\text { index (BMI), CD4 count, and } \\
\text { viral load (VL). }\end{array}$ & $\begin{array}{l}348 \text { HIV-positive adult } \\
\text { male with a } \mathrm{BMI}>\text { or }= \\
20.5\end{array}$ & $\begin{array}{l}\text { Individuals with fast food and fruit drinks pattern had the lowest fiber } \\
\text { intake, highest VL, and lowest CD4 count and had a lower income than } \\
\text { did subjects in the other } 2 \text { clusters. Subjects in the fruit, vegetable, and } \\
\text { low-fat dairy diet pattern had higher intakes of fiber, and micronutrients } \\
\text { and the highest BMI and CD4 count. Individuals with juice and soda } \\
\text { pattern had higher energy intakes and lowest BMI. }\end{array}$ \\
\hline $\begin{array}{l}\text { Hendricks KM, } \\
\text { Willis K, et al. } \\
2006\end{array}$ & $\begin{array}{l}\text { Describe the prevalence of } \\
\text { obesity among a cohort of } \\
\text { individuals living with HIV } \\
\text { infection, and to determine }\end{array}$ & $\begin{array}{l}321 \text { HIV-positive adults } \\
\text { (265 males, } 56 \text { females) } \\
\text { living in the greater } \\
\text { Boston, MA and }\end{array}$ & $\begin{array}{l}13 \% \text { and } 29 \% \text { males and females were respectively obese. Energy } \\
\text { intake per kilogram decreased as body mass index (BMI) decreased in } \\
\text { both genders }(\mathrm{p}<0.05) \text {. Mean total fat and saturated fat intakes were } \\
\text { above recommendations for both genders and for all BMI categories, }\end{array}$ \\
\hline
\end{tabular}




\begin{tabular}{|c|c|c|c|}
\hline $\begin{array}{l}\text { Cross- sectional } \\
\text { study }\end{array}$ & $\begin{array}{l}\text { differences in dietary intake } \\
\text { among those subjects who are } \\
\text { normal weight, overweight, and } \\
\text { obese }\end{array}$ & Providence, RI, areas & $\begin{array}{l}\text { while total grams dietary fiber decreased as BMI increased. } \\
\text { Micronutrient intakes were below the Dietary Reference Intakes for } \\
\text { individuals in all BMI categories. Serum markers of insulin resistance } \\
\text { differed significantly by BMI category for both genders. Diet quality for } \\
\text { the HIV infected may have implications for cardiovascular disease, } \\
\text { metabolic syndrome, and other health risks associated with overweight } \\
\text { and obesity }\end{array}$ \\
\hline $\begin{array}{l}\text { Campa A, Zhifang } \\
\text { Y et al. }{ }^{49} 2005\end{array}$ & $\begin{array}{l}\text { Document the prevalence of } \\
\text { HIV-related wasting and of } \\
\text { associated factors, including } \\
\text { food intake, viral load, quality } \\
\text { of life, and HAART use }\end{array}$ & $\begin{array}{l}119 \text { HIV infected } \\
\text { homeless drug users in } \\
\text { Miami FL }\end{array}$ & $\begin{array}{l}\text { The prevalence of HIV-related wasting was } 17.6 \% \text {. A greater number of } \\
\text { participants experiencing wasting received HAART, however, their } \\
\text { HIV RNA levels were more than twice as high (mean } \pm \text { standard } \\
\text { deviation }[\mathrm{SD}], 166,689 \pm 238,002 \text { copies } / \mathrm{mL} \text {; median log HIV RNA } \\
\text { level } \pm \mathrm{SD}, 10.2 \pm 2.7 \log _{10} \text { copies } / \mathrm{mL} \text { ) compared to those not } \\
\text { experience wasting (mean } \pm \mathrm{SD}, 72,156 \pm 149,080 \text {; median log HIV } \\
\text { RNA level } \pm \mathrm{SD}, 9.2 \pm 2.3 \log _{10} \text { copies } / \mathrm{mL} \text { ). Wasting was related to } \\
\text { heavy alcohol drinking and cocaine use. HIV-related wasting continues } \\
\text { to be common among HIV infected drug users, even among HAART } \\
\text { recipients. }\end{array}$ \\
\hline
\end{tabular}


Table 3: Literature Review: HIV and Food Insecurity

\begin{tabular}{|c|c|c|c|}
\hline Author/Study design & Study Purpose & Population & Findings \\
\hline $\begin{array}{l}\text { Weiser SD, Hatcher } \\
\text { A et al. }{ }^{112} \\
2013\end{array}$ & $\begin{array}{l}\text { Examined association between } \\
\text { food insecurity and } \\
\text { hospitalizations, emergency } \\
\text { department (ED) visits, and } \\
\text { non-ED outpatient visits. }\end{array}$ & $\begin{array}{l}347 \text { marginally housed } \\
\text { and homeless HIV } \\
\text { infected individuals in } \\
\text { San Francisco }\end{array}$ & $\begin{array}{l}56 \% \text { participants were food insecure at baseline. Compared with } \\
\text { food-secure persons, individuals reporting severe food insecurity had } \\
\text { increased odds of hospitalizations [(AOR) }=2.16,(95 \% \mathrm{CI})=1.50- \\
3.09] \text { and ED visits }(\mathrm{AOR}=1.71,95 \% \mathrm{CI}=1.06-2.30) \text {. Odds of an } \\
\text { outpatient visit were } 41 \% \text { higher for severely food insecure } \\
\text { individuals, results were not statistically significant. Mild/moderate } \\
\text { food insecurity was also associated with increased hospitalizations } \\
(\mathrm{AOR}=1.56,95 \% \mathrm{CI}=1.06-2.30) \text {, ED visits }(\mathrm{AOR}=1.57,95 \% \\
\mathrm{CI}=1.22-2.03) \text {, and outpatient visits (AOR }=1.68,95 \% \mathrm{CI}=1.20 \text { - } \\
2.17) \text {. Food insecurity is related to greater health services utilization } \\
\text { HIV infected individuals. }\end{array}$ \\
\hline $\begin{array}{l}\text { Weiser SD, Tsai AC } \\
\text { et al., }{ }^{6} \\
2012 \\
\text { Longitudinal cohort } \\
\text { study }\end{array}$ & $\begin{array}{l}\text { Understand the association } \\
\text { between food insecurity and } \\
\text { morbidity as well as healthcare } \\
\text { utilization patterns among HIV } \\
\text { infected individuals receiving } \\
\text { antiretroviral therapy program. }\end{array}$ & $\begin{array}{l}458 \text { HIV infected } \\
\text { individuals in Uganda }\end{array}$ & $\begin{array}{l}40 \% \text { participants were severely food insecure at baseline. } \\
\text { Opportunistic infections, increased hospitalizations and worse } \\
\text { physical health summary were associated with severe food insecurity. } \\
\text { Mild/moderate food insecurity was associated with missed clinic } \\
\text { visits. Policies and programs are needed to address food insecurity as } \\
\text { part HIV treatment programs. }\end{array}$ \\
\hline $\begin{array}{l}\text { Wang EA, } \\
\text { McGinnis KA et } \\
\text { al.,93 } \\
2011 \\
\text { Observational study }\end{array}$ & $\begin{array}{l}\text { Examine the impact of food } \\
\text { insecurity on HIV disease } \\
\text { outcomes among HIV infected } \\
\text { patients receiving antiretroviral } \\
\text { medications. }\end{array}$ & $\begin{array}{l}2353 \mathrm{HIV} \text { infected } \\
\text { veterans receiving } \\
\text { antiretroviral treatment }\end{array}$ & $\begin{array}{l}24 \% \text { were food insecure. Food insecure participants were more likely } \\
\text { to have an unsuppressed HIV-1 RNA (AOR } 1.37,95 \% \text { CI 1.09, 1.73) } \\
\text { compared to food secure participants. Antiretroviral medication } \\
\text { adherence and body mass index did not mediate the association } \\
\text { between food insecurity and unsuppressed HIV-1 RNA. Food } \\
\text { insecurity was not independently associated with low CD4 counts. }\end{array}$ \\
\hline $\begin{array}{l}\text { Weiser SD, } \\
\text { Frongillo EA et al. } \\
2009 \\
\text { Cross-sectional } \\
\text { study }\end{array}$ & $\begin{array}{l}\text { Assess the effect of food } \\
\text { insecurity on viral load } \\
\text { suppression and antiretroviral } \\
\text { adherence. }\end{array}$ & $\begin{array}{l}104 \text { marginally housed } \\
\text { and homeless HIV } \\
\text { infected individuals in } \\
\text { San Francisco }\end{array}$ & $\begin{array}{l}51 \% \text { experienced food security, } 24 \% \text { were mildly/ moderately food } \\
\text { insecure and } 25 \% \text { experienced severe food insecurity. Individuals } \\
\text { with severe food insecurity were less likely to achieve adherence } \\
\geq 80 \% \text {. Severe food insecurity was associated with a } 77 \% \text { decreased } \\
\text { odds of viral suppression }(95 \% \mathrm{CI}=0.06-0.82) \text {. Severe food } \\
\text { insecurity was associated with an } 85 \% \text { lower odds of viral } \\
\text { suppression }(95 \% \mathrm{CI}=0.02-0.99) \text { among those with } \leq 80 \% \text { adherence } \\
\text { and a } 66 \% \text { lower odds among those with }>80 \% \text { adherence }(95 \% \mathrm{CI}= \\
0.06-1.81) \text {. }\end{array}$ \\
\hline
\end{tabular}




\begin{tabular}{|c|c|c|c|}
\hline $\begin{array}{l}\text { Weiser SD, } \\
\text { Fernandes K et al. }^{65} \\
2008\end{array}$ & $\begin{array}{l}\text { Assess the associations between } \\
\text { food insecurity and mortality in } \\
\text { HIV infected antiretroviral } \\
\text { therapy (ART)-treated and } \\
\text { whether body max index (BMI) } \\
\text { modified associations. }\end{array}$ & $\begin{array}{l}1119 \text { HIV infected } \\
\text { individuals initiating } \\
\text { ART treatment in } \\
\text { Vancouver, British } \\
\text { Columbia (BC) }\end{array}$ & $\begin{array}{l}48 \% \text { were food insecure and } 14 \% \text { were underweight }(\mathrm{BMI}<18.5) \text {. } \\
14 \% \text { died from non-accidental deaths after a median follow-up time } \\
\text { of } 8.2 \text { years. After controlling for covariates variables, food insecure } \\
\text { and underweight individuals were nearly two times more likely to die } \\
{[(\mathrm{AHR})=1.90,(95 \% \mathrm{CI})=1.05-3.46] \text { compared with food secure and }} \\
\text { normal weight individuals. A trend towards increased mortality risk } \\
\text { was observed among food insecure and not underweight individuals } \\
(\mathrm{AHR}=1.40,95 \% \mathrm{CI}=0.91-2.16) \text {. In contrast, being underweight and } \\
\text { yet food secure was not associated with risk of death }(\mathrm{AOR}=0.83 \text {, } \\
95 \% \mathrm{CI}=0.33-2.11) . \text { Food insecurity is a risk factor for mortality } \\
\text { among ART-treated individuals in } \mathrm{BC} \text {, particularly among individuals } \\
\text { who are underweight. }\end{array}$ \\
\hline $\begin{array}{l}\text { Weiser SD, Leiter K } \\
\text { et al., } \\
2007 \\
\text { Cross-sectioanl } \\
\text { study }\end{array}$ & $\begin{array}{l}\text { Examine the association } \\
\text { between food insufficiency and } \\
\text { inconsistent condom use, sex } \\
\text { exchange, and other measures } \\
\text { of risky sex. }\end{array}$ & $\begin{array}{l}1,255 \text { HIV -infected } \\
\text { adults in Botswana and } \\
796 \text { adults in Swaziland }\end{array}$ & $\begin{array}{l}\text { Food insufficiency was reported among } 32 \% \text { and } 22 \% \text { of women and } \\
\text { men respectively. Food insufficiency was associated with inconsistent } \\
\text { condom use with a non-primary partner }[(\mathrm{AOR})=1.73,(95 \% \mathrm{CI})= \\
1.27-2.36] \text {, sex exchange (AOR } 1.84,95 \% \text { CI } 1.74-1.93), \\
\text { intergenerational sexual relationships (AOR } 1.46,95 \% \text { CI } 1.03-2.08) \text {, } \\
\text { and lack of control in sexual relationships (AOR } 1.68,95 \% \text { CI } 1.24- \\
2.28 \text { ). Food insufficiency is an important risk factor for increased } \\
\text { sexual risk-taking among women. }\end{array}$ \\
\hline
\end{tabular}


Table 4: Literature Review: HIV, Nutrition Programs and Impact on Health Outcomes

\begin{tabular}{|c|c|c|c|}
\hline Author & Study Purpose & Population & Findings \\
\hline $\begin{array}{l}\text { Tirivayi N, Koethe } \\
\text { JR et al. }{ }^{111} \\
2012 \\
\text { Cohort study }\end{array}$ & $\begin{array}{l}\text { Compare antiretroviral therapy } \\
\text { (ART) adherence, weight gain, } \\
\text { and CD4+ lymphocyte count } \\
\text { change in HIV infected food } \\
\text { assistance recipients to control } \\
\text { non-recipients. }\end{array}$ & $\begin{array}{l}145 \text { HIV infected adults } \\
\text { receiving food } \\
\text { assistance and } 147 \text { HIV } \\
\text { infected non-recipient } \\
\text { control group in Lusaka } \\
\text { Zambia }\end{array}$ & $\begin{array}{l}\text { Food assistance recipients had higher ART adherence compared to } \\
\text { non-recipients }(98.3 \% \text { vs. } 88.8 \% \text {; }<0.01 \text { ) after } 6 \text { months. No } \\
\text { significant effects were observed for weight or CD4+ lymphocyte } \\
\text { count change. Adherence rates was greater for individuals who } \\
\text { received ART for }<230 \text { days, and among those with BMI }<18.5 \\
\mathrm{~kg} / \mathrm{m}^{2} \text {, a higher HIV disease stage, or a CD } 4+\text { lymphocyte count } \leq \\
350 \text { cells } / \mu \mathrm{l} \text {. }\end{array}$ \\
\hline $\begin{array}{l}\text { Ivers LC, Chang Y } \\
\text { et al. } \\
2010 \\
\text { Prospective } \\
\text { observational cohort } \\
\text { study }\end{array}$ & $\begin{array}{l}\text { Evaluate the impact of food } \\
\text { assistance on patient outcomes } \\
\text { in a comprehensive HIV } \\
\text { program }\end{array}$ & $\begin{array}{l}600 \text { HIV infected } \\
\text { individuals enrolled in } \\
\text { HIV care in Partners In } \\
\text { Health (PIH) programs } \\
\text { in rural Haiti. }\end{array}$ & $\begin{array}{l}\text { Food security improved significantly among food assistance } \\
\text { recipients compared to controls }(-3.55 \text { vs. }-0.16 ; \mathrm{P}<0.0001) \text {; BMI } \\
\text { decreased significantly less in the intervention group compared to } \\
\text { controls }(-0.20 \text { vs. }-0.66 ; \mathrm{P}=0.020) \text {. Food assistance was associated } \\
\text { with improved food security }(-3.49 \text { vs. }-1.89, \mathrm{P}=0.011) \text { and BMI } \\
(0.22 \text { vs. }-0.67, \mathrm{P}=0.036) \text { at } 12 \text { months. At } 6 \text { month and } 12 \text { months, } \\
\text { food assistance was associated with improved adherence to monthly } \\
\text { clinic visits; }(\mathrm{P}<0.001) \text { and }(\mathrm{P}=0.033) \text { respectively. }\end{array}$ \\
\hline $\begin{array}{l}\text { Rawat R, Kadiyala S } \\
\text { et al. }{ }^{160} \\
2010 \\
\text { Cohort study }\end{array}$ & $\begin{array}{l}\text { Evaluate the impact of food } \\
\text { assistance (FA) on change in } \\
\text { weight and disease progression }\end{array}$ & $\begin{array}{l}14,481 \text { HIV infected } \\
\text { FA recipients and } \\
\text { control non-recipients } \\
\text { from the AIDS Support } \\
\text { Organization (TASO) } \\
\text { in Uganda }\end{array}$ & $\begin{array}{l}\text { Among individuals receiving food assistance but not anti-retroviral } \\
\text { the assistance resulted in a mean weight gain of } 0.36 \mathrm{~kg} \text { compared to } \\
\text { their matched controls. The highest weight gain of } 1.9 \mathrm{~kg} \text { was } \\
\text { observed among individuals with the most advanced disease at } \\
\text { baseline. Receiving food assistance had only minimal impact on } \\
\text { disease progression. }\end{array}$ \\
\hline $\begin{array}{l}\text { Kaiser } \mathrm{L}^{152} \\
2008 \\
\text { Longitudinal study }\end{array}$ & $\begin{array}{l}\text { Determine the factors } \\
\text { associated with Food Stamp } \\
\text { Program (FSP) participation in } \\
\text { a potentially eligible population }\end{array}$ & $\begin{array}{l}527 \text { FSP female } \\
\text { participants and } 1405 \\
\text { potentially eligible non- } \\
\text { participants in } \\
\text { California }\end{array}$ & $\begin{array}{l}\text { Factors associated with participation: single mother with children; } \\
\text { unemployed; on welfare; on WIC (the Special Supplemental Nutrition } \\
\text { Program for Women, Infants, and Children); and US-born. } \\
\text { Barriers to participation: females }<25 \text { years and }>54 \text { years, being } \\
\text { Hispanic, perception of need and or eligibility for program, lack of } \\
\text { knowledge about application process, stigma, and citizenship status. }\end{array}$ \\
\hline $\begin{array}{l}\text { Perez-Escamilla R, } \\
\text { Ferris AM et al. }{ }^{132} \\
2000\end{array}$ & $\begin{array}{l}\text { Examine the association of the } \\
\text { Food Stamp Program (FSP) } \\
\text { with the food security and } \\
\text { dietary intake of low income } \\
\text { children }\end{array}$ & $\begin{array}{l}99 \text { low income FSP } \\
\text { participating and non- } \\
\text { participating } \\
\text { preschoolers enrolled in } \\
\text { the WIC from } \\
\text { Hartford, CT }\end{array}$ & $\begin{array}{l}\text { Among FSP recipients, benefits lasting }<4 \text { weeks was associated with } \\
\text { food security }(\mathrm{OR}=0.10,95 \% \mathrm{CI}=0.02-0.56) \mathrm{FSP} \text { use was related to } \\
\text { above-median intakes of vitamin B-6 }(3.13,1.16-8.45) \text {, folate }(2.92 \text {, } \\
1.09-7.81) \text { and iron }(3.72,1.31-10.54) \text {. The NFS children were more } \\
\text { likely to consume }<8 \mathrm{mg} \text { iron/d }(3.73,1.09-12.80) \text {. FSP is associated } \\
\text { with preschoolers' food security and micronutrient intake. }\end{array}$ \\
\hline
\end{tabular}


Table 5: Literature Review: Nutrition Education in HIV infected Individuals

\begin{tabular}{|c|c|c|c|}
\hline Author & Study Purpose & Population & Findings \\
\hline $\begin{array}{l}\text { Segal-Isaacson CJ, } \\
\text { Tobin JN et al. } \\
2006 \\
\text { Quasi-experimental } \\
\text { design }\end{array}$ & $\begin{array}{l}\text { Determine whether nutrition } \\
\text { education can succeed in } \\
\text { improving longer-term dietary } \\
\text { patterns in disadvantaged } \\
\text { populations with HIV/AIDS }\end{array}$ & $\begin{array}{l}466 \text { disadvantaged } \\
\text { women with HIV/AIDS }\end{array}$ & $\begin{array}{l}\text { Nutrition education led to significant improvement in dietary patterns } \\
\text { for all participants even after } 18 \text { months after intervention. There } \\
\text { were decreases in the consumption of high fat and high sugar foods. }\end{array}$ \\
\hline $\begin{array}{l}\text { McDermott AY, } \\
\text { Shevitz A et al. } \\
2003 \\
\text { Quasi-experimental } \\
\text { design }\end{array}$ & $\begin{array}{l}\text { Determine the effectiveness of } \\
\text { intensive dietary counseling } \\
\text { plus an oral nutrition } \\
\text { supplement on energy and } \\
\text { protein intake, weight, and } \\
\text { fat-free mass }\end{array}$ & $\begin{array}{l}39 \text { HIV infected } \\
\text { persons with } \\
\text { documented wasting } \\
\text { receiving nutrition } \\
\text { intervention and } 56 \\
\text { controls who did not } \\
\text { receive intervention }\end{array}$ & $\begin{array}{l}\text { Nutrition education resulted in marked improvements in dietary } \\
\text { intake, weight, and body composition, during and after intervention. }\end{array}$ \\
\hline $\begin{array}{l}\text { Van Niekerk C, } \\
\text { Smego RA et al. } \\
2000 \\
\text { Randomized control } \\
\text { trial }\end{array}$ & $\begin{array}{l}\text { Determine the effect of } \\
\text { nutritional education and } \\
\text { dietary counseling on body } \\
\text { weight in HIV/AIDS patients. }\end{array}$ & $\begin{array}{l}90 \mathrm{HIV} / \mathrm{AIDS} \\
\text { antiretroviral naïve } \\
\text { treatment(ART) naïve } \\
\text { individuals }\end{array}$ & $\begin{array}{l}\text { After a mean follow-up period of } 4.2 \text { months, body weight compared } \\
\text { to baseline was greater in intervention group compared to controls } \\
(P<0.01) \text {. Intervention helped to offset the adverse effects of } \\
\text { gastrointestinal tract or systemic infection (especially in patients with } \\
\left.\text { CD4+ counts }<200 \text { cells } \mathrm{mm}^{-3}\right) \text {. }\end{array}$ \\
\hline $\begin{array}{l}\text { Berneis K, Battegay } \\
\text { M et al. } \\
2000 \\
\text { Quasi-experimental } \\
\text { design }\end{array}$ & $\begin{array}{l}\text { Assess the effect of an oral } \\
\text { nutritional supplement } \\
\text { combined with nutritional } \\
\text { counseling on whole body } \\
\text { protein metabolism }\end{array}$ & $\begin{array}{l}8 \mathrm{HIV} \text { infected patients } \\
\text { with a body mass index } \\
<21 \mathrm{~kg} \mathrm{~m}-2 \text { or CD4-T } \\
\text { cells }<500 \text { in stable } \\
\text { clinical condition who } \\
\text { received intervention } \\
\text { and } 7 \text { identical controls. }\end{array}$ & $\begin{array}{l}\text { Leucine oxidation decreased in nutritional intervention after } 12 \text { weeks } \\
(\mathrm{P}<0.05) \text { with no change in the control group. Lean body mass } \\
\text { increased in the intervention group }(\mathrm{P}<0.05) \text { and fat mass decreased } \\
(\mathrm{P}<0.05) \text { with no changes in the control group. The intervention had } \\
\text { no significant effect on lymphocyte } \mathrm{CD} 4 \text { counts and on quality of life. }\end{array}$ \\
\hline $\begin{array}{l}\text { Schwenk A, Steuck } \\
\text { H et al. }{ }^{170} \\
1999 \\
\text { Randomized non- } \\
\text { blinded control trial }\end{array}$ & $\begin{array}{l}\text { Compare nutritional counseling } \\
\text { with and without oral } \\
\text { supplements in HIV infected } \\
\text { patients with recent weight loss }\end{array}$ & $\begin{array}{l}\text { HIV infected patients } \\
\text { with recent weight loss. } \\
n=24 \text { : counseling and } \\
\text { normal food } \\
n=26: \text { counseling and } \\
\text { fortified supplements }\end{array}$ & $\begin{array}{l}\text { Fat free mass increased from baseline to week } 8(\mathrm{P}<0.05) \text { with no } \\
\text { difference between the two groups }(\mathrm{P}=0.97) \text {. Body cell mass and } \\
\text { weight gain were not significant and equal between groups. Total } \\
\text { energy intake was not different between groups at weeks } 6 \text { and } 8 \text {. }\end{array}$ \\
\hline
\end{tabular}




\section{References}

1. HIV in the United States: At A Glance. Centers for Disease Control Web site. http://www.cdc.gov/hiv/resources/factsheets/us.htm. Assessed September 10, 2012.

2. Campsmith ML, Rhodes PH, Hall HI, Green TA. Undiagnosed HIV Prevalence Among Adults and Adolescents in the United States at the End of 2006. J Acquir Immune Defic Syndr 2010;53(5):619-624.

3. Marks G, Crepaz N, Janssen RS. Estimating sexual transmission of HIV from persons aware and unaware that they are infected with the virus in the USA. AIDS. 2006;20(10):1447-1450.

4. Florida Annual Report 2011, Aquired Immune Deficiency Styndrome/Human Immunodeficiency Virus. Florida Deparment of Health Web site. www.doh.state.fl.us/disease ctrl/aids/trends/epiprof/HIVAIDS annual_morbidity 2011.pdf. Accessed September 10, 2012.

5. Florida Charts: Community Health Assessment Resource Tool Set. Office of Health Statistics and Assessments. Florida Deparment of Health Website. http://www.floridacharts.com/charts/report.aspx?domain=01\&IndNumber=0141. Accessed September 10, 2012.

6. State Health Profiles: Florida Profile. 2010. Centers for Disease Control and Prevention Website. www.cdc.gov/nchhstp/stateprofiles/pdf/florida profile.pdf. Accessed September 10, 2012.

7. HIV/AIDS in Miami-Dade County: Fact Sheet. 2011. Miami-Dade County Health Department Web site. http://www.dadehealth.org/downloads/FS-2011MIAMIDADE-New.pdf. Accessed September 10, 2012.

8. Miami-Dade HIV/AIDS Partnership 2009-2011 Comprehensive Plan for HIV/AIDS. 2009. Mimai-Dade County Health Department Web site. http://www.aidsnet.org/newmain/partnershipall/partnership/0911 compplan.pdf. Accessed September 10, 2012.

9. Katona P, Katona-Apte J. The Interaction between Nutrition and Infection. Clin Infect Dis. 2008;46(10):1582-1588. 
10. Piwoz E, Preble E. HIV / AIDS and nutrition: a review of the literature and recommendations for nutritional care and support in sub-Saharan Africa Washington, DC: Academy for Educational Development [AED], Support for Analysis and Research in Africa Project [SARA]. 2000.

11. Semba RD, Tang AM. Micronutrients and the pathogenesis of human immunodeficiency virus infection. Bri J of Nutr. 1999;81(03):181-189.

12. McCorkindale C, Dybevik K, Coulston AM, Sucher KP. Nutritional status of HIV-infected patients during the early disease stages. $J$ Am Diet Assoc. 1990;90(9):1236-1241.

13. Kim JH, Spiegelman D, Rimm E, Gorbach SL. The correlates of dietary intake among HIV-positive adults. Am J Clin Nutri. 2001;74(6):852-861.

14. Baum M, Cassetti L, Bonvehi P, Shor-Posner G, Lu Y, Sauberlich H. Inadequate dietary intake and altered nutrition status in early HIV-1 infection. Nutr. 1994;10(1):16-20.

15. Mangili A, Murman DH, Zampini AM, Wanke CA, Mayer KH. Nutrition and HIV Infection: Review of Weight Loss and Wasting in the Era of Highly Active Antiretroviral Therapy from the Nutrition for Healthy Living Cohort. Clin Infect Dis. 2006;42(6):836-842.

16. Babameto G, Kotler DP. Malnutrition in HIV infection. Gastroenterol Clin North Am. 1997;26(2):393-415.

17. Keating J, Bjarnason I, Somasundaram S, et al. Intestinal absorptive capacity, intestinal permeability and jejunal histology in HIV and their relation to diarrhoea. Gut. 1995;37(5):623-629.

18. Cunningham-Rundles S. Effects of nutritional status on immunological function. Am J Clin Nutr. 1982;35(5):1202-1210.

19. Meydani SN, Beharka AA. Recent developments in vitamin E and immune response. Nutr Rev. 1998;56(1 Pt 2):S49-58. 
20. Maggini S, Wintergerst ES, Beveridge S, Hornig DH. Selected vitamins and trace elements support immune function by strengthening epithelial barriers and cellular and humoral immune responses. Br J Nutr. 2007;98(1):S29-35.

21. WHO. Nutrient Requirements for People Living with HIV/. AIDS: Report of a Technical Consultation, Geneva:WHO. 2003.

22. Shevitz AH, Knox TA, Spiegelman D, Roubenoff R, Gorbach SL, Skolnik PR. Elevated resting energy expenditure among HIV-seropositive persons receiving highly active antiretroviral therapy. AIDS. 1999;13(11):1351-1357.

23. FANTA. Food Assistance Programming in the Context of HIV. Food and Nutrition Technical Assistance (FANTA) Project and World Food Programme (WFP). Washington, DC: FANTA Project, Academy for Educational Development 2007.

24. Mosby's Medical Dictionary. 8th ed: Elsevier Inc. 2009.

25. Melchior J-C, Niyongabo T, Henzel D, Durack-Bown I, Henri S-C, Boulier A. Malnutrition and wasting, immunodepression, and chronic inflammation as independent predictors of survival in HIV-infected patients. Nutr. 1999;15(1112):865-869.

26. Chlebowski RT, Grosvenor MB, Bernhard NH, Morales LS, Bulcavage LM. Nutritional status, gastrointestinal dysfunction, and survival in patients with AIDS. Am J Gastroenterol. 1989;84(10):1288-1293.

27. Scrimshaw NS. Effect of infection on nutritional status. Proc Natl Sci Counc Repub China B. 1992;16(1):46-64.

28. Liu E, Spiegelman D, Semu H, et al. Nutritional status and mortality among HIVinfected patients receiving antiretroviral therapy in Tanzania. J Infect Dis. 2011;204(2):282-290.

29. Koethe JR, Heimburger DC. Nutritional aspects of HIV-associated wasting in sub-Saharan Africa. Am J Clin Nutr.. 2010; 91(4):1138S-1142S 
30. Semba RD, Shah N, Strathdee SA, Vlahov D. High prevalence of iron deficiency and anemia among female injection drug users with and without HIV infection. $J$ Acquir Immune Defic Syndr. 2002;29(2):142-144.

31. Periquet BA, Jammes NM, Lambert WE, et al. Micronutrient levels in HIV-1infected children. AIDS. 1995;9(8):887-893.

32. Beach RS, Mantero-Atienza E, Shor-Posner G, et al. Specific nutrient abnormalities in asymptomatic HIV-1 infection. AIDS. 1992;6(7):701-708.

33. Lacey CJ, Murphy ME, Sanderson MJ, Monteiro EF, Vail A, Schorah CJ. Antioxidant-micronutrients and HIV infection. Int J STD AIDS. 1996;7(7):485489.

34. Tang AM, Lanzillotti J, Hendricks K, et al. Micronutrients: current issues for HIV care providers. AIDS. 2005;19(9):847-61.; 2005.

35. Tang AM, Smit E. Selected vitamins in HIV infection: a review. AIDS Patient Care STDS. 1998;12(4):263-273.

36. Baum MK. Role of Micronutrients in HIV-Infected Intravenous Drug Users. $J$ Acquir Immune Defic Syndr. 2000;25:S49-S52.

37. Haug CJ, Aukrust P, Haug E, Mørkrid L, Müller F, Frøland SS. Severe Deficiency of 1,25-Dihydroxyvitamin D3 in Human Immunodeficiency Virus Infection: Association with Immunological Hyperactivity and Only Minor Changes in Calcium Homeostasis. J Clin Endocrinol Metab. 1998;83(11):38323838 .

38. Wanke CA, Silva M, Knox TA, Forrester J, Speigelman D, Gorbach SL. Weight Loss and Wasting Remain Common Complications in Individuals Infected with Human Immunodeficiency Virus in the Era of Highly Active Antiretroviral Therapy. Clin Infect Dis. 2000;31(3):803-805.

39. Batterham M, Gold J, Naidoo D, et al. A preliminary open label dose comparison using an antioxidant regimen to determine the effect on viral load and oxidative stress in men with HIV/AIDS. Eur J Clin Nutr. 2001;55(2):107-114. 
40. Look MP, Riezler R, Berthold HK, et al. Decrease of elevated N,Ndimethylglycine and N-methylglycine in human immunodeficiency virus infection during short-term highly active antiretroviral therapy. Metabolism. 2001;50(11):1275-1281.

41. Remacha AF, Cadafalch $J$, Sardà $P$, Barceló M, Fuster M. Vitamin B-12 metabolism in HIV-infected patients in the age of highly active antiretroviral therapy: role of homocysteine in assessing vitamin B-12 status. Am J Clin Nutr. $2003 ; 77(2): 420-424$.

42. Rousseau MC, Molines C, Moreau J, Delmont J. Influence of highly active antiretroviral therapy on micronutrient profiles in HIV-infected patients. Ann Nutr Metab. 2000;44(5-6):212-216.

43. Tang AM, Smit E, Semba RD, et al. Improved antioxidant status among HIVinfected injecting drug users on potent antiretroviral therapy. J Acquir Immune Defic Syndr. 2000;23(4):321-326.

44. Toma E, Devost D, Lan NC, Bhat PV. HIV-protease inhibitors alter retinoic acid synthesis. AIDS. 2001;15(15):1979-1984.

45. Wellinghausen N, Kern WV, Jochle W, Kern P. Zinc serum level in human immunodeficiency virus-infected patients in relation to immunological status. Biol Trace Elem Res. 2000;73(2):139-149.

46. Woods MN, Tang AM, Forrester J, et al. Effect of Dietary Intake and Protease Inhibitors on Serum Vitamin B12 Levels in a Cohort of Human Immunodeficiency Virus-Positive Patients. Clin Infect Dis. 2003;37(2):S124S131.

47. Khalili H, Soudbakhsh A, Hajiabdolbaghi M, et al. Nutritional status and serum zinc and selenium levels in Iranian HIV infected individuals. BMC Infect Dis. 2008;8:165. doi:10.1186/1471-2334-8-165.

48. Wheeler DA, Gibert CL, Launer CA, et al. Weight Loss as a Predictor of Survival and Disease Progression in HIV Infection. J. Acquir Immune Defic Syndr. 1998;18(1):80-85. 
49. Campa A, Zhifang Y, Lai S, et al. HIV-Related Wasting in HIV-Infected Drug Users in the Era of Highly Active Antiretroviral Therapy. Clin Infect Dis. 2005;41(8):1179-1185.

50. Tang AM, Jacobson DL, Spiegelman D, Knox TA, Wanke C. Increasing Risk of $5 \%$ or Greater Unintentional Weight Loss in a Cohort of HIV-Infected Patients, 1995 to 2003. J. Acquir Immune Defic Syndr. 2005;40(1):70-76.

51. Tang AM, Forrester J, Spiegelman D, Knox TA, Tchetgen E, Gorbach SL. Weight Loss and Survival in HIV-Positive Patients in the Era of Highly Active Antiretroviral Therapy. J. Acquir Immune Defic Syndr. 2002;31(2):230-236.

52. Hendricks KM, Willis $\mathrm{K}$, Houser R, Jones CY. Obesity in HIV-Infection: Dietary Correlates. J Am Coll Nutr. 2006;25(4):321-331.

53. Shevitz AH, Knox TA. Nutrition in the Era of Highly Active Antiretroviral Therapy. Clin Infect Dis. 2001;32(12):1769-1775.

54. Amorosa V, Synnestvedt M, Gross R, et al. A Tale of 2 Epidemics: The Intersection Between Obesity and HIV Infection in Philadelphia. J. Acquir Immune Defic Syndr. 2005;39(5):557-561.

55. Crum-Cianflone N, Roediger MP, Eberly L, et al. Increasing Rates of Obesity among HIV-Infected Persons during the HIV Epidemic. PLOS ONE. 2010;5(4):e10106.

56. Crum-Cianflone N, Tejidor R, Medina S, Barahona I, Ganesan A. Obesity among patients with HIV: the latest epidemic. AIDS Patient Care STDS. 2008;22(12):925-930.

57. Hodgson LM, Ghattas H, Pritchitt H, Schwenk A, Payne L, Macallan DC. Wasting and obesity in HIV outpatients. AIDS. 2001;15(17):2341-2342.

58. Campa A, Yang Z, Sales S, PhIllips J, Lai J, Lai S. Inadequate Food and Micronutrient Intake in HIV+ Drug users. International Conference on AIDS. Barcelona 2002. 
59. Anema A, Weiser SD, Fernandes KA, et al. High prevalence of food insecurity among HIV-infected individuals receiving HAART in a resource-rich setting. AIDS Care. 2011;23(2):221-230.

60. Quach LA, Wanke CA, Schmid CH, et al. Drug use and other risk factors related to lower body mass index among HIV-infected individuals. Drug Alcohol Depend. 2008;95(1-2):30-36.

61. Normen L, Chan K, Braitstein P, et al. Food Insecurity and Hunger Are Prevalent among HIV-Positive Individuals in British Columbia, Canada. J. Nutr. 2005;135(4):820-825.

62. Vogenthaler N, Hadley C, Rodriguez A, Valverde E, del Rio C, Metsch L. Depressive Symptoms and Food Insufficiency Among HIV-Infected Crack Users in Atlanta and Miami. AIDS Behav. 2011;15(7):1520-1526.

63. Weiser S, Bangsberg D, Kegeles S, Ragland K, Kushel M, Frongillo E. Food Insecurity Among Homeless and Marginally Housed Individuals Living with HIV/AIDS in San Francisco. AIDS Behavior. 2009;13(5):841-848.

64. Weiser S, Frongillo E, Ragland K, Hogg R, Riley E, Bangsberg D. Food Insecurity is Associated with Incomplete HIV RNA Suppression Among Homeless and Marginally Housed HIV-infected Individuals in San Francisco. $J$ Gen Intern Med. 2009;24(1):14-20.

65. Weiser SD, Fernandes KA, Brandson EK, et al. The association between food insecurity and mortality among HIV-infected individuals on HAART. J Acquir Immune Defic Syndr. 2009;52(3):342-349.

66. Weiser SD, Tsai AC, Gupta R, et al. Food insecurity is associated with morbidity and patterns of healthcare utilization among HIV-infected individuals in a resource-poor setting. AIDS. 2012;26(1):67-75.

67. Baum MK, Jayaweera DT, Duan R, et al. Quality of Life, Symptomatology and Healthcare Utilization in HIV/HCV Co-Infected Drug Users in Miami. J. Addict Dis. 2008;27(2):37-48.

68. Dorey-Stein Z, Amorosa VK, Kostman JR, Lo Re V, 3rd, Shannon RP. Severe weight gain, lipodystrophy, dyslipidemia, and obstructive sleep apnea in a human 
immunodeficiency virus-infected patient following highly active antiretroviral therapy. J Cardiometab Syndr. 2008;3(2):111-114.

69. Grinspoon S. Insulin resistance in the HIV-lipodystrophy syndrome. Trends in Endocrinology \& Metabolism. 2001;12(9):413-419.

70. Batterham MJ, Garsia R, Greenop PA. Dietary intake, serum lipids, insulin resistance and body composition in the era of highly active antiretroviral therapy 'Diet FRS Study'. AIDS. 2000;14(12):1839-1843.

71. Jaime PC, Florindo AA, Latorre Mdo R, Segurado AA. Central obesity and dietary intake in HIV/AIDS patients. Rev Saude Publica. 2006;40(4):634-640.

72. Joy T, Keogh HM, Hadigan C, et al. Dietary fat intake and relationship to serum lipid levels in HIV-infected patients with metabolic abnormalities in the HAART era. AIDS. 2007;21(12):1591-1600.

73. Samaras K, Wand H, Law M, Emery S, Cooper DA, Carr A. Dietary intake in HIV-infected men with lipodystrophy: relationships with body composition, visceral fat, lipid, glucose and adipokine metabolism. Curr HIV Res. 2009;7(4):454-461.

74. Chlebowski RT, Grosvenor M, Lillington L, Sayre J, Beall G. Dietary Intake and Counseling, Weight Maintenance, and the Course of HIV Infection. J. Am Diet Assoc. 1995;95(4):428-435.

75. Hendricks KM, Dong KR, Tang AM, et al. High-fiber diet in HIV-positive men is associated with lower risk of developing fat deposition. Am. J Clin Nutr. 2003;78(4):790-795.

76. Hendricks KM, Mwamburi DM, Newby P, Wanke CA. Dietary patterns and health and nutrition outcomes in men living with HIV infection. Am. J Clin Nutr. 2008;88(6):1584-1592.

77. Hendricks KM, Sansavero M, Houser RF, Tang AM, Wanke CA. Dietary supplement use and nutrient intake in HIV-infected persons. AIDS Read. 2007;17(4):211-216. 
78. Smit E, Graham NMH, Tang A, Flynn C, Solomon L, Vlahov D. Dietary intake of community-based HIV-1 seropositive and seronegative injecting drug users.

Nutrition. 1996;12(7-8):496-501.

79. Swaminathan S, Padmapriyadarsini C, Sukumar B, et al. Nutritional Status of Persons with HIV Infection, Persons with HIV Infection and Tuberculosis, and HIV-Negative Individuals from Southern India. Clin Infect Dis. 2008;46(6):946949.

80. Vorster HH, Kruger A, Margetts BM, et al. The nutritional status of asymptomatic HIV-infected Africans: directions for dietary intervention. Public Health Nutr. 2004;7(08):1055-1064.

81. Luder E, Godfrey E, Godbold J, Simpson DM. Assessment of Nutritional, Clinical, and Immunologic Status of HIV-Infected, Inner-City Patients with Multiple Risk Factors. J Am Diet Assoc. 1995;95(6):655-660.

82. Chlebowski RT, Grosvenor M, Kruger S, Bulcavage L, Beck K, Beall G. Dietary intake in HIV infection: relative caloric deficiency in patients with AIDS. Internationa Confonference on AIDS. 1989 Jun 4-9;5:467 (abstract no. Th.B.P.307).

83. Woods MN, Spiegelman D, Knox TA, et al. Nutrient intake and body weight in a large HIV cohort that includes women and minorities. J Am Diet Assoc. 2002;102(2):203-211.

84. Steenkamp L, Dannhauser A, Walsh D, et al. Nutritional, immune, micronutrient and health status of HIV-infected children in care centres in Mangaung. South Afr J Clin Nutr. 2009;22(3):131-136.

85. Dusingize J-C, Hoover DR, Shi Q, et al. Association of Serum Albumin with Markers of Nutritional Status among HIV-Infected and Uninfected Rwandan Women. PLoS ONE. 2012;7(4):e35079.

86. Graham SM, Baeten JM, Richardson BA, et al. A decrease in albumin in early HIV type 1 infection predicts subsequent disease progression. AIDS Res Hum Retroviruses. 2007;23(10):1197-1200. 
87. Feldman JG, Burns DN, Gange SJ, et al. Serum albumin as a predictor of survival in HIV-infected women in the Women's Interagency HIV Study. AIDS. 2000;14(7):863-870.

88. Andersen SA. Core indicators of nutritional state for difficult-to-sample populations. J Nutr. 1990;11:1559-1600.

89. Keenan DP, Olson C, Hersey JC, Parmer SM. Measures of Food Insecurity/Security. J Nutr. Edu. 2001;33(1):S49-S58.

90. Food Security in the US. 2012, Economic Research Service. United States Department of Agriculture Website. http://www.ers.usda.gov/topics/foodnutrition-assistance/food-security-in-the-us.aspx. Accessed September 18, 2012.

91. Vogenthaler NS, Hadley C, Lewis SJ, Rodriguez AE, Metsch LR, Del Rio C. Food insufficiency among HIV-infected crack-cocaine users in Atlanta and Miami. Public Health Nutr. 2010;15:1-7.

92. Anema A, Kerr T, Weiser SD, Montaner JSG, Wood E. Prevalence and correlates of self-reported hunger among HIV+ and HIV- injection drug users in Canada 5th International AIDS Society Conference on HIV Pathogenesis and Treatment Cape Town, South Africa 2009.

93. Wang E, McGinnis K, Fiellin D, et al. Food Insecurity is Associated with Poor Virologic Response among HIV-Infected Patients Receiving Antiretroviral Medications. J. Gen Intern Med. 2011;26(9):1012-1018.

94. Mamlin J, Kimaiyo S, Lewis S, et al. Integrating nutrition support for foodinsecure patients and their dependents into an HIV care and treatment program in Western Kenya. Am J Public Health. 2009;99(2):215-221.

95. Bukusuba J, Kikafunda JK, Whitehead RG. Food security status in households of people living with HIV/AIDS (PLWHA) in a Ugandan urban setting. Br J Nutr. 2007;98(1):211-217.

96. Anema A, Vogenthaler N, Frongillo E, Kadiyala S, Weiser S. Food insecurity and HIV/AIDS: current knowledge, gaps, and research priorities. Curr HIV/AIDS Rep. 2009;6:224-231. 
97. Dunkle KL, Jewkes RK, Brown HC, Gray GE, McIntryre JA, Harlow SD. Transactional sex among women in Soweto, South Africa: prevalence, risk factors and association with HIV infection. Soc Sci Med. 2004;59(8):1581-1592.

98. Oyefara JL. Food insecurity, HIV/AIDS pandemic and sexual behaviour of female commercial sex workers in Lagos metropolis, Nigeria. Sahara J. 2007;4(2):626-635.

99. Gillespie S, Kadiyala S, Greener R. Is poverty or wealth driving HIV transmission? AIDS. 2007;21(7):S5-S16.

100. Weiser SD, Leiter K, Bangsberg DR, et al. Food Insufficiency Is Associated with High-Risk Sexual Behavior among Women in Botswana and Swaziland. PLoS Med. 2007;4(10):e260.

101. Shannon $K$, Kerr T, Zhang R, et al. Hunger and food insufficiency are independently correlated with unprotected sex among HIV+ injection drug users both on and not on HAART 5th International AIDS S Conference on HIV Pathogenesis and Treatment. Cape Town, South Africa 2009.

102. Gillespie S, Kadiyala S, International Food Policy Research I. HIV /AIDS and food and nutrition security: from evidence to action. Washington, DC: IFPRI; 2005 .

103. Mshana GH, Wamoyi J, Busza J, et al. Barriers to accessing antiretroviral therapy in Kisesa, Tanzania: a qualitative study of early rural referrals to the national program. AIDS Patient Care STDS. 2006;20(9):649-657.

104. Tuller DM, Bangsberg DR, Senkungu J, Ware NC, Emenyonu N, Weiser SD. Transportation costs impede sustained adherence and access to HAART in a clinic population in southwestern Uganda: a qualitative study. AIDS Behav. 2010;14(4):778-784.

105. Unge C, Johansson A, Zachariah R, Some D, Van Engelgem I, Ekstrom AM. Reasons for unsatisfactory acceptance of antiretroviral treatment in the urban Kibera slum, Kenya. AIDS Care. 2008;20(2):146-149.

106. Wig N, Bhatt SP, Sakhuja A, Srivastava S, Agarwal S. Dietary adequacy in Asian Indians with HIV. AIDS Care. 2008;20(3):370-375. 
107. Ramirez Garcia P, Cote JK. Factors affecting adherence to antiretroviral therapy in people living with HIV/AIDS. J Assoc Nurses AIDS Care. 2003;14(4):37-45.

108. Olupot-Olupot P, Katawera A, Cooper C, Small W, Anema A, Mills E. Adherence to antiretroviral therapy among a conflict-affected population in Northeastern Uganda: a qualitative study. AIDS. 2008;22(14):1882-1884.

109. Cantrell RA, Sinkala M, Megazinni K, et al. A Pilot Study of Food Supplementation to Improve Adherence to Antiretroviral Therapy Among FoodInsecure Adults in Lusaka, Zambia. J Acquir Immune Defic Syndr. 2008;49(2):190-195.

110. Byron E, Gillespie S, Nangami M. Integrating nutrition security with treatment of people living with HIV: lessons from Kenya. Food Nutr Bull. 2008;29(2):87-97.

111. Tirivayi N, Koethe JR, Groot W. Clinic-Based Food Assistance is Associated with Increased Medication Adherence among HIV-Infected Adults on Long-Term Antiretroviral Therapy in Zambia. J AIDS Clin Res. 2012;3(7):24.

112. Weiser SD, Hatcher A, Frongillo EA, et al. Food insecurity is associated with greater acute care utilization among HIV-infected homeless and marginally housed individuals in San Francisco. J Gen Intern Med. 2013;28(1):91-98.

113. Weiser S, Fernandes $\mathrm{K}$, Brandson E, et al. The impact of food insecurity and body mass index on mortality among HIV-infected individuals first initiating HAART XVII International AIDS Conference 2008.

114. U.S.C. FOOD AND NUTRITION ACT OF 2008.

115. Supplemental Nutrition Assistance Program: Eligibility. United States Department of Agriculture Web site. http://www.fns.usda.gov/snap/applicant_recipients/eligibility.htm. Accessed July $5,2012$.

116. Building a Healthy America: A Profile of the Supplemental Nutrition Assistance Program.USDA In: FNS, ed 2012. 
117. Ponza M, Ohls JC, Moreno L, Zambrowski A, Cohen R. Customer Service in the Food Stamp Program. NJ: Mathematical Policy Resaerch Inc. 1999.

118. Supplemental Nutrition Assisstant Program Participation and Cost. United States Department of Agriculture Website. http://www.fns.usda.gov/pd/SNAPsummary.htm. Accessed November 8, 2012.

119. Hama MY, Chern WS. Food Expenditure and Nutrient Availability in Elderly Households. J Consum Aff. 1988;22(1):3-9.

120. LeBlanc M, Lin B-H, Smallwood D. Food Assisstance: How strong id the safety net? Amber Waves. 2006;4(4).

121. Fox M, Hamilton W, Lin B-H. Effects of food assistance and Nutrition Programs on nutrition and health;Volume 4 Executive Summaryof the Literature Review: Food Assisstance and Nutrition Research. 2004. FANRR 19-24.

122. Allen JE, Gadson KE. Nutrient Consumption Patterns of Low-Income Households: USDA, Economic Research Service. 1983.

123. Devaney B, Moffitt R. Dietary Effects of the Food Stamp Program. Am J Agric Econ. 1991;73(1):202-211.

124. Beebout H, Cavin E, Devaney B. Evaluation of the Nutrition Assistance Program in Puerto Rico: Volume II, Effects on Food Expenditures and Diet Quality. Washington, DC: Mathematica Policy Research, Inc. 1985.

125. Fraker TM, Martini AP, Ohls JC. The Evaluation of the Alabama Food Stamp Cash-out Demonstration: Volume 1, Recipient Impacts. USDA, Food and Nutrition Service. 1992.

126. Ohls JC, Fraker TM, Martini AP. The Effects of Cash-out on Food Use by Food Stamp Program Participants in San Diego. USDA, Food and Nutrition Service. 1992.

127. Cohen BE, YounG N. Impacts of the Washington State Food Stamp Cashout Demonstration on Household Expenditures and Food Use. In: N. Fasciano DH, and H. Beebout, ed. New Directions in Food Stamp Policy Research. Papers 
Presented at the Food and Nutrition Service Research Conference. Washington DC. 1993:83-100.

128. Scearce WK, Jensen RB. Food Stamp Program Effects On Availablity Of Food Nutrients For Low Income Families In The Southern Region Of The United States South. J Ag Econ. 1979;11(2).

129. Bishop JA, Formby JP, Zeager LA. The effect of food stamp cashout on undernutrition. Economics Letters. 2000;67(1):75-85.

130. Fraker TM, Long SK, Post CE. Analysis of the 1985 continuing survey of food intake by individuals Volume 1. Washington DC: USDA Food and Nutrition Service. 1990.

131. Gleason P, Rangarajan A, Olson C. Dietary intake and dietary attitudes among food stamp participants and other low-income individuals. Nutrition and Evaluation, USDA, Food and Nutrition Service. Princeton, NJ: Mathematica Policy Research, Inc. 2000.

132. Perez-Escamilla R, Ferris AM, Drake L, et al. Food Stamps Are Associated with Food Security and Dietary Intake of Inner-City Preschoolers from Hartford, Connecticut. J Nutr. 2000;130(11):2711-2717.

133. Fey-Yensan N, English C, Pacheco HE, Belyea M, Schuler D. Elderly food stamp participants are different from eligible nonparticipants by level of nutrition risk but not nutrient intake. J Am Diet Assoc. 2003;103(1):103-107.

134. Cook JT, Sherman, L.P., Brown, J.L. Impact of food stamps on the dietary adequacy of poor children. Medford, MA: Center on Hunger, Poverty and Nutrition Policy, Tufts Univ. 1995.

135. Lopez LM, Habitcht JP. Food stamps and the energy status of the U.S. elderly poor. J Am Diet Assoc. 87(8):1020-1024.

136. Rose D, Habicht J-P, Devaney B. Household Participation in the Food Stamp and WIC Programs Increases the Nutrient Intakes of Preschool Children. J Nutr. 1998;128(3):548-555. 
137. Dixon LB, Winkleby MA, Radimer KL. Dietary Intakes and Serum Nutrients Differ between Adults from Food-Insufficient and Food-Sufficient Families: Third National Health and Nutrition Examination Survey, 1988-1994. J Nutr. 2001;131(4):1232-1246.

138. Lopez LM, Habicht JP. Food stamps and the iron status of the U.S. elderly poor. $J$ Am Diet Assoc. 1987;87(5):598-603.

139. Bhattacharya J, Currie J. Youths at Nutritional Risk: Malnourished or Misnourished? SSRN eLibrary. 2000.

140. Jensen HH. Food insecurity and the Food Stamp Program. Am J Agric Econ. 2002; 84:1215-1228.

141. Gundersen C, Oliveira V. The Food Stamp Program and Food Insufficiency. Am J Agric Econ. 2001;83(4):875-887.

142. Huffman S, Jensen H. Do Food Assistance Programs Improve Household Food Security? Recent Evidence from the United States: Center for Agricultural and Rural Development, Iowa State Univ. 2003:Working Paper 03-WP 335.

143. Ratcliffe C, McKernan S-M, Zhang S. How Much Does the Supplemental Nutrition Assistance Program Reduce Food Insecurity? Am J Agric Econ. 2011;93(4):1082-1098.

144. Yen ST, Andrews M, Chen Z, Eastwood DB. Food Stamp Program Participation and Food Insecurity: An Instrumental Variables Approach. Am J Agric Econ. 2008;90(1):117-132.

145. Mykerezi E, Mills B. The Impact of Food Stamp Program Participation on Household Food Insecurity. Am J Agric Econ. 2010;92(5):1379-1391.

146. Nord M. How much does the Supplemental Nutrition Assistance Program alleviate food insecurity? Evidence from recent programme leavers. Public Health Nutr. 2012;15(05):811-817.

147. Nord M, Coleman-Jensen A. Food Insecurity After Leaving SNAP. J Hunger Environ Nutr. 2010;5(4):434-453. 
148. Leftin J, Eslami E, Strayer M. Trends in Supplemental Nutrition Assistance Program Participation Rates: 2002-2009. Prepared by Mathematica Policy Research, for the Food and Nutrition Service. 2011.

149. Cunnyham K. Reaching Those In Need: State Supplemental Nutrition Assistance Program Participation Rates in 2009. Mathematica Policy Reasearch. USDA. 2011.

150. Supplemental Nutrition Assistance Program:Outreach Grants. USDA. http://www.fns.usda.gov/snap/outreach/grants.htm. Accessed July 9, 2012.

151. Bartlett S, Burstein N. Food Stamp Program Access Study:Eligible Nonparticipants. Report Submitted to USDA Economic Research Service. Cambridge, MA:Abt Associates Inc. 2004.

152. Kaiser LL. Why do low-income women not use food stamps? Findings from the California Women's Health Survey. Public Health Nutr. 2008;11(12):1288-1295.

153. Access and Access Barriers to Getting Food Stamps: A Review of the Literature. Washington DC: Food Research and Action Center. 2008.

154. Algert SJ, Reibel M, Renvall MJ. Barriers to Participation in the Food Stamp Program Among Food Pantry Clients in Los Angeles. Am J Public Health. 2006;96(5):807-809.

155. Martin KS, Cook JT, Rogers BL, Joseph HM. Public versus Private Food Assistance: Barriers to Participation Differ by Age and Ethnicity. J Nutr Educ Behav. 2003;35(5):249-254.

156. Gabor V, Williams S, Bellamy H, Hardison B. Senior's view of the Food Stamp Program and Ways to Improve Participation-Focus Group Finding in Washington State. 2002: USDA,Economics Research Service, E-FAN No. (02-012).

157. Daponte BO. Private versus Public Relief: Use of Food Pantries versus Food Stamps among Poor Households. J Nutr Educ. 2000;32(2):72-83.

158. Kadiyala S, Gillespie S. Rethinking food aid to fight AIDS. Food Nutr Bull. 2004;25(3):271-282. 
159. Shekar $M$, Heaver $R$, Lee $Y-K$. Repositioning nutrition as central to the development agenda : a strategy for large scale action. Washington, D.C. World Bank; 2005.

160. Rawat R, Kadiyala $S, M c N a m a r a ~ P E$. The impact of food assistance on weight gain and disease progression among HIV-infected individuals accessing AIDS care and treatment services in Uganda. BMC Public Health. 2010;10:316.

161. Koethe JR, Chi BH, Megazzini KM, Heimburger DC, Stringer JS. Macronutrient supplementation for malnourished HIV-infected adults: a review of the evidence in resource-adequate and resource-constrained settings. Clin Infect Dis 2009;49(5):787-798.

162. Ndekha MJ, Oosterhout JJGv, Zijlstra EE, Manary M, Saloojee H, Manary MJ. Supplementary feeding with either ready-to-use fortified spread or corn-soy blend in wasted adults starting antiretroviral therapy in Malawi: randomised, investigator blinded, controlled trial. BMJ. 2009;338.

163. Clark RH, Feleke G, Din M, et al. Nutritional treatment for acquired immunodeficiency virus-associated wasting using beta-hydroxy betamethylbutyrate, glutamine, and arginine: a randomized, double-blind, placebocontrolled study. J Parenter Enteral Nutr. 2000;24(3):133-139.

164. McDermott AY, Shevitz A, Must A, Harris S, Roubenoff R, Gorbach S. Nutrition Treatment for HIV Wasting: A Prescription for Food as Medicine. Nutr Clin Pract. 2003;18(1):86-94.

165. Pichard C, Sudre P, Karsegard V, et al. A randomized double-blind controlled study of 6 months of oral nutritional supplementation with arginine and 3 fatty acids in HIV-infected patients. AIDS. 1998;12(1):53-63.

166. Stack JA, Bell SJ, Burke PA, Forse RA. High-Energy, High-Protein, Oral, Liquid, Nutrition Supplementation in Patients with HIV Infection: Effect on Weight Status in Relation to Incidence of Secondary Infection. J Am Diet Assoc. 1996;96(4):337-341.

167. Keithley JK, Swanson B, Zeller JM, et al. Comparison of standard and immuneenhancing oral formulas in asymptomatic HIV-infected persons: a multicenter randomized controlled clinical trial. J Parenter Enteral Nutr. 2002;26(1):6-14. 
168. Rabeneck L, Palmer A, Knowles JB, et al. A randomized controlled trial evaluating nutrition counseling with or without oral supplementation in malnourished HIV-infected patients. J Am Diet Assoc. 1998;98(4):434-438.

169. Shabert JK, Winslow C, Lacey JM, Wilmore DW. Glutamine-antioxidant supplementation increases body cell mass in AIDS patients with weight loss: a randomized, double-blind controlled trial. Nutrition. 1999;15(11-12):860-864.

170. Schwenk A, Steuck H, Kremer G. Oral supplements as adjunctive treatment to nutritional counseling in malnourished HIV-infected patients: randomized controlled trial. Clin Nutr. 1999;18(6):371-374.

171. Ivers LC, Chang Y, Gregory Jerome J, Freedberg KA. Food assistance is associated with improved body mass index, food security and attendance at clinic in an HIV program in central Haiti: a prospective observational cohort study. AIDS Res Ther. 2010;7:33.

172. Ball K, Crawford D, Mishra G. Socio-economic inequalities in women's fruit and vegetable intakes: a multilevel study of individual, social and environmental mediators. Public Health Nutr. 2006;9(5):623-630.

173. Forshee R, Storey M. Demographics, not beverage consumption, is associated with diet quality. Int J Food Sci Nutr. 2006;57(7-8):494-511.

174. Beydoun MA, Wang Y. Do nutrition knowledge and beliefs modify the association of socio-economic factors and diet quality among US adults? Prev Med. 2008;46(2):145-153.

175. Gittelsohn J, Anliker JA, Sharma S, Vastine AE, Caballero B, Ethelbah B. Psychosocial Determinants of Food Purchasing and Preparation in American Indian Households. J Nutr Educ Behav. 2006;38(3):163-168.

176. Dickson-Spillmann M, Siegrist M. Consumers' knowledge of healthy diets and its correlation with dietary behaviour. J Hum Nutr Diet 2011;24(1):54-60.

177. Havas $\mathrm{S}$, Treiman $\mathrm{K}$, Langenberg $\mathrm{P}$, et al. Factors Associated with Fruit and Vegetable Consumption among Women Participating in WIC. J Am Diet Assoc. 1998;98(10):1141-1148. 
178. Krebs-Smith SM, Heimendinger J, Patterson BH, Subar AF, Kessler R, Pivonka E. Psychosocial factors associated with fruit and vegetable consumption. Am J Health Promot. 1995;10(2):98-104.

179. Blanchard CM, Fisher J, Sparling PB, et al. Understanding Adherence to 5 Servings of Fruits and Vegetables per Day: A Theory of Planned Behavior Perspective. J Nutr Educ Behav. 2009;41(1):3-10.

180. Dissen AR, Policastro P, Quick V, Byrd-Bredbenner C. Interrelationships among nutrition knowledge, attitudes, behaviors and body satisfaction. Health Educ. 2011;111(4):283-295.

181. Shepherd R, Towler G. Nutrition knowledge, attitudes and fat intake: application of the theory of reasoned action... Reprinted from Journal of Human Nutrition and Dietetics (1992), 5:387-397. J Hum Nutr Diet. 2007;20(3):159-169.

182. Bandura A. Social Foundations of Thought and Action: A social cognitive theory. Englewood Cliffs, N.J. Prentice Hall; 1986.

183. AbuSabha R, Achterberg C. Review of Self-Efficacy and Locus of Control for Nutrition- and Health-Related Behavior. J Am Diet Assoc. 1997;97(10):11221132 .

184. Contento IR, Balch GI, Bronner YL, et al. The effectiveness of nutrition education and implications for nutrition education policy, programs, and research. A review of research. 1995. J Nutr Educ Behav. 1995;17:279-418.

185. Michie S, Jochelson K, Markham WA, Bridle C. Low-income groups and behaviour change interventions: a review of intervention content, effectiveness and theoretical frameworks. J Epidemiol Community Health. 2009;63(8):610-622.

186. Auslander W, Haire-Joshu D, Houston C, Rhee C-W, Williams JH. A Controlled Evaluation of Staging Dietary Patterns to Reduce the Risk of Diabetes in AfricanAmerican Women. Diabetes Care. 2002;25(5):809-814.

187. Emmons KM, Stoddard AM, Fletcher R, et al. Cancer Prevention Among Working Class, Multiethnic Adults: Results of the Healthy Directions-Health Centers Study. Am J Public Health. 2005;95(7):1200-1205. 
188. Shankar S, Klassen AC, Garrett-Mayer E, et al. Evaluation of a nutrition education intervention for women residents of Washington, DC, public housing communities. Health Educ Res. 2007;22(3):425-437.

189. van Assema P, Steenbakkers M, Rademaker C, Brug J. The impact of a nutrition education intervention on main meal quality and fruit intake in people with financial problems. J Hum Nutr Diet. 2005;18(3):205-212.

190. Cason KL, Scholl JF, Kassab C. A Comparison of Program Delivery Methods for Low Income Nutrition Audiences. Top Clin Nutr. 2002;17(4):63-73.

191. Goodner CH, Wolman PG, Stallings SF, Meacham SL, Cason KL. Do Food Stamps without Nutrition Education Improve Food Intake Patterns? Top Clin Nutr. 2000;15(2):49-58.

192. Cason KL, Cox RH, Burney JL, Poole K, Wenrich TR. Do Food Stamps Without Education Improve the Nutrient Intake of Recipients? Top Clin Nutr. 2002;17(4):74-82.

193. Cason KL, Cox RH, Wenrich TR, Poole KP, Burney JL. Food Stamp and NonFood Stamp Program Participants Show Similarly Positive Change With Nutrition Education. Top Clin Nutr. 2004;19(2):136-147.

194. Campbell MK, Honess-Morreale L, Farrell D, Carbone E, Brasure M. A tailored multimedia nutrition education pilot program for low-income women receiving food assistance. Health Educ Res. 1999;14(2):257-267.

195. Campbell MK, Carbone E, Honess-Morreale L, Heisler-MacKinnon J, Demissie $\mathrm{S}$, Farrell D. Randomized trial of a tailored nutrition education CD-ROM program for women receiving food assistance. J Nutr Educ Behav. 2004;36(2):58-66.

196. ADA. Position of the American Dietetic Association and Dietitians of Canada: Nutrition Intervention in the Care of Persons with Human Immunodeficiency Virus Infection. J Am Diet Assoc. 2004;104(9):1425-1441.

197. Kaye HL, Moreno-Leguizamon CJ. Nutrition education and counselling as strategic interventions to improvehealth outcomes in adult outpatients with HIV: a literature review. Afr J AIDS Res. 2010;9(3):271-283. 
198. Torres K, Zive MM, Scolari R, Olshefsky A, Zúñiga ML. Acceptance of a Nutrition Curriculum for HIV-Positive Latinos Living on the U.S.- Mexico Border. J Transcult Nurs. 2008;19(2):107-113.

199. Ryan White Care Act Title II Manual - 2003 Version X. Appendices, US Department of Health and Human Services.Health Resources and Services Administration, HIV/AIDS Bureau Web site. http://hab.hrsa.gov/resources/partbmanual/servicecategory.html. Accessed September 22, 2012.

200. Segal-Isaacson CJ, Tobin JN, Weiss SM, et al. Improving dietary habits in disadvantaged women with HIV/AIDS: the SMART/EST women's project. AIDS Behav. 2006;10(6):659-670.

201. Van Niekerk C, Smego RA, Sanne I. Effect of nutritional education and dietary counselling on body weight in HIV-seropositive South Africans not receiving antiretroviral therapy. J Hum Nutr Diet. 2000;13(6):407-412.

202. Berneis $K$, Battegay $M$, Bassetti $S$, et al. Nutritional supplements combined with dietary counselling diminish whole body protein catabolism in HIV-infected patients. Eur J Clin Invest. 2000;30(1):87-94.

203. Prochaska JO, Velicer WF, Rossi JS, et al. Stages of change and decisional balance for 12 problem behaviors. Health Psychol. 1994;13(1):39-46.

204. Prochaska JO, DiClemente CC. Stages and processes of self-change of smoking: toward an integrative model of change. J Consult Clin Psychol. 1983;51(3):390395.

205. Norcross JC, Krebs PM, Prochaska JO. Stages of change. J Clin Psychol. 2011;67(2):143-154. 


\section{CHAPTER III: SUPPLEMENTAL NUTRITION ASSISTANCE PROGRAM (SNAP) AND THE HIV INFECTED POPULATION IN MIAMI: WHO PARTICIPATES, WHO DOESN'T AND WHY.}

\section{Abstract}

The Supplemental Nutrition Assistance Program (SNAP), formerly the Food

Stamp Program (FSP) is the largest food assistance program in the country. ${ }^{1,2}$ With approximately 45 million participants in 2011 , it is the safety net for low income households, alleviating some negative effects of poverty in the country. ${ }^{2,3}$ Though participation has surged in recent years among several of the demographic and economic subgroups, ${ }^{4}$ mainly due to changes in the economic environment, ${ }^{2}$ little is known about the participation of low income individuals who are chronically ill. A cross-sectional study was conducted to examine the nutrition and health impact of SNAP participation in 123 HIV infected SNAP participants, compared to 52 eligible HIV infected SNAP nonparticipants. In addition, we evaluated the barriers for participation among the latter group. Student's t-test, Chi square tests, and logistic regression were used in the data analysis. SNAP participation rate was $70.3 \%$ which is close to the national participation rate of $72 \%$ for all eligible persons in 2009 . Antiretroviral use, having income less than $\$ 1000$ per month and being born in the US remained positively and independently associated with SNAP participation, $P<.001, P=.006$ and $P<.001$ respectively. Twenty seven percent (26.9\%) of non-participants cited the rejection of their application as the reason for not participating in the program. Recent incarceration was a barrier for $17.4 \%$ of program non-participants. Equal percentages (15.4\%) were non-participants either because they were not aware of eligibility or they lived in shelters that didn't allow participation. Our study findings are similar to those reported in other populations at 
nutritional risk ${ }^{5-7}$ however, recent incarceration and living in a shelter are barriers that seem to be specific to HIV infected people in Miami. Outreach programs similar to Community Partnerships and Supportive Services for HIV Infected People Leaving Jail (COMPASS) are needed in Miami, which are especially developed for people living with HIV. These programs will enhance linkages to healthcare after leaving jail, improve management of the HIV disease, and develop strategies to overcome barriers to participation in social services such as nutrition programs. ${ }^{8}$

Keywords: Supplemental Nutrition Assistance Program (SNAP), Food assistance program, HIV infection 


\section{Introduction}

The purpose of the Supplemental Nutrition Assistance Program (SNAP), formerly the Food Stamp Program (FSP) is to increase purchasing power and permit low income households to obtain a nutritious diet. ${ }^{1,2}$ Being the most funded ( $\$ 70$ billion in 2011$)$ of the domestic nutrition assistance programs, the program has been successful in alleviating some of the negative effects of growing poverty in the United States. ${ }^{2,3}$ Evidence from the literature suggests that participation in SNAP has been beneficial in consistently increasing household food expenditure compared to non-participation, with a recent report by the United States Department of Agriculture (USDA) indicating that individuals participating in SNAP spend more on food and wouldn't have done so without the program. ${ }^{2,9,10}$ As such, SNAP has been described as a safety net for low income individuals and families.

Participation in the SNAP program increased substantially from a low of 54\% in 2001 and 2002 to $72 \%$ in 2009 among eligible individuals, although an estimated $33 \%$ of SNAP eligible participants do not participate in the program. ${ }^{2,4,11}$ The participation surge has been credited to changes in eligibility requirements, economic changes, and increased outreach. ${ }^{2}$ Generally, reasons identified for non-participation among eligible non-participants include fear of stigmatization, the desire for personal independence, lack of awareness about program eligibility and benefits, confusion with requirements for eligibility, homelessness, length and cost of application, inadequacy of benefits, and past bad experiences. ${ }^{5-7,12,13}$ A California study of pantry users listed homelessness and limited English language skills as the primary barriers to SNAP participation. ${ }^{7}$ Other studies among immigrants, which are relevant to the State of Florida and Miami-Dade County, 
listed the following as barriers: language, having to payback benefits, and consequences on future citizenship application. ${ }^{14,15}$ The latter two are misconceptions primarily identified by Hispanic immigrants. ${ }^{14}$ Senior adults listed stigma and misinformation with program rules as participation barriers. ${ }^{16}$ Among low income women in California, lack of perceived need was the most identified reason for non-participation, with almost $43 \%$ stating that they did not need SNAP. ${ }^{5}$ Some eligible non-participants may have a low perception of need for SNAP because of personal pride or relatively low allotment or benefits, even though they may be experiencing food insufficiency. ${ }^{5,17}$ Ninety six percent of eligible non-participants are aware of the SNAP program and $66 \%$ would participate if eligibility were certain. ${ }^{13}$ As the federal government is adopting several strategies to increase SNAP participation among eligible non-participants, ${ }^{11}$ it is important to "understand what leads some and not others to use food assistance"18 among various subgroups in order to maximize participation rates.

Participation varies among different population groups and according to recent USDA reports, children have the highest participation rate at $92 \%$ while the elderly have the lowest rate at $34 \% .{ }^{2}$ Participation rates among the various ethnicities have been inconsistent, as some studies report higher rates among Blacks, while others reported their rates to be lower when compared to other ethnicities. ${ }^{6,17,19}$ While little is known about the rate at which low income, chronically ill individuals access the SNAP program, for HIV infected individuals living below the poverty rate, participation may be an essential part of success with disease management. ${ }^{20}$ Food insufficiency is prevalent in this population and has been suggested to be a health threat as it affects disease transmission, progression, management and survival. ${ }^{20-23}$ Without adequate and nutritious 
food, HIV infected individuals are less likely to adhere to treatment, leading to poor disease outcomes, such as difficulty with viral load suppression; an association that has been reported in several HIV infected populations. ${ }^{24-26}$ Food insufficiency among HIV infected persons has also been associated with risky sexual behavior ${ }^{27-29}$ and increased utilization of healthcare, ${ }^{30,31}$ two situations that affect the national cost of HIV disease management. There is limited research on the utilization of food assistance programs, especially the SNAP program by HIV infected persons. Surveys conducted among these high risk populations suggest that less than one-third of those eligible are receiving benefits. ${ }^{32}$ Since the program has shown to be effective in alleviating poverty and food insufficiency among the general public, ${ }^{2,33,34}$ it is critical to examine whether it is being utilized by low income HIV infected persons who are known to experience food insufficiency at rates higher than the general public. The aim of this study was to (1) describe the characteristics of HIV infected eligible SNAP participants, (2) determine factors associated with SNAP participation in this population and (3) identify barriers to participation.

\section{Methods}

\section{Study Design and Setting}

This was a cross-sectional study conducted in Miami, Florida and was approved by the Institutional Review Board of the Florida International University. From April 2011 to August 2012, participants were recruited by a trained researcher from the Borinquen Health Care Center (BHCC), and other centers that provide HIV-related services to individuals in Miami-Dade County. The BHCC provides comprehensive range of health and social services to a culturally diverse low income community in 
Miami-Dade County. To qualify for inclusion in the study, participants must be 18 years or older, provide documentation of HIV seropositive status, have income below $130 \%$ of the federal poverty level and be eligible to participate in the Supplemental Nutrition Assistance Program, even if they are not currently participating. Determination for SNAP eligibility was achieved using the ACCESS Florida's Pre-screening eligibility tool. ${ }^{35}$ This tool gathers information on income, assets, household size, and expenditure and is used as a basic prescreening tool by the State for SNAP eligibility. Potential participants were approached for enrollment in the study and, once eligibility was determined, willing participants gave their written informed consent. After obtaining informed consent, the study visit included completing the field-tested self-administered questionnaire to assess sociodemographic and health-related characteristics, barriers to participation (among eligible non-participants), incidence of pathological symptoms, and quality of life. Participants were given $\$ 10$ in appreciation for completing the survey. Participation in the supplemental nutrition assistance program was defined as having received SNAP benefits for at least one month in the last 12 months.

\section{Survey Instruments}

The questionnaires used in the study were pre-tested using twenty one $(\mathrm{N}=21)$ low income HIV infected persons, with characteristics similar to the study population. The questionnaire was minimally revised, based on pre-testing results.

Demographic and Socioeconomic Information: Several questions were used to assess the participants' sociodemographic and economic state. Information collected included age, gender, ethnicity, country of birth, marital status, education, employment, household size, monthly income, and use of other community food resources such as food banks. In 
addition, the questionnaire assessed health-related characteristics such as smoking status, recreational drug use and alcohol use. It also queried the type and frequency of each substance used, and assessed regular intake of vitamins.

Participation Barriers: A list of possible barriers were identified and compiled based on the researcher's interviews with dietitians and case managers serving this population and also from the literature. Several reasons were identified as barriers for non-participation and are summarized under the following categories: (a) perceived need, (b) stigma, (c) awareness of eligibility, (d) access, and (e) eligibility restrictions. To the best of our knowledge, this study was the first that identified and reported recent incarceration as a reason for non-participation. This questionnaire lists various reasons for non-participation in the SNAP program and was used to assess barriers to participation among individuals who qualified for the program and yet did not participate.

Food Security: The six-item US Household Food Security Survey Module was used to assess food security status. Scores of this survey ranges from $0-6$, with higher scores indicating severity of food security. Scores of 0-1 were classified as food secure, while 24 and 5-6 were classified as low food security and very low food security respectively. Low food security and very low food security were merged as food insecurity during analysis.

Incidence of Pathological Symptom: At the assessment visit, study participants were asked if within the past month, they had experienced symptoms pertaining to general malaise and also those related to HIV. These included diarrhea, constipation, nausea, fever, fatigue, and unexplained changes in weight. 
Quality of Life: Quality of life was assessed using the Spitzer Quality of Life Index (SQLI). This is a brief questionnaire measuring an individual's physical, social and emotional wellbeing as well as the capability to perform the tasks of ordinary living without much hindrance. It contains five main domains namely activity, daily living, health, social support and outlook. Each domain has a three point scale ranging from 0 to 2 , with the highest number regarded as the best quality of life. The total score ranges from 0 to 10 , with scores $\leq 8$ deemed as having a reduced quality of life. The SQLI has demonstrated both construct validity and reliability among patients with chronic physical diseases and has been successfully used in HIV infected populations. Assessment of internal consistency yielded a Cronbach's $\alpha$ of 0.775 and an interrater Spearman rank correlation (rho) of 0.81 , which was significant $(P<0.001) .{ }^{37}$

\section{Statistical Analysis}

Descriptive statistics were used in characterizing the participants and were expressed as mean \pm standard deviation, or percentages. Univariate analysis was performed to determine differences in characteristics between SNAP participants and eligible non-participants. Student's t-test was used to compare continuous variables and Chi square test for categorical variables. Analysis of barriers to participation was limited to eligible non-SNAP participants. Chi-square tests were used to identify factors associated with SNAP participation. To determine which characteristics independently predicted SNAP participation, logistic regression was used. Statistical significance of $P<$ .05 was used in all analyses. SPSS version 21 was used in conducting all analysis. 


\section{Results}

\section{Participant Characteristics}

A total of $175 \mathrm{HIV}$ infected adults participated in the study with an average age of $46.9 \pm 7.8$. Two thirds of the respondents were male $(66 \%, n=116)$, three quarters were African-American $(74 \%, n=130)$ and $70 \%$ were single $(n=123)$. Approximately eighty two $(81.7 \%)$ percent had incomes less than $\$ 1000$ per month, with almost eighty seven percent $(86.6 \%)$ being unemployed and/ or on disability. Over half $(53 \%, n=93)$ of respondents had more than a high school education. Thirty one percent reported using recreational drugs with nearly double that number (63\%) reporting they smoke cigarettes. Alcohol use was reported by nearly $55 \%$ of participants. Only $30 \%$ of the population had reduced quality of life, scoring less than eight on the quality of life composite score. About $43 \%$ of participants reported reduced activity levels, scoring less than 2 on the quality of life activity index. The top five most reported pathological symptoms were: headache (41.1\%); fatigue (34.3\%); unexplained changes in weight $(34.3 \%)$; cough $(28.3 \%)$; and diarrhea (24\%). The rate of SNAP participation in this population was $70.3 \%$, with $58.3 \%$ of the population experiencing food insecurity.

\section{Factors Associated with SNAP Participation}

SNAP participants were more likely than non- participants (91.1\% vs. 67.3\%, $P<.001)$ to be born in the United States or its territories, to have incomes less than $\$ 1000$ per month $(85.4 \%$ vs. $73.1 \%, P=.055)$ and be on disability $(48.8 \%$ vs. $25 \%, P=.012)$, (Table 1). SNAP participants also reported more recreational drug use (38.2\% vs. 15.4\%, $P=.003)$ but were also more likely to be receiving antiretroviral treatment than nonparticipants (94.3 vs. 67.3, $P=.001)$, (Table 2$)$. Sixty four percent of SNAP non- 
participants experienced food insecurity compared to $56 \%$ among SNAP participants although it did not reach significance (Table 3).

There was a significant difference in mean quality of life composite score, with SNAP participants having a significantly higher mean score $(\mathrm{M}=8.40)$ compared to nonparticipants $(\mathrm{M}=7.69), P=.037$. As shown in Table 4 , there was no significant difference between the two groups with regards to percent reaching cut-off point scores of quality of life, measured by a composite score of less than 8 , and individual sub-scores less than 2. In general, however, a higher percentage of non-SNAP participants (36.5\%) reported reduced quality of life (SQOL score $<8$ ) compared to SNAP participants $(27 \%)$.

Non-SNAP participants also reported a higher prevalence of pathological symptoms compared to SNAP participants, although only fever reached significance, $P=$ .047. Twenty three percent of non-SNAP participants reported having fever in the last month compared to only $11 \%$ in the SNAP group.

Results from the logistic regression analysis showed that being born in the United States and territories, antiretroviral use and having income less than $\$ 1000$ per month remained positively and independently associated with SNAP participation (Table 6). HIV infected adults born in the US were 16.5 times more likely to participate in SNAP than those born in other countries $(P<.001)$. Those with incomes less than $\$ 1000$ per month were more than five times likely to participate in $\operatorname{SNAP}(\mathrm{AOR}=5.28 ; P=.006)$ while those on treatment were fifteen times more likely to participate in the program $(\mathrm{AOR}=15.18 ; P<.001)$. The regression analysis also indicated that individuals with less than high school education were 50\% less likely to receive SNAP benefits $(\mathrm{AOR}=$ $0.33 ; P=.003)$. This may be due to the inability to complete all paper work required for 
SNAP participation. Univariate analysis using unadjusted odds ratio indicated that SNAP participants were almost three times more likely to be on disability, and half as likely to be unemployed, however, these differences disappeared in the multivariate analysis.

\section{Barriers to SNAP Non-Participation}

Barriers given by SNAP non-participants are shown in Table 7. The main barrier given by HIV infected persons for not participating in the program was "I was denied participation." Though they had thought themselves eligible and applied for SNAP, nearly $27 \%$ of non-participating respondents stated they were denied. Seventeen percent of respondents stated that they had been released from prison in the last 12 months and that was the reason for not participating in the SNAP program. About $15 \%$ stated they were not aware of their eligibility status, while an equal percentage indicated that they lived in shelters and as a result were not allowed to participate in the program. An equal percentage of respondents $(9.6 \%)$ stated that it was "too hard to apply" or that they were "worried about citizenship requirements." Only approximately $6 \%$ of non-SNAP participants indicated they didn't need the benefits of the program. Stigma, which has been reported as barriers in other cohorts, was not reported as a reason for not participating in SNAP among this HIV infected population.

\section{Discussion}

Findings from this study indicates that the SNAP participation rate (70.3\%) among this HIV positive cohort is fairly close to that reported for all eligible persons in the United States for fiscal year $2009(72 \%) .{ }^{4}$ The rate is also similar to the $69 \%$ participation rate reported in 2009 for the State of Florida. ${ }^{38}$ The findings are also

consistent with the characteristics reported by other studies of SNAP participants. ${ }^{5,7}$ 
Similar to these studies, HIV infected SNAP participants tend to be low income and US citizens. ${ }^{5,7}$ Characteristics that were associated with participation in this study, such as being unemployed, disabled or having a household with children were not expressed by the study participants as reasons for SNAP participation. ${ }^{17,19}$ Our findings also did not show ethnicity to be an independent predictor of SNAP participation, as it has been found in other studies. ${ }^{6,17}$ In contrast with results by Duffy et al., ${ }^{39}$ our study showed that individuals with higher education were more likely to participate in SNAP. This may be due to ease of understanding eligibility requirements, including completing the paperwork for application.

A strong association was found between SNAP participants and receiving antiretroviral treatment. This finding has implication for HIV disease management as adherence to treatment has been associated with food sufficiency. ${ }^{30,40,41}$ Antiretroviral therapy in HIV infection is most effective when adherence to treatment is high (>95\%). ${ }^{42}$ Some studies have identified that HIV infected individuals, who are food insufficient, are less likely to adhere to treatment compared to their food sufficient counterparts. ${ }^{25,43} \mathrm{As}$ shown in the findings from this study, SNAP participants experience less food insecurity than non-participants. This is consistent with previous findings in the general population showing that SNAP participation plays a role in increasing food sufficiency. ${ }^{33,44} \mathrm{HIV}$ infected SNAP participants, who are also receiving treatment, are more connected into the healthcare system, and receive intense case management. These circumstances may translate into receiving more social benefits such as SNAP participation.

SNAP participants also had a better quality of life compared to non-participants. Quality of life measures the burden of a chronic disease on several aspects of life and 
HIV disease has been reported to decrease quality of life among those infected. ${ }^{45}$ The finding that SNAP participants had a better quality of life may be an indication of the programs ability to reduce the psychological and emotional burden associated with having to maintain adequate nutritional status and its economic costs due to presence of a strongly nutrition-related disease. SNAP participation may decrease stress associated with acquisition of food in this low income population. It may also provide the ability to transfer income to other health related spending, lessening the pressures associated with achieving good health.

The main reason chosen by non-participants as a barrier for receiving SNAP was denial of participation into the program. This was not unexpected as the screening tool used in the study is not used as the final determinant of eligibility by the SNAP office. Besides not meeting eligibility requirements, there are several reasons for SNAP denials; including failure to provide verification of needed documentation and non-compliance with rules regarding application and recertification. Another important barrier to SNAP participation in this study sample was recent incarceration. This is important as the USDA has recently started working in conjunction with other state agencies to assist those released from prison to transition into society. ${ }^{46}$ The State of Florida, however, still maintains a ban put in place by the Personal Responsibility and Work Opportunity Act of 1996, preventing states from providing SNAP benefits to drug related convicted felons. ${ }^{47,48}$ It is possible for low income HIV infected adults who are prone to recreational drug use, to also be prone to possible incarceration as drug related felons. As such, although only $15.4 \%$ of non-SNAP participants indicated they used drugs, there could be high felony convictions rate within the group, disqualifying them from SNAP 
participation. This study did not gather data on reason for incarceration, and we cannot assess if incarceration was related solely to illegal drug felony. For program nonparticipants who were indeed incarcerated as drug related felons, they currently cannot receive SNAP benefits in Florida. SNAP program administrators, however, need to work with the local justice system to seek out and reach out to other felons in transition, as there is a myth of SNAP ineligibility for all felonies. ${ }^{47}$ In addition, access to social services such as the SNAP program have been shown to contribute in providing stability for felons after release from jail and to prevent relapse to substance abuse ${ }^{8}$

Living in a shelter was another reason for non-participation. Since food insecurity is common in HIV infected populations and having adequate nutrition is essential for their disease management, it is important for SNAP and shelter administrators to work together to give program access to individuals who may need it the most. Other barriers listed were in relationship to knowledge about eligibility and difficulty with the eligibility process. These findings are similar to those reported by Martin et al. ${ }^{6}$ among Food Stamp (aka SNAP) participants. Outreach efforts need to be invested in this population to increase participation rates. Compared to a study among women, a greater proportion of respondents in our study did not apply for program benefits because they were worried about their citizenship status. ${ }^{5}$ Again, only $6 \%$ of our study non-SNAP participating respondents stated that they did not need the benefits provided by the program, a much smaller percent than that reported in a study conducted among women in California where $42 \%$ of non-participants cited "don't need them" as a reason for not applying for program benefits. ${ }^{5}$ 
The findings from our study are not generalizable, since the data were collected from one city in South Florida. There needs to be caution in trying to generalize results to other HIV infected populations, as there is evidence that persons living with HIV in Miami-Dade may have specific characteristics that make them unique, such as being a

more heterosexual with higher rates of drug use than other populations. ${ }^{21,49}$ Similar studies need to be conducted among persons infected with HIV in other cities and areas in the country to help better understand how different socio-economic conditions and risk factors relate to participation in food assistance programs such as the SNAP program.

\section{Acknowledgements}

Support funding for data collection was provided by the University Graduate School Data and Evidence Acquisition Fellowship, Florida International University, Miami, FL. 
Table 1: Demographic characteristics of HIV infected by SNAP participation status

\begin{tabular}{|c|c|c|c|c|}
\hline Variable & $\begin{array}{l}\text { Total } \\
(\mathrm{N}=175)\end{array}$ & $\begin{array}{l}\text { SNAP } \\
(\mathrm{n}=123)\end{array}$ & $\begin{array}{l}\text { Non-SNAP } \\
(\mathrm{n}=52)\end{array}$ & $P$-value \\
\hline $\operatorname{Age}^{a *}$ & $46.89 \pm 7.78$ & $46.96 \pm 7.48$ & $46.65 \pm 8.57$ & .813 \\
\hline Gender & & & & .870 \\
\hline Male & $166(66.3)$ & $82(66.7)$ & $34(65.4)$ & \\
\hline Female & $59(33.7)$ & $41(33.3)$ & $18(34.6)$ & \\
\hline Ethnicity & & & & .426 \\
\hline African American & $130(74.3)$ & $94(76.4)$ & $36(69.2)$ & \\
\hline Hispanic & $28(16.0)$ & $20(16.3)$ & $8(15.4)$ & \\
\hline White & $9(4.1)$ & $5(4.1)$ & $4(7.7)$ & \\
\hline Other & $8 \quad(4.6)$ & $4(3.3)$ & $4(7.7)$ & \\
\hline Country of Birth $^{* *}$ & & & & $<.001$ \\
\hline US born & $147(84.0)$ & $112(91.1)$ & $35(67.3)$ & \\
\hline Non-US born & $28(16.0)$ & $11(8.9)$ & $17(32.7)$ & \\
\hline Marital Status & & & & .714 \\
\hline Married & $17(9.7)$ & $13(10.6)$ & $4(7.7)$ & \\
\hline Single & $123(70.3)$ & $87(70.7)$ & $36(69.2)$ & \\
\hline Divorced/Widowed & $35(20.0)$ & $23(18.7)$ & $12(23.1)$ & \\
\hline Child Status & & & & .301 \\
\hline Children at home & $22(12.6)$ & $14(14.4)$ & $8(15.4)$ & \\
\hline Children not at home & $69(39.4)$ & $53(43.1)$ & $16(30.8)$ & \\
\hline No Children & $84(48.0)$ & $56(45.5)$ & $28(53.8)$ & \\
\hline Education & & & & .228 \\
\hline$<$ High School & $82(46.9)$ & $54(43.9)$ & $28(53.8)$ & \\
\hline$\geq$ High School & $93(53.1)$ & $69(56.1)$ & $24(46.2)$ & \\
\hline Employment Status* & & & & .012 \\
\hline Unemployed & $79(45.1)$ & $50(40.7)$ & $29(53.8)$ & \\
\hline Employed & $23(13.1)$ & $13(10.6)$ & $10(19.2)$ & \\
\hline On disability & $73(41.7)$ & $60(48.8)$ & $13(25.0)$ & \\
\hline Income/ month & & & & .055 \\
\hline$<\$ 1000$ & $143(81.7)$ & $105(85.4)$ & $38(73.1)$ & \\
\hline$\geq \$ 1000$ & $32(18.3)$ & $18(14.6)$ & $14(26.9)$ & \\
\hline Living condition & & & & .569 \\
\hline Alone & $67(38.3)$ & $48(39.0)$ & $19(36.5)$ & \\
\hline With family & $79(45.1)$ & $57(46.3)$ & $22(42.3)$ & \\
\hline Shelter & $29(16.6)$ & $18(14.6)$ & $11(21.2)$ & \\
\hline Uses of other food assistance & & & & .736 \\
\hline Yes & $26(14.9)$ & $19(15.4)$ & $7(13.5)$ & \\
\hline No & $149(85.1)$ & $104(84.9)$ & $45(86.5)$ & \\
\hline
\end{tabular}

a* Reported as mean $\pm \mathrm{SD}$; All other variables are reported as $\mathrm{n}(\%)$

$* P<.05, * * P<.01$ 
Table 2: Health related characteristics of HIV infected by SNAP participation status

\begin{tabular}{lcccc}
\hline Variable & $\begin{array}{c}\text { Total } \\
(\mathrm{N}=175)\end{array}$ & $\begin{array}{c}\text { SNAP } \\
(\mathrm{n}=123)\end{array}$ & $\begin{array}{c}\text { Non-SNAP } \\
(\mathrm{n}=52)\end{array}$ & $P$-value \\
\hline Smokes Cigarettes & $110(62.9)$ & $80(65.0)$ & $30(57.7)$ & .358 \\
Alcohol use & $88(50.3)$ & $67(54.5)$ & $21(40.4)$ & .089 \\
Drug use* & $55(31.4)$ & $47(38.2)$ & $8(15.4)$ & .003 \\
On ART* & $151(87.3)$ & $116(94.3)$ & $35(67.3)$ & .001 \\
Vitamins intake & $81(46.3)$ & $56(45.5)$ & & .757 \\
\end{tabular}

${ }^{*} P<.05,{ }^{\dagger}$ All variables reported as $\mathrm{n}(\%)$

ART: Antiretroviral therapy.

Table 3: Food security status of HIV infected adults by SNAP participation status

\begin{tabular}{lcccc}
\hline Food Security Status & $\begin{array}{c}\text { Total } \\
\%(\mathrm{n})\end{array}$ & $\begin{array}{c}\text { SNAP } \\
\%(\mathrm{n})\end{array}$ & $\begin{array}{c}\text { Non-SNAP } \\
\%(\mathrm{n})\end{array}$ & $P$-value \\
\hline Food Security & $41.7(74)$ & $27.0(33)$ & $36.5(19)$ & $\mathrm{NS}$ \\
Food Insecurity & $58.3(102)$ & $56.1(69)$ & $63.5(33)$ & NS \\
\hline
\end{tabular}

NS: Not Significant 
Table 4: Quality of Life (QOL) of HIV infected by SNAP participation status

\begin{tabular}{lccc}
\hline $\begin{array}{l}\text { Quality of Life } \\
(\mathrm{QOL})^{\dagger}\end{array}$ & $\begin{array}{c}\text { SNAP } \\
\%(\mathrm{n})\end{array}$ & $\begin{array}{c}\text { Non-SNAP } \\
\%(\mathrm{n})\end{array}$ & $P$-value \\
\hline Composite $<8$ & $27.0(33)$ & $36.5(19)$ & .211 \\
Activity $<2$ & $39.3(48)$ & $51.9(27)$ & .125 \\
Daily Living $<2$ & $14.8(18)$ & $21.2(11)$ & .300 \\
Health $<2$ & $32.0(39)$ & $36.5(19)$ & .558 \\
Support $<2$ & $21.3(26)$ & $30.8(16)$ & .182 \\
Outlook $<2$ & $23.8(29)$ & $28.8(15)$ & .481 \\
\hline
\end{tabular}

${ }^{\dagger}$ Composite scores $<8$ and Sub-score $<2=$ poor quality of life

Table 5: Pathological symptoms of HIV infected by SNAP participation status

\begin{tabular}{lccc}
\hline Symptoms & $\begin{array}{c}\text { SNAP } \\
\%(\mathrm{n})\end{array}$ & $\begin{array}{c}\text { Non-SNAP } \\
\%(\mathrm{n})\end{array}$ & $P$-value \\
\hline Headache & $37.4(46)$ & $50.0(26)$ & .122 \\
Weight changes & $34.1(42)$ & $34.6(18)$ & .952 \\
Fatigue & $32.5(40)$ & $38.5(20)$ & .449 \\
Diarrhea & $22.8(28)$ & $26.9(14)$ & .556 \\
Sharp pains & $20.3(5)$ & $11.5(6)$ & .164 \\
Mood changes & $19.5(24)$ & $11.5(6)$ & .201 \\
Constipation & $19.5(24)$ & $13.5(7)$ & .338 \\
Visual changes & $18.7(23)$ & $17.6(9)$ & .870 \\
Chills & $17.9(22)$ & $19.2(10)$ & .833 \\
Difficulty breathing & $16.3(20)$ & $17.3(9)$ & .865 \\
Impaired concentration & $16.3(20)$ & $15.4(8)$ & .855 \\
Shortness of breath & $15.4(19)$ & $17.3(9)$ & .759 \\
Numbness & $14.6(18)$ & $17.3(9)$ & .655 \\
Abdominal discomfort & $12.2(15)$ & $23.1(12)$ & .069 \\
Fever* & $11.4(14)$ & $23.1(12)$ & .047 \\
\hline
\end{tabular}

$* P<.05$ 
Table 6: Factors associated with SNAP participation among HIV infected

\begin{tabular}{|c|c|c|c|c|c|c|}
\hline Variable & $\begin{array}{c}\text { Unadjusted } \\
\text { OR }\end{array}$ & $95 \% \mathrm{CI}$ & P-value & $\begin{array}{c}\text { Adjusted } \\
\text { OR }\end{array}$ & $95 \% \mathrm{CI}$ & $P$-value \\
\hline US born & $4.95 * *$ & $2.12,11.55$ & .001 & $16.50 * *$ & $3.61,75.47$ & .001 \\
\hline Unemployed & 0.54 & $0.28,1.05$ & .066 & 0.81 & $0.20,3.26$ & .755 \\
\hline On disability & $2.86 * *$ & $1.39,5.87$ & .004 & 1.32 & $0.33,5.30$ & .696 \\
\hline$<$ High school & 0.67 & $0.35,1.29$ & .228 & $0.33 * *$ & $0.12,0.87$ & .003 \\
\hline $\begin{array}{l}<\$ 1000 \\
\text { income }\end{array}$ & 2.15 & $0.98,4.74$ & .055 & $5.28 * *$ & $1.62,16.95$ & .006 \\
\hline Alcohol use & 1.77 & $0.92,3.41$ & .089 & 1.59 & $0.56,4.49$ & .387 \\
\hline Drug use & $3.40^{* *}$ & $1.47,7.85$ & .003 & 2.15 & $0.62,7.42$ & .228 \\
\hline On ART & $8.05 * *$ & $3.09,20.98$ & .001 & $15.18^{* *}$ & $4.34,52.65$ & .001 \\
\hline
\end{tabular}

${ }^{*} P<.05,{ }^{* *} P<.01, \mathrm{ART}$ : Antiretroviral therapy

Table 7: Barriers to SNAP participation among HIV infected ( $\mathrm{N}=52)$

\begin{tabular}{lcc}
\hline Reason & $\mathrm{n}$ & $\%$ \\
\hline I was denied participation & 14 & 26.9 \\
Recent incarceration & 9 & 17.3 \\
Not aware of eligibility & 8 & 15.4 \\
Not allowed in shelter & 8 & 15.4 \\
Too hard to apply & 5 & 9.6 \\
Worried about citizenship & 5 & 9.6 \\
I don't need them & 3 & 5.8 \\
\hline
\end{tabular}




\section{References}

1. U.S.C. FOOD AND NUTRITION ACT OF 2008.

2. USDA. Building a Healthy America: A Profile of the Supplemental Nutrition Assistance Program. In: FNS, ed 2012.

3. Supplemental Nutrition Assisstant Program Participation and Cost. USDA. http://www.fns.usda.gov/pd/SNAPsummary.htm. Accessed November 8, 2010.

4. Leftin J, Eslami E, Strayer M. Trends in Supplemental Nutrition Assistance Program Participation Rates: 2002 - 2009. Prepared by Mathematica Policy Research, for the Food and Nutrition Service. 2011.

5. Kaiser LL. Why do low-income women not use food stamps? Findings from the California Women's Health Survey. Public Health Nutr. 2008;11(12):1288-1295.

6. Martin KS, Cook JT, Rogers BL, Joseph HM. Public versus Private Food Assistance: Barriers to Participation Differ by Age and Ethnicity. J Nutr Educ Behav. 2003;35(5):249-254.

7. Algert SJ, Reibel M, Renvall MJ. Barriers to Participation in the Food Stamp Program Among Food Pantry Clients in Los Angeles. Am J Public Health. 2006;96(5):807-809.

8. Nunn A, Cornwall A, Fu J, Bazerman L, Loewenthal H, Beckwith C. Linking HIV-positive jail inmates to treatment, care, and social services after release: results from a qualitative assessment of the COMPASS Program. J Urban Health. 2010;87(6):954-968.

9. Hama MY, Chern WS. Food Expenditure and Nutrient Availability in Elderly Households. J Consum Affair. 1988;22(1):3-9.

10. LeBlanc M, Lin B-H, Smallwood D. Food Assisstance:How strong id the safety net? Amber Waves. 2006;4(4).

11. Supplemental Nutrition Assistance Program:Outreach Grants. USDA. http://www.fns.usda.gov/snap/outreach/grants.htm. Accessed July 9,2012.

12. Access and Access Barriers to Getting Food Stamps: A Review of the Literature. Washington DC: Food Research and Action Center. 2008.

13. Bartlett S, Burstein N. Food Stamp Program Access Study:Eligible Nonparticipants. Report Submitted to USDA Economic Research Service. Cambridge, MA:Abt Associates Inc. 2004. 
14. Chavez R. Perceptions of the Food Stamp Program among Limited Household Income Residents of California:Results from Focus Groups. In: Cancer Prevention and Nutrition Section CDoH, ed. Sacramento 2002:1-58.

15. Sugerman S, Backman D, Foerster SB, Ghirardelli A, Linares A, Fong A. Using an Opinion Poll to Build an Obesity-Prevention Social Marketing Campaign for Low-Income Asian and Hispanic Immigrants: Report of Findings. J Nutr Educ Behav. 2011;43(2):S53-S66.

16. Gabor V, Williams S, Bellamy H, Hardison B. Senior's view of the Food Stamp Program and Ways to Improve Participation-Focus Group Finding in Washington State. Washington DC, 2002: USDA,Economics Research Service, E-FAN No. (02-012).

17. Gundersen C, Oliveira V. The Food Stamp Program and Food Insufficiency. Am J Agric Econ. 2001;83(4):875-887.

18. Daponte BO. Private versus Public Relief: Use of Food Pantries versus Food Stamps among Poor Households. J Nutr Educ. 2000;32(2):72-83.

19. Biggerstaff MA, Morris PM, Nichols-Casebolt A. Living on the edge: examination of people attending food pantries and soup kitchens. Soc Work. 2002;47(3):267-277.

20. Bouvier G. Food Insecurity is Health Threat to HIV+ Patients. HIV Clinician. 2011;23(4):6-7.

21. Campa A, Zhifang Y, Lai S, et al. HIV-Related Wasting in HIV-Infected Drug Users in the Era of Highly Active Antiretroviral Therapy. Clin Infect Dis. 2005;41(8):1179-1185.

22. Vogenthaler NS, Hadley C, Lewis SJ, Rodriguez AE, Metsch LR, Del Rio C. Food insufficiency among HIV-infected crack-cocaine users in Atlanta and Miami. Public Health Nutr. 2010;15:1-7.

23. Weiser S, Bangsberg D, Kegeles S, Ragland K, Kushel M, Frongillo E. Food Insecurity Among Homeless and Marginally Housed Individuals Living with HIV/AIDS in San Francisco. AIDS Behav. 2009;13(5):841-848.

24. Wang E, McGinnis K, Fiellin D, et al. Food Insecurity is Associated with Poor Virologic Response among HIV-Infected Patients Receiving Antiretroviral Medications. J Gen Intern Med. 2011;26(9):1012-1018.

25. Weiser S, Frongillo E, Ragland K, Hogg R, Riley E, Bangsberg D. Food Insecurity is Associated with Incomplete HIV RNA Suppression Among Homeless and Marginally Housed HIV-infected Individuals in San Francisco. $J$ Gen Intern Med. 2009;24(1):14-20. 
26. Weiser SD, Fernandes KA, Brandson EK, et al. The association between food insecurity and mortality among HIV-infected individuals on HAART. J Acquir Immune Defic Syndr. 2009;52(3):342-349.

27. Weiser SD, Leiter K, Bangsberg DR, et al. Food Insufficiency Is Associated with High-Risk Sexual Behavior among Women in Botswana and Swaziland. PLoS Med. 2007;4(10):e260.

28. Shannon K, Kerr T, Milloy MJ, et al. Severe food insecurity is associated with elevated unprotected sex among HIV-seropositive injection drug users independent of HAART use. AIDS. 2011;25(16):2037-2042.

29. Shannon K, Kerr T, Zhang R, et al. Hunger and food insufficiency are independently correlated with unprotected sex among HIV+ injection drug users both on and not on HAART 5th International AIDS S Conference on HIV Pathogenesis and Treatment. Cape Town, South Africa 2009.

30. Weiser SD, Tsai AC, Gupta R, et al. Food insecurity is associated with morbidity and patterns of healthcare utilization among HIV-infected individuals in a resource-poor setting. AIDS. 2012;26(1):67-75

31. Weiser SD, Hatcher A, Frongillo EA, et al. Food Insecurity Is Associated with Greater Acute Care Utilization among HIV-Infected Homeless and Marginally Housed Individuals in San Francisco. J Gen Intern Med. 2012;18:18.

32. Campa A, Yang Z, Sales S, PhIllips J, Lai J, Lai S. Inadequate Food and Micronutrient Intake in HIV+ Drug users. International Conference on AIDS. Barcelona 2002.

33. Nord M. How much does the Supplemental Nutrition Assistance Program alleviate food insecurity? Evidence from recent programme leavers. Public Health Nutr. 2012;15(05):811-817.

34. Nord M, Golla A, M. Does SNAP decrease food insecurity? Untangling the selfselection effect. ERR: no. 85: U.S. Dept. of Agriculture, Economic Research Service 2009.

35. ACCESS Florida Online Pre-screening Tool, Department of Child and Families. https://dcfaccess.dcf.state.fl.us/access2florida/access/default.do?performAction=i nit. Accessed September 1, 2012.

36. Chesney MA. Factors affecting adherence to antiretroviral therapy. Clin Infect Dis. 2000;30(2):S171-176.

37. Spitzer WO, Dobson AJ, Hall J, et al. Measuring the quality of life of cancer patients: a concise QL-index for use by physicians. J Chronic Dis. 1981;34(12):585-597. 
38. Cunnyham K. Reaching Those In Need: State Supplemental Nutrition Assistance Program Participation Rates in 2009. Mathematica Policy Reasearch. USDA. 2011.

39. Duffy P, Bhattarai G, Irimia-Vladu M, . Regional Differences in Use of Food Stamps and Food Pantries by Low Income Households in the United States. Annual meeting, July 24-27, Providence, RI 2005.

40. Mshana GH, Wamoyi J, Busza J, et al. Barriers to accessing antiretroviral therapy in Kisesa, Tanzania: a qualitative study of early rural referrals to the national program. AIDS Patient Care STDS. 2006;20(9):649-657.

41. Wig N, Bhatt SP, Sakhuja A, Srivastava S, Agarwal S. Dietary adequacy in Asian Indians with HIV. AIDS Care. 2008;20(3):370-375.

42. Ramirez Garcia $\mathrm{P}$, Cote JK. Factors affecting adherence to antiretroviral therapy in people living with HIV/AIDS. J Assoc Nurses AIDS Care. 2003;14(4):37-45.

43. Tuller DM, Bangsberg DR, Senkungu J, Ware NC, Emenyonu N, Weiser SD. Transportation costs impede sustained adherence and access to HAART in a clinic population in southwestern Uganda: a qualitative study. AIDS Behav. 2010;14(4):778-784.

44. Mykerezi E, Mills B. The Impact of Food Stamp Program Participation on Household Food Insecurity. Am J Agric Econ. 2010;92(5):1379-1391.

45. O'Keefe EA, Wood R. The impact of human immunodeficiency virus (HIV) infection on quality of life in a multiracial South African population. Qual Life Res. 1996;5(2):275-280.

46. Federal Interagency Reentry Council. NRRC. http://www.nationalreentryresourcecenter.org/reentry-council.

47. Reentry Mythbuster on SNAP Benefits. Federal Interagency Reentry Council; NRRC. www.fns.usda.gov/snap/government/pdf/SNAP_mythbusters.pdf.

48. McCarty M, Falk G, Aussenberg R, Carpenter D. Drug Testing and CrimeRelated Restrictions in TANF, SNAP, and Housing Assistance: Congressional Research Service; 2012.

49. CareResource. Statistics. http://www.careresource.org/hivaids/statistics/. Accessed April 19, 2013. 


\section{CHAPTER IV: ASSOCIATION OF SUPPLEMENTAL NUTRITION ASSISTANCE PROGRAM (SNAP), WITH FOOD SECURITY AND NUTRITIONAL STATUS OF HIV INFECTED PATIENTS}

\section{Abstract}

The high rates of morbidity and mortality among persons infected with HIV have decreased since the introduction of antiretroviral treatment (ART). Issues of poor nutritional status are, however, still common with HIV infection. ${ }^{1,2}$ Poor nutritional status in HIV infected persons is a predictor of morbidity and mortality. ${ }^{3,4}$ Therefore, it is critical to institute interventions to improve nutritional status, prevent disease progression and improve disease management.

Nutritional status can also be compromised by food insecurity which is common among HIV infected persons. ${ }^{5-7}$ Recent studies have shown that food assistance programs help to improve food insecurity and nutritional status among HIV infected. ${ }^{8}$ We conducted a cross-sectional study to evaluate the effect of participating in the largest food assistance program in the United States: the Supplemental Nutrition Assistance Program, (SNAP) on food insecurity and nutritional status among $159 \mathrm{HIV}$ infected adults. Univariate and multivariate analyses showed no significant differences in the food security level and nutritional status between SNAP participants and eligible non-participants, even after controlling for demographic and health characteristics. More than half $(56 \%)$ of the sample experienced food insecurity and had inadequate intake of half of the nutrients assessed. More than $90 \%$ of the sample had inadequate intakes for vitamin D, E, and magnesium. Food security and adequacy of nutrient intake were negatively associated with drug and alcohol use, which were prevalent among SNAP participants. After controlling for demographic and health characteristics, including SNAP participation, 
individuals experiencing very low food security compared to those who were food secure, were 4.7 times more likely (95\% CI: 1.29-17.38) to use illicit drugs, but were 5 times less likely [0.21 (95\% CI: 0.06-0.67)] to drink alcohol, and were 8.3 times less likely [0.12 (95\% CI: 0.02-0.85)] to have children at home. Drug use was also associated with intakes below Dietary Reference Intake (DRI) requirements for vitamins $\mathrm{B}_{1}(\mathrm{AOR}$ : $2.86, P=.032$ ) and $\mathrm{B}_{2}$ (AOR: $3.29, P=.021$ ), with marginal association for vitamin $\mathrm{B}_{6}$ (AOR: $2.48 P=.063$ ). Our results do not support an association between SNAP participation and food security or nutritional status in this cohort of HIV infected individuals. However, it demonstrates that food insecurity and inadequate nutrient intake continue to be prevalent among HIV infected adults.

Keywords: Supplemental Nutrition Assistance Program (SNAP), Food security, Nutritional status. 


\section{Introduction}

HIV disease and poor nutrition create a vicious cycle that aggravates disease progression and affects chances of survival. ${ }^{9}$ Whereas poor nutritional status may accelerate disease progression and lead to poorer outcomes, HIV infection also impairs nutrient intake and utilization which leads to further deficiencies, compromised immunity and weight loss. ${ }^{9,10}$

Nutritional status is a good predictor of morbidity and mortality in the course of HIV infection, ${ }^{3,4}$ even during antiretroviral treatment. ${ }^{2,11}$ When compared to non-infected counterparts, HIV infected patients have lower serum concentration of nutrients and are more susceptible to nutritional deficiencies. ${ }^{12-15}$ With the advent of antiretroviral treatment, morbidity and mortality in HIV infected individuals have improved, and HIV has become a chronic disease; however, poor nutritional status is still being reported among some populations. ${ }^{1,2}$ In an effort to improve nutritional status, nutrition interventions that include the provision of food assistance for HIV infected individuals have been conducted in several settings. In resource-limited settings, where relatively few of these studies have been conducted, provision of food assistance was beneficial in improving nutritional status and adherence to therapy but did not have any effect on immunologic outcomes. ${ }^{16-19}$ A recent study conducted in Haiti found that HIV infected adults who lived in severe socioeconomic conditions and with low BMI, were able to significantly increase their BMI when provided food assistance. ${ }^{8}$ Similar results have been observed in resource adequate settings like the United States, although the interventions were in the form of supplemental formulas with occasional counseling. ${ }^{20-23}$ Even though none of these interventions provided actual food, some of the interventions 
were associated with significant changes in nutritional status among participants, ${ }^{20,24}$ an indication that nutritional assistance in some form is beneficial especially for HIV patients with poor socioeconomic status.

Food insecurity, defined as an individual's limitation or uncertainty to acquire healthy and adequate foods in socially acceptable ways, ${ }^{25}$ has been associated with several indicators of poor socioeconomic status such as low income, unemployment, homelessness, as well as poor physical and mental conditions. ${ }^{6,7,26}$ Food insecurity has also been reported to be prevalent among HIV infected individuals regardless of setting. ${ }^{6,7,26-31}$ Food insecurity and HIV disease are intricately linked by poverty, poor outlook of life, diminished functional capacity and unemployment, in a cycle that affects the severity of each condition. ${ }^{32}$ Food insecurity impacts HIV disease transmission, through increases in risky behaviors. ${ }^{31,33-35}$ It has also been associated with poor access to healthcare, and under circumstances where treatment is accessed, food insecurity may affect adherence to ART which leads to poor disease progression and survival. ${ }^{7,31,35}$

Food insecurity in the HIV infected person increases the chances of experiencing compromised nutrition. ${ }^{5,32}$ Provision of food assistance, in the presence or absence of food insecurity and compromised nutritional status, has, in most cases, ameliorated the adverse effects of the disease on nutrition. ${ }^{16-20,24,36,37}$

The Supplemental Nutrition Assistance Program (SNAP), formerly the Food Stamp Program, is the largest food assistance program in the country, and is provided by the federal government to alleviate problems of food insufficiency in low income families. ${ }^{38}$ Several studies have reported that SNAP has been effective in ameliorating 
food insecurity in the general population, and demonstrated nutritional and health benefits from participation. However, these results have been inconsistent. ${ }^{39-43}$ SNAP is possibly the food assistance program mostly used by low income HIV infected adults, because it is the largest food assistance program for adults in the United States. There are, however, very few studies that have evaluated the SNAP participation rate of HIV infected individuals, and to date, there is no known study that has investigated the potential benefits derived from SNAP participation with regards to nutritional status and perceived food security in HIV infected adults. The aim of this study was to investigate the impact of SNAP participation on food security and nutritional status of HIV infected adults in Miami, FL.

\section{Methods}

\section{Study Design and Setting}

This was a cross-sectional study that compared nutritional status and food security among HIV infected adults who were participating in SNAP or were eligible for SNAP but who were not currently participating. It was approved by the institutional Review Board of the Florida International University (FIU). Participants were a convenience sample recruited consecutively through the FIU-Borinquen HIV Research clinic, located in the Borinquen Health Care Center (BHCC), and other local centers that provide HIV related services. BHCC provides healthcare and social services to low income HIV infected individuals in the Miami-Dade County. Participants were considered eligible if they: (1) were 18 years or older,

(2) were participating in and/or were eligible to participate in SNAP

(3) had medical documentation of HIV seropositive status. 
Eligibility for SNAP was determined by the ACCESS Florida's Pre-screening eligibility tool, which gathers information on income, assets, household size, and expenditure, and is used as a basic prescreening tool by the State of Florida for SNAP eligibility. Informed consent was obtained from willing participants, after which they were scheduled to complete a study visit that included completing a self-administered questionnaire, as well as dietary, anthropometric and body composition assessments. Participants were also required to bring documentation of recent blood work (within three months of visit) done for their medical follow-ups. The questionnaire was pre-tested among 21 HIV infected individuals, a sample recruited from the same sources as the rest of the study population, and was minimally revised as needed, based on pre-testing results. The study visit lasted approximately one hour and all assessments were completed by a trained nutritionist. Participants were given $\$ 10.00$ for completing the study requirements. This study was conducted between April 2011 and August 2012.

\section{Survey Instruments}

Demographic, Socioeconomic and lifestyle Information: Several questions were used to assess the participants' socio-demographic and economic status. Information collected included age, gender, race/ethnicity, country of birth, marital status, child status, education, employment, living conditions, monthly income, smoking status, recreational drug use, alcohol use, antiretroviral (ART) medication use, vitamin use and the use of other food assistance programs.

Food Security: Recent food security status was measured using the 6-Item US Household Food Security Survey Module developed by the National Center for Health Statistics. This brief survey was selected in order to decrease participant's response 
burden, instead of the longer versions. Although it is short in length, it has been shown to measure food security and distinguish it from food insecurity with enough specificity, sensitivity and minimal bias compared to the original modules. ${ }^{44}$ Food security scores were coded and calculated using standard methods. Responses of "often true", "sometimes true", 'almost every month", "some months but not every month" and "yes" were coded as affirmative (1) and the total sum of affirmatives for all questions was considered the food security score. The maximum score that can be obtained is 6 with higher scores indicating severity of food insecurity. Scores of 0-1 were classified as food secure, while 2-4 and 5-6 were classified as low food security and very low food security respectively.

\section{Nutritional Status Assessment}

Nutrient Intake: A 24-hour dietary recall was used to assess dietary and nutrient intake by a trained Dietitian. At the study visit, participants were queried about foods and beverages consumed the day before. The brand of food, cooking method used, and the amount consumed were all recorded to ensure the comprehensiveness of information collected. Food models and measuring cups were used as props to accurately estimate the quantity of food consumed. The dietary information collected was analyzed using NutriBase Professional Nutrition Software Version 9 (Cybersoft Inc, 2011) to determine caloric and micro- /macronutrient composition.

Body Composition: Participants 'height and weight were measured at the time of data collection. Height was measured without shoes using a wall mounted stadiometer and was recorded to the nearest 0.5 inch. Measurement was done with participants' heels touching the base of the stadiometer. Weight was obtained to the nearest $0.1 \mathrm{lbs}$. using a 
standard calibrated scale, without shoes and in light clothing. BMI was calculated using Weight $(\mathrm{kg}) /$ Height $\left(\mathrm{m}^{2}\right)$. Body composition assessments were conducted using the bioelectrical impedance analysis (BIA) method. As part of body composition measurements, participants' waist circumference $(\mathrm{cm})$ was measured using a non-stretch tape measure at the narrowest point of the waist and hip circumference $(\mathrm{cm})$ was measured, at the widest point of the hip. ${ }^{45}$ These were used to calculate waist-to-hip ratio.

Biochemical Indicators: Laboratory measurements of serum albumin, hemoglobin and hematocrit concentration were obtained to assess nutritional status. These measurements were provided as part of the documentation of recent (within the last three months) laboratory work from their last follow-up visit with their primary care physician. This documentation was required to be less than 3 months old from the day of the study visit and needed to contain complete blood chemistry results.

\section{Statistical Analysis}

Statistical analyses were conducted using IBM SPSS version 2.10 for Windows (Released 2012. Armonk, NY: IBM Corp). Descriptive statistics were used in characterizing the participants and were expressed as mean \pm standard deviation, or percentages. Differences in characteristics by SNAP participation status were compared using student's t-test for continuous normally distributed variables, chi-square test for categorical variables, and Mann-Whitney $\mathrm{U}$ test for continuous variables that were not normally distributed.

Average nutrient intakes were adjusted for total calorie intake and the MannWhitney $\mathrm{U}$ test assessed the differences in mean nutrient intakes between SNAP participants and eligible non-participants. Some of the body composition and blood 
chemistry variables were not normally distributed; as a result, both the Mann-Whitney U test and student's t-test were used to assess the differences in the variables between the groups. When the results from both tests were similar, thus, only the results from the student's t-test were reported. Adequacy of nutrient intake was determined using the Estimated Average Intake (EAR) requirements for each nutrient and Adequate Intake (AI) for nutrients whose EAR are yet to be determined. ${ }^{46}$ The differences in percentages were compared using chi square tests.

Chi-square tests were used to compare the severity of food insecurity by SNAP participation status. The associations between SNAP participation and 1) food insecurity and 2) nutritional status (dietary intake), were examined using logistic regression. The association between SNAP participation and nutritional status indicators (body composition and blood chemistries) was assessed using multiple linear regression. Variables controlled for in the logistic and multiple linear regression analyses were age, gender, ethnicity, country of birth, child status, work status, household size, ART use, smoking status, alcohol use, drug use, vitamin use, and use of other food assistance programs. $P<0.05$ was set as the significance level for all analyses.

\section{Results}

\section{Demographic Characteristics}

After providing informed consent, 175 participants were recruited. However, due to missing data $(n=16)$ only 159 were included in the final analyses. There were no differences in demographic characteristics between those used in analyses and those who were not. Participants were mostly male (67.3\%), African-American (74.8\%), with a mean age of $46.81 \pm 8.03$ years. Over $90 \%$ were single, with nearly half $(48.4 \%)$ of the 
total having no children. Over half $(53.2 \%)$ reported having more than a high school education, with about $45 \%$ of participants claiming unemployment (Table 1). More SNAP participants $(48.7 \%)$ were on disability than non-participants $(23.9 \%)$, but fewer (39.8\%) were unemployed compared to the non-participants (56.5\%). As shown in Table 2, more SNAP participants used drugs (38.1\%) than non-participants $(13.0 \%)$, and nearly all SNAP participants $(83.8 \%)$ were on ART compared to the non-participants $(65.2 \%)$.

Using the Mann-Whitney U test, the distribution of alcohol use between the two groups differed significantly $(P=.031)$, with $44 \%$ of SNAP participants drinking alcohol at least 2-3 times/week compared to only $26 \%$ of non-participants.

\section{Association between SNAP Participation and Food Security}

About thirty-two percent of the sample experienced low food security while $23.9 \%$ experienced very low food security. There was no significant difference in the level of food security between groups. Nearly half (46\%) of SNAP participants were food secure while $39 \%$ of non-SNAP participants experienced food security (Table 3 ).

Logistic regression examined the association between food security and SNAP participation controlling for age, gender, ethnicity, country of birth, child status, work status, household size, ART use, smoking status, alcohol use, drug use, vitamin use, and use of other food assistance programs (Table 4). SNAP participation status was not significant in the logistic regression.

The logistic regression also identified relationships between some demographic characteristics and experiencing lower levels of food security (Table 5). In the model, individuals experiencing very low food security compared to those food secure were 4.7 times more likely (95\% CI: 1.29-17.38) to use illicit drugs, but were 5 times less likely 
[0.21 (95\% CI: 0.06-0.67)] to drink alcohol, and were 8.3 times less likely [0.12 (95\% CI:

$0.02-0.85)]$ to have children at home. Those experiencing low food insecurity compared to those who were food secure were 3.6 (95\% CI: 1.10-11.48) times more likely to be drug users, but were 5.6 [0.18 (95\% CI: 0.06-0.51)] times less likely to use alcohol and were 4.2 (95\% CI: 1.21-14.37) times more likely to use other food assistance programs.

\section{Association between SNAP Participation and Nutritional status}

Nutrient Intake: As shown in Table 6, no significant differences were seen in the macro and micronutrient intake between SNAP participants and non-participants. Mean caloric intake for both groups was below 2000 kcals per day. Energy adjusted protein intake for both groups was below the recommendation for healthy adults while carbohydrate intake was above recommendation. For about half of the nutrients assessed, more than $50 \%$ of the sample had intakes below the recommended Dietary Reference Intakes (DRI), whether EAR or AI. More than $90 \%$ had intakes below DRI requirements for choline, vitamin E, potassium and magnesium. Vitamin D intake was below EAR for $100 \%$ of the study sample. There were no statistically significant differences in percentages with intake below DRI for any of the nutrients by SNAP participation status (Table 7).

Logistic regressions of SNAP participation status on adequacy of nutrient intakes showed no significant results (Table 8). Several demographic characteristics were associated with the ability to achieve adequacy of nutrient intakes. Adequacy of calcium intake was associated with older age $(P=.042)$, while adequacy of vitamin A intake was associated with younger age $(P=.009)$ and not having children at home $(P=.023)$. Adequacy of vitamin $\mathrm{B}_{12}$ and iron intake was associated with being male $(P=.021, .007$, 
respectively). Of the lifestyle related variables, drug and alcohol use were found to be associated with below EAR intake for some nutrients. After adjusting for control variables, the odds of drug users having below EAR intakes were 2.9 (95\% CI: 1.09-7.49) for vitamin $\mathrm{B}_{1}, 3.3$ (95\% CI: 1.20-9.01) for vitamin $\mathrm{B}_{2}, 2.5$ (95\% CI: 0.95-6.45) for vitamin $\mathrm{B}_{6}$, and 2.6 (95\% CI: 1.00-6.56) for zinc. Alcohol users were 2.5 (95\% CI: $1.02-$ 6.14) times more likely to have below EAR intake for copper compared to non-drinkers. Use of ART was associated with above EAR intake for iron. (AOR=5.6, 95\% CI: 1.1726.40).

Body Composition and Biochemical Indicators: Average BMI for this population was $27.81 \pm 5.82$ with an average waist-to-hip ratio close to 1 . There were no significant differences in mean values of body composition and biochemical indicator variables by SNAP participation status (Table 9). Gender was significantly related to all variables except albumin. Being female was associated with having higher body mass index $(\beta=$ $0.34, P<.001)$, higher fat mass $(\beta=0.47, P<.001)$, lower lean body mass $(\beta=-0.50, P$ $<.001)$ and lower waist-to-hip ratio $(\beta=-0.27, P=.004)$. Multiple linear regression analyses were conducted to assess the association of SNAP participation status on body composition and biochemical variables. As indicated in Table 10, about $30 \%$ of the variability of most variables (with the exception of albumin and waist-to-hip ratio) was explained by the control variables. However, SNAP participation status explained less or equal to $1.4 \%$ additional variability of body composition and biochemical variables after controlling for these variables. 


\section{Discussion}

The current study did not find an association between SNAP participation and food security, although some ${ }^{47,48}$ but not all studies ${ }^{49,50}$ have found that participation in SNAP alleviates food insecurity in the general population. More than half $(56 \%)$ of the participants in this study experienced lower levels of food security. This rate is higher than both the national food insecurity rate of $14.9 \%$ and the state of Florida rate of $15.4 \%$ reported in $2011 .^{51}$ The prevalence of very low food security in our study population was more than four times what was reported for the general public in the same year. ${ }^{51}$ High food insecurity rates have consistently been reported among persons living with HIV in North America. Eighty one percent of HIV infected adults in a study conducted in Miami, with a similar population, experienced food insecurity in addition to wasting. ${ }^{26}$ Another study by Vogenthaler et al., ${ }^{29}$ in Atlanta and Miami, reported a 34\% food insecurity rate among those living with HIV. In Canada, rates of between $48-64 \%$ have been reported, with studies from California also reporting similar rates. ${ }^{6,7,27,31}$ It is possible that the ability of SNAP to alleviate the effects of heightened food insecurity in HIV infected people is minimal compared to that observed in the general population, due to the increased nutritional demands, poor nutritional status and the severe socio-economic conditions surrounding this population in Miami.

Illicit drug use had a strong association with lower levels of food security in our population. Drug users were more than three times likely to experience food insecurity. Our findings are consistent with those noted in other HIV infected cohorts across the country. ${ }^{52,53}$ Similarly, Himmelgreen et al. ${ }^{54}$ reported that drug using Hispanic women in 
Connecticut experienced higher levels of food insecurity compared to non-drug users. The use of other food assistance programs was also associated with food insecurity and this finding was not surprising. Individuals having difficulty attaining food sufficiency are more likely to use several food assistance programs. Demographic characteristics like income, unemployment and instability in housing were not associated with food insecurity in this study sample. An unexpected finding was that alcohol use was associated higher levels of food security. The association between food security and alcohol use has rarely been explored; however, our results indicate that this relationship needs further research using measures of alcohol intake, alcohol-related behaviors and alcoholism.

The progression and management of HIV infection is mediated by several factors including diet and nutritional status. Nutrients are especially important because of the roles they play in immunity, cell differentiation, and enzymatic processes..$^{10}$ Due to the collaborative interaction between nutrient status, infection and immunity, marginal or low nutrient intake becomes a cause for concern in HIV infection. ${ }^{10,55}$ Several studies have reported differently on the caloric and macronutrient intake of persons infected with HIV ${ }^{56-59}$ Our data shows that calorie and macronutrient intake in this population is lower than what is recommended for healthy adults. Due to the demands of the disease, individuals infected with HIV have increased caloric and macronutrients needs. ${ }^{60}$ Vitamins A, E and B12 have all been associated with HIV disease progression. Low serum levels of these vitamins have been linked to neurological abnormalities, increased oxidative stress and increased risk of mortality. ${ }^{61,62}$ Our HIV infected cohort had 
inadequate intake of $\mathrm{B}_{12}$ ( $46 \%$ of participants), and Vitamins $\mathrm{A}$ and $\mathrm{E}$ ( $>80 \%$ of participants). These percentages with inadequate nutrient intakes were higher than those reported for another HIV cohort, where $21 \%-64 \%$ of the women had below DRI intakes for several vitamins including vitamins $\mathrm{A}$ and $\mathrm{E} .{ }^{59}$ Other studies conducted in resource adequate setting have also reported lower intakes for vitamins $\mathrm{A}$ and $\mathrm{E}$; however, in these studies the researchers compared mean/median intakes to DRI's (specifically, RDA: Recommended Daily Allowance) without specifying proportions consuming below the DRIs. ${ }^{56,57,63}$ Other studies have investigated the potential role of vitamin D in HIV infection due to its identified effect on immunity, and its association with decreased CD4 cell count and increased mortality. ${ }^{64} \mathrm{~A}$ recent study found vitamin D status to be positively associated with disease progression, anemia and mortality. ${ }^{65}$ Vitamin D deficiency is common among HIV infected adults, and Blacks or Hispanics have been found to be at increased risk for deficiency. ${ }^{66}$ In our study, $100 \%$ of participants had below DRI intake for vitamin $\mathrm{D}$, which is a concern, as more than half of the standard ART combinations used in Miami include tenofovir, which have been known to contribute to altered Vitamin D metabolism. ${ }^{67}$ In addition, $75 \%$ of our participants are African Americans and 15\% Hispanics; two ethnic groups at heightened risk for vitamin D deficiency. Vitamin D status needs to be a priority for Nutrition Practitioners in South Florida. Further investigation to assess serum vitamin D levels is warranted for this population, as deficiency may be a mediator of disease progression and other comorbidities. 
Two key micronutrients identified to influence HIV progression are selenium and zinc. As part of selenoproteins, selenium plays a role in immunity especially as an antioxidant. ${ }^{68}$ Its deficiency, which may be due to malabsorption and depletion, is common in HIV infection, especially among persons not using ART. ${ }^{69,70}$ Poor selenium status is associated with increased disease progression and risk of mortality. ${ }^{55,61,71}$ Selenium supplementation, however, is not routinely recommended during HIV infection due to lack of sufficient evidence in support of the benefits of supplementation. ${ }^{72}$ The absolute selenium intake range for our population was between $72 \mu \mathrm{g}-81 \mu \mathrm{g}$ which seems to be higher that the recommended DRI of $45 \mu \mathrm{g}$ for health adults. With energy adjustments, however, this range decreased to $36 \mu \mathrm{g}-42 \mu \mathrm{g}$, with more than a third of our participants also consuming below DRI requirements. Selenium deficiency has been suggested to be prevalent only among HIV infected individuals with poor dietary intakes as not all HIV cohorts have reported deficiencies. ${ }^{55}$ Several studies have reported low intake and serum concentration of zinc among HIV infected persons, which seem to increase with increasing disease progression. ${ }^{56,69,73}$ We found nearly $62 \%$ of our study population to have inadequate zinc intake. With zinc deficiency still common among persons living with HIV, emphasis to increase zinc intake may play an important role for disease management. Baum et al. ${ }^{74}$ recently showed that adequacy of zinc intake achieved through supplementation leads to a fourfold decrease in the chances of developing immunological failures.

Recent HIV studies reported a trend of increasing weight among several cohorts ${ }^{75-}$ ${ }^{77}$ and this was shown in our study as well. About $32 \%$ of our population was overweight 
and $30 \%$ obese, with only $1.9 \%$ being underweight. This trend reflects the nations' obesity epidemic. Interestingly in this cohort, although calorie and macronutrient intakes were low, overweight and obesity were still prevalent. The cause of overweight and obesity observed among HIV infected persons are multifaceted as in the general population; however, diet and specific ART agents are mediators of weight gain. ${ }^{78}$ Other important biochemical indices for measuring nutritional status during HIV infection are hemoglobin, hematocrit and albumin levels, with the latter predicting survival ${ }^{58,79,80}$ The averages for these indicators in our study population are within normal limit set for healthy individuals. A similar finding was reported for albumin in another HIV infected cohort. ${ }^{58,79}$ Overall, we did not find any significant association between SNAP participation and nutritional status. However, we think our results may have been mediated by significant alcohol and drug use among SNAP participants. Findings of inadequate nutrient intake and poor diet quality have been reported among HIV drug users compared to non-users. To the best of our knowledge, this is the first study examining the nutrition and food security benefits derived from the participation in SNAP of persons living with HIV. Several other studies have explored the use of food assistance programs to improve the nutritional status of HIV infected adults. ${ }^{8,20,24,37,81}$ This research differs from the others in two ways: 1) participants received financial assistance to spend on food and not food ration/supplemental formulas and 2) participants and not the researchers controlled the type of food consumed. Findings from this study could serve as basis for other studies exploring the use of public food assistance programs to help improve the food security and nutritional status of HIV infected persons. Such 
studies will help us better understand where to invest resources to improve the lives of persons living with HIV.

The limitations of this study include its cross-sectional nature, relying on selfreported data which may weaken links between SNAP participation and better food security and nutritional outcomes. Our study did not take into account the differences in amounts received as SNAP benefits, neither did it have information on the food security nutritional status of SNAP participants prior to participation in the program. The external validity of the study is also decreased because we used a convenience sample of HIV infected persons from Miami. The generalization of study results to other HIV infected populations needs to be executed with caution. Finally adequacy of nutrient intakes was based only on one 24-hr recall, which may not represent usual intake.

In light of these limitations, however, this study confirms that food insecurity and inadequate nutrient intake continues to exist among persons infected with HIV. This has implications for treatment, management, and cost of disease, as such resources and efforts are needed to address food insecurity among HIV infected.

\section{Acknowledgements}

The authors would like to acknowledge the Florida International University, Graduate School for the Data and Evidence Acquisition Fellowship support during data collection for this study. 
Table 1: Demographic characteristics by SNAP participation status among HIV infected adults

\begin{tabular}{|c|c|c|c|}
\hline Variable & Total $(\mathrm{N}=159)$ & $\begin{array}{c}\text { SNAP } \\
(\mathrm{n}=113)\end{array}$ & $\begin{array}{c}\text { Non-SNAP } \\
(\mathrm{n}=46)\end{array}$ \\
\hline $\operatorname{Age}^{\mathrm{a} *}$ & $46.81 \pm 8.03$ & $46.81 \pm 7.52$ & $46.80 \pm 8.76$ \\
\hline \multicolumn{4}{|l|}{ Gender } \\
\hline Male & $107(67.3)$ & $77(68.1)$ & $30(65.1)$ \\
\hline Female & $52(32.7)$ & $36(31.9)$ & $16(34.8)$ \\
\hline \multicolumn{4}{|l|}{ Ethnicity } \\
\hline African American & $119(74.8)$ & $88(77.9)$ & $31(67.4)$ \\
\hline Hispanic & $24(15.1)$ & $17(15.0)$ & $7(15.2)$ \\
\hline White & $8(5.0)$ & $4(3.5)$ & $4(8.7)$ \\
\hline Other & $8(5.0)$ & $4(3.5)$ & $4 \quad(8.7)$ \\
\hline \multicolumn{4}{|l|}{ Country of Birth** } \\
\hline US born & $133(83.6)$ & $103(91.2)$ & $30(65.2)$ \\
\hline Non-US born & $26(16.4)$ & $10(8.8)$ & $16(34.8)$ \\
\hline \multicolumn{4}{|l|}{ Marital Status } \\
\hline Married & $14(8.8)$ & $11(9.7)$ & $3(6.5)$ \\
\hline Single & $145(91.2)$ & $102(90.3)$ & $43(93.5)$ \\
\hline \multicolumn{4}{|l|}{ Child Status } \\
\hline Children at home & $21(13.2)$ & $13(11.5)$ & $8(17.4)$ \\
\hline Children not at home & $61(38.4)$ & $47(41.6)$ & $14(30.4)$ \\
\hline No Children & $77(48.4)$ & $53(46.9)$ & $24(48.8)$ \\
\hline \multicolumn{4}{|l|}{ Education } \\
\hline$<$ High School & $76(47.8)$ & $50(44.2)$ & $26(56.5)$ \\
\hline$\geq$ High School & $83(52.2)$ & $63(55.8)$ & $20(43.5)$ \\
\hline \multicolumn{4}{|l|}{ Employment Status* } \\
\hline Unemployed & $71(44.7)$ & $45(39.8)$ & $26(56.5)$ \\
\hline Employed & $22(13.8)$ & $13(11.5)$ & $9(19.6)$ \\
\hline On disability & $66(41.5)$ & $55(48.7)$ & $11(23.9)$ \\
\hline \multicolumn{4}{|l|}{ Income/ month } \\
\hline$<\$ 1000$ & $129(81.1)$ & $95(84.1)$ & $34(73.9)$ \\
\hline$\geq \$ 1000$ & $30(18.9)$ & $18(15.9)$ & $12(26.1)$ \\
\hline \multicolumn{4}{|l|}{ Living condition } \\
\hline Alone & $62(39.0)$ & $44(38.9)$ & $18(39.1)$ \\
\hline With family & $70(44.0)$ & $52(46.0)$ & $18(39.1)$ \\
\hline Shelter & $27(17.0)$ & $17(15.0)$ & $11(21.7)$ \\
\hline \multicolumn{4}{|c|}{ Uses of other food assistance } \\
\hline Yes & $23(14.9)$ & $16(14.2)$ & $7(15.2)$ \\
\hline No & $136(85.5)$ & $97(85.8)$ & $39(84.8)$ \\
\hline
\end{tabular}

$\mathrm{a} *$ Reported as mean $\pm \mathrm{SD}$; All other variables are reported as $\mathrm{n}(\%)$

$* P<.05,{ }^{* *} P<.01$ 
Table 2: Lifestyle related characteristics by SNAP participation status among HIV infected adults

\begin{tabular}{|c|c|c|c|c|}
\hline Variable & $\begin{array}{c}\text { Total } \\
(\mathrm{N}=159)\end{array}$ & $\begin{array}{l}\text { SNAP } \\
(n=113)\end{array}$ & $\begin{array}{c}\text { Non-SNAP } \\
(n=46)\end{array}$ & $P$-value \\
\hline Smokes Cigarettes & & & & .133 \\
\hline Yes & $104(65.4)$ & $78(69.0)$ & $26(56.5)$ & \\
\hline No & $55(34.6)$ & $35(31.0)$ & $20(43.5)$ & \\
\hline Alcohol use & & & & .057 \\
\hline Yes & $81(50.9)$ & $63(55.8)$ & $18(39.1)$ & \\
\hline No & $78(49.1)$ & $50(44.2)$ & $28(60.9)$ & \\
\hline Drug use* & & & & .002 \\
\hline Yes & $49(30.8)$ & $43(38.1)$ & $6(13.0)$ & \\
\hline No & $110(69.2)$ & $70(61.9)$ & $40(87.0)$ & \\
\hline On ART* & & & & .001 \\
\hline Yes & $136(85.5)$ & $106(93.8)$ & $30(65.2)$ & \\
\hline No & $23(14.5)$ & $7(6.2)$ & $16(34.8)$ & \\
\hline Vitamins intake & & & & .952 \\
\hline Yes & $81(46.3)$ & $51(45.1)$ & $21(45.1)$ & \\
\hline No & $94(53.7)$ & $62(54.9)$ & $25(54.3)$ & \\
\hline
\end{tabular}

${ }^{*} P<.05$, ART: Antiretroviral therapy

All variables reported as $\mathrm{n}(\%)$

Table 3: Food security status by SNAP participation status among HIV infected adults*

\begin{tabular}{lccc}
\hline Food Security Status & $\begin{array}{c}\text { Total } \\
(\mathrm{N}=159)\end{array}$ & $\begin{array}{c}\text { SNAP } \\
(\mathrm{n}=113)\end{array}$ & $\begin{array}{c}\text { Non-SNAP } \\
(\mathrm{n}=46)\end{array}$ \\
\hline Food Security & $70(44.0)$ & $52(46.0)$ & $18(39.1)$ \\
\hline Low food security & $51(32.1)$ & $35(31.0)$ & $16(34.8)$ \\
Very low food security & $38(23.9)$ & $26(23.0)$ & $12(26.1)$ \\
\hline \multicolumn{2}{l}{ Variables are reported as: $\mathrm{n}(\%)$} & ${ }^{*} P$-value between groups not significant.
\end{tabular}


Table 4: Logistic regression of food security on SNAP participation status among HIV infected adults

\begin{tabular}{lcccc}
\hline & \multicolumn{3}{c}{ SNAP Participation } \\
Food Security Status & OR & $95 \%$ CI & OR & Adjusted \\
\hline Food Secure & ---- & ---- & ---- & ---- \\
Low food security & 0.76 & $0.34-1.68$ & 0.69 & $0.24-1.98$ \\
Very low food security & 0.75 & $0.32-1.79$ & 0.45 & $0.14-1.46$ \\
\hline
\end{tabular}

Model controlled for age, gender, ethnicity, country of birth, child status, work status, household size, ART use, smoking status, alcohol use, drug use, vitamin use, and use of other food assistance programs

Table 5: Logistic regression of food security on demographic and health characteristics among HIV infected adults

\begin{tabular}{lllllll}
\hline Variable & \multicolumn{3}{c}{ Low Food Security $^{\text {a }}$} & \multicolumn{4}{c}{ Very Low Food Security $^{\mathrm{a}}$} \\
& OR & $95 \% \mathrm{CI}$ & $P_{-}$ & OR & $95 \% \mathrm{CI}$ & $P_{-}$ \\
& & & value & & & value \\
\hline Drug use & $3.56^{*}$ & $1.10-11.48$ & .033 & $4.73^{* *}$ & $1.29-17.38$ & .019 \\
Alcohol use & $0.18^{* *}$ & $0.06-0.51$ & .001 & $0.21^{* *}$ & $0.06-0.67$ & .009 \\
Children at home $^{\mathrm{b}}$ & 0.32 & $0.07-1.47$ & .142 & $0.12^{*}$ & $0.02-0.85$ & .034 \\
Have no children $^{\mathrm{b}}$ & 0.40 & $0.16-1.03$ & .057 & 0.57 & $0.21-1.58$ & .278 \\
Use other food assistance $^{4}$ & $4.18^{*}$ & $1.21-14.37$ & .023 & 3.62 & $0.92-14.25$ & .066 \\
\hline
\end{tabular}

$* P<.05, * * P<.01$

Other variables in the model included: age, gender, ethnicity, country of birth, work status, household size, smoking status, vitamin use and SNAP use.

${ }^{\mathrm{a}}$ Reference: Food Security

${ }^{\mathrm{b}}$ Reference: Children not at home 
Table 6: Mean nutrient intake by SNAP participation status among HIV infected adults

\begin{tabular}{|c|c|c|c|c|c|c|}
\hline \multirow[b]{2}{*}{ Nutrient } & \multirow[b]{2}{*}{ SNAP Status } & \multicolumn{2}{|c|}{ Unadjusted Intake } & \multicolumn{3}{|c|}{ Energy-adjusted Intake } \\
\hline & & Mean \pm SD & $P$-value & Mean & $\pm \mathrm{SD}$ & $\begin{array}{c}P- \\
\text { value }\end{array}$ \\
\hline \multirow[t]{2}{*}{ Calories $k c a l$} & Yes & $1977.92 \pm 787.87$ & .829 & \multicolumn{2}{|c|}{$\overline{-}$} & - \\
\hline & No & $1977.45 \pm 838.91$ & & & & \\
\hline \multirow[t]{2}{*}{ Protein $g$} & Yes & $84.40 \pm 39.91$ & .302 & $44.14 \pm$ & 16.34 & 203 \\
\hline & No & $78.61 \pm 37.48$ & & $41.32 \pm$ & 15.19 & \\
\hline \multirow[t]{2}{*}{ Carbohydrates $g$} & Yes & $247.68 \pm 115.48$ & .568 & $126.13 \pm$ & 34.04 & .253 \\
\hline & No & $261.77 \pm 123.00$ & & $132.25 \pm$ & 28.75 & \\
\hline \multirow[t]{2}{*}{ Fats $g$} & Yes & $70.29 \pm 35.72$ & .172 & $34.67 \pm$ & 11.14 & .149 \\
\hline & No & $63.50 \pm 35.86$ & & $31.89 \pm$ & 10.29 & \\
\hline \multirow[t]{2}{*}{ Vitamin A $\mu g$} & Yes & $347.29 \pm 437.98$ & .371 & $165.65 \pm$ & 183.98 & .286 \\
\hline & No & $274.02 \pm 311.91$ & & $131.90 \pm$ & 144.15 & \\
\hline \multirow[t]{2}{*}{ Thiamin $m g$} & Yes & $1.32 \pm$ & .958 & $0.66 \pm$ & 0.57 & 909 \\
\hline & No & $1.12 \pm$ & & $0.57 \pm$ & 0.33 & \\
\hline \multirow[t]{2}{*}{ Riboflavin $m g$} & Yes & $1.40 \pm$ & .566 & $0.72 \pm$ & 0.61 & .231 \\
\hline & No & $1.17 \pm$ & & $0.59 \pm$ & 0.35 & \\
\hline \multirow[t]{2}{*}{ Niacin $m g$} & Yes & $17.32 \pm 12.59$ & .789 & $8.93 \pm$ & 6.35 & .823 \\
\hline & No & $16.43 \pm 12.09$ & & $8.23 \pm$ & 5.02 & \\
\hline \multirow{2}{*}{ Pantothenic acid $m g$} & Yes & $3.39 \pm \quad 2.51$ & .647 & $1.80 \pm$ & 1.64 & .657 \\
\hline & No & $3.35 \pm$ & & $1.78 \pm$ & 1.00 & \\
\hline \multirow[t]{2}{*}{ Vitamin B6 $m g$} & Yes & $1.43 \pm$ & .349 & $0.72 \pm$ & 0.81 & .344 \\
\hline & No & $1.24 \pm$ & & $0.60 \pm$ & 0.44 & \\
\hline \multirow{2}{*}{ Vitamin B12 $\mu \mathrm{g}$} & Yes & $3.72 \pm$ & .391 & $1.74 \pm$ & 1.96 & .439 \\
\hline & No & $2.69 \pm$ & & $1.47 \pm$ & 1.56 & \\
\hline \multirow[t]{2}{*}{ Vitamin C $m g$} & Yes & $68.70 \pm 88.44$ & 261 & $35.98 \pm$ & 47.43 & .216 \\
\hline & No & $47.67 \pm 52.85$ & & $26.33 \pm$ & 35.20 & \\
\hline \multirow{2}{*}{ Calcium $m g$} & Yes & $632.58 \pm 429.01$ & .470 & $339.71 \pm$ & 237.25 & .161 \\
\hline & No & $582.57 \pm 401.94$ & & $289.31 \pm$ & 184.00 & \\
\hline \multirow[t]{2}{*}{ Choline $m g$} & Yes & $198.68 \pm 180.36$ & .955 & $98.61 \pm$ & 80.55 & .952 \\
\hline & No & $188.99 \pm 154.34$ & & $94.30 \pm$ & 69.25 & \\
\hline \multirow[t]{2}{*}{ Vitamin D $\mu g$} & Yes & $1.00 \pm$ & .164 & $0.51 \pm$ & 0.75 & .148 \\
\hline & No & $1.19 \pm$ & & $0.59 \pm$ & 0.65 & \\
\hline Vitamin E $m g$ & Yes & $2.50 \pm$ & .404 & $1.19 \pm$ & 1.54 & .203 \\
\hline & No & $1.78 \pm$ & & $0.87 \pm$ & 0.75 & \\
\hline Folate $\mu g$ & Yes & $328.91 \pm 315.17$ & .911 & $164.29 \pm$ & 153.41 & .955 \\
\hline & No & $315.31 \pm 294.47$ & & $161.05 \pm$ & 143.00 & \\
\hline Magnesium $m g$ & Yes & $156.40 \pm 112.54$ & .783 & $80.32 \pm$ & 46.44 & 992 \\
\hline & No & $150.32 \pm 90.46$ & & $78.79 \pm$ & 43.92 & \\
\hline Phosphorus $m g$ & Yes & $836.84 \pm 524.84$ & .644 & $415.56 \pm$ & 186.66 & .599 \\
\hline & No & $755.04 \pm 409.41$ & & $395.53 \pm$ & 187.99 & \\
\hline Potassium $m g$ & Yes & $1507.20 \pm 1033.53$ & .522 & $787.01 \pm$ & 483.95 & .332 \\
\hline & No & $1301.87 \pm 811.50$ & & $670.51 \pm$ & 369.31 & \\
\hline Sodium $m g$ & Yes & $3334.06 \pm 1510.84$ & .492 & $1760.08 \pm$ & 728.07 & .356 \\
\hline & No & $3228.60 \pm 1741.62$ & & $1301.87 \pm$ & 603.01 & \\
\hline Copper $m g$ & Yes & $0.69 \pm \quad 0.54$ & .714 & $0.36 \pm$ & 0.23 & .918 \\
\hline & No & $0.67 \pm$ & & $0.36 \pm$ & 0.26 & \\
\hline Iron $m g$ & Yes & $16.38 \pm 11.93$ & .352 & $8.19 \pm$ & 5.11 & .234 \\
\hline & No & $13.84 \pm$ & & $6.96 \pm$ & 3.20 & \\
\hline Selenium $\mu g$ & Yes & $72.71 \pm 56.65$ & .229 & $36.53 \pm$ & 23.75 & .141 \\
\hline & No & $81.00 \pm 55.87$ & & $43.45 \pm$ & 26.60 & \\
\hline Zinc $m g$ & Yes & $8.98 \pm$ & .358 & $4.37 \pm$ & 2.99 & .302 \\
\hline & No & $1.24 \pm$ & & $3.96 \pm$ & 2.92 & \\
\hline
\end{tabular}


Table 7: Percentages with nutrient intakes below Estimated Average Requirements (EAR) by SNAP participation status among HIV infected adults

\begin{tabular}{|c|c|c|c|c|}
\hline Nutrient & $\begin{array}{l}\text { Total } \\
(\mathrm{N}=159)\end{array}$ & $\begin{array}{l}\text { SNAP } \\
(n=113)\end{array}$ & $\begin{array}{c}\text { Non-SNAP } \\
(n=46)\end{array}$ & $P$-values \\
\hline Vitamin A $\mu g$ & $130(81.8)$ & $92(81.4)$ & $38(82.6)$ & .860 \\
\hline Thiamin $m g$ & $77(48.4)$ & $56(49.6)$ & $21(45.7)$ & .655 \\
\hline Riboflavin $m g$ & $74(46.5)$ & $53(46.9)$ & $21(45.7)$ & .866 \\
\hline Niacin $m g$ & $60(37.7)$ & $43(38.1)$ & $17(37.0)$ & .897 \\
\hline Pantothenic acid $m g^{\dagger}$ & $129(81.1)$ & $91(80.5)$ & $38(82.6)$ & .771 \\
\hline Vitamin B6 $m g$ & $87(54.7)$ & $60(53.1)$ & $27(58.7)$ & .520 \\
\hline Vitamin B12 $\mu g$ & $73(45.9)$ & $50(44.2)$ & $23(50.0)$ & .509 \\
\hline Vitamin C $m g$ & $108(67.9)$ & $75(66.4)$ & $33(71.7)$ & .511 \\
\hline Calcium $m g$ & $115(72.3)$ & $82(72.6)$ & $33(71.7)$ & .916 \\
\hline Choline $m g^{*}$ & $149(93.7)$ & $105(92.9)$ & $44(95.7)$ & .520 \\
\hline Vitamin $\mathrm{D} \mu g$ & $159(100.0)$ & $113(100.0)$ & $46(100.0)$ & 1.00 \\
\hline Vitamin E $m g$ & $57(98.7)$ & $111(98.2)$ & $46(100.0)$ & .364 \\
\hline Folate $\mu g$ & $98(61.6)$ & $70(61.9)$ & $28(60.9)$ & .899 \\
\hline Magnesium $m g$ & $146(91.8)$ & $102(90.3)$ & $44(95.7)$ & .261 \\
\hline Phosphorus $m g$ & $56(35.2)$ & $41(36.3)$ & $15(32.6)$ & .660 \\
\hline Potassium $m g^{*}$ & 157 (98.7) & $111(98.2)$ & $46(100.0)$ & .364 \\
\hline Sodium $m g^{*}$ & $16(10.1)$ & $10(8.8)$ & $6(13.0)$ & .425 \\
\hline Copper $m g$ & $92(57.9)$ & $68(60.2)$ & $24(52.2)$ & .354 \\
\hline Iron $m g$ & $20(15.7)$ & $18(15.9)$ & $7(15.2)$ & .911 \\
\hline Selenium $\mu g$ & $54(34.0)$ & $43(38.1)$ & $11(23.9)$ & .088 \\
\hline Zinc $m g$ & $98(61.6)$ & $67(59.3)$ & $31(67.4)$ & .341 \\
\hline
\end{tabular}

${ }^{\dagger}$ AI was used; EAR for nutrient not yet determined 
Table 8: Logistic regressions of adequacy of nutrient intakes on SNAP participation status among HIV infected adults

\begin{tabular}{lcccc}
\hline & \multicolumn{4}{c}{ SNAP Participation } \\
Nutrient & OR & $95 \%$ CI & OR & $95 \%$ CI \\
\hline Vitamin A $\mu g$ & 1.08 & $0.44-2.66$ & 1.69 & $0.43-6.63$ \\
Thiamin $m g$ & 0.86 & $0.43-1.70$ & 0.84 & $0.34-2.07$ \\
Riboflavin $m g$ & 0.95 & $0.48-1.89$ & 0.79 & $0.44-3.28$ \\
Niacin $m g$ & 0.95 & $0.47-1.94$ & 0.80 & $0.32-1.97$ \\
Pantothenic acid $m g$ & 1.15 & $0.47-2.81$ & 1.58 & $0.47-5.38$ \\
Vitamin B6 & 1.26 & $0.63-2.51$ & 0.79 & $0.31-2.04$ \\
Vitamin B12 $\mu g$ & 1.26 & $0.63-2.51$ & 0.93 & $0.38-2.27$ \\
Vitamin C $m g$ & 1.29 & $0.61-2.73$ & 1.49 & $0.56-4.01$ \\
Calcium $m g$ & 0.96 & $0.45-2.06$ & 0.81 & $0.32-2.07$ \\
Folate $\mu g$ & 0.96 & $0.47-1.93$ & 1.03 & $0.41-2.57$ \\
Phosphorus $m g$ & 0.85 & $0.41-1.76$ & 0.52 & $0.19-1.46$ \\
Copper $m g$ & 0.72 & $0.36-1.44$ & 0.62 & $0.24-1.60$ \\
Iron $m g$ & 0.95 & $0.37-2.45$ & 0.32 & $0.08-1.35$ \\
Selenium $\mu g$ & 0.51 & $0.24-1.11$ & 0.38 & $0.20-1.82$ \\
Zinc $m g$ & 1.42 & $0.69-2.92$ & 1.26 & $0.67-5.55$ \\
\hline
\end{tabular}

Models controlled for age, gender, ethnicity, country of birth, child status, work status, household size, ART use, smoking status, alcohol use, drug use, vitamin use and use of other food assistance programs 
Table 9: Mean values for body composition and biochemical indicators by SNAP participation status among HIV infected adults

\begin{tabular}{lccc}
\hline Variable & SNAP Status & Mean \pm SD & $P$-value \\
\hline Height $i n$ & Yes & $68.39 \pm 3.67$ & .033 \\
Weight $l b s$ & No & $67.03 \pm 3.43$ & .441 \\
Waist/Hip ratio & No & $183.64 \pm 39.67$ & \\
& Yes & $178.44 \pm 35.65$ & .844 \\
BMI $l b s / i n^{2}$ & No & $0.90 \pm 0.08$ & .172 \\
LBM $l b s$ & Yes & $27.54 \pm 5.65$ & \\
& No & $28.07 \pm 5.98$ & .255 \\
Fat mass $l b s$ & Yes & $134.05 \pm 24.71$ & \\
& No & $129.31 \pm 21.28$ & .965 \\
Hemoglobin $g / d l$ & Yes & $49.60 \pm 27.32$ & .968 \\
Hematocrit $\%$ & No & $49.39 \pm 28.68$ & .631 \\
Albumin $g / d l$ & Yes & $13.18 \pm 1.84$ & .231 \\
& No & $13.18 \pm 1.64$ & \\
\hline BMI: Body & Yes & $39.28 \pm 5.59$ & \\
& No & $39.73 \pm 4.88$ & \\
\end{tabular}

BMI: Body Mass Index, LBM: Lean body mass

Table 10: Multiple linear regressions of body composition and biochemical indicators on SNAP participation status among HIV infected adults

\begin{tabular}{lccccc}
\hline Variable & $\mathrm{R}^{2}$ Change $^{\mathrm{b}}$ & $\mathrm{B}$ & $\mathrm{SE}(\mathrm{B})$ & $\beta$ & $P$-value \\
\hline Waist/Hip Ratio & 0.000 & -0.002 & 0.016 & -0.010 & .918 \\
BMI $l b s / \mathrm{in}^{2}$ & 0.001 & -0.590 & 1.081 & -0.047 & .586 \\
LBM $l b s$ & 0.002 & 2.728 & 4.431 & 0.052 & .539 \\
Fat mass $l b s$ & 0.000 & -0.067 & 4.877 & -0.001 & .989 \\
Hemoglobin $g / d l$ & 0.000 & -0.160 & 0.329 & -0.041 & .627 \\
Hematocrit $\%$ & 0.006 & -1.141 & 1.027 & -0.097 & .268 \\
Albumin $g / d l$ & 0.014 & 1.122 & 0.084 & 0.141 & .148 \\
\hline
\end{tabular}

BMI: Body Mass Index, LBM: Lean body mass

Full model $\mathrm{R}^{2}$ (Waist-to-Hip ratio) $=0.158, \mathrm{R}^{2}(\mathrm{BMI})=0.296, \mathrm{R}^{2}(\mathrm{LBM})=0.312, \mathrm{R}^{2}$ (Fat mass) $=0.379, \mathrm{R}^{2}$ (Hemoglobin $)=0.323, \mathrm{R}^{2}($ Hematocrit $)=0.267, \mathrm{R}^{2}($ Albumin $)=0.094$,

${ }^{b} R^{2}$ Change after controlling for: age, gender, ethnicity, country of birth, child status, work status, household size, ART use, smoking status, alcohol use, drug use, vitamin use and use of other food assistance programs 


\section{References}

1. Wanke CA, Silva M, Knox TA, Forrester J, Speigelman D, Gorbach SL. Weight Loss and Wasting Remain Common Complications in Individuals Infected with Human Immunodeficiency Virus in the Era of Highly Active Antiretroviral Therapy. Clin Infect Dis. 2000;31(3):803-805.

2. Koethe JR, Heimburger DC. Nutritional aspects of HIV-associated wasting in sub-Saharan Africa. Am J Clin Nutr. 2010;91(4):1138S-1142S

3. Chlebowski RT, Grosvenor MB, Bernhard NH, Morales LS, Bulcavage LM. Nutritional status, gastrointestinal dysfunction, and survival in patients with AIDS. Am J Gastroenterol.1989;84(10):1288-1293.

4. Melchior J-C, Niyongabo T, Henzel D, Durack-Bown I, Henri S-C, Boulier A. Malnutrition and wasting, immunodepression, and chronic inflammation as independent predictors of survival in HIV-infected patients. Nutrition. 1999;15(11-12):865-869.

5. Gillespie S, Kadiyala S, International Food Policy Research I. HIV /AIDS and food and nutrition security: from evidence to action. Washington, DC: IFPRI; 2005.

6. Normen L, Chan K, Braitstein P, et al. Food Insecurity and Hunger Are Prevalent among HIV-Positive Individuals in British Columbia, Canada. J. Nutr. 2005;135(4):820-825.

7. Weiser SD, Tsai AC, Gupta R, et al. Food insecurity is associated with morbidity and patterns of healthcare utilization among HIV-infected individuals in a resource-poor setting. AIDS. 2012;26(1):67-75

8. Ivers LC, Chang Y, Gregory Jerome J, Freedberg KA. Food assistance is associated with improved body mass index, food security and attendance at clinic in an HIV program in central Haiti: a prospective observational cohort study. AIDS Res Ther. 2010;7:33. doi: 10.1186/1742-6405-7-33

9. Semba RD, Tang AM. Micronutrients and the pathogenesis of human immunodeficiency virus infection. Br J Nutr. 1999;81(03):181-189. 
10. Piwoz E, Preble E. HIV / AIDS and nutrition: a review of the literature and recommendations for nutritional care and support in sub-Saharan Africa Washington, DC: Academy for Educational Development [AED], Support for Analysis and Research in Africa Project [SARA]; 2000.

11. Liu E, Spiegelman D, Semu H, et al. Nutritional status and mortality among HIVinfected patients receiving antiretroviral therapy in Tanzania. J Infect Dis. 2011;204(2):282-290.

12. Semba RD, Shah N, Strathdee SA, Vlahov D. High prevalence of iron deficiency and anemia among female injection drug users with and without HIV infection. $J$ Acquir Immune Defic Syndr. 2002;29(2):142-144.

13. Periquet BA, Jammes NM, Lambert WE, et al. Micronutrient levels in HIV-1infected children. AIDS. 1995;9(8):887-893.

14. Beach RS, Mantero-Atienza E, Shor-Posner G, et al. Specific nutrient abnormalities in asymptomatic HIV-1 infection. AIDS. 1992;6(7):701-708.

15. Lacey CJ, Murphy ME, Sanderson MJ, Monteiro EF, Vail A, Schorah CJ. Antioxidant-micronutrients and HIV infection. Int J STD AIDS. 1996;7(7):485489.

16. Kadiyala S, Gillespie S. Rethinking food aid to fight AIDS. Food Nutr Bull. 2004;25(3):271-282.

17. Shekar M, Heaver R, Lee Y-K, World B. Repositioning nutrition as central to the development agenda : a strategy for large scale action. Washington, D.C.: World Bank; 2005.

18. Rawat R, Kadiyala $\mathrm{S}, \mathrm{McNamara} \mathrm{PE}$. The impact of food assistance on weight gain and disease progression among HIV-infected individuals accessing AIDS care and treatment services in Uganda. BMC Public Health. 2010;10:316.

19. Cantrell RA, Sinkala M, Megazinni K, et al. A Pilot Study of Food Supplementation to Improve Adherence to Antiretroviral Therapy Among FoodInsecure Adults in Lusaka, Zambia. J Acquir Immune Defic Syndr. 2008;49(2):190-195. 
20. Clark RH, Feleke G, Din M, et al. Nutritional treatment for acquired immunodeficiency virus-associated wasting using beta-hydroxy betamethylbutyrate, glutamine, and arginine: a randomized, double-blind, placebocontrolled study. J Parenter Enteral Nutr. 2000;24(3):133-139.

21. McDermott AY, Shevitz A, Must A, Harris S, Roubenoff R, Gorbach S. Nutrition Treatment for HIV Wasting: A Prescription for Food as Medicine. Nutr Clin Pract. 2003;18(1):86-94.

22. Pichard C, Sudre P, Karsegard V, et al. A randomized double-blind controlled study of 6 months of oral nutritional supplementation with arginine and 3 fatty acids in HIV-infected patients. AIDS. 1998;12(1):53-63.

23. Stack JA, Bell SJ, Burke PA, Forse RA. High-Energy, High-Protein, Oral, Liquid, Nutrition Supplementation in Patients with HIV Infection: Effect on Weight Status in Relation to Incidence of Secondary Infection. J Am Diet Assoc. 1996;96(4):337-341.

24. Shabert JK, Winslow C, Lacey JM, Wilmore DW. Glutamine-antioxidant supplementation increases body cell mass in AIDS patients with weight loss: a randomized, double-blind controlled trial. Nutrition. 1999;15(11-12):860-864.

25. Andersen SA. Core indicators of nutritional state for difficult-to-sample populations. J Nutr. 1990;11:1559-1600.

26. Campa A, Zhifang Y, Lai S, et al. HIV-Related Wasting in HIV-Infected Drug Users in the Era of Highly Active Antiretroviral Therapy. Clin Infect Dis. 2005;41(8):1179-1185.

27. Anema A, Kerr T, Weiser SD, Montaner JSG, Wood E. Prevalence and correlates of self-reported hunger among HIV+ and HIV- injection drug users in Canada 5th International AIDS Society Conference on HIV Pathogenesis and Treatment Cape Town, South Africa 2009.

28. Mamlin J, Kimaiyo S, Lewis S, et al. Integrating nutrition support for foodinsecure patients and their dependents into an HIV care and treatment program in Western Kenya. Am J Public Health. 2009;99(2):215-221. 
29. Vogenthaler NS, Hadley C, Lewis SJ, Rodriguez AE, Metsch LR, Del Rio C. Food insufficiency among HIV-infected crack-cocaine users in Atlanta and Miami. Public Health Nutr. 2010;15:1-7.

30. Wang E, McGinnis K, Fiellin D, et al. Food Insecurity is Associated with Poor Virologic Response among HIV-Infected Patients Receiving Antiretroviral Medications. J Gen Intern Med. 2011;26(9):1012-1018.

31. Weiser S, Frongillo E, Ragland K, Hogg R, Riley E, Bangsberg D. Food Insecurity is Associated with Incomplete HIV RNA Suppression Among Homeless and Marginally Housed HIV-infected Individuals in San Francisco. $J$ Gen Intern Med. 2009;24(1):14-20.

32. Anema A, Vogenthaler N, Frongillo E, Kadiyala S, Weiser S. Food insecurity and HIV/AIDS: current knowledge, gaps, and research priorities. Curr HIV/AIDS Rep. 2009;6:224-231.

33. Dunkle KL, Jewkes RK, Brown HC, Gray GE, McIntryre JA, Harlow SD. Transactional sex among women in Soweto, South Africa: prevalence, risk factors and association with HIV infection. Soc Sci Med. 2004;59(8):1581-1592.

34. Oyefara JL. Food insecurity, HIV/AIDS pandemic and sexual behaviour of female commercial sex workers in Lagos metropolis, Nigeria. Sahara J. 2007;4(2):626-635.

35. Weiser S, Bangsberg D, Kegeles S, Ragland K, Kushel M, Frongillo E. Food Insecurity Among Homeless and Marginally Housed Individuals Living with HIV/AIDS in San Francisco. AIDS Behav. 2009;13(5):841-848.

36. Keithley JK, Swanson B, Zeller JM, et al. Comparison of standard and immuneenhancing oral formulas in asymptomatic HIV-infected persons: a multicenter randomized controlled clinical trial. J Parenter Enteral Nutr. 2002;26(1):6-14.

37. Rabeneck L, Palmer A, Knowles JB, et al. A randomized controlled trial evaluating nutrition counseling with or without oral supplementation in malnourished HIV-infected patients. J Am Diet Assoc. 1998;98(4):434-438.

38. USDA. Building a Healthy America: A Profile of the Supplemental Nutrition Assistance Program. In: FNS, ed 2012. 
39. Allen JE, Gadson KE. Nutrient Consumption Patterns of Low-Income Households: USDA, Economic Research Service. 1983.

40. Beebout H, Cavin E, Devaney B, . Evaluation of the Nutrition Assistance Program in Puerto Rico: Volume II, Effects on Food Expenditures and Diet Quality. Washington, DC: Mathematica Policy Research, Inc. 1985.

41. Devaney B, Moffitt R. Dietary Effects of the Food Stamp Program. Am J Agric Econ. 1991;73(1):202-211.

42. Fox M, Hamilton $\mathrm{W}$, Lin B-H. Effects of food assistance and Nutrition Programs on nutrition and health;Volume 4 Executive Summaryof the Literature Review: Food Assisstance and Nutrition Research. 2004. FANRR19-4.

43. Fraker TM, Martini AP, Ohls JC. The Evaluation of the Alabama Food Stamp Cash-out Demonstration: Volume 1, Recipient Impacts. USDA, Food and Nutrition Service. 1992.

44. Blumberg SJ, Bialostosky K, Hamilton WL, Briefel RR. The Effectiveness of a Short Form of the Household Food Security Scale. Am J Public Health. 1999;89(8):1231-1234.

45. Chan DC, Watts GF, Barrett PHR, Burke V. Waist circumference, waist-to-hip ratio and body mass index as predictors of adipose tissue compartments in men. QJM. 2003;96(6):441-447.

46. Dietary Reference Intakes: Application for Dietary Assessment. National Academy of Science. Institute of Medicine. 2000.

47. Nord M. How much does the Supplemental Nutrition Assistance Program alleviate food insecurity? Evidence from recent programme leavers. Public Health Nutr. 2012;15(05):811-817.

48. Ratcliffe C, McKernan S-M, Zhang S. How Much Does the Supplemental Nutrition Assistance Program Reduce Food Insecurity? Am J Agric Econ. 2011;93(4):1082-1098. 
49. Gundersen C, Oliveira V. The Food Stamp Program and Food Insufficiency. Am J Agric Econ. 2001;83(4):875-887.

50. Huffman S, Jensen H. Do Food Assistance Programs Improve Household Food Security? Recent Evidence from the United States: Center for Agricultural and Rural Development, Iowa State Univ. 2003:Working Paper 03-WP 335.

51. Coleman-Jensen A, Nord M, Andrews M, Carlson S. Household Food Security in the United States in 2011. In: USDA, ed: Economic Research Services. 2011.

52. Kalichman S, Cherry C, Amaral C, et al. Health and Treatment Implications of Food Insufficiency among People Living with HIV/AIDS, Atlanta, Georgia. $J$ Urban Health. 2010;87(4):631-641.

53. Hendricks KM, Erzen HD, Wanke CA, Tang AM. Nutrition Issues in the HIVInfected Injection Drug User: Findings from the Nutrition for Healthy Living Cohort. J Am Coll Nutr. 2010;29(2):136-143.

54. Himmelgreen DA, Perez-Escamilla R, Segura-Millan S, Romero-Daza N, Tanasescu M, Singer M. A comparison of the nutritional status and food security of drug-using and non-drug-using Hispanic women in Hartford, Connecticut. Am J Phys Anthropol. 1998;107(3):351-361.

55. Bogden JD, Oleske JM. The essential trace minerals, immunity, and progression of HIV-1 infection. Nutr Res. 2007;27(2):69-77.

56. Kim JH, Spiegelman D, Rimm E, Gorbach SL. The correlates of dietary intake among HIV-positive adults. Am J Clin Nutr. 2001;74(6):852-861.

57. Onyango AC, Walingo MK, Mbagaya G, Kakai R. Assessing Nutrient Intake and Nutrient Status of HIV Seropositive Patients Attending Clinic at Chulaimbo SubDistrict Hospital, Kenya. J Nutr Metab. 2012;2012:6.

58. Vorster HH, Kruger A, Margetts BM, et al. The nutritional status of asymptomatic HIV-infected Africans: directions for dietary intervention? Public Health Nutr. 2004;7(08):1055-1064. 
59. Woods MN, Spiegelman D, Knox TA, et al. Nutrient intake and body weight in a large HIV cohort that includes women and minorities. $J$ Am Diet Assoc. 2002;102(2):203-211.

60. FANTA. Food Assistance Programming in the Context of HIV. Food and Nutrition Technical Assistance (FANTA) Project and World Food Programme (WFP). Washington, DC: FANTA Project, Academy for Educational Development 2007.

61. Baum MK, Shor-Posner G, Lai S, et al. High Risk of HIV-Related Mortality Is Associated With Selenium Deficiency. J Acquir Immune Defic Syndr. 1997;15(5):370-374.

62. Tang AM, Smit E. Selected vitamins in HIV infection: a review. AIDS Patient Care STDS. 1998;12(4):263-273.

63. Smit E, Graham NMH, Tang A, Flynn C, Solomon L, Vlahov D. Dietary intake of community-based HIV-1 seropositive and seronegative injecting drug users.

Nutrition. 1996;12(7-8):496-501.

64. Villamor E. A Potential Role for Vitamin D on HIV Infection? Nutr Rev. 2006;64(5):226-233.

65. Mehta S, Giovannucci E, Mugusi FM, et al. Vitamin D Status of HIV-Infected Women and Its Association with HIV Disease Progression, Anemia, and Mortality. PLoS ONE. 2010;5(1):e8770.

66. Dao CN, Patel P, Overton ET, et al. Low Vitamin D among HIV-Infected Adults: Prevalence of and Risk Factors for Low Vitamin D Levels in a Cohort of HIVInfected Adults and Comparison to Prevalence among Adults in the US General Population. Clin Infect Dis. 2011;52(3):396-405.

67. Childs KE, Fishman SL, Constable C, et al. Short communication: Inadequate vitamin $\mathrm{D}$ exacerbates parathyroid hormone elevations in tenofovir users. AIDS Res Hum Retroviruses. 2010;26(8):855-859.

68. Gill H, Walker G. Selenium, immune function and resistance to viral infections. Nutr Diet. 2008;65:S41-S47. 
69. Jones CY, Tang AM, Forrester JE, et al. Micronutrient levels and HIV disease status in HIV-infected patients on highly active antiretroviral therapy in the Nutrition for Healthy Living cohort. J Acquir Immune Defic Syndr. 2006;43(4):475-482.

70. Patrick L. Nutrients and HIV: Part one -- beta carotene and selenium. Altern Med Rev. 1999;4(6):403-413.

71. Singhal N, Austin J. A Clinical Review of Micronutrients in HIV Infection. J Int Assoc Physicians AIDS Care 2002;1(2):63-75.

72. NIH. Dietary Supplement Fact Sheet:Selenium. Office of Dietary Supplements. http://ods.od.nih.gov/factsheets/Selenium-HealthProfessional. Accessed October 23, 2012.

73. Lai H, Lai S, Shor-Posner G, Ma F, Trapido E, Baum MK. Plasma zinc, copper, copper:zinc ratio, and survival in a cohort of HIV-1-infected homosexual men. $J$ Acquir Immune Defic Syndr. 2001;27(1):56-62.

74. Baum MK, Lai S, Sales S, Page JB, Campa A. Randomized, controlled clinical trial of zinc supplementation to prevent immunological failure in HIV-infected adults. Clin Infect Dis. 2010;50(12):1653-1660.

75. Crum-Cianflone N, Roediger MP, Eberly L, et al. Increasing Rates of Obesity among HIV-Infected Persons during the HIV Epidemic. PLOS ONE. 2010;5(4):e10106.

76. Crum-Cianflone N, Tejidor R, Medina S, Barahona I, Ganesan A. Obesity among patients with HIV: the latest epidemic. AIDS Patient Care STDS. 2008;22(12):925-930.

77. Hendricks KM, Willis K, Houser R, Jones CY. Obesity in HIV-Infection: Dietary Correlates. J Am Coll Nutr 2006;25(4):321-331.

78. Dorey-Stein Z, Amorosa VK, Kostman JR, Lo Re V, 3rd, Shannon RP. Severe weight gain, lipodystrophy, dyslipidemia, and obstructive sleep apnea in a human immunodeficiency virus-infected patient following highly active antiretroviral therapy. J Cardiometab Syndr. 2008;3(2):111-114. 
79. Feldman JG, Burns DN, Gange SJ, et al. Serum albumin as a predictor of survival in HIV-infected women in the Women's Interagency HIV Study. AIDS.

2000;14(7):863-870.

80. Knox TA, Zafonte-Sanders M, Fields-Gardner C, Moen K, Johansen D, Paton N. Assessment of Nutritional Status, Body Composition, and Human Immunodeficiency Virus-Associated Morphologic Changes. Clin Infect Dis 2003;36(2):S63-S68.

81. Schwenk A, Steuck H, Kremer G. Oral supplements as adjunctive treatment to nutritional counseling in malnourished HIV-infected patients: randomized controlled trial. Clin Nutr. 1999;18(6):371-374. 


\section{CHAPTER V: ASSOCIATION OF SUPPLEMENTAL NUTRITION ASSISTANCE PROGRAM (SNAP) WITH HEALTH RELATED QUALITY OF LIFE AND DISEASE STATE OF HIV INFECTED PATIENTS}

\section{Abstract}

As with other chronic diseases, HIV infection can cause devastation to health and quality of life. ${ }^{1}$ The literature on the potential clinical and non-clinical benefits of participation in food assistance programs for individuals infected with HIV is scanty. ${ }^{2-5}$ We conducted a cross-sectional study of 165 HIV infected adults to determine the impact of the Supplemental Nutrition Assistance Program (SNAP) on HIV disease status and health related quality of life (HRQOL). SNAP is the assistance program most widely used by the majority of low income HIV infected persons in the United States ${ }^{6}$ to supplement their diet. There was no significant association between participation in SNAP and disease status; CD4 cell count $(\beta=0.02, P=.837)$ and viral load $(\beta=0.02, P$ $=.836)$. The mean scores for all the HRQOL domains, categorized further into physical and mental components, were lower compared to the US population, but none were associated with SNAP participation status. Higher scores on the general health $(\mathrm{GH})$ domain, were marginally associated with SNAP participation $(\beta=0.16, P=.071)$. CD4 cell count was not associated with any of the quality of life components. Viral load, however, was inversely associated with the mental component score of the HRQOL $(\beta=$ $-0.30, P=.003)$. Having increased pathological symptoms was associated with having low physical and mental components scores for HRQOL $(\beta=-0.20, P=.013$ and $\beta=-$ $0.38, P<.001)$ respectively. Higher scores on the HRQOL were associated with being younger, not being born in the US, not using other food assistance programs, not having symptoms, not using ART, and having lower viral loads. Drug and alcohol use were not 
associated HRQOL. Alcohol use was associated with decreased CD4 cell count $(\beta=-$

$0.16, P=.05)$, while drug use was strongly associated with increased viral load $(\beta=0.20$, $P=.008)$. In our study of HIV infected adults, SNAP participation status was not associated with disease status or health related quality of life.

Keywords: Health related quality of life, HIV disease state, Supplemental Nutrition Assistance Program. 


\section{Introduction}

There are approximately 34 million people infected with the human immunodeficiency syndrome (HIV) worldwide. ${ }^{7}$ The introduction of antiretroviral treatment (ART) has led to declines in disease associated morbidity and mortality, making HIV infection a chronic disease. ${ }^{8}$ As a result, the focus of healthcare providers have shifted from being focused only on the clinical status, towards a balance between clinical outcomes and patient centered health related quality of life (HRQOL).

HRQOL is a subjective measure of a patients' view of their wellbeing and functionality in relation to their chronic disease. Poor quality of life has long been associated with HIV disease progression, therefore, measuring HRQOL among persons living with HIV gives practitioners valuable feedback on treatment efficacy and effectiveness as well as disease prognosis. ${ }^{9}$ Improved quality of life has consistently being associated with survival and healthcare utilization in this population. ${ }^{10-13}$

Patient demographic and lifestyle characteristics associated with poor quality of life during HIV infection include being Black or Hispanic, being female, older age, having less education and using recreational drugs. ${ }^{14-17}$ Immunologic and virologic status also affects HRQOL with decreased CD4 cell counts always associated with poorer quality of life. Such association, however, has not been consistently reported with higher viral load. ${ }^{14,18-21}$ Other disease related factors of HRQOL are the presence of symptoms, whether HIV related or not. ${ }^{17,22,23}$ Antiretroviral therapy (ART) may improve HRQOL; ${ }^{9}$ however, other investigators have found a negative impact with long term ART use due to treatment side effects and toxicities. ${ }^{24}$ In addition, several studies have reported that psychological and social support influences HRQOL in this population, sometimes even 
mediating the relationship of quality of life with symptomatology and/or treatment side effects. $^{25-28}$

The importance of nutrition in improving health related quality of life for the chronically ill has been documented for other conditions. ${ }^{29,30}$ It is possible that such a relationship exits with HIV disease, but there is currently no evidence from research. It is well known, however, that the presence of adequate nutrition during HIV infection produces better nutritional and clinical outcomes, allowing for better disease management. ${ }^{31}$ This has led to recommendations to incorporate food assistance as part of HIV treatment, as well as in other support programs, especially in the developing world..$^{32,33}$ These recommendations, however, are not based on evidence-based research that has been conducted with groups similar to the target beneficiaries. ${ }^{34}$ Therefore, documentation on quantitative benefits derived from providing targeted food assistance is scarce. ${ }^{35}$ A recent study showed that such a program improved treatment adherence but not clinical outcomes. ${ }^{3}$ Another study reported vast improvements in body composition and food security among food assistant recipients compared to non-recipients, but no relationship with quality of life. ${ }^{4}$ In the United States, the largest food assistance program is the Supplemental Nutrition Assistance Program (SNAP) ${ }^{6}$ and we recently reported that the participation rate in this program among our cohort is fairly high, similar to nationwide participation levels (unpublished). While there are no food assistance programs targeted specifically at HIV infected individuals, these types of programs may be beneficial in ameliorating clinical disease burden and improving quality of life. To our knowledge, no study has investigated such a relation with SNAP which is not specific for the HIV infected population. The aim of this study, therefore, was to determine the 
impact of participation in SNAP on HIV disease status and health related quality of life in HIV infected individuals.

\section{Methods}

\section{Study Design and Setting}

This was a cross-sectional study approved by the institutional Review Board of the Florida International University. The research was conducted among HIV infected adults eligible to participate or participating in SNAP. The study was conducted between April 2011 and August 2012 and participants were a consecutive convenience sample recruited mainly from the Florida International University HIV Research clinic located in the Borinquen Health Care Center (BHCC), as well as other centers providing care to HIV patients. BHCC provides various HIV-related services to persons with low socioeconomic status living with HIV/AIDS in Miami-Dade County. Eligibility for SNAP was determined using ACCESS Florida's Pre-screening eligibility tool. This is a basic prescreening tool by the State to determine SNAP eligibility using information such as income, assets, household size, and expenditure. Other inclusion criteria were being 18 years or older and documentation of HIV seropositive status. Individuals, who signed informed consent after being informed of study protocol, were included in the study. At the study visit, participants completed a self-administered questionnaire that gathered information on sociodemographic characteristics as well as information on health related quality of life. Presence of symptoms, immunologic (CD4 cell count) and virologic (viral load) variables were also assessed. Patients were required to present documentation of their most recent virology and immunology results from their last medical visit. Each 
participant was given $\$ 10$ as appreciation for completing the study requirements and as reimbursement for expenses derived from participation.

\section{Survey Instruments and Variables Assessed}

Demographic and Socioeconomic Information: Information collected to determine socio-demographic and economic status were age, gender, ethnicity, marital status, education, employment status, monthly income, country of birth, antiretroviral medication use, use of community food resources and substance abuse (smoking, drug use, alcohol use).

Health Related Quality of Life: The SF-36v $2^{36}$ health survey was used to assess health related quality of life. It consists of 36 items aggregated into eight health domains scales, and further into two component summary measures, namely the Physical and Mental summary scores (PCS and MCS) respectively. The physical health measure is made up of (1) Physical Functioning (PF), which measures limitations for performing physical activity, (2) Role-Physical (RP), which measures limitations in the kind of work/activities and capacity to work or engage in usual activities, (3) Bodily Pain (BP), which measures intensity of bodily pain and the magnitude to which it affects normal work activities, and (4) General Health (GH), which covers perceptions and expectation of the respondent's health.

The mental health measures are comprised of (1) Vitality (VT), which measures energy and fatigue levels, (2) Social Functioning (SF), which assesses health related burden on the number and quality of social activities, (3) Role Emotional (RE), which is a measure of the impact of mental health on time spent on work/activities, the amount of work/activity achieved and the care devoted to activities performed, and lastly (4) Mental 
Health (MH) which addresses four mental health dimensions: anxiety, depression, loss of behavioral/emotional control and psychological wellbeing. ${ }^{36}$

The reliability scores for all the domains are reported to be high, ranging from 0.84-0.95. ${ }^{36}$ Scoring for the scales was performed using the Quality Metric Health Outcome Software and two scores were computed, one based on a standard scoring scale between 0 and 10, a second based on norm-based T-scores. The norm-based scores were used in calculating the component summary scores. ${ }^{37}$ The norm-based scoring, allows for comparison both between and within the domains and summary scores. It also allows for a direct comparison with the general US population scores where the normed mean is 50 and the standard deviation is 10 . A low score on any of the domains is indicative of a poor state. ${ }^{37}$ The scores using the scoring software were exported to SPSS for analysis.

Disease Status: Viral load and CD4 cell counts were assessed as part of clinical outcomes. These were obtained from participant's medical reports. The participants either provided the documentations themselves or signed a medical release form to obtain information directly from their provider.

Symptoms: A symptomatology questionnaire developed for use in a similar HIV population was used to evaluate incidence of symptoms ${ }^{38}$ Study participants were asked about any symptoms that were experienced (pertaining to general malaise and also those related to HIV) within the past month. These included diarrhea, constipation, nausea, fever, fatigue, and unexplained changes in weight. Number of symptoms ranged from 0 to 9 . 


\section{Statistical Analysis}

A descriptive analysis of participants' sociodemographic, lifestyle and clinical profile was completed and the results were expressed as mean \pm standard deviation or percentages. The square root of CD4 cell count and the log of viral load were calculated and used in the analysis, since their distributions were not normal. Viral load was also categorized based on levels indicative of degree of virologic control while CD4 cell count was categorized based on guidelines for initiating treatment. ${ }^{39}$ To test differences in variables between SNAP participants and non-participants, Student's t-test was used for continuous variables and chi-square test for categorical variables. The means of the various quality of life health domain scales and component summaries were calculated and compared with the US general population using a one sample t-test.

Univariate analysis using Pearson's correlation was performed to test the relationship of demographic characteristics with immunological and virologic variables as well as quality of life domains. Pearson's correlation analysis was also performed to assess association of SNAP participation with disease status and health related quality of life. Multiple linear regression models were used to further assess the associations. Regression models were constructed with log viral load, square root CD4 cell count, MCS, PCS and all the other HRQOL scales as dependent variables. Independent variables used in the analysis were identified from the literature. These were age, gender, ethnicity, education, employment status, income, marital, child status, household number, ART use, smoking status, alcohol and drug use. All statistical analyses were performed using SPSS version 21. Statistical significance for all analyses was $P<.05$. 


\section{Results}

A total of 165 participant were included in the study of which $109(66 \%)$ were male. The mean age of the sample was $46.99 \pm 7.87$ years. As shown in Table 1 , most study participants were African American (74.5\%) and were born in the US (83.6\%), with the latter being significantly different between the SNAP participation and nonparticipation groups $(91.5 \%$ vs. $64.6 \%, P<.001)$. Significantly more non-SNAP participants were employed and fewer reported disability compared to SNAP participants. Also a significantly higher percentage of SNAP participants reported having less than $\$ 1000$ monthly income $(84.6 \%$ vs. $70.8 \%, P<.042)$. Table 2 compares the two groups on health and lifestyle characteristics. A significantly greater percentage of SNAP participants used recreational drugs $(36.8 \%)$ than the non-participants $(12.5 \%), P=.002$. On the other hand, a significantly higher percentage of the SNAP participants received ART treatment compared to non-participants $(94 \%$ vs. $70.8 \%, P<0.001)$. The means of the standard and norm-based scores for the study sample for the HRQOL domains and component summaries are reported in Table 3. Both PCS and MCS scores were significantly lower than the US general norms.

\section{Relationship between SNAP Participation and HRQOL}

Table 4 compares the domain and summary scores between groups and also with the general population. SNAP participants $(M=45.63)$ had somewhat more bodily pain than the non-participants $(M=49.69), P=.065$, (highest score indicates "no pain or limitations due to pain"). SNAP participants scored significantly lower on all HRQOL domains than the general population, with the exception of vitality. The non-SNAP participants scored significantly lower on four of the HRQOL domains. Multiple 
regression models were constructed to further assess the relationship of all of the HRQOL domain scales on SNAP participation status. All the models, which included SNAP participation and all the independent variables, were significant. The models for PCS and MCS explained $23.4 \%$ and $38 \%$ of their respective variance. After controlling for the independent variables, neither PCS nor MCS were significantly associated with SNAP participation status. SNAP participation status was not significant for any of the HRQOL domain scales, although it approached significance in the regression model for general health. In this model, SNAP participation status explained $1.6 \%$ additional variability, $\beta=0.16, P=.071$. Higher general health scores were associated with SNAP participation.

Several demographic characteristics were significantly associated with many of the HRQOL domains, however only those related to PCS and MCS are reported. In the regression model, higher PCS scores were associated with having fewer symptoms $(\beta=$ $0.20, P=.013)$, being younger $(\beta=0.21, P=.014)$, not using other food assistance programs $(\beta=0.19, P=.017)$, and not being born in the US ( $\beta=0.22, P=.035)$. Higher MCS scores were associated with having fewer symptoms $(\beta=0.38, P<.001)$, having a lower viral load $(\beta=0.30, P=.003)$, having more than a high school education $(\beta=0.20$, $P=.009)$, not using ART $(\beta=0.18, P=.030)$, and not being born in the US $(\beta=0.18$, $P=.050)$.

\section{Relationship between SNAP Participation and Disease Status}

In the univariate analysis, participation in SNAP was not associated with the disease parameters, although a higher observed percentage of SNAP participants had controlled viral load compared to non-participants; $49.6 \%$ vs. 37.5\% (Table 5). Further 
analysis of these relationships did not show significance, even though the regression models were significant at $P<.001$ (Tables $8 \mathrm{a}$ and $8 \mathrm{~b}$ ). Participation in SNAP, in addition to all the control variables, explained $41 \%$ and $52.5 \%$ of the variability in CD4 cell count and viral load respectively. In these models, several demographic characteristics were associated with these parameters. Higher CD4 cell counts were associated with having a lower viral load $(\beta=-0.63, P<.001)$, not using ART $(\beta=-$ $0.24, P=.003)$, having monthly income higher than $\$ 1000(\beta=-0.18, P=.019)$, and not drinking alcohol $(\beta=-0.16, P=.05)$. Lower viral loads were associated with using ART $(\beta=-0.26, P<.001)$, higher $\mathrm{CD} 4$ cell count $(\beta=-0.51, P<.001)$, larger household size $(\beta=-0.22, P=.003)$, not using drugs $(\beta=0.21, P=.008)$, using vitamins $(\beta=-0.18, P=$ $.006)$, and more symptoms $(\beta=-0.12, P=.043)$.

\section{Discussion}

Most of the findings from the analyses of demographic data were expected. Individuals who were US citizens, disabled, unemployed, and had lower income were more likely to participate in SNAP. ${ }^{40}$ The larger number of males and African Americans represented in this study population is a reflection of the epidemic's distribution pattern with respect to gender and ethnicity in Miami-Dade County. The epidemic also disproportionally affects African-Americans compared to other ethnicities. ${ }^{41}$ The differences observed between SNAP participants and non-participants with respect to drug and alcohol use, with those participating in SNAP using more alcohol, may be related to having more income to spend on non-nutritive items, since the income for food was supplemented by SNAP. Those participating in SNAP were more likely to receive 
ART, which may be related to the fact that they were more connected into service systems.

The low norm-based score (less than 47) reported for both the physical and mental domain of the HRQOL among this sampled population, compared to the US general population, was expected and this is an indication of the functional impairment from having a chronic disease ${ }^{43}$ Compared to individuals with other types of chronic diseases, however, the mean physical and mental health components summaries of this cohort of HIV infected individuals were higher, although they were low compared to general population scores. ${ }^{43}$ Similar to other chronic diseases, HIV infection has been shown to affect HRQOL. ${ }^{14,18,19}$.

\section{SNAP Participation, HRQOL and Disease Status}

The main goal of our study was to examine whether participation in SNAP could ameliorate the detrimental effect that HIV disease has on clinical outcomes and quality of life, with the aim of determining if there was any relationship between participating in SNAP and improved disease status and quality of life. The relationships between HRQOL domains and participation in SNAP in the present study were not significant. Nor were the relationships between parameters of disease status and SNAP participation significant. These results are consistent with those from previous studies that evaluated the relationship of nutritional status and food assistance with disease parameters among individuals infected with HIV. After a 12 week nutrition intervention which provided macro and micronutrients, Barneis et al. ${ }^{2}$ found no significant improvement in CD4 cell counts and health related quality of life. Similarly, Keithly et al. ${ }^{5}$ reported finding no differential effect on immune parameters after providing oral food assistance to HIV 
infected persons for 1 year. In a recent study conducted in Zambia, food supplementation was not found to significantly improve clinical outcomes. ${ }^{3}$ Most of these studies were conducted in conditions where ART was not readily available. Another study that provided food assistance to HIV infected Haitians found only marginal improvements in HRQOL, with none of the results being significant. ${ }^{4}$ This lack of relationship might be due to the severity of the impact of the disease on quality of life, or to the inadequacy of the food assistance to improve nutritional status by itself or both. However, provision of food assistance may indirectly affect disease status and quality of life through its association with improved food security, dietary/nutrient intake and adherence to medication, all of which have been shown to positively influence disease status and HRQOL. ${ }^{3,435}$ Some other factors may mediate the relationships between attaining adequate diet/nutrition and improved disease states as well as attainment of a sense of wellbeing. It is possible that several negative psychosocial factors weaken this relationship, even negating improvements achieved by attaining optimum nutrition. Therefore, studies are warranted to investigate the possible synergy between nutrition and psychosocial factors as pertaining to clinical and non-clinical outcomes of HIV disease.

\section{Immunologic Parameters, Demographic Characteristics and HRQOL}

As part of further analysis, we looked at the relationships between immunological parameters and HRQOL. There is inconsistency in the literature concerning these relationships. Most studies found higher CD4 cell counts to be associated with better HRQOL. ${ }^{17-19}$ This was not found in our cohort; CD4 cell count was not associated with any of the HRQOL domains or scales. Decreased viral load, on the other hand, was associated with improvements in the mental component of the HRQOL but not with the 
physical component. This finding contrasts with that reported by Call et al., ${ }^{19}$ who found viral load to be an independent predictor of the physical component score (PCS), role physical (RP), and bodily pain (BP), all of which describe physical health. Role Physical was the only physical scale we found to be associated with viral load. Though not a surprising finding, the number of symptoms was associated with increased viral load and poor scores on all the HRQOL domain and scales except physical function (PF). This supports what has already been reported by other studies, emphasizing the need to treat these symptoms immediately, in order to decrease their impact on the consequence of the disease. $^{18,22,23}$

Several studies investigating the demographic and behavior related factors that affect HRQOL have reported older age, being of Hispanic origin, having less education and using recreational drugs as common factors. ${ }^{14,15,17}$ These were all consistent with our findings, and in addition, our study identified being born in the United States, using other food assistance programs, and use of antiretroviral agents as factors associated with HRQOL. Drug and alcohol use were not associated with HRQOL in our study, which is contrary to reports from other studies. ${ }^{14-16,42}$ Drug and alcohol use were, however, associated with decreased CD4 and increased viral load.

A major limitation of our study is its cross-sectional nature and small sample size. Generalizability of our findings is also limited because study participants were recruited from only one US city and may not reflect results from varying HIV infected populations. Nevertheless, this study shed light on the relationships between HIV disease state and HRQOL outcome in SNAP and non-SNAP participants. For people living with HIV in 
Miami, SNAP participation may need to be adjusted to improve the management of the disease and the impact of the program on their quality of life.

\section{Acknowledgements}

The authors would like to acknowledge the Florida International University, Graduate

School for providing support during data collection for this study through the Data and Evidence Acquisition Fellowship. 
Table 1: Sociodemographic characteristics by SNAP participation status

\begin{tabular}{|c|c|c|c|}
\hline Variables & $\begin{array}{c}\text { Total } \\
(\mathrm{N}=165)\end{array}$ & $\begin{array}{l}\text { SNAP } \\
(n=117)\end{array}$ & $\begin{array}{c}\text { Non-SNAP } \\
(\mathrm{n}=48)\end{array}$ \\
\hline & \multicolumn{3}{|c|}{$\mathrm{n}(\%)$} \\
\hline Male & $109(66.1)$ & $77(65.8)$ & $32(66.7)$ \\
\hline \multicolumn{4}{|l|}{ Ethnicity } \\
\hline African American & $123(74.5)$ & $90(76.9)$ & $33(68.8)$ \\
\hline Hispanic American & $27(16.4)$ & $19(16.2)$ & $8(16.7)$ \\
\hline White & $7(4.2)$ & $4(3.4)$ & $3(6.2)$ \\
\hline Other & $8(4.8)$ & $4(3.4)$ & $4(8.3)$ \\
\hline US Born*** & $138(83.6)$ & $107(91.5)$ & $31(64.6)$ \\
\hline Single & $148(89.7)$ & $82(88.9)$ & $44(91.7)$ \\
\hline No children & $76(46.1)$ & $50(42.7)$ & $26(54.2)$ \\
\hline Less than High School & $77(46.7)$ & $52(44.4)$ & $25(52.1)$ \\
\hline \multicolumn{4}{|l|}{ Employment Status*** } \\
\hline Unemployed & 77 (46.7) & $49(41.9)$ & $28(58.3)$ \\
\hline Employed & $19(11.5)$ & $11(9.4)$ & $8(16.7)$ \\
\hline On disability & $69(41.8)$ & 57 (48.7) & $12(25.0)$ \\
\hline Monthly income $<1000^{*}$ & $133(80.6)$ & $99(84.6)$ & $34(70.8)$ \\
\hline \multicolumn{4}{|l|}{ Living condition } \\
\hline Alone & $63(38.2)$ & $46(39.3)$ & $17(35.4)$ \\
\hline With Family & $75(45.5)$ & $54(46.2)$ & $21(43.8)$ \\
\hline Shelter & $27(16.4)$ & $17(14.5)$ & $10(20.8)$ \\
\hline Uses other food assistance & $24(14.5)$ & $18(15.4)$ & $6(12.5)$ \\
\hline
\end{tabular}

$* P<.05, * * * P<.001$ 
Table 2: Health and behavior related characteristics by SNAP participation status

\begin{tabular}{lcccc}
\hline Variable & $\begin{array}{c}\text { Total } \\
(\mathrm{N}=165)\end{array}$ & $\begin{array}{c}\text { SNAP } \\
(\mathrm{n}=117)\end{array}$ & $\begin{array}{c}\text { Non-SNAP } \\
(\mathrm{n}=48)\end{array}$ & $P$-value \\
\hline Has Symptoms & $128(77.6)$ & $90(76.9)$ & $38(79.2)$ & .753 \\
Smokes Cigarettes & $103(62.4)$ & $77(65.8)$ & $26(54.2)$ & .161 \\
Uses Drugs** $^{*}$ & $49(29.7)$ & $43(36.8)$ & $6(12.5)$ & .002 \\
Drink Alcohol $^{+}$ & $80(48.5)$ & $62(53.0)$ & $18(37.5)$ & .071 \\
On ART*** $^{*}$ & $144(87.3)$ & $110(94.0)$ & $34(70.8)$ & $<.001$ \\
Takes Vitamins & $77(46.7)$ & $54(46.2)$ & $23(47.9)$ & .837 \\
\hline
\end{tabular}

$+P<.10, * * P<.01, * * * P<.001$

ART: Antiretroviral therapy.

All variables reported as n (\%)

Table 3: Standard and T-scores for HIV infected cohort in Miami compared to the general population $(\mathrm{N}=165)$

\begin{tabular}{|c|c|c|c|c|}
\hline \multirow[t]{2}{*}{ SF-36 Domains and Summaries } & \multicolumn{2}{|c|}{ Standard Scores } & \multicolumn{2}{|c|}{ Norm-based (T) Scores } \\
\hline & Mean & SD & Mean $^{\mathrm{a}}$ & SD \\
\hline Physical Component Summary & & & $46.58 * * *$ & 10.77 \\
\hline Physical Functioning & 71.97 & 28.12 & $45.23 * * *$ & 11.83 \\
\hline Role-Physical & 63.33 & 30.90 & $42.49 * * *$ & 12.11 \\
\hline Bodily Pain & 63.77 & 30.40 & $46.81 * *$ & 12.85 \\
\hline General Health & 65.52 & 23.83 & $47.46^{* *}$ & 11.36 \\
\hline Mental Component Summary & & & $44.64 * * *$ & 13.18 \\
\hline Vitality & 61.67 & 22.50 & $51.67+$ & 11.24 \\
\hline Social Functioning & 68.33 & 26.39 & $43.03 * * *$ & 11.52 \\
\hline Role-Emotional & 65.66 & 32.86 & $39.86 * * *$ & 15.33 \\
\hline Mental Health & 68.21 & 21.93 & $46.19 * * *$ & 12.35 \\
\hline
\end{tabular}

SD: Standard Deviation; ${ }^{a}$ Comparison with general population mean of 50

$+P<.10, * * P<.01, * * * P<.001$ 
Table 4: Mean T scores by SNAP participation status compared to the general population $(\mathrm{N}=165)$

\begin{tabular}{ccccc}
\hline SF-36 Domains and Summaries & \multicolumn{2}{c}{ SNAP Participants } & \multicolumn{2}{c}{ Non-SNAP Participants } \\
\cline { 2 - 5 } & Mean $^{\text {a }}$ & SD & Mean $^{\text {a }}$ & SD \\
\hline Physical Component Summary & $45.90^{* * *}$ & 10.76 & 48.25 & 10.71 \\
Physical Functioning & $44.51^{* * *}$ & 11.76 & 46.99 & 11.96 \\
Role-Physical & $41.57^{* * *}$ & 12.08 & $44.71^{* *}$ & 12.02 \\
Bodily Pain & $45.63^{* * *}$ & 12.70 & 49.69 & 12.89 \\
General Health & $47.67^{*}$ & 11.30 & 46.96 & 11.61 \\
\hline Mental Component Summary & $44.20^{* * *}$ & 13.55 & $45.72^{*}$ & 12.30 \\
Vitality & 51.26 & 10.71 & 52.68 & 12.50 \\
Social Functioning & $42.59^{* * *}$ & 11.46 & $44.12^{* *}$ & 11.71 \\
Role -Emotional & $38.77^{* * *}$ & 15.11 & $42.52^{* *}$ & 15.69 \\
Mental Health & $45.89^{* *}$ & 12.68 & 46.90 & 11.62 \\
\hline$* P<.05, * P<.01, * * P<.001$ & & & &
\end{tabular}

$* P<.05, * * P<.01, * * * P<.001$

SD: Standard Deviation, ${ }^{a}$ Comparison with general population mean of 50

Table 5: Immunologic and virologic parameters by SNAP participation status

\begin{tabular}{ccccc}
\hline Variable & Total $(\mathrm{N}=165)$ & $\begin{array}{c}\text { SNAP Participants } \\
(\mathrm{n}=117)\end{array}$ & $\begin{array}{c}\text { Non-SNAP Participants } \\
(\mathrm{n}=48)\end{array}$ & $P$-value \\
\hline $\begin{array}{c}\text { CD4 cell count } \\
<199\end{array}$ & $32(19.4)$ & $21(17.9)$ & $11(22.9)$ & .166 \\
$\quad 200-499$ & $52(31.5)$ & $42(35.9)$ & $10(20.8)$ & \\
$\quad>500$ & $81(49.1)$ & $54(46.2)$ & $27(56.2)$ & \\
$\quad$ Viral Load & & & & \\
$\quad<=75$ & $76(46.1)$ & $58(49.6)$ & $18(37.5)$ & \\
$76-9999$ & $49(29.7)$ & $29(24.8)$ & $20(41.7)$ & \\
$>10000$ & $40(24.2)$ & $30(25.6)$ & $10(20.8)$ & \\
\hline
\end{tabular}

All variables reported as n (\%) 
Table 6: Pearson's correlations of disease status parameters and quality of life domains with SNAP participation status $(\mathrm{N}=165)$

\begin{tabular}{lcc}
\hline Variables & Correlation Coefficient & $P$-value \\
\hline Log viral load & -0.053 & .500 \\
Sqrt CD4 cell count & -0.022 & .782 \\
PCS & -0.100 & .203 \\
MCS & -0.053 & .502 \\
Physical Function (PF) & -0.095 & .223 \\
Role Physical (RP) & -0.118 & .131 \\
Bodily Pain (BP) & -0.144 & .065 \\
General Health (GH) & 0.028 & .716 \\
Vitality (VT) & -0.057 & .465 \\
Social Functioning (SF) & -0.061 & .437 \\
Role Emotional (RE) & -0.111 & .154 \\
Mental Health (MH) & -0.037 & .636
\end{tabular}

PCS: Physical Component Summary; MCS: Mental Component Summary

Table 7a: Regression of Physical Component Summary (PCS) on SNAP participation status $(\mathrm{N}=165)$

\begin{tabular}{lcccc}
\hline Variable & $\mathrm{B}$ & $\mathrm{SE}(\mathrm{B})$ & $\beta$ & $P$-value \\
\hline SNAP participation & 0.31 & 2.16 & 0.01 & 0.888 \\
Significant control variables: & & & & \\
Number of symptoms & -1.11 & 0.44 & $-0.20^{*}$ & .013 \\
Age & -0.28 & 0.11 & $-0.21^{*}$ & .014 \\
Use other food assistance & -5.71 & 2.36 & $-0.19^{*}$ & .017 \\
US born & -6.35 & 2.98 & $-0.22^{*}$ & .035 \\
\hline
\end{tabular}

$* P<.05$

Note: Model $\mathrm{R}^{2}=.234, \mathrm{~F}(23,141)=1.87, P=.015 . \Delta \mathrm{R}^{2}($ SNAP participation $)=.000$

Other control variables were gender, ethnicity, education, child status, employment status, income, household size, smoking status, alcohol use, drug use, ART use, vitamin use, viral load and CD4 cell counts. 
Table 7b: Regression of Mental Component Summary (MCS) on SNAP participation status $(\mathrm{N}=165)$

\begin{tabular}{lcccc}
\hline Variable & $\mathrm{B}$ & $\mathrm{SE}(\mathrm{B})$ & $\beta$ & $P$-value \\
\hline SNAP participation & 1.47 & 2.38 & 0.05 & .538 \\
Significant control Variables: & & & & \\
Number of symptoms & -2.62 & 0.48 & $-0.38^{* * *}$ & $<.001$ \\
Viral load & -2.69 & 0.88 & $-0.30^{* *}$ & .003 \\
Less than high school & -5.37 & 2.03 & $-0.20^{* *}$ & .009 \\
ART use & -7.08 & 3.23 & $-0.18^{*}$ & .030 \\
US born & -6.48 & 3.29 & $-0.18^{*}$ & .050 \\
\hline
\end{tabular}

$* P<.05, * * P<.01, * * * P<.001$

Note: Model $\mathrm{R}^{2}=.380, \mathrm{~F}(23,141)=3.75, P<.001 . \Delta \mathrm{R}^{2}$ (SNAP participation $)=.002$

Other control variables were age, gender, ethnicity, child status, employment status, income, household size, smoking status, alcohol use, drug use, vitamin use, use other food assistance, and CD4 cell count.

Table 7c: Regression of Physical Functioning Score (PF) on SNAP participation status $(\mathrm{N}=165)$

\begin{tabular}{lcccc}
\hline Variable & $\mathrm{B}$ & $\mathrm{SE}(\mathrm{B})$ & $\beta$ & $P$-value \\
\hline SNAP participation & -0.13 & 2.43 & -0.01 & .957 \\
Significant control variables: & & & & \\
Age & -0.40 & 0.13 & $-0.26^{* *}$ & .003 \\
US born & -8.54 & 3.36 & $-0.27^{*}$ & .012
\end{tabular}

$* P<.05, * * P<.01$

Note: Model $\mathrm{R}^{2}=.194, \mathrm{~F}(23,141)=1.48, P=.088 . \Delta \mathrm{R}^{2}$ (SNAP participation $)=.000$

Other control variables were gender, ethnicity, child status, education, employment status, income, household size, smoking status, alcohol use, drug use, ART use, vitamin use, use of other food assistance programs, presence of symptoms, viral load and CD4 cell count. 
Table 7d: Regression of Role Physical Score (RP) on SNAP participation status (N=165)

\begin{tabular}{lcccc}
\hline Variable & $\mathrm{B}$ & $\mathrm{SE}(\mathrm{B})$ & $\beta$ & $P$-value \\
\hline SNAP participation & 0.58 & 2.37 & 0.02 & 0.807 \\
Significant control variables: & & & & \\
Number of symptoms & -1.87 & 0.48 & $-0.30^{* * *}$ & $<.001$ \\
US born & -9.52 & 3.27 & $-0.29^{* *}$ & .004 \\
Viral load & -2.22 & 0.87 & $-0.27^{*}$ & .012 \\
Use other food assistance & -6.16 & 2.59 & $-0.18^{*}$ & .019 \\
Household size & -1.99 & 0.90 & $-0.20^{*}$ & .029 \\
\hline
\end{tabular}

$* P<.05, * * P<.01, * * * P<.001$

Note: Model $\mathrm{R}^{2}=.272, \mathrm{~F}(23,141)=2.29, P<.001 . \Delta \mathrm{R}^{2}$ (SNAP participation $)=.000$

Other control variables were age, gender, ethnicity, child status, education, employment status, income, smoking status, alcohol use, drug use, ART use, vitamin use, and CD4 cell counts.

Table 7e: Regression of Bodily Pain Score (BP) on SNAP participation status (N=165)

\begin{tabular}{lcccc}
\hline Variable & $\mathrm{B}$ & $\mathrm{SE}(\mathrm{B})$ & $\beta$ & $P$-value \\
\hline SNAP participation & -1.67 & 2.53 & -0.06 & .511 \\
Significant control variables: & & & & \\
Use other food assistance & -8.58 & 2.77 & $-0.24^{* *}$ & .002 \\
Number of symptoms & -1.55 & 0.52 & $-0.23^{* *}$ & .003 \\
Hispanic & -11.26 & 4.13 & $-0.33^{* *}$ & .007 \\
\hline
\end{tabular}

$* * P<.01$

Note: Model $\mathrm{R}^{2}=.260, \mathrm{~F}(23,141)=2.15, P=.003 . \Delta \mathrm{R}^{2}($ SNAP participation $)=.002$

Other control variables were age, gender, country of birth, child status, education, employment status, income, household size, smoking status, alcohol use, drug use, ART use, vitamin use, viral load and CD4 cell count. 
Table 7f: Regression of General Health Score (GH) on SNAP participation status $(\mathrm{N}=165)$

\begin{tabular}{lcccc}
\hline Variable & $\mathrm{B}$ & $\mathrm{SE}(\mathrm{B})$ & $\beta$ & $P$-value \\
\hline SNAP participation & 3.89 & 2.14 & 0.16 & .071 \\
Significant control variables: & & & & \\
Number of symptoms & -2.11 & 0.44 & $-0.36^{* * *}$ & $<.001$ \\
No children & 4.48 & 1.87 & $0.20^{*}$ & .018 \\
Hispanic & -8.31 & 3.49 & $-0.27^{*}$ & .019 \\
Use other food assistance & -5.08 & 2.34 & $-0.16^{*}$ & .031 \\
Disability & -5.98 & 2.89 & $-0.26^{*}$ & .040 \\
& & & &
\end{tabular}

$* P<.05,{ }^{* * *} P<.001$

Note: Model $\mathrm{R}^{2}=.326, \mathrm{~F}(23,141)=2.96, P<.001 . \Delta \mathrm{R}^{2}$ (SNAP participation $)=.016$

Other control variables were age, gender, country of birth, education, income, household size, smoking status, alcohol use, drug use, ART use, vitamin use, viral load and CD4 cell count.

Table 7g: Regression of Vitality Score (VT) on SNAP participation status (N=165)

\begin{tabular}{lcccc}
\hline Variable & $\mathrm{B}$ & $\mathrm{SE}(\mathrm{B})$ & $\beta$ & $P$-value \\
\hline SNAP participation & -0.19 & 2.18 & -0.01 & .930 \\
$\begin{array}{l}\text { Significant control variables: } \\
\text { Number of symptoms }\end{array}$ & -2.14 & 0.44 & $-0.37^{* * *}$ & $<.001$ \\
\hline
\end{tabular}

$* * * P<.001$

Note: Model $\mathrm{R}^{2}=.283, \mathrm{~F}(23,141)=2.42, P=.001 . \Delta \mathrm{R}^{2}$ (SNAP participation $)=.000$

Other control variables were age, gender, ethnicity, country of birth, child status, education, employment status, income, household size, smoking status, alcohol use, drug use, ART use, vitamin use, use of other food assistance programs, viral load and CD4 cell counts. 
Table 7h: Regression of Social Functioning Score (SF) on SNAP participation status $(\mathrm{N}=165)$

\begin{tabular}{lcccc}
\hline Variable & $\mathrm{B}$ & $\mathrm{SE}(\mathrm{B})$ & $\beta$ & $P$-value \\
\hline SNAP participation & -3.32 & 2.11 & 0.13 & .117 \\
Significant control variables: & & & & \\
Number of symptoms & -2.11 & 0.43 & $-0.35^{* * *}$ & $<.001$ \\
US born & -9.54 & 2.92 & $-0.31^{* *}$ & .001 \\
ART use & -6.16 & 2.87 & $-0.18^{*}$ & .033 \\
Hispanic & -7.40 & 3.45 & $-0.24^{*}$ & .034 \\
\hline
\end{tabular}

$* P<.05, * * P<.01, * * * P<.001$

Note: Model $\mathrm{R}^{2}=.359, \mathrm{~F}(23,141)=3.44, P<.001 . \Delta \mathrm{R}^{2}($ SNAP participation $)=.011$

Other control variables were age, gender, child status, education, employment status, income, household size, smoking status, alcohol use, drug use, vitamin use, use of other food assistance programs, viral load and CD4 cell count.

Table 7i: Regression of Role Emotional Score (RE) on SNAP participation status $(\mathrm{N}=165)$

\begin{tabular}{lcccc}
\hline Variable & $\mathrm{B}$ & $\mathrm{SE}(\mathrm{B})$ & $\beta$ & $P$-value \\
\hline SNAP participation & -0.33 & 2.91 & 0.01 & .911 \\
Significant control Variables: & & & & \\
Number of symptoms & -2.33 & 0.59 & $-0.29^{* * *}$ & $<.001$ \\
US born & -11.22 & 4.02 & $-0.27^{* *}$ & .006 \\
Less than high school & -5.14 & 2.49 & $-0.17^{* *}$ & .008 \\
Use other food assistance & -8.53 & 3.18 & $-0.20^{*}$ & .016 \\
Viral load & -2.61 & 1.07 & $-0.25^{*}$ & .041 \\
\hline
\end{tabular}

${ }^{*} P<.05,{ }^{* *} P<.01,{ }^{* * *} P<.001$.

Note: Model $\mathrm{R}^{2}=.314, \mathrm{~F}(23,141)=2.80, P<.001 . \Delta \mathrm{R}^{2}$ (SNAP participation $)=.000$

Other control variables were age, gender, ethnicity, child status, employment status, income, household size, smoking status, alcohol use, drug use, ART use, vitamin use, and CD4 cell count. 
Table 7j: Regression of Mental Health Score (MH) on SNAP participation status $(\mathrm{N}=165)$

\begin{tabular}{lcccc}
\hline Variable & $\mathrm{B}$ & $\mathrm{SE}(\mathrm{B})$ & $\beta$ & $P$-value \\
\hline SNAP participation & 0.86 & 2.23 & 0.03 & .702 \\
Significant control variables: & & & & \\
Number of symptoms & -2.35 & 0.46 & $-0.37^{* * *}$ & $<.001$ \\
Viral load & -2.95 & 0.82 & $-0.35^{* * *}$ & $<.001$ \\
Less than high school & -4.22 & 1.91 & $-0.17^{*}$ & .029 \\
Smoking & -4.17 & 2.00 & $-0.16^{*}$ & .039 \\
ART use & -6.11 & 3.03 & $-0.17^{*}$ & .046 \\
\hline
\end{tabular}

$* P<.05, * * * P<.001$.

Note: Model $\mathrm{R}^{2}=.377, \mathrm{~F}(23,141)=3.71, P<.001 . \Delta \mathrm{R}^{2}($ SNAP participation $)=.001$

Other control variables were age, gender, ethnicity, country of birth, child status, employment status, income, household size, alcohol use, drug use, vitamin use, use of other food assistance and CD4 cell count.

Table 8a: Regression of CD4 cell count on SNAP participation status $(\mathrm{N}=165)$

\begin{tabular}{lcccc}
\hline Variable & $\mathrm{B}$ & $\mathrm{SE}(\mathrm{B})$ & $\beta$ & $P$-value \\
\hline SNAP participation & 0.26 & 1.28 & 0.02 & .837 \\
Significant control variables: & & & & \\
Viral load & -3.19 & 0.39 & $-0.63^{* * *}$ & $<.001$ \\
ART use & -5.16 & 1.69 & $-0.24^{* *}$ & .003 \\
Income $<1000$ & -3.35 & 1.42 & $-0.18^{*}$ & .019 \\
Alcohol use & -2.29 & 1.17 & $-0.16^{*}$ & .052
\end{tabular}

$* P<.05,{ }^{* *} P<.01, * * * P<.001$.

Note: Model $\mathrm{R}^{2}=.411, \mathrm{~F}(23,141)=4.5, P<.001 . \Delta \mathrm{R}^{2}$ (SNAP participation $)=.000$

Other control variables were age, gender, ethnicity, country of birth, education, child status, employment status, household size, smoking status, drug use, vitamin use, number of symptoms, and using other food assistance programs. 
Table 8b: Regression of SNAP Viral Load on SNAP participation status $(\mathrm{N}=165)$

\begin{tabular}{lcccc}
\hline Variable & $\mathrm{B}$ & $\mathrm{SE}(\mathrm{B})$ & $\beta$ & $P$-value \\
\hline SNAP participation & 0.05 & 0.23 & 0.02 & .836 \\
Significant control variables: & & & & \\
CD4 cell count & -0.10 & 0.01 & $-0.51^{* * *}$ & $<.001$ \\
ART use & -1.14 & 0.29 & $-0.26^{* * *}$ & $<.001$ \\
Household size & -0.26 & 0.08 & $-0.22^{* *}$ & .003 \\
Vitamin use & -0.52 & 0.19 & $-0.18^{* *}$ & .006 \\
Drug use & 0.65 & 0.24 & $0.21^{* *}$ & .008 \\
Number of symptoms & -0.09 & 0.05 & $-0.12^{*}$ & .043
\end{tabular}

$* P<.05, * * P<.01, * * * P<.001$.

Note: Model $\mathrm{R}^{2}=.525, \mathrm{~F}(23,141)=7.13, P<.001 . \Delta \mathrm{R}^{2}(\mathrm{SNAP}$ participation $)=.000$

Other control variables were age, gender, ethnicity, country of birth, education, child status, employment status, income, smoking status, alcohol use, and using other food assistance programs. 


\section{References}

1. O'Keefe EA, Wood R. The impact of human immunodeficiency virus (HIV) infection on quality of life in a multiracial South African population. Qual Life Res. 1996;5(2):275-280.

2. Berneis K, Battegay M, Bassetti S, et al. Nutritional supplements combined with dietary counselling diminish whole body protein catabolism in HIV-infected patients. Eu J CliN Invest. 2000;30(1):87-94.

3. Cantrell RA, Sinkala M, Megazinni K, et al. A Pilot Study of Food Supplementation to Improve Adherence to Antiretroviral Therapy Among FoodInsecure Adults in Lusaka, Zambia. J Acquir Immune Defic Syndr. 2008;49(2):190-195.

4. Ivers LC, Chang Y, Gregory Jerome J, Freedberg KA. Food assistance is associated with improved body mass index, food security and attendance at clinic in an HIV program in central Haiti: a prospective observational cohort study. AIDS Res Ther. 2010;7:33.

5. Keithley JK, Swanson B, Zeller JM, et al. Comparison of standard and immuneenhancing oral formulas in asymptomatic HIV-infected persons: a multicenter randomized controlled clinical trial. J Parenter Enteral Nutr. 2002;26(1):6-14.

6. USDA. Building a Healthy America: A Profile of the Supplemental Nutrition Assistance Program. In: FNS, ed 2012.

7. Global Summary of the AIDS epidemic, 2011. W.H.O http://www.who.int/hiv/data/2012_epi_core_en.png. Accessed November 8, 2012.

8. Palella FJ, Delaney KM, Moorman AC, et al. Declining Morbidity and Mortality among Patients with Advanced Human Immunodeficiency Virus Infection. $N$ Engl J Med. 1998;338(13):853-860.

9. Liu C, Weber K, Robison E, Hu Z, Jacobson L, Gange S. Assessing the effect of HAART on change in quality of life among HIV-infected women. AIDS Res Ther. 2006;3(1):6. 
10. Cunningham WE, Crystal S, Bozzette S, Hays RD. The association of healthrelated quality of life with survival among persons with HIV infection in the United States. J Gen Intern Med. 2005;20(1):21-27.

11. de Boer-van der Kolk IM, Sprangers MAG, Prins JM, Smit C, de Wolf F, Nieuwkerk PT. Health-Related Quality of Life and Survival among HIV-Infected Patients Receiving Highly Active Antiretroviral Therapy: A Study of Patients in the AIDS Therapy Evaluation in the Netherlands (ATHENA) Cohort. Clin Infect Dis. 2010;50(2):255-263.

12. Jacobson DL, Wu AW, Feinberg J, for the Outcomes Committee of the Adult ACTG. Health-related quality of life predicts survival, cytomegalovirus disease, and study retention in clinical trial participants with advanced HIV disease. J Clin Epidemiol. 2003;56(9):874-879.

13. Mathews W, May S. EuroQol (EQ-5D) measure of quality of life predicts mortality, emergency department utilization, and hospital discharge rates in HIVinfected adults under care. Health Qual Life Out. 2007;5(1):5.

14. Campsmith M, Nakashima A, Davidson A. Self-reported health-related quality of life in persons with HIV infection: results from a multi-site interview project. Health Qual Life Out. 2003;1(1):12.

15. Kauf TL, Roskell N, Shearer A, et al. A Predictive Model of Health State Utilities for HIV Patients in the Modern Era of Highly Active Antiretroviral Therapy. Value in Health. 2008;11(7):1144-1153.

16. Korthuis PT, Zephyrin LC, Fleishman JA, et al. Health-related quality of life in HIV-infected patients: the role of substance use. AIDS Patient Care \& STDs. 2008;22(11):859-867.

17. Briongos Figuero LS, Bachiller Luque P, Palacios Martín T, González Sagrado M, Eiros Bouza JM. Assessment of factors influencing health-related quality of life in HIV-infected patients. HIV Medicine. 2011;12(1):22-30.

18. Bing EG, Hays RD, Jacobson LP, et al. Health-related quality of life among people with HIV disease: Results from the Multicenter AIDS Cohort Study. Qual Life Res. 2000;9(1):55-63. 
19. Call SA, Klapow JC, Stewart KE, et al. Health-related Quality of Life and Virologic outcomes in an HIV Clinic. Qual Life Res. 2000;9(9):977-985.

20. Weinfurt KP, Willke RJ, Glick HA, Freimuth WW, Schulman KA. Relationship between CD4 Count, Viral Burden, and Quality of Life over Time in HIV-1Infected Patients. Medical Care. 2000;38(4):404-410.

21. Rao D, Hahn EA, Cella D, Hernandez L. The health related quality of life outcomes of English and Spanish speaking persons living with HIV/AIDS from the continental United States and Puerto Rico. AIDS Patient Care \& STDs. 2007;21(5):339-346.

22. Lorenz KA, Shapiro MF, Asch SM, Bozzette SA, Hays RD. Associations of Symptoms and Health-Related Quality of Life: Findings from a National Study of Persons with HIV Infection. Ann Intern Med. 2001;134(90:854-860.

23. Bastardo YM, Kimberlin CL. Relationship between quality of life, social support and disease-related factors in HIV-infected persons in Venezuela. AIDS Care. 2000;12(5):673-684.

24. Burgoyne RW, Tan DHS. Prolongation and quality of life for HIV-infected adults treated with highly active antiretroviral therapy (HAART): a balancing act. $J$ Antimicrob Chemother. 2008;61(3):469-473.

25. Burgoyne R, Renwick R. Social support and quality of life over time among adults living with HIV in the HAART era. Soc Sci Med. 2004;58(7):1353-1366.

26. Bekele T, Rourke SB, Tucker R, et al. Direct and indirect effects of perceived social support on health-related quality of life in persons living with HIV/AIDS. AIDS Care. 2012:1-10.

27. Douaihy A, Singh N. Factors affecting quality of life in patients with HIV infection. AIDS Read. 2001;11(9):450-454.

28. Aranda-Naranjo B. Quality of life in the HIV-positive patient: implications and consequences. J Assoc Nurses AIDS Care. 2004;15(5):20S-27S. 
29. Marín Caro MM, Laviano A, Pichard C. Impact of nutrition on quality of life during cancer. Curr Opin Clin Nutr Metab Care. 2007;10(4):480-487.

30. Ravasco P, Monteiro-Grillo I, Camilo ME. Does nutrition influence quality of life in cancer patients undergoing radiotherapy? Radiother Oncol. 2003;67(2):213220.

31. Nutrient Requirements for People Living with HIV/AIDS: Report of a Technical Consultation, Geneva:W.H.O. 2003.

32. FANTA. Food Assistance Programming in the Context of HIV. Food and Nutrition Technical Assistance (FANTA) Project and World Food Programme (WFP). Washington, DC: FANTA Project, Academy for Educational Development 2007.

33. W.F.P. HIV/AIDS Analysis: Integrating HIV/AIDS in Food Security and Vulnerability Analysis. Vulnerability Analysis and Mapping Branch and HIV/AIDS Service. United Nations World Food Programme. Rome, Italy 2008.

34. Ivers LC, Cullen KA, Freedberg KA, et al. HIV/AIDS, Undernutrition, and Food Insecurity. Clin Infect Dis. 2009;49(7):1096-1102.

35. Koethe JR, Chi BH, Megazzini KM, Heimburger DC, Stringer JS. Macronutrient supplementation for malnourished HIV-infected adults: a review of the evidence in resource-adequate and resource-constrained settings. Clin Infect Dis. 2009;49(5):787-798.

36. Ware JEJ, Kosinski M, Bjorner JB, Turner-Bowker DM, Gandek B, M.E. M. Health Survey: Administration guide for clinical trial investigators. 2008.

37. Saris-Baglama R, Dewey C, Chisolm G, et al. QualityMetric Health Outcpmes Scoring Software 4.0 User's Guide Lincoln: QualityMetric Incorporated. 2007.

38. Baum MK, Jayaweera DT, Duan R, et al. Quality of Life, Symptomatology and Healthcare Utilization in HIV/HCV Co-Infected Drug Users in Miami. J Addict Dis. 2008;27(2):37-48. 
39. OARAC. Panel on Antiretroviral Guidelines for Adults and Adolescents. Guidelines for the use of antretroviral agents in HIV-1 infected adults and adolescents.

http://www.aidsinfo.nih.gov/contentfiles/lvguidelines/adultandadolescentgl.pdf, eds 2012 .

40. Kaiser LL. Why do low-income women not use food stamps? Findings from the California Women's Health Survey. Public Health Nutr. 2008;11(12):1288-1295.

41. CareResource. Statistics. http://www.careresource.org/hivaids/statistics/. Accessed April 19, 2013.

42. Riley ED, Wu AW, Perry S, et al. Depression and drug use impact health status among marginally housed HIV-infected individuals. AIDS Patient Care \& STDs. 2003;17(8):401-406.

43. Nacul L, Lacerda E, Campion P, et al. The functional status and well being of people with myalgic encephalomyelitis/chronic fatigue syndrome and their carers. BMC Public Health. 2011;11(1):1-11. 


\section{CHAPTER VI: NUTRITION EDUCATION PROGRAM FOR LOW INCOME HIV INFECTED ADULTS}

\section{Abstract}

The obesity rate among persons living with HIV is on the rise, reaching a proportion similar to that observed in the general public. ${ }^{1-3}$ As a result, susceptibility to comorbidities that are usually associated with increasing weight are also on the increase. ${ }^{4}$ There are several reasons for the increased obesity rate, including poor dietary habits. ${ }^{5}$ Among the potential interventions for reducing this obesity epidemic in HIV infected patients may be a nutrition education intervention targeted at improving dietary habits through improvements in nutrition knowledge, self-efficacy and readiness to change. ${ }^{5-7}$

This pilot study evaluated the effect of a nutrition education intervention on nutrition knowledge, stage of change, nutritional status, disease state and the quality of life of HIV infected adults. Participants were randomized into intervention and control groups and completed pretest, posttest, and 3 month assessments and surveys administered before and after the intervention program. The program's outcomes were not statistically significant in any of the areas evaluated after the two-month intervention. However there was a trend towards improved nutrition knowledge and self-efficacy scores in the intervention group compared to the control group. In addition, fewer individuals in the control group progressed in the stage of change continuum compared to intervention group for all dietary habits assessed. Although the intervention was tailored and targeted for the HIV population, there may be several possible explanations for the lack of program effect, such as small sample size, and duration and intensity of the intervention. Despite these limitations, the program's results were encouraging and showed positive outcomes. 


\section{Introduction}

Nutritional status during HIV infection is related to disease outcome and health status. $^{8}$ As such, the maintenance of optimal nutritional status is essential for health and immune system support in people living with HIV, making nutrition management an integral part of HIV care. ${ }^{7}$ Nutrition intervention, through education and counseling, has been shown to be effective in improving health outcomes in HIV infected individuals. ${ }^{9}$ Though limited in number, research providing this evidence has been conducted among HIV infected individuals, most of whom were experiencing undernutrition and weight loss ${ }^{9-11}$ some of these studies combined oral nutrient supplementation with counseling. ${ }^{12-}$

${ }^{14}$ Nutrition education and counseling interventions led to increases in weight and lean body mass, greater adherence to treatment medication, and an improved dietary patterns even though immunologic parameters did not improve. ${ }^{10-13}$

While HIV disease continues to put infected individuals at nutritional risk, nutritional issues have shifted from undernutrition and weight loss to obesity and metabolic imbalances, ${ }^{1,15}$ even though inadequacy in nutrient intake persists. This is especially true in resource adequate settings where there is widespread use of antiretroviral agents. ${ }^{16}$ Regardless of the use of the agents, however, the trend towards obesity observed among HIV infected individuals mirrors that observed in the general public, making them susceptible to comorbidities. ${ }^{1,3,15}$ The consequences of obesity include a higher cardiovascular disease (CVD) risk, dyslipidemia, atherosclerosis, and risk for type 2 diabetes. ${ }^{4}$ Among persons living with HIV, earlier studies showed increased BMI to be associated with slower disease progression. ${ }^{17,18}$ Recent studies, however, found obesity to be associated with lower levels of immune cell counts. ${ }^{2,19}$ In 
addition, a recent study reported obesity to increase the adverse effects that HIV infection has on functional impairment, especially as related to balance and gait. ${ }^{20}$

Lifestyle modification, including consuming a healthy diet, is the number one approach to the management of obesity observed in people living with HIV ${ }^{5-7}$ Nutrition education focusing on healthy dietary intake and patterns, while emphasizing requirement for disease state, may be the most appropriate way of confronting the current nutritional issues related to HIV infection. There are, however, several factors, such as socioeconomic status (SES), and psychological state, that affect dietary intake with those who are economically disadvantaged, adhering less to dietary guidelines, or having poor diet quality. ${ }^{21-23}$ In addition, dietary habits are affected by knowledge and beliefs about nutrition and health, and by patient's self-efficacy in implementing dietary changes. ${ }^{22,24}$ Taking such variables into consideration when planning and implementing nutrition education interventions have been shown to improve behavior outcomes. ${ }^{22}$ Michie et al..$^{25}$ suggested that interventions that are effective among low income individuals, and promote behavior change, are those that are focused and involve few intervention techniques. Nutrition education interventions conducted among HIV infected individuals rarely take into account these factors. In light of this, a pilot nutrition education intervention was designed and implemented among HIV infected adults, with the following aims: 1) to determine the effect of a nutrition education on nutrition knowledge, stage of change, and self-efficacy in HIV infected adults and 2) to determine the effect of nutrition education on nutritional status, disease stage, and quality of life. 


\section{Methods}

\section{Study design and setting}

This study was approved by the Institutional Review Board (IRB) of Florida International University. Participants included in the study were recruited from the Borinquen Healthcare Center in Miami Florida. This center provides healthcare services to low income HIV infected individuals in Miami-Dade County. Participants were considered eligible if they were HIV positive, were 18 years old or older and were low income (defined as eligibility to participate or participating in the Supplemental Nutrition Assistance Program (SNAP) for the purpose of this study). SNAP eligibility was ascertained using the state of Florida's ACCESS Pre-screening eligibility tool. After signing informed consent, SNAP participants were randomly assigned to intervention (15 participants) or control (15 participants), while the 15 eligible non-SNAP participants were assigned to intervention randomly from the larger group of 97 eligible non-SNAP participants in the study. However, due to small sample sizes, the two intervention groups were combined for the analysis (Figure 1). A study visit was then scheduled to complete baseline data collection. Survey and assessment data collected during the baseline visit were repeated immediately following the intervention (posttest) and again at three months post intervention (follow-up). The entire duration of the study was 6 months. Study visits lasted approximately 45 minutes. Individuals in the control group did not receive any intervention during the follow-up period. They were however provided with intervention education materials at follow-up visits. 
Figure 1: Randomization Flowchart

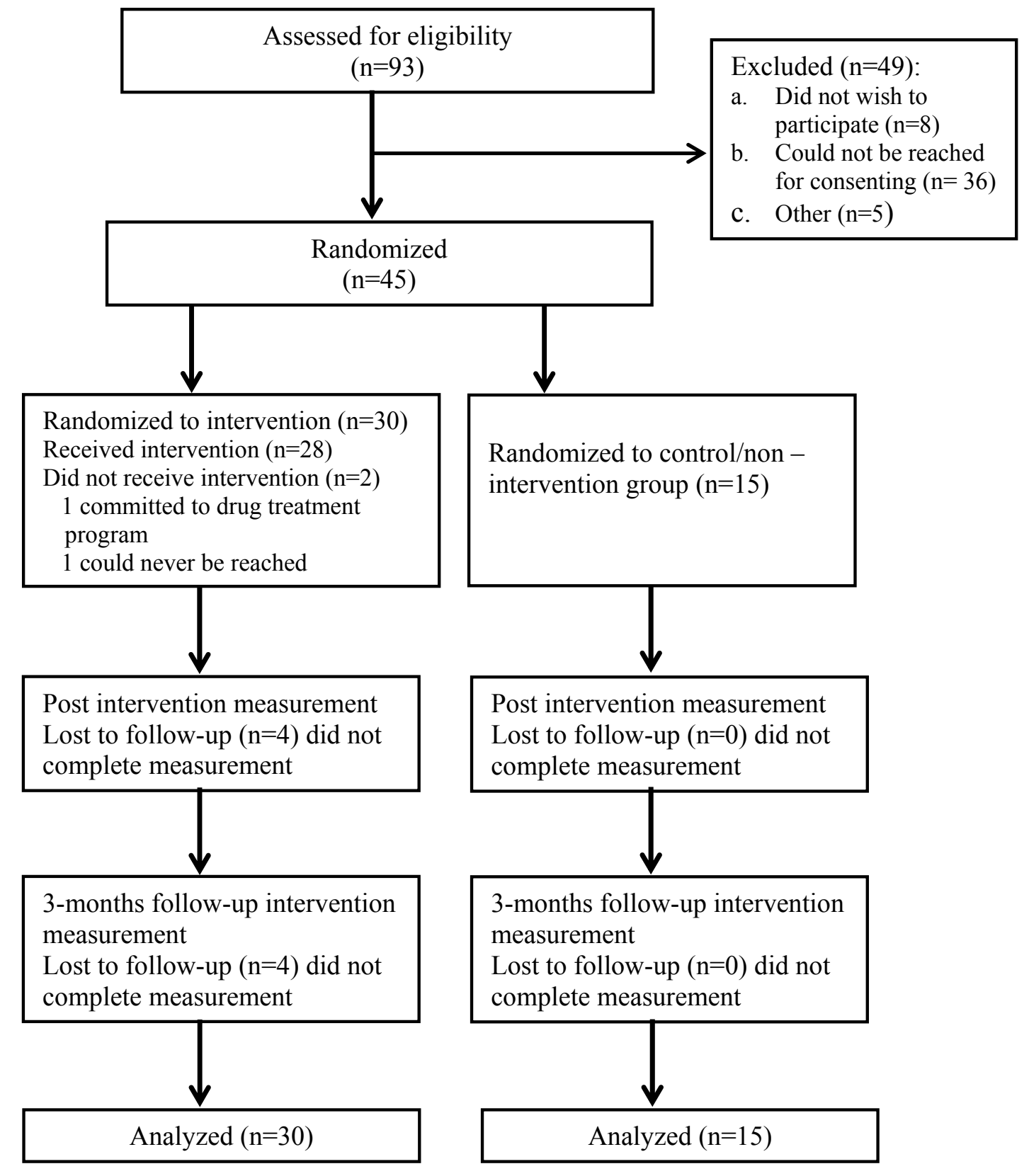




\section{Variables Measured}

Demographic Characteristics: Structured questions were used to assess participant characteristics. Variables assessed included gender, age, ethnicity, education, employment status, monthly income, marital status, drug use, alcohol use, smoking status, and use of antiretroviral treatment (ART).

Nutrition Knowledge: Participants nutrition knowledge was assessed using a 20item instrument developed by Pawlak et al. ${ }^{26}$ It assessed knowledge on the nutrient content of food, recommendation for fruit and vegetable intake and association between diet and chronic diseases. Possible range for the knowledge score was 0-20 for summed items (or 0-100 for percent of correct answers).

Stage of Change: Staging algorithms validated for measuring readiness to make changes of intakes of fruits and vegetables, dietary fiber as well as dietary fat ${ }^{27}$ were used to categorize participants into one of the five stages of the Transtheoretical framework described by Prochaska. ${ }^{28}$ First, the algorithms determined if the recommendation regarding intake for the particular food was being met. Participants who met the recommendations were classified into the action or maintenance stage depending on how long they had been meeting recommendations (i.e. less than, or greater than or equal to 6 months). Depending on their intention to change behavior, participants who were not meeting the recommendation criteria were categorized into precontemplation (no intention of changing behavior in the next 6 months), contemplation (intend to change behavior in the next 6 months) and preparation (intend to change behavior in the next 30 days). ${ }^{27}$ 
Self-Efficacy: Participants ability to confidently make changes in their dietary intake was assessed using a survey developed by Robinson et al. ${ }^{27}$ The self-efficacy scale for fruit and vegetable intake was made up of six items, while that for dietary fiber and dietary fat intakes had eight and five items, respectively. The items were measured using a five point scale with 1 being "not confident at all" and 5 being "extremely confident". Statements regarding grocery shopping self-efficacy were also included in the questionnaire. They were developed by Pawlak et al., ${ }^{26}$ and measured confidence in the ability to shop for healthy food options. The scale used was $1=$ not confident at all, $2=$ not confident, $3=$ somewhat confident and $4=$ very confident.

Nutritional Status: Macronutrient and caloric intake were measured using a 24 hour recall questionnaire. Participants were asked at each study visit about foods consumed in the last 24 hours prior to visit. Food models were used during the dietary recall interviews in order to achieve accuracy with estimates of the amount of food consumed. This data was later analyzed using the NutriBase Professional Nutrition Software Version 9 (Cybersoft Inc., 2011). Participants' hemoglobin, hematocrit and albumin levels were also evaluated as part of nutritional status. These were obtained from participants' recent (within three months of the study visit) medical records from their follow up visits with their primary care physician. In addition, each participant's height and weight were measured and these were used to calculate their body mass index (BMI). Height was measured to the nearest 0.5 inch using a stadiometer; weight was measured to the nearest $0.1 \mathrm{lbs}$ using a standard calibrated scale. 
Disease State: Clinical state of HIV disease was assessed by viral load and CD4 cell counts. These clinical data were also obtained from medical reports (within six months before study visit), and it detailed results from participants' recent blood work.

Health Related Quality of Life (HRQOL): Participants wellbeing and functionality as related to quality of life was measured using SF-36Vv2 health survey. It has 36-items categorized into eight health domains, which are further summarized into two component scores; the Physical Component Summary (PCS) score and the Mental Component Summary (MCS) score. The PCS and MCS scores were both used in the analysis.

\section{Intervention}

The conceptual model in this intervention was developed based on the StampSmart model by Campbell et al. (Figure 2). This model is rooted in the Social Cognitive Theory and the Transtheoretical model of stages of change. Our model differs from the StampSmart model in that multimedia was not used in delivering the nutrition message. In addition, the messages were not individualized. However, needs assessment was conducted to identify nutritional needs and concerns of participants. Major nutritional needs and areas of interest identified were associated with food acquisition, preparation and food safety. Over $60 \%$ of participants were interested in learning how to shop for healthy foods, $54.8 \%$ in how to shop on a limited budget, $54.2 \%$ in healthy cooking habits, $49.7 \%$ in food safety, and $48 \%$ in making healthy food choices when eating out.

Other areas covered by the needs assessment were: dealing with side effects of medication, learning how to read food labels, weight management, physical activity, fatigue, and stress management. However, very few study participants indicated these as 
areas of concern. Intervention materials were therefore developed to address the major topics of interest, making the education intervention targeted specifically to the interests of this study sample.

The education program consisted of four sessions delivered twice a month over a period of two months. Each session was delivered on the same day to two groups, each with approximately 15 participants per group. The sessions were taught from a manual that was developed based on results from the needs assessment and each session was taught by the same nutritionist. Figure 2 details the elements covered in each session. The sessions lasted about 45-60 minutes, each was comprised of both information delivery and activity sessions. All the sessions ended by providing take home reinforcers to participants, reminding them of the concepts discussed in the session. To reinforce healthy eating habits, participants were provided healthy snacks at each session. In addition, participation in discussions was encouraged by giving the most involved participant a token at the end of each session. This was usually vouchers of $\$ 10.00$ for use in the neighborhood grocery store.

One of the aims of this nutrition education intervention was to effect possible progression in the stages of change with dietary behavior. Several components of the education program were designed to target each stage, focusing on the processes involved in each stage. Examples of some of these stages include providing knowledge and information to raise consciousness about behavior, and using discussions with peer role models to promote self-evaluation. ${ }^{29}$ Reinforcement management (giving praise and recognition) and role playing were some of the strategies used to promote self-efficacy. ${ }^{30}$ 


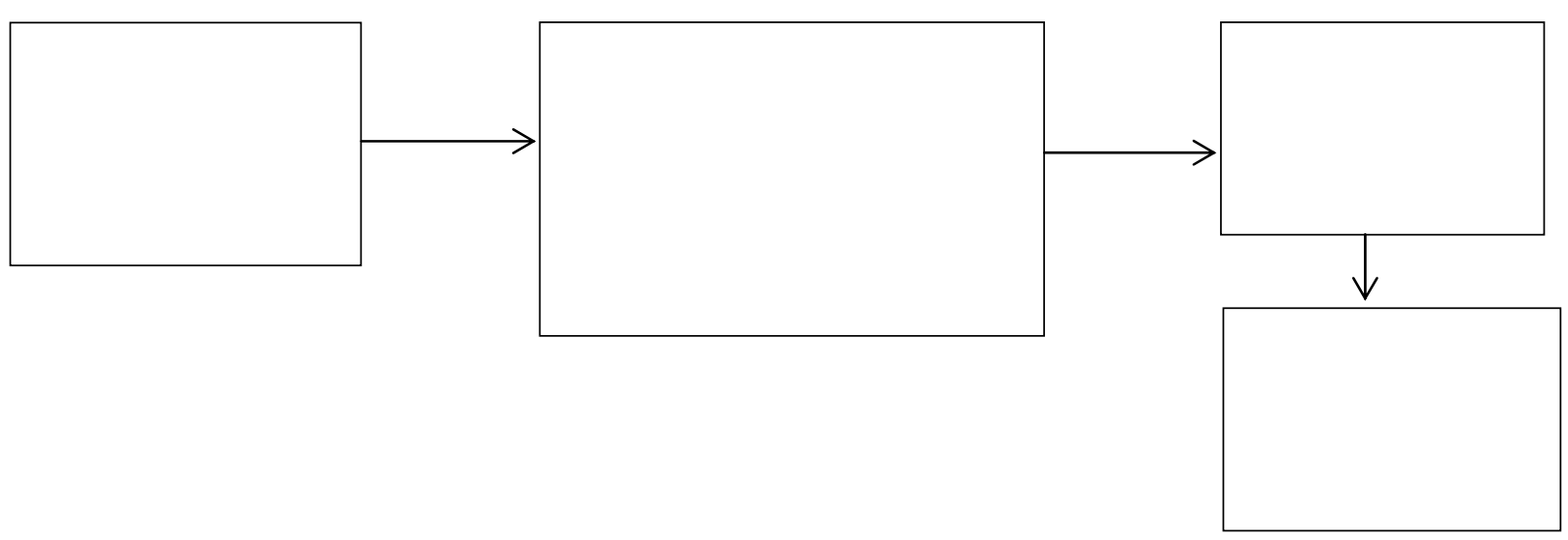

Figure 2: Adapted from "Stamp Smart Model”, Campbell M K et al. Health Educ. Res. $1999 ; 14: 257-267$

Session 1: What Happens Between HIV and Nutrition

- Information about HIV effect on the body

- Discussion about the importance of nutrition during HIV infection

- Discussion on obtaining and maintaining adequate diet

Session 2: The Green Effect: Eating on a Shoestring Budget

- Discussion on how to navigate a grocery store (product placement relative to food item being healthy or not.

- Tips for saving money and price conscious grocery shopping

- Discussion and practice on how to read food labels

- Discussion of participants current shopping practices (Acknowledgement of good practices and suggestions on what could be done differently during the next shopping trip for the "not so good practices").

Session 3: Take Charge of your Diet

- Practice knowledge on which food belongs with which food group

- Information on recommended servings from each food group and illustrations of adequate portion sizes.

- Discussion and tips on healthy cooking methods.

- Re-enforcement activity on "Making Healthful Changes to Diet"

Session 4: Keep the Bugs Out

- Discussion and activity on how to practice food safety when grocery shopping

- Discussion and activity on how to store food safely (Temperature and environment)

- Discussion and activity on food safety during meal preparation

Figure 3: Elements discussed during education sessions. 


\section{Statistical Analysis}

PASW Statistics 21 (SPSS, Inc., 2011, Chicago, IL) was used in analyzing group comparisons at various stages of the study. All participants were included in the analyses and had at least one study and/or intervention visit. To minimize the effects of loss of subjects to follow-up, the Last Outcome Measure Carried Forward (LOCF) technique was employed. Data from baseline was imputed for missed follow-up visits for 4 participants in the intervention group. A descriptive analysis for the baseline demographic data was carried out using Student's t-test for continuous variables and chisquare test for categorical variables. For non-normally distributed variables, the MannWhitney $\mathrm{U}$ test was used. The results were reported as mean $\pm \mathrm{SD}$ or as percentages. The Mann-Whitney $U$ test was also used to test the difference in changes along the stages of change continuum between the two groups. The program's impact on outcome variables (knowledge, self-efficacy, nutritional status, disease stage and quality of life) over time was analyzed using repeated measures analysis of variance, with group (intervention and control) and time (baseline, posttest and follow-up) as independent variables. $P$-value of less than .05 was termed as statistically significant for all analyses.

\section{Results}

\section{Participant characteristics}

This pilot study had a sample of 45 participants with an average age of 47.4 years. The majority of the individuals were male (60\%), African-American (77.8\%), and single (73.3\%). Sixty-seven percent of the participants had at least high school education. Only $8.9 \%$ were employed; most were either on disability (46.9\%) or unemployed $(44.4 \%)$. The two groups were comparable in baseline characteristics as shown in Table 1. Table 2 
depicts the comparability of the groups with regards to behavior and health related characteristics. About eight percent of the population used recreational drugs, while $44 \%$ drank alcohol and $64 \%$ smoked cigarettes.

\section{Nutrition Knowledge}

There was no difference in nutrition knowledge scores between the intervention and control groups at baseline (Table 3). Although the intervention group showed a consistent increase in their mean knowledge score at posttest and follow-up visits compared to the control group, there was not a significant interaction by groups and time on the nutrition knowledge score, $F(2,86)=0.68 ; P=.49$.

\section{Self-Efficacy}

Self-efficacy scores, as related to healthy eating and shopping were similar between the groups at baseline, with both groups reporting moderate scores for all four efficacy items. There was an immediate (posttest) increase in self-efficacy scores among participants in both groups for all categories except dietary fat intake. The intervention group's confidence in the ability to increase fruit and vegetable intake continued to increase, even at the 3-month follow-up visit (Table 4). However, no significant interaction of groups by time were found on any of the self-efficacy scores fruit and vegetable intake $F(2,86)=1.167 ; P=.31$, dietary fiber intake $F(2,86)=0.47 ; P=.60$,

dietary fat intake $F(2,86)=1.13 ; P=.32$, or healthy shopping $F(2,86)=0.20, P=.82$.

\section{Stages of Change}

Increasing fruits and vegetables intake to the recommended amounts was the most difficult dietary behavior to achieve and maintain in this population. As shown in Table 5, at baseline and during the follow-up periods, none of the participants identified being 
at action or maintenance phase for consumption of more fruits and vegetables. There were similar percentages of individuals at the precontemplation stage in the two groups at baseline for fruit and vegetable intake, but at the 3-month follow-up visit, this percentage decreased to $30 \%$ in the intervention group while the control group actually increased to $53.3 \%$. Similarly, $10 \%$ of the intervention group and $13 \%$ of the control group reported being at the contemplation stage at baseline with fruit and vegetable intake, but at the follow-up visit, this percentage increased to $20 \%$ in the intervention group while that for the control group decreased to $0 \%$.

With regards to dietary fiber staging, more than half (53\%) of the control group did not progress in their readiness to increase their fiber intake, compared to only $27 \%$ in the intervention group. Similarly, only $23 \%$ of the intervention group did not improve in their readiness to lowering dietary fat intake compared to $47 \%$ in the control group.

\section{Dietary Intake and Nutritional Status}

As shown in Table 6, caloric and micronutrient intakes were higher in the control group compared to intervention group at baseline, although the difference was not statistically significant. Further analysis shows that the intervention did not significantly impact nutrient intake although the intervention group increased their calorie intake compared to the control group. Table 7 shows the mean values for nutritional status indicators. Overall, there were no significant interactions on mean scores by group and time for BMI: $F(2,86)=1.22, P=.28$; hemoglobin: $F(2,86)=1.10, P=.90$; hematocrit: $F(2,86)=0.13, P=.88$ and albumin $F(2,86)=0.39, P=.63$ 


\section{Disease State and Quality of Life}

There were no significant differences between groups at baseline for viral load, CD4 cell count, PCS, or MCS. Similar to other results, the nutrition intervention did not make any significant impact compared to the control group; on viral load: $F(2,84)=2.25$, $P=0.16$; CD4 cell count: $F(2,86)=0.49, P=.60 ;$ PCS: $F(2,86)=1.09, P=.34$ and MCS: $F(2,86)=2.30, P=.11$.

\section{Discussion}

Dietary intake has been associated with obesity and metabolic changes observed in HIV infected individuals. ${ }^{5}$ Previous studies showed that HIV infected individuals who had significantly higher intakes of dietary fiber and complex carbohydrates and low intakes of dietary fat were less likely to have fat deposits. ${ }^{31-33}$ Among the general population, promotion of lifestyle modification which includes healthy eating habits has been significant in managing obesity. ${ }^{34,35}$ In the present pilot study, the intervention program did not have significant impact on any of the targeted behavior areas. As a result, there were no significant changes in nutritional status, disease state and quality of life.

Participants in the control group reported positive gains in many of the targeted behavior areas, similar to that of the intervention group at the posttest and follow-up visits, although they were not exposed to the intervention. It is possible that multiple exposures to survey materials and assessments (where researchers sometimes explained assessment measures) led to the realization of research outcome and, in an attempt to impress researchers, reported favorable information. In addition, although the aim of the intervention was to improve dietary and nutrient intake intakes, only caloric intake 
increased consistently in the intervention group with a subsequent increase in BMI over the study period. This could be explained by possible overeating by the participants under the guise of eating "healthy".

Our findings are similar to that of Almeda et al. ${ }^{36}$ who provided a 12-month nutrition counseling intervention to improve diet and prevent morphological and metabolic changes related to HIV treatment. Though their intervention produced slight dietary and morphological changes in the intervention group, the differences were not statistically significant. Similar to the present study, Almeda et al. ${ }^{36}$ did not provide nutritional supplementation in addition to the counseling, however, they provided individualized counseling as opposed to the group education method utilized in our current study. The literature is scanty on the successful use of nutrition education and counseling to achieve dietary behavior change and subsequent positive nutrition and health outcomes, especially weight loss and/or weight management as opposed to weight gain in the HIV population. ${ }^{9}$ There are, however, a few studies that showed the successful use of nutrition education intervention to improve cardiovascular disease risk factors. ${ }^{37,38}$ In a recent study, Lazzaretti et al. ${ }^{38}$ reported a decrease in fat intake and an increase in carbohydrate and fiber intake in a randomized control trial with HIV infected individuals. The intervention also resulted in improvement in lipid profile. It is important to note that the nutrition education provided in that study was focused on changes in dyslipidemia and not on modification in dietary habits, as was the focus of our pilot study. In addition, their intervention also provided individual diet programs as part of their nutrition intervention. 
Previous studies evaluating the effectiveness of nutrition education to improve health and nutritional status in HIV infected individuals used various education strategies that included group and one-on-one counseling sessions to achieve the intervention goal. One major difference between our study and prior studies is that intervention was tailored towards the sample population based on a needs assessment. Although that was necessary to promote participation interest, the minimal intervention impact indicates a mixed education strategy that included group and one-on-one sessions may have been beneficial for our target population to achieve intervention goals. The use of one-on-one counseling would have been consistent with the concept of the Transtheoretical model. This model targets intervention at each stage to move individuals forward in the stages of change. We utilized observational learning (using demonstrations and role-play strategies) in our intervention which is consistent with the Social Cognitive theory. We believe that achieving self-efficacy to implement dietary behavior changes and subsequent improvement in dietary habits would have been achieved with a mixed education strategy.

The lack of intervention effect observed in our pilot study can also be explained by other factors. First, the participation rate in intervention sessions was low; only $56.7 \%$ of the intervention group attended two or more of the four education sessions. Another possible explanation may be that the intervention lacked the intensity needed to affect behavior and health outcome changes. An increase in the number of sessions provided may have produced changes in dietary behavior. Other study limitations may have been small sample sizes and relatively short study duration. The duration of our study was supported by the literature; although, a longer duration may have produced better 
intervention results. Several outcomes from the pilot study were encouraging, because it helped participants improve their readiness for behavior change. Further studies are needed to ascertain the use of a nutrition education intervention to effect changes in the nutritional status, disease state and quality of life of HIV infected individuals.

\section{Acknowledgements}

The authors acknowledge the Graduate School at Florida International University, for the Data and Evidence Acquisition Fellowship support during data collection for this study. 
Table 1: Baseline sociodemographic characteristics by group

\begin{tabular}{|c|c|c|}
\hline Variables & $\begin{array}{c}\text { Intervention } \\
(\mathrm{n}=30)\end{array}$ & $\begin{array}{l}\text { Control } \\
(n=15)\end{array}$ \\
\hline Mean Age (SD) & $\begin{array}{c}48.33(7.06) \\
n(\%)\end{array}$ & $\begin{array}{c}46.40(9.13) \\
\text { n }(\%)\end{array}$ \\
\hline \multicolumn{3}{|l|}{ Gender } \\
\hline Male & $19(63.3)$ & $8(53.3)$ \\
\hline Female & $11(36.7)$ & $7(46.7)$ \\
\hline \multicolumn{3}{|l|}{ Ethnicity } \\
\hline African American & $22(73.3)$ & $13(68.8)$ \\
\hline Other $^{\mathrm{a}}$ & $8(26.7)$ & $2(16.7)$ \\
\hline \multicolumn{3}{|l|}{ Marital Status } \\
\hline Married & $8(26.7)$ & $1(6.7)$ \\
\hline Single & $22(73.3)$ & $14(93.3)$ \\
\hline \multicolumn{3}{|l|}{ Education } \\
\hline$<$ High School & $10(33.3)$ & $5(33.3)$ \\
\hline$\geq$ High School & $20(66.6)$ & $10(66.7)$ \\
\hline \multicolumn{3}{|l|}{ Employment Status } \\
\hline Unemployed & $12(40.0)$ & $8(53.3)$ \\
\hline Employed & $3(10.0)$ & $1(6.7)$ \\
\hline On disability & $15(50.0)$ & $6(40.0)$ \\
\hline \multicolumn{3}{|l|}{ Monthly income } \\
\hline$<\$ 1000$ & $26(86.7)$ & $12(80.0)$ \\
\hline$\geq \$ 1000$ & $4(13.3)$ & $3(20.0)$ \\
\hline
\end{tabular}

${ }^{\mathrm{a}}$ Other includes White, Hispanics and other ethnicities 
Table 2: Health and behavior related characteristics by group

\begin{tabular}{lcc}
\hline Variable & $\begin{array}{c}\text { Intervention } \\
(\mathrm{n}=30) \\
\mathrm{n}(\%)\end{array}$ & $\begin{array}{c}\text { Control } \\
(\mathrm{n}=15) \\
\mathrm{n}(\%)\end{array}$ \\
\hline Smokes Cigarettes & $19(63.3)$ & $10(66.7)$ \\
Uses Drugs & $4(13.3)$ & $4(26.7)$ \\
Drink Alcohol & $12(40.0)$ & $8(53.3)$ \\
On ART & $28(93.3)$ & $15(100.0)$ \\
Takes Vitamins & $15(50.0)$ & $9(60.0)$
\end{tabular}

ART: Antiretroviral therapy

Table 3: Nutrition knowledge scores across the three assessment periods by group ${ }^{\dagger}$

\begin{tabular}{lcc}
\hline & Intervention & Control \\
\hline & \multicolumn{3}{c}{ Nutrition knowledge Score } \\
\hline Study Period & Mean \pm SD & Mean \pm SD \\
\hline Baseline & $67.33 \pm 13.69$ & $63.67 \pm 18.75$ \\
Posttest & $68.83 \pm 15.57$ & $70.00 \pm 17.74$ \\
Follow-up & $68.50 \pm 14.21$ & $67.67 \pm 20.67$ \\
\hline
\end{tabular}

'Scores are based on the percentage of correct answers 
Table 4: Diet and shopping self-efficacy scores across the three assessment periods by $\operatorname{group}^{\dagger}$

\begin{tabular}{lcc}
\hline & Intervention & Control \\
\hline \multicolumn{1}{c}{ Self-Efficacy Score } \\
\hline Study Period & Mean \pm SD & Mean \pm SD \\
\hline Fruit and Vegetable Intake & $2.81 \pm 1.22$ & $2.65 \pm 0.77$ \\
$\quad$ Baseline & $2.90 \pm 0.88$ & $3.23 \pm 0.92$ \\
$\quad$ Posttest & $3.09 \pm 0.93$ & $2.91 \pm 0.88$ \\
$\quad$ Follow-up & $2.71 \pm 1.12$ & $2.53 \pm 1.01$ \\
\hline Dietary Fiber Intake & $2.94 \pm 1.00$ & $2.95 \pm 1.15$ \\
$\quad$ Baseline & $2.79 \pm 0.83$ & $2.46 \pm 1.07$ \\
$\quad$ Posttest & & \\
$\quad$ Follow-up & $2.62 \pm 1.28$ & $2.44 \pm 0.80$ \\
\hline Dietary Fat Intake & $2.49 \pm 0.90$ & $2.84 \pm 1.08$ \\
$\quad$ Baseline & $2.60 \pm 1.10$ & $2.43 \pm 0.80$ \\
$\quad$ Posttest & & \\
Follow-up & $3.05 \pm 0.91$ & $2.91 \pm 0.96$ \\
\hline Shopping & $3.10 \pm 0.81$ & $3.06 \pm 0.90$ \\
$\quad$ Baseline & $2.97 \pm 0.78$ & $2.78 \pm 0.99$ \\
$\quad$ Posttest & Follow-up &
\end{tabular}

${ }^{\dagger}$ Scores ranged from a1-5 scale for dietary self-efficacy and a 1- 4 scale for shopping selfefficacy ( 4 or $5=$ very/extremely confident) 
Table 5: Dietary stages of change across the three assessment periods by group

\begin{tabular}{|c|c|c|c|c|c|}
\hline & \multicolumn{5}{|c|}{ Stages of Change } \\
\hline & $\begin{array}{c}\text { Precontemplation } \\
\mathrm{n}(\%)\end{array}$ & $\begin{array}{c}\text { Contemplation } \\
\mathrm{n}(\%)\end{array}$ & $\begin{array}{l}\text { Preparation } \\
\mathrm{n}(\%)\end{array}$ & $\begin{array}{l}\text { Action } \\
\mathrm{n}(\%)\end{array}$ & $\begin{array}{c}\text { Maintenance } \\
\mathrm{n}(\%)\end{array}$ \\
\hline \multicolumn{6}{|l|}{$\begin{array}{l}\text { Fruit and Vegetable } \\
\text { Intervention }(\mathrm{n}=30)\end{array}$} \\
\hline Baseline & $13(43.3)$ & $14(46.7)$ & $3(10.0)$ & --- & --- \\
\hline Posttest & $10(33.3)$ & $16(53.3)$ & $4(13.3)$ & --- & --- \\
\hline Follow-up & $9(30.0)$ & $15(50.0)$ & $6(20.0)$ & --- & --- \\
\hline \multicolumn{6}{|l|}{$\operatorname{Control}(n=15)$} \\
\hline Baseline & $6(40.0)$ & $7(46.7)$ & $2(13.3)$ & --- & --- \\
\hline Posttest & $5(33.3)$ & $6(40.0)$ & $4(26.7)$ & --- & --- \\
\hline Follow-up & $8(53.3)$ & $7(46.7)$ & $0(0.00)$ & --- & --- \\
\hline \multicolumn{6}{|l|}{ Dietary Fiber } \\
\hline Baseline & $7(23.3)$ & $8(26.7)$ & $0(0.00)$ & $5(16.7)$ & $10(33.3)$ \\
\hline Posttest & $3(10.0)$ & $3(10.0)$ & $4(13.3)$ & $6(20.0)$ & $14(46.7)$ \\
\hline Follow-up & $5(16.7)$ & $3(10.0)$ & $3(10.0)$ & $9(30.0)$ & $10(33.3)$ \\
\hline \multicolumn{6}{|l|}{ Control $(n=15)$} \\
\hline Baseline & $2(13.3)$ & $4(26.7)$ & $1(6.7)$ & $4(26.7)$ & $4(26.7)$ \\
\hline Posttest & $5(33.3)$ & $2(13.3)$ & $1(6.7)$ & $2(13.3)$ & $5(33.3)$ \\
\hline Follow-up & $5(33.3)$ & $4(26.7)$ & $0(0.0)$ & $5(33.3)$ & $1 \quad(6.7)$ \\
\hline \multicolumn{6}{|l|}{ Dietary Fat } \\
\hline Baseline & $4(13.3)$ & $7(23.3)$ & $0(0.00)$ & $10(33.3)$ & $9(30.0)$ \\
\hline Posttest & $3(10.0)$ & $4(13.3)$ & $5(16.7)$ & $12(40.0)$ & $6(20.0)$ \\
\hline Follow-up & $4(13.3)$ & $2(6.7)$ & $0(0.00)$ & $16(53.3)$ & $8(26.7)$ \\
\hline \multicolumn{6}{|l|}{ Control (n=15) } \\
\hline Baseline & $2(13.3)$ & $0(0.00)$ & $2(13.3)$ & $6(40.0)$ & $5(33.3)$ \\
\hline Posttest & $3(20.0)$ & $1 \quad(6.7)$ & $1(6.7)$ & $5(33.3)$ & $5(33.3)$ \\
\hline Follow-up & $4(26.7)$ & $5(33.3)$ & $3(0.0)$ & $3(20.0)$ & $3(20.0)$ \\
\hline
\end{tabular}


Table 6: Dietary intake across the three assessment periods by group

\begin{tabular}{|c|c|c|}
\hline & Intervention & Control \\
\hline Study Period & Mean $\pm \mathrm{SD}$ & Mean $\pm \mathrm{SD}$ \\
\hline \multicolumn{3}{|c|}{ Total Calories (kcal) } \\
\hline Baseline & $1855.93 \pm 981.26$ & $1953.76 \pm 748.02$ \\
\hline Posttest & $2035.88 \pm 979.65$ & $1942.38 \pm 1004.62$ \\
\hline Follow-up & $2048.80 \pm 926.40$ & $1886.77 \pm 633.80$ \\
\hline \multicolumn{3}{|c|}{ Carbohydrates Intake (g) } \\
\hline Baseline & $228.64 \pm 123.65$ & $257.13 \pm 105.54$ \\
\hline Posttest & $255.52 \pm 121.58$ & $269.07 \pm 166.10$ \\
\hline Follow-up & $254.54 \pm 120.35$ & $245.44 \pm 111.41$ \\
\hline \multicolumn{3}{|c|}{ Protein Intake $(\mathrm{g})$} \\
\hline Baseline & $80.99 \pm 48.65$ & $89.14 \pm 47.80$ \\
\hline Posttest & $82.14 \pm 41.34$ & $75.40 \pm 40.14$ \\
\hline Follow-up & $83.25 \pm 45.01$ & $86.66 \pm 28.75$ \\
\hline \multicolumn{3}{|l|}{ Fat Intake (g) } \\
\hline Baseline & $62.98 \pm 43.29$ & $61.71 \pm 32.37$ \\
\hline Posttest & $73.50 \pm 43.83$ & $62.39 \pm 31.28$ \\
\hline Follow-up & $74.37 \pm 39.73$ & $63.13 \pm 30.45$ \\
\hline
\end{tabular}

Table 7: Nutritional status indicators across the three assessment periods by group

\begin{tabular}{lcc}
\hline & Intervention & Control \\
\hline Study Period & Mean \pm SD & Mean \pm SD \\
\hline BMI (lbs/in ${ }^{2}$ & & \\
$\quad$ Baseline & $28.84 \pm 6.61$ & $27.91 \pm 4.88$ \\
Posttest & $29.05 \pm 6.6$ & $28.32 \pm 4.68$ \\
Follow-up & $28.26 \pm 4.94$ & $28.60 \pm 4.61$ \\
\hline Hemoglobin (g/dl) & & \\
Baseline & $13.76 \pm 1.39$ & $13.47 \pm 1.49$ \\
Posttest & $13.63 \pm 1.61$ & $13.45 \pm 1.17$ \\
Follow-up & $13.76 \pm 1.51$ & $13.53 \pm 1.21$ \\
\hline Hematocrit $(\%)$ & & \\
Baseline & $41.13 \pm 4.03$ & $40.76 \pm 4.67$ \\
Posttest & $40.93 \pm 4.84$ & $40.58 \pm 3.80$ \\
Follow-up & $41.23 \pm 4.06$ & $40.53 \pm 3.79$ \\
\hline Albumin (g/dl) & & \\
$\quad$ Baseline & $4.24 \pm 0.32$ & $4.20 \pm 0.54$ \\
Posttest & $4.28 \pm 0.26$ & $4.16 \pm 0.45$ \\
Follow-up & $4.27 \pm 0.27$ & $4.14 \pm 0.32$ \\
\hline
\end{tabular}


Table 8: Disease state and quality of life indicators across the three assessment periods by

\begin{tabular}{lcc}
\hline group & Intervention & Control \\
\hline Study Period & Mean \pm SD & Mean \pm SD \\
\hline Log Viral load & & \\
Baseline & $2.18 \pm 1.27$ & $3.14 \pm 1.75$ \\
Posttest & $2.06 \pm 1.10$ & $3.04 \pm 1.63$ \\
Follow-up & $2.25 \pm 1.17$ & $2.58 \pm 1.55$ \\
\hline Square root CD4 & & \\
$\quad$ Baseline & $22.88 \pm 6.76$ & $18.67 \pm 7.62$ \\
Posttest & $22.97 \pm 6.55$ & $17.84 \pm 7.92$ \\
Follow-up & $23.16 \pm 5.55$ & $19.22 \pm 8.43$ \\
\hline PCS & & \\
Baseline & $47.23 \pm 8.50$ & $43.77 \pm 8.27$ \\
Posttest & $44.90 \pm 12.09$ & $45.12 \pm 10.37$ \\
Follow-up & $46.15 \pm 9.39$ & $43.95 \pm 10.12$ \\
\hline MCS & & \\
Baseline & $47.14 \pm 11.83$ & $43.07 \pm 9.87$ \\
Posttest & $44.50 \pm 11.71$ & $45.97 \pm 11.81$ \\
Follow-up & $42.45 \pm 13.81$ & $44.54 \pm 14.01$ \\
\hline
\end{tabular}

PCS: Physical Component Summary MCS: Mental Component Summary

PCS and MCS scores are norm-based T-scores ranging from 0-50 


\section{References}

1. Crum-Cianflone N, Tejidor R, Medina S, Barahona I, Ganesan A. Obesity among patients with HIV: the latest epidemic. AIDS Patient Care STDS. 2008;22(12):925-930.

2. Crum-Cianflone NF, Roediger M, Eberly LE, et al. Obesity among HIV-infected persons: impact of weight on CD4 cell count. AIDS. 2010;24(7):1069-1072.

3. Shah K, Alio AP, Hall WJ, Luque AE. The Physiological Effects of Obesity in HIV-Infected Patient. J AIDS Clin Res. 2012;3(151).

4. Klein S, Allison DB, Heymsfield SB, et al. Waist circumference and cardiometabolic risk: a consensus statement from Shaping America's Health: Association for Weight Management and Obesity Prevention; NAASO, The Obesity Society; the American Society for Nutrition; and the American Diabetes Association. Am J Clin Nutr. 2007;85(5):1197-1202.

5. Hadigan C. Dietary habits and their association with metabolic abnormalities in human immunodeficiency virus-related lipodystrophy. Clin Infect Dis. 2003;37(2):S101-104.

6. Keithley JK, Fields-Gardner C. Antiretroviral-related nutritional problems: closing the science and practice gap. $J$ Assoc Nurses AIDS Care. 2001;12:85-87.

7. Nerad J, Romeyn M, Silverman E, et al. General nutrition management in patients infected with human immunodeficiency virus. Clin Infect Dis. 2003;36(2):S52-62.

8. ADA. Position of the American Dietetic Association and Dietitians of Canada: Nutrition Intervention in the Care of Persons with Human Immunodeficiency Virus Infection. J Am Diet Assoc. 2004;104(9):1425-1441.

9. Kaye HL, Moreno-Leguizamon CJ. Nutrition education and counselling as strategic interventions to improvehealth outcomes in adult outpatients with HIV: a literature review. Afr J AIDS Res. 2010;9(3):271-283.

10. McDermott AY, Shevitz A, Must A, Harris S, Roubenoff R, Gorbach S. Nutrition Treatment for HIV Wasting: A Prescription for Food as Medicine. Nutr Clin Pract. 2003;18(1):86-94. 
11. Van Niekerk C, Smego RA, Sanne I. Effect of nutritional education and dietary counselling on body weight in HIV-seropositive South Africans not receiving antiretroviral therapy. J Hum Nutr Diet. 2000;13(6):407-412.

12. Berneis $K$, Battegay $M$, Bassetti $S$, et al. Nutritional supplements combined with dietary counselling diminish whole body protein catabolism in HIV-infected patients. Eur J Clin Invest. 2000;30(1):87-94.

13. Schwenk A, Steuck H, Kremer G. Oral supplements as adjunctive treatment to nutritional counseling in malnourished HIV-infected patients: randomized controlled trial. Clin Nutr. 1999;18(6):371-374.

14. Segal-Isaacson CJ, Tobin JN, Weiss SM, et al. Improving dietary habits in disadvantaged women with HIV/AIDS: the SMART/EST women's project. AIDS Behav. 2006;10(6):659-670.

15. Crum-Cianflone N, Roediger MP, Eberly L, et al. Increasing Rates of Obesity among HIV-Infected Persons during the HIV Epidemic. PLoS ONE. 2010;5(4):e10106.

16. Dorey-Stein Z, Amorosa VK, Kostman JR, Lo Re V, 3rd, Shannon RP. Severe weight gain, lipodystrophy, dyslipidemia, and obstructive sleep apnea in a human immunodeficiency virus-infected patient following highly active antiretroviral therapy. J Cardiometab Syndr. 2008;3(2):111-114.

17. Jones CY, Hogan JW, Snyder B, et al. Overweight and human immunodeficiency virus (HIV) progression in women: associations HIV disease progression and changes in body mass index in women in the HIV epidemiology research study cohort. Clin Infect Dis. 2003;37(2):S69-80.

18. Shor-Posner G, Campa A, Zhang G, et al. When obesity is desirable: a longitudinal study of the Miami HIV-1-infected drug abusers (MIDAS) cohort. $J$ Acquir Immune Defic Syndr. 2000;23(1):81-88.

19. Crum-Cianflone NF, Roediger M, Eberly LE, et al. Impact of weight on immune cell counts among HIV-infected persons. Clin Vaccine Immunol. 2011;18(6):940946. 
20. Bauer LO, Wu Z, Wolfson LI. An obese body mass increases the adverse effects of HIV/AIDS on balance and gait. Phys Ther. 2011;91(7):1063-1071.

21. Ball K, Crawford D, Mishra G. Socio-economic inequalities in women's fruit and vegetable intakes: a multilevel study of individual, social and environmental mediators. Public Health Nutr. 2006;9(5):623-630.

22. Beydoun MA, Wang Y. Do nutrition knowledge and beliefs modify the association of socio-economic factors and diet quality among US adults? Prev Med. 2008;46(2):145-153.

23. Forshee R, Storey M. Demographics, not beverage consumption, is associated with diet quality. Int J Food Sci Nutr. 2006;57(7-8):494-511.

24. Gittelsohn J, Anliker JA, Sharma S, Vastine AE, Caballero B, Ethelbah B. Psychosocial Determinants of Food Purchasing and Preparation in American Indian Households. J Nutr Educ Behav. 2006;38(3):163-168.

25. Michie S, Jochelson K, Markham WA, Bridle C. Low-income groups and behaviour change interventions: a review of intervention content, effectiveness and theoretical frameworks. J Epidemiol Community Health. 2009;63(8):610-622.

26. Pawlak R, Colby S. Benefits, barriers, self-efficacy and knowledge regarding healthy foods; perception of African Americans living in eastern North Carolina. Nutr Res Pract. 2009;3(1):56-63.

27. Robinson AH, Norman GJ, Sallis JF, Calfas KJ, Rock CL, Patrick K. Validating stage of change measures for physical activity and dietary behaviors for overweight women. Int J Obes. 2008;32(7):1137-1144.

28. Prochaska JO, DiClemente CC. Stages and processes of self-change of smoking: toward an integrative model of change. J Consult Clin Psychol. 1983;51(3):390395.

29. Norcross JC, Krebs PM, Prochaska JO. Stages of change. J Clin Psychol. 2011;67(2):143-154. 
30. Bandura A. Social Foundations of Thought and Action: A social cognitive theory. Englewood Cliffs, N.J: Prentice Hall; 1986.

31. Hendricks KM, Dong KR, Tang AM, et al. High-fiber diet in HIV-positive men is associated with lower risk of developing fat deposition. Am J Clin Nutr. $2003 ; 78(4): 790-795$.

32. Shah M, Tierney $\mathrm{K}$, Adams-Huet B, et al. The role of diet, exercise and smoking in dyslipidaemia in HIV-infected patients with lipodystrophy. HIV Med. 2005;6(4):291-298.

33. Jaime PC, Florindo AA, Latorre Mdo R, Segurado AA. Central obesity and dietary intake in HIV/AIDS patients. Rev Saude Publica. 2006;40(4):634-640.

34. Elizondo-Montemayor L, Gutierrez NG, Moreno DM, Martinez U, Tamargo D, Trevino M. School-based individualised lifestyle intervention decreases obesity and the metabolic syndrome in Mexican children. J Hum Nutr Diet. 2013;19(10):12070.

35. Siwik V, Kutob R, Ritenbaugh C, et al. Intervention in overweight children improves body mass index (BMI) and physical activity. $J$ Am Board Fam Med. 2013;26(2):126-137.

36. Almeida LB, Segurado AC, Duran AC, Jaime PC. Impact of a nutritional counseling program on prevention of HAART-related metabolic and morphologic abnormalities. AIDS Care. 2011;23(6):755-763.

37. Fitch KV, Anderson EJ, Hubbard JL, et al. Effects of a lifestyle modification program in HIV-infected patients with the metabolic syndrome. AIDS. 2006;20(14):1843-1850.

38. Lazzaretti RK, Kuhmmer R, Sprinz E, Polanczyk CA, Ribeiro JP. Dietary intervention prevents dyslipidemia associated with highly active antiretroviral therapy in human immunodeficiency virus type 1-infected individuals: a randomized trial. J Am Coll Cardiol. 2012;59(11):979-988. 


\section{CHAPTER VII: SUMMARY AND CONCLUSIONS}

The present study characterized a convenience sample of HIV infected low income participants in Miami, who participate in the Supplemental Nutrition Assistance Program (SNAP) and compared them to HIV positive low income adults who are eligible for this program but do not participate. Additionally, our study examined the barriers to SNAP participation, and investigated the association of SNAP participation in this cohort with food insecurity, nutritional status, disease stage, and quality of life. The study also examined the effectiveness of a pilot nutrition education intervention in improving nutritional status, disease state and quality of life through improvements in nutrition knowledge, stage-of-change and self-efficacy in people living with HIV.

SNAP is the largest food assistance program in the United States aimed at alleviating problems of food insecurity in low income families. ${ }^{1}$ Many studies have reported its effectiveness and success in achieving this aim in the general population, in addition to providing other nutrition and health benefits. ${ }^{2-6}$ The results from these previous studies prompted the current study, since food insecurity and inadequacy in nutritional status are common issues for persons living with HIV. SNAP is the program of choice for most low income HIV infected adults, for whom nutritional status and adequate food intake are critical to treatment. As a result, there is the need to investigate SNAP's impact on their nutrition and health.

We found that the SNAP participation rate among this study population is high at $70.3 \%$, similar to State of Florida and national participation rates of $69 \%$ and $72 \%$ respectively. ${ }^{7,8}$ In our study, SNAP participants were mostly lower income earners and US citizens, characteristics which are consistent with results from other populations 
participating in the program. ${ }^{9,10} \mathrm{HIV}$ infected adults participating in SNAP had a higher tendency to use antiretroviral therapy (ART), when compared to those who were not receiving SNAP. This is an important finding with implications for HIV disease management since infected individuals are more likely to adhere to treatment when receiving some form of food assistance. ${ }^{11}$ We did not find employment status, ethnicity, or household status to be associated with SNAP participation; however, ${ }^{12-15}$ having higher education was associated with participation. This could be explained by the greater capacity of such individuals to understand eligibility requirements and complete paperwork for application with ease. We found the following to be barriers to SNAP participation: (1) denial of participation by the program, (2) recent incarceration, (3) not allowed if staying in a shelter, (4) lack of awareness of eligibility status, (5) difficulty with application, and (6) worry about consequences for future citizenship application. These barriers were consistent with those reported in the literature., ${ }^{9,10,15-17}$ It wasn't surprising to find recent incarceration as a barrier to participation. The State of Florida prevents individuals with drug related convictions from receiving SNAP. Our study didn't gather data on reasons for incarceration. It is important to consider allowing such individuals access to these nutritional services as they contribute to establishing stability upon release from jail and prevents relapse to substance abuse. ${ }^{18}$ In addition, participation in nutritional programs has been associated with increased ART adherence. ${ }^{11,19}$

When we assessed the association between SNAP participation, food security and nutritional status, we found no significant difference in these variables between SNAP participants and non-participants. However, we found $56 \%$ of the population to experience food insecurity. This rate is similar to those reported among other HIV 
populations. ${ }^{20-23}$ It was, however, higher than the State of Florida and the national food insecurity rate for the general population in 2011 which were $15.4 \%$ and $14.9 \%$ respectively. ${ }^{24}$

Additionally, we found that drug use was associated with lower levels of food security and was also strongly associated with poor nutrient intakes. More than $50 \%$ of our cohort had inadequate intakes in approximately half of the nutrients assessed. For all participants, vitamin D intake was below the estimated average requirements. Vitamin D deficiency is related to HIV disease progression ${ }^{25}$ and is common among HIV infected persons, especially those from Black and Hispanic descent. ${ }^{26}$ The majority of the individuals living with HIV in South Florida are Blacks or Hispanics, ${ }^{27}$ who have higher rates of vitamin D deficiency ${ }^{26}$ More than $50 \%$ of the HIV infected participants on ART received a combinations with tenofovir, an antiretroviral associated with low circulating levels of vitamin $\mathrm{D}$, and that further exposes them to vitamin D deficiency. ${ }^{28}$ In addition further research is needed to investigate serum levels of vitamin D in this South Florida population and how this may be affecting HIV disease progression and management. Analysis of the relationship between SNAP participation and the parameters determining disease status and health related quality of life (HRQOL) showed no significant associations. Our findings are consistent with reports from previous studies. ${ }^{19,29}$ It has been shown, however, that provision of food assistance improves food security, dietary/nutrient intake, and adherence to medication among persons living with HIV. ${ }^{11,29}$ On the other hand, changes in these variables are known to influence disease status and HRQOL. It is possible that other factors, such as psychosocial events, mediate the relationship of improved food/nutritional status, with disease status, and quality of 
life. Further studies are necessary to investigate any possible interactions between nutrition and psychosocial factors as pertaining to clinical and non-clinical outcomes of HIV disease.

We also conducted a pilot intervention study investigating the effect of nutrition education on nutritional status, disease status, and health related quality of life through improvements in nutrition knowledge, self-efficacy to eating healthy and stage of change. The intervention provided did not make a significant impact on the variables measured, although there was a trend towards improvement in readiness to change. The literature is sparse on the successful use of nutrition education to improve dietary behavior and disease status of persons living with HIV as it relates to obesity. ${ }^{30,31}$ Previous studies focused on using nutrition/counseling to achieve weight gain, as a means of improving disease status. ${ }^{32-34}$ A recent study by Lazzaretti et al. ${ }^{35}$ reported improvements in dietary intake (fat, carbohydrates, and fiber) among HIV infected individuals in a clinical trial where nutrition education was employed. This reported intervention, however, was aimed at improving dyslipidemia and not at modifying dietary habits, which was the focus of our pilot study. Additionally, their intervention provided individual diet programs as part of their nutrition intervention. The following are possible explanations to the lack of effect observed in our pilot study (1) low participation rate (56.7\%) in the education sessions, (2) lack in program intensity needed to effect behavior and health outcome changes, (3) small sample size and (4) relatively short study duration. Despite these limitations, the results from the pilot study were encouraging, as the readiness for change in dietary behavior was increased. 


\section{References}

1. Building a Healthy America: A Profile of the Supplemental Nutrition Assistance Program. USDA. In: FNS, ed 2012.

2. Allen JE, Gadson KE. Nutrient Consumption Patterns of Low-Income Households: USDA, Economic Research Service. 1983.

3. Beebout H, Cavin E, Devaney B, . Evaluation of the Nutrition Assistance Program in Puerto Rico: Volume II, Effects on Food Expenditures and Diet Quality. Washington, DC: Mathematica Policy Research, Inc. 1985.

4. Devaney B, Moffitt R. Dietary Effects of the Food Stamp Program. Am J Agric Econ. 1991;73(1):202-211.

5. Fox M, Hamilton W, Lin B-H. Effects of food assistance and Nutrition Programs on nutrition and health;Volume 4 Executive Summaryof the Literature Review: Food Assisstance and Nutrition Research. 2004. FANRR19-4.

6. Fraker TM, Martini AP, Ohls JC. The Evaluation of the Alabama Food Stamp Cash-out Demonstration: Volume 1, Recipient Impacts.: USDA, Food and Nutrition Service.1992.

7. Leftin J, Eslami E, Strayer M. Trends in Supplemental Nutrition Assistance Program Participation Rates: 2002 - 2009. Prepared by Mathematica Policy Research, for the Food and Nutrition Service. 2011.

8. Cunnyham K. Reaching Those In Need: State Supplemental Nutrition Assistance Program Participation Rates in 2009. Mathematica Policy Reasearch. USDA. 2011.

9. Algert SJ, Reibel M, Renvall MJ. Barriers to Participation in the Food Stamp Program Among Food Pantry Clients in Los Angeles. Am J Public Health. 2006;96(5):807-809.

10. Kaiser LL. Why do low-income women not use food stamps? Findings from the California Women's Health Survey. Public Health Nutr. 2008;11(12):1288-1295. 
11. Tirivayi N, Koethe JR, Groot W. Clinic-Based Food Assistance is Associated with Increased Medication Adherence among HIV-Infected Adults on Long-Term Antiretroviral Therapy in Zambia. J AIDS Clin Res. 2012;3(7):24.

12. Biggerstaff MA, Morris PM, Nichols-Casebolt A. Living on the edge: examination of people attending food pantries and soup kitchens. Soc Work. 2002;47(3):267-277.

13. Duffy P, Bhattarai G, Irimia-Vladu M. Regional Differences in Use of Food Stamps and Food Pantries by Low Income Households in the United States. Annual meeting, July 24-27, Providence, RI 2005.

14. Gundersen C, Oliveira V. The Food Stamp Program and Food Insufficiency. Am J Agric Econ. 2001;83(4):875-887.

15. Martin KS, Cook JT, Rogers BL, Joseph HM. Public versus Private Food Assistance: Barriers to Participation Differ by Age and Ethnicity. J Nutr Educ Behav. 2003;35(5):249-254.

16. Bartlett S, Burstein N. Food Stamp Program Access Study:Eligible Nonparticipants. Report Submitted to USDA Economic Research Service. Cambridge, MA:Abt Associates Inc. 2004.

17. Access and Access Barriers to Getting Food Stamps: A Review of the Literature. Washington DC: Food Research and Action Center. 2008.

18. Nunn A, Cornwall A, Fu J, Bazerman L, Loewenthal H, Beckwith C. Linking HIV-positive jail inmates to treatment, care, and social services after release: results from a qualitative assessment of the COMPASS Program. J Urban Health. 2010;87(6):954-968.

19. Cantrell RA, Sinkala M, Megazinni K, et al. A Pilot Study of Food Supplementation to Improve Adherence to Antiretroviral Therapy Among FoodInsecure Adults in Lusaka, Zambia. J Acquir Immune Defic Syndr. 2008;49(2):190-195.

20. Weiser S, Fernandes K, Brandson E, et al. The impact of food insecurity and body mass index on mortality among HIV-infected individuals first initiating HAART XVII International AIDS Conference 2008. 
21. Weiser S, Frongillo E, Ragland K, Hogg R, Riley E, Bangsberg D. Food Insecurity is Associated with Incomplete HIV RNA Suppression Among Homeless and Marginally Housed HIV-infected Individuals in San Francisco. $J$ Gen Intern Med. 2009;24(1):14-20.

22. Weiser SD, Hatcher A, Frongillo EA, et al. Food insecurity is associated with greater acute care utilization among HIV-infected homeless and marginally housed individuals in San Francisco. J Gen Intern Med. 2013;28(1):91-98.

23. Weiser SD, Tsai AC, Gupta R, et al. Food insecurity is associated with morbidity and patterns of healthcare utilization among HIV-infected individuals in a resource-poor setting. AIDS. 2012;26(1):67-75.

24. Coleman-Jensen A, Nord M, Andrews M, Carlson S. Household Food Security in the United States in 2011. In: USDA, ed: Economic Research Services; 2011.

25. Villamor E. A Potential Role for Vitamin D on HIV Infection? Nutr Rev. 2006;64(5):226-233.

26. Mehta S, Giovannucci E, Mugusi FM, et al. Vitamin D Status of HIV-Infected Women and Its Association with HIV Disease Progression, Anemia, and Mortality. PLoS ONE. 2010;5(1):e8770.

27. Care Resource. Statistics. http://www.careresource.org/hivaids/statistics/. Accessed April 19, 2013.

28. Childs KE, Fishman SL, Constable C, et al. Short communication: Inadequate vitamin $\mathrm{D}$ exacerbates parathyroid hormone elevations in tenofovir users. AIDS Res Hum Retroviruses. 2010;26(8):855-859.

29. Ivers LC, Chang Y, Gregory Jerome J, Freedberg KA. Food assistance is associated with improved body mass index, food security and attendance at clinic in an HIV program in central Haiti: a prospective observational cohort study. AIDS Res Ther. 2010;7:33.

30. Kaye HL, Moreno-Leguizamon CJ. Nutrition education and counselling as strategic interventions to improvehealth outcomes in adult outpatients with HIV: a literature review. Afr J AIDS Res. 2010;9(3):271-283. 
31. Segal-Isaacson CJ, Tobin JN, Weiss SM, et al. Improving dietary habits in disadvantaged women with HIV/AIDS: the SMART/EST women's project. AIDS Behav. 2006;10(6):659-670.

32. Berneis K, Battegay M, Bassetti S, et al. Nutritional supplements combined with dietary counselling diminish whole body protein catabolism in HIV-infected patients. Eu J Clin Invest. 2000;30(1):87-94.

33. McDermott AY, Shevitz A, Must A, Harris S, Roubenoff R, Gorbach S. Nutrition Treatment for HIV Wasting: A Prescription for Food as Medicine. Nutr Clin Pract. 2003;18(1):86-94.

34. Van Niekerk C, Smego RA, Sanne I. Effect of nutritional education and dietary counselling on body weight in HIV-seropositive South Africans not receiving antiretroviral therapy. J Hum Nutr Diet. 2000;13(6):407-412.

35. Lazzaretti RK, Kuhmmer R, Sprinz E, Polanczyk CA, Ribeiro JP. Dietary intervention prevents dyslipidemia associated with highly active antiretroviral therapy in human immunodeficiency virus type 1-infected individuals: a randomized trial. J Am Coll Cardiol. 2012;59(11):979-988. 


\section{CHAPTER VIII: STRENGTHS AND LIMITATIONS}

This work will provide valuable information to the Supplemental Nutrition Assistance Program (SNAP) and other food and nutrition program administrators by helping them to identify and target individuals at high nutritional risk and creating outreach activities that overcome the most frequent barriers to participation. This is the first study to characterize HIV infected participants receiving SNAP benefits and to identify barriers to SNAP participation in this population.

The results from our study may be used to improve nutritional services and maximize SNAP participation and its potential benefits to people living with HIV. In addition, our study is also the first to evaluate the program's effect on the nutrition and health of HIV infected people. Though in many cases we were not able to disprove our null hypothesis, our findings are a prelude to further studies investigating the benefits derived from participating in SNAP by low income individuals with chronic diseases. Our findings may be the result of the lack of specificity of these programs for people with nutrition-related diseases, and the fact, that SNAP does not have an integrated nutrition education component similar to the one found in the Special Supplemental Nutrition Program for Women, Infants and Children (WIC).

There are several limitations to this study which may have contributed to some of the non-significant findings we observed. First, the cross-sectional design used in the observational study eliminated any causal link that might have existed between SNAP participation, food security, and nutrition and health outcomes. Another limitation is the small sample size used in the pilot intervention study. The sample was also a convenience sample, decreasing the external validity of the study findings. Also, because study 
participants were recruited from only one US city, results may not reflect differences that might be observed from varying HIV infected populations, affecting the generalizability of findings. Although the intervention study had a rigorous design to decrease study limitations, its sample size was small and the duration of the intervention was short, compared to other effective nutrition interventions in the literature. 


\section{CHAPTER IX: FUTURE RESEARCH}

Findings from our study, confirm that food insecurity and other nutrition related issues still plague persons living with HIV, especially when they live within limited resources. More resources and efforts are needed to address food insecurity in this group with special needs, because food insecurity has implications for the treatment, management, and costs of the HIV disease. The Supplemental Nutrition Assistance Program (SNAP) has been beneficial in alleviating some of these problems in the general population. A better understanding is needed on why SNAP is not making a difference in the HIV infected population, and how other factors such as substance abuse, incarceration, stigma and comorbidities affect participation and program effect. Lack of participation in the program might be associated with lack of access to other services. Many of the barriers and conditions affecting the participation of HIV infected individuals in SNAP are local, and need to be addressed at the local level. A possible lesson to be learned from this research is that HIV infected persons, and in general persons living with chronic nutrition-related diseases need food and nutrition programs that are tailored to their specific needs and that nutrition education can foster readiness to eating healthy. Our pilot study was useful in developing educational tools that addressed the stated needs of this group. The preliminary results from our pilot educational intervention will be used to estimate sample size, duration and sustainability of a larger study, and to develop an application for external funding to ascertain the use of a nutrition education intervention to effect changes in the nutritional status, disease state and quality of life of HIV infected individuals. 
APPENDICES 
Appendix A: Nutrition Education Intervention Manual 
NUTRITION EDUCATION MANUAL FOR LOW INCOME HIV INFECTED

ADULTS

Strategies and Lesson Plans

Irene Hatsu

2011

Florida International University

Department of Dietetics and Nutrition 


\section{Overview of Manual}

The Nutrition for HIV Healthy Living is a four session nutrition education intervention developed to enhance changes in dietary intake and behavior among lowincome HIV infected individuals. It is developed based on results from needs assessment conducted in the target group and is intended to be conducted over a two month period, with sessions being conducted bi-monthly.

The intervention is designed using the social cognitive theory and the transtheoretical model of the stages of change concept. It is conducted by a trained nutritionist; with each session lasting between 45 minutes to an hour. The sessions are client-centered, interactive and utilize methods that enhance adult learning. Topics covered include the importance of nutrition during HIV infection, healthy eating and food safety. The intervention encourages a pre-post measurement of variables that determine the effectiveness of intervention. These variables and the tools for assessment are detailed in this manual.

This manual is organized into four sections. The first section is "introduction", which details the goals of the intervention, the theoretical framework used, and a description of the target population. Section two is made of four lesson plans, each for the four sessions. Lesson 1 focuses on the bi-directional relationship between HIV and nutrition; lesson 2, teaches how to purchase healthy foods even on a low income budget, lesson 3 focuses on cooking and eating healthy while lesson 4 discusses food safety. Each lesson plan contains:

- Preparation Tips

- Materials Needed (to implement session) 
- Measures to take "Before Beginning Session"

- Objectives for session

- Teaching guide (The teaching guide provides information on what is discussed during the session).

- Interactive "Activity"

Section three discusses variables that will be used to determine the effectiveness of this intervention. The final section of this manual includes several handouts and activities, most of which are adapted from existing resources. These handouts and activity packets can be found in the appendix section of the manual. 


\section{Introduction}

\section{Nutrition Problems in HIV infection}

HIV infection is associated with the destruction of the immune system. As a result the nutritional status of HIV infected individuals is critical. The disease and malnutrition create a vicious cycle that aggravates disease progression and affects chances of survival. ${ }^{1}$ Poor nutritional status may accelerate disease progression and lead to poor outcome. On the other hand, HIV infection can also impair the intake, digestion, absorption and utilization of nutrients. This can lead to weight loss, nutrient deficiencies compromised immune function and competence as well as susceptibility to infection. ${ }^{1}$ Factors that could contribute to poor nutrition include inadequate nutrient intake and absorption, poor appetite, metabolic problems, chronic infection, and limited food availability among others. ${ }^{2}$ HIV disease is linked to conditions (such as sore mouths and throats) that affect food intake. Side effects of treatment may also lead to nausea, diarrhea, vomiting, and loss of appetite, all of which can affect dietary intake.

As with many infections, HIV infection affects the body's ability to absorb nutrients due to damages to the gastrointestinal tract. ${ }^{2}$ Malabsorption could also occur from diarrhea that is caused by infections from pathogens. ${ }^{2} \mathrm{HIV}$ infected individuals are more susceptible to these infections because of compromised immunity. The chronic infection also increases the nutritional requirements of HIV infected individuals above those of the uninfected population. ${ }^{3-5}$ Antiretroviral therapy (ART) medications can also affect energy expenditure, contributing to higher caloric needs. ${ }^{4}$ HIV infected individuals who are asymptomatic require $10 \%$ more energy intake than is recommended for noninfected healthy individuals, for the same age and gender. This requirement increases to 
20\%-30\% during the symptomatic phase. For the above-mentioned reasons among others, optimal nutrition is critical for managing the HIV disease. ${ }^{6}$

\section{Why Nutrition Education Intervention}

Lack of optimal nutrition has been linked to the development and severity of most chronic diseases; 5 out of the 10 leading causes of death have been linked to poor diet. $^{7}$ Despite the abundance of information on nutrition in the media and other sources as well as the availability of healthy foods, most Americans are considered to have suboptimal nutrition. ${ }^{7}$ Even with the development of the Dietary Guidelines for Americans, several American do not know what and how much of food to consume from each food group. This could be due to the public's confusion as to which information is correct and also how to filter and apply acquired nutrition information. For example, even though the Healthy People 2010 objective was for $75 \%$ of American's over age 2 to consume more than 2 fruits and vegetables per day, the Nation Action Guide 2009 Report indicates only $32.8 \%$ and $32.2 \%$ of adults and adolescents respectively consume more than 2 servings of fruits and vegetables per day. ${ }^{8}$

The aim of nutrition and health professionals has therefore been to facilitate dietary behaviors favorable to nutritional and overall health through education intervention. Nutrition Education is defined as " a combination of educational strategies, accompanied by environmental supports, designed to facilitate voluntary adoption of food choices and other food- and nutrition related behaviors conducive to health and well-being" ${ }^{9}$ Among individuals infected with HIV, nutrition education is especially needed to foster healthy eating habits and optimal nutrition. 
Cason et al., ${ }^{10}$ indicated that food stamp participants and non-participants who received nutrition education significantly improved their dietary and nutrient intake, as well as food related behaviors. According to evidence from literature, nutrition education positively influences dietary practices such as food buying, meal planning and preparation, as well as food safety practices and nutrient intakes of low income individuals. $^{11-13}$

\section{Goals and Objectives}

The goal of this intervention is to optimize nutrition and health status and the overall well-being of low income HIV infected individuals through changes in dietary habits. The objectives are to significantly:

1. Increase participant's nutrition knowledge.

2. Improve participant's self-efficacy with dietary behavior.

3. Move participant forward in the stage of change continuum as related dietary behavior.

4. Increase participants' nutrient intakes.

\section{Target Population}

Participants in this intervention are low-income HIV adults, who either participate or do not participate in the food stamp program and live in Miami-Dade County. Most of the participants either attend Jackson Memorial Hospital and Borinquen Health Care Clinic. These health centers serve majority of the HIV infected population in Miami. The ages of the participants from Jackson Memorial Hospital ranges between 35-72 years, with a mean of 46.3 years. Sixty-six percent of these patients are males, with $69 \%$ being African-American and 24\% Hispanics. Borinquen clinic participants have similar age 
characteristics as those from Jackson Hospital; however, the racial distribution is about 45\% African-American and 45\% Hispanic. These characteristics are similar to that of the general HIV infected population living in Miami. ${ }^{14}$ According to reports from research that has been conducted in this population, participants have a mean monthly income of $\$ 326$ and have an average education level of $11^{\text {th }}$ grade. ${ }^{15}$ Other characteristics of this population are that $29 \%$ are asymptomatic and $38 \%$ symptomatic to HIV, $62 \%$ are receiving antiretroviral therapy treatment while $38 \%$ are not, with the mean number of years since diagnosis being 10 years. ${ }^{15}$

\section{Intervention setting}

The intervention is conducted at the Borinquen Health Care Clinic (BHCC), which was established in Miami Dade County to provide comprehensive range of health and social services to its' culturally diverse community. ${ }^{16}$ Among the primary care services provided by BHCC are internal medicine, pediatrics, HIV care, behavioral health, psychiatry, case management, etc. They also provide specialty care such as podiatry and optometry. The clinic mainly serves the county's low income population and has several locations. This intervention is conducted at the main clinic location in midtown Miami (which is located in the target population's community) and serves the highest number of their patients. ${ }^{16}$

\section{Theoretical Framework}

The conceptual model used in this intervention is adapted from the StampSmart model, (see figure 1) used by Campbell et al, 1999. ${ }^{17}$ This model employs both the Stages -of- Change concept of the Transtheoretical model and the Social Cognitive Theory in its development. ${ }^{17}$ Although the same theoretical framework is being used, two features 
have been changed, namely the content of the education material and the method of data dissemination. The Stage of Change theory is widely used in health promotion and has been applied to intervention in several areas including nutrition. ${ }^{18}$ This theory applies the logic that individuals go through different stages of change before developing a new behavior. The stages included in this theory are precontemplation, contemplation, preparation, action, and maintenance. ${ }^{19}$ Components of the educational program are developed to target each stage focusing on processes involved in each stage. Some of these processes include consciousness raising through information and knowledge provision, self re-evaluation by discussion with peer role models, self-liberation (belief in the ability to change by drawing attention to individuals who have already made commitment to eat healthy), reinforcement management (giving praise and recognition) and counter conditioning ( using activities to learn how to substitute healthy behaviors for unhealthy ones). ${ }^{20}$

The Social Cognitive Theory integrates an individual with the social environment in which he or she is learning. ${ }^{21}$ It purports that learning is determined by an interrelationship between environmental influences, personal factors, and behavioral attributes. ${ }^{21}$ The focus of this theory is self-efficacy, which is an individual's selfconfidence in performing a particular behavior at a certain competence level. ${ }^{21}$ To be able to perform a behavior, an individual must believe in their ability to do so and this makes self-efficacy an important characteristic to consider in behavior change. This intervention seeks to increase self-efficacy through skills development and training to raise individual confidence. The intervention also points out and emphasizes outcomes 
(long term benefits to eating healthy) as well as provides incentives that will motivate behavior change.

As a modification to the original model, this model utilizes the operant conditioning method to disseminating information. Operant conditioning is defined as "a type of learning in which behaviors are altered primarily by regulating the consequence

that follows then" ${ }^{22}$. Some tenets of this learning method are goal setting, reinforcement, and provision of feedback. Other learning methods applied in the model are lecture/discussion, practice and role plays. These, however, are drawn from the social cognitive theory discussed earlier. This conceptual model requires conducting a needs assessment prior to implementing nutrition education. It is based on the belief that nutrition education tailored to the needs of the population will increase self-efficacy and help individuals progress in stages of change, leading to change in eating behavior. 
Figure1: Conceptual Model

Needs Assessment

Focused Nutrition Education

Outcome Measures

\begin{tabular}{|l|l|l|}
\hline $\begin{array}{l}\text { Identify nutrition } \\
\text { concerns, interests, and } \\
\text { dietary habits }\end{array}$ & $\begin{array}{l}\text { Risk information regarding poor nutrition } \\
\text { and HIV disease } \\
\text { Information to promote healthy eating } \\
\text { Modeling healthy behavior changes } \\
\text { Character involved activities on selecting } \\
\text { and preparing healthy foods }\end{array}$ \\
\cline { 3 - 3 }
\end{tabular}

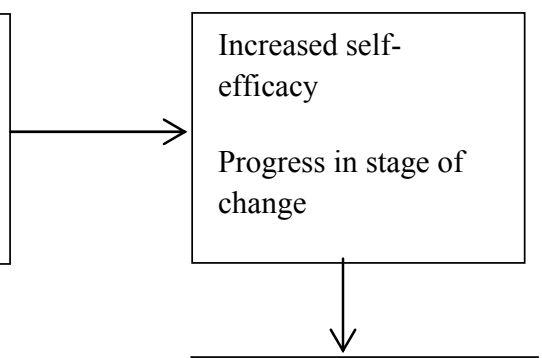

Changes in eating behavior Increased dietary and nutrient intake

Adapted from "Stamp Smart Model”, Campbell M K et al. Health Educ. Res. 1999; 14:257-26

\section{Key Strategies for Nutrition Education Intervention}

\begin{tabular}{|c|c|c|c|c|c|}
\hline $\begin{array}{l}\text { Key Strategies } \\
\text { And Activities }\end{array}$ & $\begin{array}{l}\text { Target } \\
\text { Group }\end{array}$ & $\begin{array}{l}\text { Group } \\
\text { Size }\end{array}$ & Lead Staff & Frequency & Evaluation \\
\hline $\begin{array}{l}\text { Assessment } \\
\text { Information } \\
\text { dissemination } \\
\text { /Education } \\
\text { - Lecture } \\
\text { - Group } \\
\text { Discussion } \\
\text { - Handouts/P } \\
\text { osters } \\
\text { - Recipes } \\
\text { Skill training } \\
\text { - Experiential } \\
\text { activities }\end{array}$ & $\begin{array}{l}\text { Low income } \\
\text { HIV } \\
\text { infected } \\
\text { individuals }\end{array}$ & $\begin{array}{l}15 \text { per } \\
\text { group }\end{array}$ & $\begin{array}{l}\text { A trained } \\
\text { nutritionist }\end{array}$ & $\begin{array}{l}\text { Twice a } \\
\text { month } \\
\text { delivery of } \\
\text { nutrition } \\
\text { information } \\
\text { for } 2 \text { months }\end{array}$ & $\begin{array}{l}\text { Progression in } \\
\text { Stage of } \\
\text { Change } \\
\text { Increase in } \\
\text { self-efficacy } \\
\text { Improvement } \\
\text { in dietary } \\
\text { practices } \\
\text { Nutritional } \\
\text { Status } \\
\text { Disease Status } \\
\text { Health Status } \\
\text { Quality of Life }\end{array}$ \\
\hline
\end{tabular}




\section{Delivery Methods}

This nutrition intervention is delivered by a trained nutritionist. As individuals learn and process information differently, the education material is delivered in a manner that meets the learning needs and styles of participants. The materials are delivered in person, in a safe learning environment, through mini-lectures, discussions and activities. Messages are tailored towards the attitude and needs of this population. For example, to create and maintain motivation, messages are structured to produce a sense of personal responsibility with nutritional and overall health among participants. Open ended questions are used to allow for discussions. Participant interaction and involvement is encouraged by giving the group the opportunity to ask questions, give them positive feedback and also praise them for accomplishments. Reinforcers in the form of points or tokens are awarded for achievement. Individuals with the highest points get a gift at the end of each session.

Although one-on-one counseling is not used in the delivery of this intervention, participants are encouraged to set personal goals, which they can choose to share with the group in terms of barriers and achievements. To make everyone comfortable, the following ground rules are established:

- Arrive on time and staying in the group meeting

- Respect each other, even when there is disagreement

- Insults or use of derogatory words is not allowed

- Can choose not to participate in an activity if not comfortable

- Listen to others without interrupting them. 


\section{Needs Assessment as Basis for Intervention Content}

As per conceptual model, the development of this nutrition intervention is based on results from a nutrition needs assessment conducted in the target population. The assessment determined nutrition concerns using tailored questions and information on dietary habits. Other demographic variables such as age, gender, education level, income, and work status of the group were also assessed. Examples of questions asked to determine nutrition concerns are:

- I would like information on how to shop healthy

- I would like education on how to shop on a limited budget

- I would like information on how to cook healthy/ diet modification

- I would like information on strategies to overcome nutritional side effects related to HIV medication intake, and

- I would like education on food safety.

Information on dietary habits was assessed and utilized to determine dietary behaviors that the target group may already engage in and this information was used to determine the need for change to healthier habits that may improve dietary and nutrient intake. A dietary habit questionnaire (Behavioral Check List) from the University of Wisconsin Cooperative Extension was used as part of the needs assessment for this intervention. Conducting a needs assessment is important in order to tailor the intervention towards a specific target population. 


\section{LESSON PLAN 1}

\section{WHAT IS THE RELATIONSHIP BETWEEN HIV AND YOUR NUTRITION}

\section{Preparation}

1. Read through the lesson and each activity before beginning session

2. Have copies of each handout; enough for every participant

3. Ensure that supplies/materials needed for the session are on hand.

\section{Materials Needed}

1. Flip Chart with markers

2. Handout: "FACTS ABOUT HIV AND NUTRITION"

3. Paper and pencil for each participant

4. Granola bars with different color wrappings

5. Token for reinforcement: Grocery store gift card

\section{Before beginning session:}

1. Introduce yourself to the group members

2. Take attendance

3. Give objectives of the session and inform participants that they can ask questions at any time during the session.

4. Inform participants of points for answering questions and the opportunity to get a prize at the end of the session for having the most points.

\section{Participant Objectives}

At the end of this session, participants will learn:

1. about HIV's effect of the body

2. the importance of nutrition during HIV infection 
3. how to achieve good nutrition.

\section{During Session:}

Using attendance sheet, give each participant a point for a correct answer to a posed question. The first participant with the highest points at the end of the session receives a grocery store gift card.

\section{Teaching Guide}

\section{Introduction}

Bring to the session, granola bars with different color wrapping for example white, green and brown. Ask participants to pick whichever color granola they like as they come in. Inform them that they can eat their snack but should keep the wrappings as it will be used in activities during the session.

Thank you all for coming to our first Nutrition for HIV Healthy Living Session! I hope everyone got a granola bar when they came in. As our first activity, I would like anyone who has a green granola wrapping to tell us what they know about HIV and what the infection does to the body. Wait for responses. Those were correct answers and will form the basis of what we will discuss today. Our topic is what happens to the body during HIV infection and how important nutrition is during this time.

\section{Effects of HIV Infection}

When the body is infected with HIV, the virus attacks its ability to fight infection (which is what the experts call the immune system). If not brought under control, the virus can destroy the immune system making it impossible to fight any other infection. This is the reason why individuals infected with HIV find it difficult to fight bacteria and viruses that their body could have easily fought without medication. Though these 
bacteria and viruses do attack any part of the body, for an individual infected with HIV, these attacks are usually in the gut. The gut starts from the mouth, though your throat, stomach, intestines and ends with the anus. This is one of the reasons why diarrhea, nausea and vomiting are common during HIV infection. An infection of the gut lowers one's ability to eat, by reducing appetite and can also interfere with the body's ability to digest and absorb the nutrients that are in food. Having less energy/calories and nutrients can lead to malnutrition and weight loss.

Another way HIV infection affects the body is the demand for energy/calorie used when fighting an infection. As a result, individuals HIV infected individuals need more energy and therefore need to eat more. If your body doesn't get enough energy and nutrients, your energy levels will be low and can cause fatigue. Eating more doesn't mean eating "junk" food but rather, healthy food that can provide both energy and nutrients. I am sure most people here are taking medication to help fight the HIV virus. While this is extremely important in managing the disease, sometimes the side effects from the medication can affect our food and nutrient intake. Side effects like nausea, vomiting and diarrhea makes some people not want to eat. However, without eating, the body can't function properly and sometimes the medications also don't work as well.

\section{Importance of Nutrition in HIV infection}

So far, we have been talking about ways the HIV virus attacks the body and how this can affect our nutritional status. Let's now look at the importance of having good nutrition when you are infected with HIV. Based on what you know about HIV, why do you think good nutrition is important? Anyone with a brown wrapping can answer this question. Wait for responses. You all gave right answers. Good nutrition is important to 
maintain health and can determine the quality of life you have. When you attain good nutrition before and during an infection, it helps you to overcome many of the negative things we said HIV infection does to the body. With a good nutritional status, you are able to build your immune system to fight off infections, you have enough energy to prevent fatigue and weight loss, and you can also keep yourself from getting other diseases like heart disease and diabetes.

\section{What is Good Nutrition?}

I am sure most of you are thinking so how do I achieve good nutrition? For an HIV infected person attaining good nutrition can be a challenge but is not impossibility. This is because the virus is constantly "robbing" you of nutrients and energy. Good nutrition means eating enough complex carbohydrates, and lean protein as well as fats in your diet. Carbohydrates provide us with energy and good sources are vegetables, grains and cereals. Proteins help us build and maintain our muscles, organs and the substances that help the body fight infections. Good sources are beans, fish, meats, and nuts. While fats provide us with the most energy, we have to be careful how much we consume. There are good and bad fats. Good fats come from foods like nuts, seeds, fish, canola and olive oil. Bad fats can contribute to heart disease and come from meats, butter, and lard. In addition to eating healthy, some people find that taking vitamin supplements help maintain good nutrition. This is a good idea, however, be sure to stay away from supplements designed to make you lose weight. A regular multivitamin or prenatal vitamin should be good enough. You can talk with your doctor about the right vitamin for you. Good nutrition also involves drinking a lot of fluids, preferably water. This helps to keep you hydrated, reduce side effects of medication, and prevent constipation. Fluids 
like sodas, coffee, tea, alcohol may make you lose fluids so be careful with how much of these you consume. In the next couple of weeks we are going to have a session where we will be discussing into detail, what and how much to eat in order to achieve and maintain good nutrition. Now let's go ahead and review what we learned today.

\section{Activity}

Using the flip-chart, lead a discussion about the "EFFECTS OF HIV INFECTION" and HOW NUTRITION CAN HELP. Cut into strips, statements/facts about both topics (see appendix). Give one strip to each participant and ask them to stick or tape their fact/statement under the correct topic. Allow participant to explain why they chose to place the sticker under the topic they chose. On a different flip-chart lead a discussion about how to attain good nutrition. Allow participant to tell you what they have learned and write them down. 


\section{LESSON PLAN 2}

\section{THE GREEN EFFECT: EATING HEALTHY ON A SHOESTRING BUDGET}

\section{Preparation}

1. Read through the lesson and each activity before beginning session

2. Have copies of each handout; enough for every participant

3. Ensure that supplies/ materials needed for the session are on hand.

\section{Materials Needed}

1. Flip Chart and markers

2. Handout: Saving Money When Food Shopping

3. Game board and Shopping Tips Cards

4. Paper and pencil for each participant

5. Grocery coupons and ads

6. A can of beans in brand name, store brand, and generic (record prices)

7. A food label reading chart/Nutrition Facts Label Chart and empty coke bottle

8. Tokens for reinforcement: Shopping List Pad

\section{Before beginning session:}

1. Introduce yourself to the group members

2. Take attendance and give objectives of the session and let inform participants that they can ask questions at any time during the session.

3. Inform participants of points for answering questions and the opportunity to get a prize at the end of the session for having the most points. 


\section{Participant Objectives}

At the end of this session, participants will learn:

1. Tips on shopping to save money

2. How to shop healthy

3. How to read food labels

During Session: Using attendance sheet, give each participant a point for a correct answer to a posed question. The first 3 participant with the highest points at the end of the session receives a shopping list pad.

\section{Teaching Guide}

\section{Introduction}

Thank you for returning to Nutrition for HIV Healthy Living! Before we begin, can anyone share with us a time that you went shopping and got a good deal? Wait for responses. Well today, we are going to talk about ways to shop healthy and save money at the same time. I am going to start with how to navigate the store and later provide money saving food shopping tips.

\section{Tip 1: Know your store}

One of the most important shopping tips rarely talked about is the need to know your grocery store. Food display and arrangement is done in special ways to attract you, the buyer. Food usually displayed in aisles is processed and as a result can last for a long time. These foods, however, tend to contain a lot of additives that can be both unhealthy and not natural. The best way to ensure you are shopping for healthy foods is to do so around the perimeter of the grocery store. These foods are fresh, rarely or less processed, and have more nutrients. 
How many of you have heard that eating healthy is expensive? Wait for

responses. Yes it is true that some healthy foods can be expensive but the notion that all healthy foods are expensive is a big misconception. There are several cheap healthy foods; let's talk about tips to buying such foods while saving money. Can anyone think about any steps you can take to help you save money? Wait for response. Those are very good tips.

\section{Tip 2: Use Grocery Advertisements}

You want to start your trip to the grocery store by first reading the free grocery ads that are mailed weekly to several homes by many grocery stores. They can also be found on the internet. Simply type the stores' name into any search engine such as "google" and when the page comes up, look for a tab that says "weekly ad or weekly specials". If these ads don't get sent to your home or you do not have internet, don't worry. Most grocery stores also have these weekly ads inside their stores; they are usually placed at the entrance. These ads help you to make a plan of what you want to eat and subsequently a grocery list. Grocery stores usually have items on special when there are too many of them available at a time. Other times, they may have items on special to attract you to the store. Prices of other items in the store may be higher than you usually buy them so be sure to check the price of other items you may want to buy. Has anyone experienced that and will want to share with us? Wait for responses. Sometimes, stores have specials such as "buy one get one free". While such deals sound good, be sure you can use both items before the date of expiration. You may also end up not saving money if you drive or take the bus around town looking for deals. Find the closest store with the best prices for the foods you want and shop from there. 


\section{Tip 3: Use Coupons}

Coupons are another way to save money for items you want to buy. Where are some places we can find coupons? Wait for responses. You are all right! Some other places to find coupons are Sunday newspapers, magazines, and grocery store ads etc. Be sure to compare brands when shopping with coupons because there might be a brand that is cheaper than the one you have a coupon for. We will talk about comparing brands in a few minutes. Now, I have here, a grocery store weekly ad and I want you to help me pick out the good deals for this week. Put ad on flipchart so participants can participate in picking out the good deals.

\section{Tip 4: Use Grocery List}

The next tip after looking through the grocery store ad and making a plan of what you want to eat is to make a grocery list. A grocery list can also be made based on what is on hand and ingredients needed for planned meals. It should include breakfast foods and snacks. How many of you shop with a grocery list. Wait for responses. Allow participants to discuss why they shop with or without a grocery list. A grocery list allows you to have control over how much you spend and prevents impulse buying. It also keeps you from forgetting needed items and having to make another trip to the store. A grocery list can be developed several days ahead of the day you plan to go to the grocery store. This can be done by keeping a paper and pencil by your pantry or on top of your refrigerator so you can make a list of needed items as and when you run out of them. While having a list when grocery shopping can save you money, it also makes the experience easy and less stressful. 


\section{Tip 5: Compare Prices}

Let's talk about our fifth tip, which is to compare prices of different brands of an item you want, before making a purchase. Comparing brand prices helps you choose the least expensive item. There are several companies that may make the same food and these companies determine the prices of the food. As a result you may find the same quantity of the same food being sold at different prices. Let's take a can of black beans for example, how many brands have you seen in the store when you go grocery shopping? Wait for responses. Based on your answers, we know there are several of them out there. Our aim is to buy the least expensive to save money. Most grocery stores also have their own brands or a generic brand (that bears no company name) of the same food item and these tend to be the cheapest. Show participants the 3 different brands of beans and tell them the price difference. Let participants discuss how much money is saved depending on which one is bought.

\section{Tip 6: Read Food Label}

Our last tip is reading food labels. Reading food labels help us choose the healthiest foods. Every food has a label which gives us a lot of information about the food. A food label can tell you the ingredients in the food, the serving size, how many calories it contains, how much fat, protein, sugar, etc. there are in a serving. I am going to put up a Food Label chart so we can practice how to read a food label. Almost every packaged food has a label and you know you are reading one, when the title is "Nutrition Facts", usually written at the top of the label. What is the next thing you notice? Wait for a response. That is right, the serving size and the number of servings in the package. This tells us what is considered a serving for this particular food item. It is usually in measures 
such as cups, ounces, etc., making it easy to visualize. The calorie amount written underneath corresponds to the serving size.

Pass Coca-Cola bottle around. For example this bottle of Coca-Cola has 2.5 servings in this bottle with a serving being $8 \mathrm{oz}$. According to the label, how many calories are there in $80 z$ of coke? Wait for a response. 110 Calories, that is correct! So if you drink the whole bottle, how many calories would you have consumed? Wait for a response. That is correct you would have consumed 275 calories. Let's focus our attention back to the chart and to the nutrients that are bolded. What do you see? Wait for responses. That is right! These are some of the nutrients available in the food, and it is important to pay attention to them when you are buying and/or consuming food. The number beside them tells us exactly how much of that nutrient there is in the food. The section to the right is called the "Percent Daily Values". Based on your nutrients needs for the day, this helps you track how much nutrients you are consuming. The goal is to reach $100 \%$ of each nutrient. What are some nutrients you see in the purple color on this chart? Wait for responses. That is correct. With nutrients like fat, sodium and cholesterol, however, be sure not to eat too much of them; it is not advisable to go over $100 \%$. The percent daily value is based on one serving so the numbers can be adjusted if you eat more or less. It is also based on a 2000 calorie diet and may change depending on your caloric need. A high percent daily value for a nutrient means it is abundant in that food. Look at the coke bottle again and tell me which nutrient you think is abundant. Wait for responses. That was a very good answer. Now that you know all about how to shop healthy, let's play our shopping game/activity. 


\section{Activity}

Cut "Shopping Tips Cards" into strips and put them in activity envelopes.

Request that the class divides into groups of 3 people and give each group an activity envelope and game board. While holding up a copy of the game board, explain the game to participants: Participants within each group takes one "Shopping Tip Card" from the activity envelope and read it aloud. The group then discusses the tip and decides where to place it on the game board. The groups have 10-15 minutes for this activity and when the time is up, the class comes together to discuss the tips they picked. Record these on the flip chart to serve as review of main points.

I hope you enjoyed that activity. There is one last activity I want us to do together before we leave. Let's look at our handout called "Saving Money When Food Shopping”. I would like each one of us to complete this form with new shopping tips we learned today. 


\section{LESSON PLAN 3}

\section{TAKE CHARGE OF YOUR DIET!}

\section{Preparation}

1. Read through the lesson and each activity before beginning session

2. Have copies of each handout; enough for every participant

3. Ensure that supplies/materials needed for the session are on hand.

\section{Materials Needed}

1. Flip Chart and markers

2. Handout: Recipes

Make Healthful Changes to your Diet

3. MyPyramid Bingo Instructions

4. MyPyramid Bingo Clue Cards

5. MyPyramid Bingo Answer Sheets

6. Paper and pencil for each participant

7. Prizes for bingo game (healthy snacks)

8. Token for reinforcement: Grocery store gift card

\section{Before beginning session:}

1. Introduce yourself to the group members

2. Take attendance

3. Give objectives of the session and let inform participants that they can ask questions at any time during the session.

4. Inform participants of points for answering questions and the opportunity to get a prize at the end of the session for having the most points. 


\section{Participant Objectives}

At the end of this session, participants will learn:

1. What and how to eat from each food group

2. How to cook healthy

During Session: Using attendance sheet, give each participant a point for a correct answer to a posed question. The first participant with the highest point at the end of the session receives a grocery store gift card.

\section{Teaching Guide}

\section{Introduction}

Welcome back to the Nutrition for HIV Healthy Living Class! I am happy to see you all. We will be discussing healthy eating today and will be paying more attention to eating whole grains, fruits and vegetables and cheap plant based proteins. What are some reasons why we eat? Wait for responses. As we all know, food is good; in fact food is very important. The body becomes weak and doesn't function properly when it does not get enough good and healthy food. As we learned from another session, food provides the body with nutrients, energy, and the ability to maintain and repair itself so that it can fight infections. As a result, good nutritional status is important especially during an infection. Good nutrition however does not come about just by eating anything in any quantity but rather eating a variety of healthy foods in the right amounts. What did we say were three main nutrients we should try and eat to help us achieve good nutrition? Wait for responses. (Answer: Carbohydrates, Protein and Fat, based on lesson 1) What are some food sources for these nutrients? Wait for response. You all gave the right answers! Let's go into detail about these food sources. 


\section{Carbohydrates}

As we have already discussed, carbohydrates are a good source of energy and we get carbohydrates from grains, cereals, fruits, and vegetables. These are the healthy sources. Other sources are sodas, cakes, cookies, ice cream, and most processed foods and sweets. We are going to focus on the healthy ones as it is important to consume more of those. There are several types of grains and grain products but the healthy ones are the whole grains. Examples are oats, brown rice, whole grain pasta, bread, muffin, crackers, breakfast cereals, flour etc. These have fiber, are low in fat and are better sources of carbohydrates than potatoes, regular pasta, white bread or white rice. With the exception of potatoes, the others have been stripped of fiber and other important nutrients. Most people complain about the texture of whole grains and as a result do not like to eat them. You can gradually introduce whole grain products into your meals by mixing them with the regular ones until your taste buds adjust to the taste and texture. A good goal will be to make half of the grains you currently eat whole and gradually make

everything whole. It is recommended that we eat 6 ounces of grains in a day. Examples of what counts as 1 ounce are a slice of bread, a cup of ready to eat cereals, and $1 / 2$ cup of cooked cereals, rice, or pasta.

\section{Vegetables}

Vegetables are another good source of carbohydrates and fiber. What are some vegetables you like to eat? Wait for response. What are some reasons why you choose these kinds of vegetables? Wait for response. Based on your answers, we can see that there are different types of vegetables, each with different nutrients. Can we name some vegetables by categories? Let's start with dark green ones (Answers: spinach, romaine 
and broccoli etc.) How about orange ones? Wait for response. (Answers: carrots, sweet potatoes, pumpkin, squash etc.) What are some starchy vegetables? Wait for response (Answers: corn, green peas, etc.). It is important to add variety when eating vegetables so we can get the various nutrients they provide. All vegetables are good regardless of how they are packaged, that is whether fresh, frozen, or canned. Buy the types of vegetables you can afford. When buying canned vegetables, however, be sure to buy those that have low sodium contents. It is recommended that we eat $2 \frac{1}{2}$ cups of vegetables in a day with $1 / 2$ cup being considered a serving.

\section{Fruits}

Does anyone know how many servings of fruit we are supposed to eat each day? Wait for response. (Answer: 4 servings or 2 cups) That is right! One small fruit or $1 / 2$ cup of fresh, frozen or canned fruit counts as a serving. A serving can also be $1 / 4$ cup of dried fruits or $1 / 2$ cup of fresh juice. Just like vegetables all fruits are good for you regardless of how they are processed or packaged.

\section{Proteins}

Let's shift our focus to proteins. Proteins do not produce as much energy as fat but are needed to maintain organs, muscles and other substances the body needs to fight infections. Good sources of protein are meats, poultry, seafood, beans and peas as well as eggs. While meats sources of protein are good, they are often high in fat so it is recommended that lean versions be consumed. Eggs and low fat dairy are cheap and good sources of protein, however, beans, peas and lentils are just as good and even cheaper. They are also easy to cook, low in fat and high in fiber. Other nutrients that can be found in beans are vitamins and minerals. Eating a lot of beans and peas helps us meet our 
protein needs without a high cost. Beans are easy to store too; they can either be frozen after cooking or can be stored dry. Most people claim that cooking beans takes time. While this can be true, depending on the kind of bean, socking them overnight reduces the cooking time. The recommendation for protein intake especially during HIV infection is $0.6-0.9$ grams per pound body weight. This translates approximately to between $100-$ $150 \mathrm{~g} / \mathrm{day}$ for $\mathrm{HIV}+$ men and about $80-100 \mathrm{~g} /$ day for $\mathrm{HIV}+$ women. A serving of protein is about 3-4 ounces for meat (which is approximately the palm of a hand or a deck of cards); $1 / 2$ cup of beans serves as 2 ounces. You can know how much protein you are eating by looking at the nutrition label; the amount of protein in a serving is always listed.

At the end of today's session, you will all receive recipes that are healthy, cheap and easy to make. Making these foods will help you practice at home what we have discussed today. Now let's all take out the handout that says "Make Healthful Changes to your Diet". We need to complete it before we play our bingo game. Write the foods you ate yesterday and better choices you could make to the future. (Allow 10 minutes for this activity). Before we play our bingo game, I would like you to listen to a success story of someone who is HIV infected and although she lived on a limited income, has been able to achieve her aim of eating healthy. Participants may discuss the changes they have seen in their health after deciding to eat healthy.

\section{Activity}

Get group together to play MyPyramid Bingo. Instruction and game cards can be found in appendix C. Give each participant a copy of Healthy Living Recipes. 


\section{LESSON PLAN 4}

\section{KEEP THE BUGS OUT!}

\section{Preparation}

1. Read through the lesson and each activity before beginning session

2. Have copies of each handout; enough for every participant

3. Ensure that supplies/materials needed for the session are on hand.

\section{Materials Needed}

1. Flip Chart with markers

2. Handout: Cooking Meat, Poultry and Seafood Safely

Food Safety Tips

3. Paper and Pencils for participants

4. Cooking thermometers for each participant

5. Copies of Food Safety bingo game

6. Dried bean pieces for bingo game

7. Snacks as prizes for bingo game

8. Token for reinforcement: Grocery store gift card

\section{Before beginning session:}

1. Introduce yourself to the group members

2. Take attendance

3. Give objectives of the session and inform participants that they can ask questions at any time during the session.

4. Inform participants of points for answering questions and the opportunity to get a prize at the end of session for having the most points. 


\section{Participant Objectives}

At the end of this session, participants will learn:

1. The basic principles of food safety

1.1. Food safety when shopping

1.2. How to store foods safely

1.3. How to cook foods safely

During Session: Using attendance sheet, give each participant a point for a correct answer to a posed question. The first participant with the highest point at the end of the session receives a grocery store gift card.

\section{Teaching Guide}

\section{Introduction}

Welcome to the last of our Nutrition for HIV Healthy Living classes! I am glad to have you all here. Today, we are going to discuss food safety. These are basically ways to overcome foodborne illnesses that are caused by bacteria or germs. These bacteria cannot be seen, tasted or smelled yet can get people very sick; sometimes they can even cause death. Has anyone gotten sick from bacteria in food? What were some of your symptoms? Wait for responses. Most people get sick from eating food that is infested with bacteria; however, older adults, babies and individuals with weakened immune system are at risk the most. HIV infected individuals are among those with weakened immune systems. This is because the virus attacks and tries to destroy the immune system. There are several ways to fight back to try and maintain your immune system. These include taking your medications as directed and eating healthy. We can also prevent attacks on our immune system by preventing bacteria that causes foodborne illnesses from entering our 
bodies. Today's class will discuss tips on how to do this. We will discuss food safety when shopping, storing and cooking food.

\section{Food Safety When Shopping}

Food safety should start from the grocery store. This is because bacteria can be transferred from one food to another even at the point of purchase. Here are some steps to take to keep your food save when grocery shopping:

- Buy food before the sell by or expiration date.

- When buying foods that are packaged, be sure that the packaging is tight. In the case of meats, this will prevent you from spilling the juice from the meat unto other foods.

- When buying eggs, open the carton to make sure that no egg is cracked.

- Be sure to check canned food before buying; do not buy those that are rusted, having dents and/or have bulging lids.

- Frozen and cool foods should be the last foods you buy so they can be kept frozen or cold until you get home.

Once you get home from the grocery shop, foods should immediately be put away especially the perishable, cold and frozen ones.

\section{Food Safety When Handling Food/ Cooking}

The next groups of tips we are going to talk about have to do with food safety when handling and cooking food. It is important to wash your hands anytime you handle food and also anytime you expose yourself to germs such as when you use the bathroom, sneeze, blow your nose, or play with pets. Your hand washes should be thorough, should last about 20 seconds and should include under the nails, between fingers and back of 
hands. It is also important to wash your utensils before and after using them. Cleaning your kitchen counters and floors often helps to prevent germs from multiplying. A cheap and easy way to do this is to use homemade disinfectant. This can be made by mixing $1 / 4$ cup chlorine bleach with $2 \frac{1}{4}$ cups water and then storing the mixture in a spray bottle.

Cross contamination is the situation when bacteria are spread from one food to another. The best way to keep this from happening is to separate cooked and raw foods like fruits and vegetables from raw meats and eggs. Juices from raw meat contain bacteria and it is dangerous to get these juices on other foods. Be sure to also wash utensils that have come in contact with raw meats with soap and water before using them for other foods like vegetables. Another way to prevent meat juice from getting onto vegetables is to cut them before cutting your meat.

\section{Food Safety and Food Temperature}

So far, I am been doing the talking. Let's go around the room and give examples of certain foods that need attention during preparation to ensure that they are cooked at well. Wait for responses. Food needs to be handled in a particular temperature to either keep bacteria from multiplying or to kill them. Bacteria thrive very well in temperatures between $41{ }^{\circ} \mathrm{F}$ and $140^{\circ} \mathrm{F}$. This is known as the danger zone and includes room temperature. As such, food that needs to be kept cold needs to be either refrigerated or frozen. This environment is below $41{ }^{\circ} \mathrm{F}$ to keep bacteria from multiplying. Foods that need to be cooked should be cooked at temperature above $140{ }^{\circ} \mathrm{F}$. Be sure to cook meats such that the center is not pink in color. The best way to make sure your food is cooked at the right temperature is to use a thermometer. Today, you are each going to receive a thermometer so you can always measure the temperature of your meats, poultry and 
seafood. Each one of you should also have the handout that says 'Cooking Meats, Poultry, and Seafood Safely" This handout has a list of the types of meat and the correct temperatures to cook them at. You can keep this on top of your refrigerator or in a cupboard in your kitchen.

Once food is cooked, it should be refrigerated within 2 hours. Leaving food at room temperature for a long time (more than 2 hours) can help bacteria growth; such a food should be thrown out. Ideally, left overs also need to be thrown out after 3 days. Every food has a distinct color, smell, flavor, texture, and taste. One can tell if food is still good to eat by changes in these characteristics. It is important not to eat any food if you think it is spoiled. For most of us, our initial instinct when we suspect food is bad is to try and recover it. This can be dangerous as food that is gone bad is full of bacteria. The rule of thumb is "If you are in doubt about whether the food is good or bad, then through it out"

Let's talk about our last food safety tip which has to do with how we thaw food. The best way to thaw or defrost meat is to do it in the microwave. It is fast and easy. Meat can also be thawed by putting it under cold running water for a while or by leaving it in the refrigerator for a couple of days before the day you actually use it. Thawing meat on the counter at room temperature is not considered good. This is because bacteria grows very fast at this temperature.

So far we have been talking about steps to take to prevent foodborne illnesses. Let's do our activity for the day to remind ourselves of what we have discussed today. 


\section{ACTIVITY: FOOD SAFETY BINGO}

Give each participant food safety bingo cards and dried beans to use as pieces for the bingo game. The bingo cards and statements can be found in the appendix D of this manual. Cut food safety statements into strips and place in a container. Shuffle, draw and read each stripe at a time. Ask participants to find that food safety fact on their bingo cards. The participant who is first to accurately declare bingo wins. Prizes can be any healthy snacks. 


\section{References}

1. Ivers LC, Cullen KA, Freedberg KA, Block S, Coates J, Webb P. HIV/AIDS, undernutrition, and food insecurity. Clin Infect Dis. 2009;49(7):1096-1102.

2. Piwoz E, Preble E. HIV / AIDS and nutrition: a review of the literature and recommendations for nutritional care and support in sub-Saharan Africa Washington, DC: Academy for Educational Development [AED], Support for Analysis and Research in Africa Project [SARA]. 2000.

3. Nutrient Requirements for People Living with HIV/. AIDS: Report of a Technical Consultation, Geneva:WHO. 2003.

4. Shevitz AH, Knox TA, Spiegelman D, Roubenoff R, Gorbach SL, Skolnik PR. Elevated resting energy expenditure among HIV-seropositive persons receiving highly active antiretroviral therapy. AIDS. 1999;13(11):1351-1357.

5. Semba RD, Tang AM. Micronutrients and the pathogenesis of human immunodeficiency virus infection. Br J Nutr. 1999;81(03):181-189.

6. FANTA. Food Assistance Programming in the Context of HIV. Food and Nutrition Technical Assistance (FANTA) Project and World Food Programme (WFP). Washington, DC: FANTA Project, Academy for Educational Development. 2007.

7. Nutrition Resources for Health Professionals. Centers for Disease Control Web site http://www.cdc.gov/nutrition/professionals/index.html. Accessed July 10, 2010

8. http://www.fruitsandveggiesmatter.gov/downloads/NationalActionGuide2009.pdf Accessed July 10, 2010

9. Contento I. Nutrition Education, Linking Research, Theory and Practice. Sudbury, Massachusetts: Jones and Barrett Publishers. 2007 
10. Cason KL, Cox RH, Wenrich TR, Poole KP, Burney JL. Food Stamp and NonFood Stamp Program Participants Show Similarly Positive Change With Nutrition Education. Top Clin Nutr. 2004;19(2):136-147.

11. Joy AB, Doisy C. Food Stamp Nutrition Education Program: Assisting Food Stamp Recipients to Become Self-sufficient. J Nutr Educ. 1996;28(2):123-126.

12. Cason KL, Cox RH, Burney JL, Poole K, Wenrich TR. Do Food Stamps Without Education Improve the Nutrient Intake of Recipients? Top Clin Nutr. 2002;17(4):74-82.

13. Melody B. Impacts of Family Nutrition Classes Taught to Food Stamp Recipients in Grant/Adams Area of Washington State J Extension. 1998;36(4).

14. HIV/AIDS Surveillance, 2008. Miami Dade County Health Department Web site http://www.dadehealth.org/downloads/FS-2008\%20FLORIDA-DADE.pdf. Accessed July 10, 2010

15. Baum MK, Lai S, Sales S, Page JB, Campa A. Randomized Controlled Clinical Trial of Zinc Supplementation to Prevent Immunological Failure in HIV-Positive Adults. Clin Infect Dis. 2010; 50(12): 1653-1660.

16. Borinquen HealthCare Inc. Website http://www.borinquenhealth.org/borinquenhealth.htm. Accessed July 10, 2010

17. Campbell MK, Honess-Morreale L, Farrell D, Carbone E, Brasure M. A tailored multimedia nutrition education pilot program for low-income women receiving food assistance. Health Educ Res. 1999;14(2):257-267.

18. Prochaska JO, Velicer WF, Rossi JS, et al. Stages of change and decisional balance for 12 problem behaviors. Health Psychol. 1994;13(1):39-46.

19. Prochaska JO, DiClemente CC. Stages and processes of self-change of smoking: toward an integrative model of change. J Consult Clin Psychol. 1983;51(3):390395. 
20. Norcross JC, Krebs PM, Prochaska JO. Statges of Change. J Clin Psychol, 2011;67(2):143-154

21. Bandura A. Social Foundations of Thought and Action: A social cognitive theory. Englewood Cliffs, N.J.: Prentice Hall; 1986.

22. Kadzin AE, Behavior Modification in Appleid Settings, $4^{\text {th }}$ Edition. Pacific Grove, CA:Brooks/Cole, 1989 
Appendices: Handouts and Activity 


\section{A: Facts about HIV and Nutrition}

Effects of HIV Infection

- Increased energy needs

- Not being able to absorb nutrients

- Side effects of drugs

- Frequent diarrhea episodes

- Nausea and vomiting

- Frequent infections, e.g. skin, mouth, etc....

- Increased nutrient requirements

- Decreased appetite 


\section{How Nutrition Can Help}

- Build immune system

- Prevent weight loss

- Slow down HIV disease progression

- Good nutrition status

- Prevent Fatigue

- Better quality of life

- Fight Infections 


\section{B1: Saving Money When Food Shopping Handout}

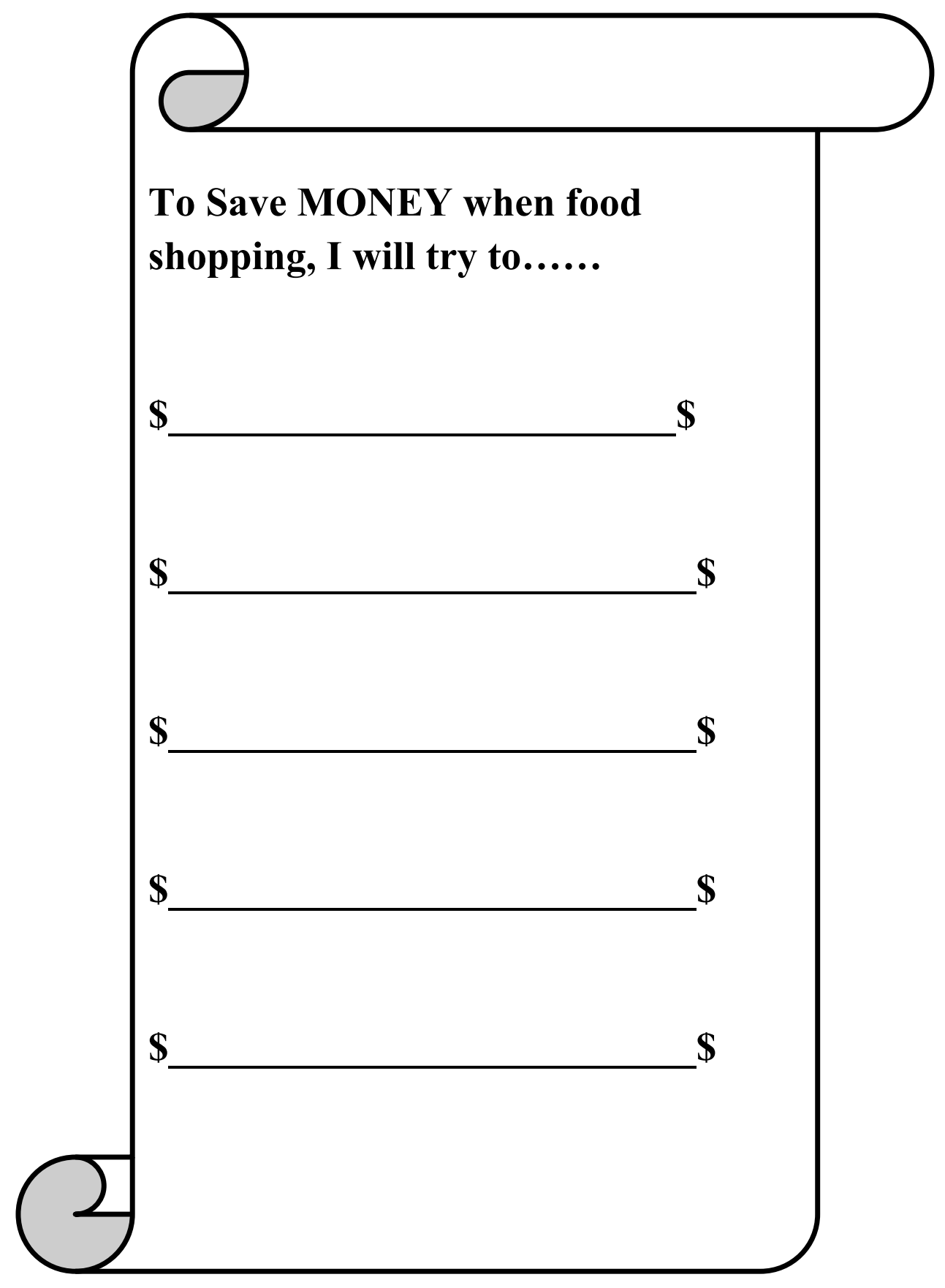

Source: University of Wisconsin Extension Nutrition Education Program 


\section{B2: Shopping Tips Cards}

\begin{tabular}{|c|c|}
\hline $\begin{array}{c}\text { Buy store brands instead of } \\
\text { national brands - they often } \\
\text { cost less. }\end{array}$ & $\begin{array}{c}\text { Choose store brands of } \\
\text { canned fruits and vegetables } \\
\text { to get good quality at a lower } \\
\text { price. }\end{array}$ \\
\hline $\begin{array}{c}\text { Learn the layout of the store } \\
\text { you usually shop at, so you } \\
\text { can find foods quickly. }\end{array}$ & $\begin{array}{c}\text { Use a grocery list every time } \\
\text { you shop for food. }\end{array}$ \\
\hline $\begin{array}{c}\text { Know how much you can } \\
\text { spend for food each week. }\end{array}$ & $\begin{array}{c}\text { Use coupons for items you } \\
\text { usually buy. }\end{array}$ \\
\hline $\begin{array}{c}\text { Look for in-store specials } \\
\text { and coupons near the } \\
\text { entrance of the store and } \\
\text { throughout the aisles. }\end{array}$ & $\begin{array}{c}\text { Check to see if multiple item } \\
\text { specials are really a good } \\
\text { price. }\end{array}$ \\
\hline $\begin{array}{c}\text { Buy foods that you use a lot } \\
\text { in large size packages, only } \\
\text { if you can use it all before it } \\
\text { spoils. }\end{array}$ & $\begin{array}{c}\text { Use an envelope to hold your } \\
\text { coupons and list when } \\
\text { shopping. }\end{array}$ \\
\hline $\begin{array}{c}\text { Check for foods on hand } \\
\text { before making grocery list }\end{array}$ & $\begin{array}{c}\text { Compare brand prices of } \\
\text { foods before and buy the least } \\
\text { expensive }\end{array}$ \\
\hline
\end{tabular}

Source: University of Wisconsin Extension Nutrition Education Program 


\begin{tabular}{|c|l|}
\hline $\begin{array}{l}\text { Buy plain frozen vegetables } \\
\text { instead of ones with special } \\
\text { sauces or seasonings. }\end{array}$ & $\begin{array}{l}\text { Cut whole chicken into } \\
\text { pieces yourself, it usually } \\
\text { costs less. }\end{array}$ \\
\hline $\begin{array}{l}\text { Buy plain pasta shapes like } \\
\text { macaroni - they are cheaper } \\
\text { than fancy shapes }\end{array}$ & $\begin{array}{l}\text { Buy brown rice, regular } \\
\text { white rice and converted rice } \\
\text { - they cost less than instant } \\
\text { rice. }\end{array}$ \\
\hline $\begin{array}{c}\text { Read food labels to limit } \\
\text { buying unhealthy foods }\end{array}$ & $\begin{array}{l}\text { Eat before going food } \\
\text { shopping. If you are hungry, } \\
\text { you will be more tempted to } \\
\text { buy foods that are not on } \\
\text { your list }\end{array}$ \\
\hline $\begin{array}{l}\text { Buy dried beans, peas and } \\
\text { lentils to make hearty, low- } \\
\text { cost soups and casseroles }\end{array}$ & $\begin{array}{l}\text { Save money by buying a } \\
\text { block of cheese and slicing } \\
\text { or grating it yourself }\end{array}$ \\
\hline $\begin{array}{l}\text { Go down only the aisles } \\
\text { where you can find foods on } \\
\text { you list. "Sight-seeing" in } \\
\text { other aisles may tempt you to } \\
\text { buy something you don't need }\end{array}$ & $\begin{array}{l}\text { Avoid foods packaged in } \\
\text { individual servings-you } \\
\text { pay a lot more for the extra } \\
\text { packaging }\end{array}$ \\
\hline $\begin{array}{l}\text { Buy fruits and vegetables that } \\
\text { are in season }\end{array}$ & $\begin{array}{l}\text { Use an envelope to hold } \\
\text { shopping }\end{array}$ \\
\hline
\end{tabular}

Source: University of Wisconsin Extension Nutrition Education Program 
B3: Game Board

ALREADY DO IT

WILL TRY IT

NOT PRACTICAL

FOR ME

OR

DON'T WANT TO DO

Source: University of Wisconsin Extension Nutrition Education Program 


\section{C1: Healthy Living Recipes}

QUICK SPANISH RICE

2 cups cooked brown rice

$1 / 3$ cup grated cheese

$1 / 2$ cup green pepper, chopped

$3 / 4$ cup condensed tomato soup
Serves 4

1 teaspoon grated onion

$1 / 4$ cup water

$1 / 8$ teaspoon pepper

3 strips bacon

1. Preheat oven to $375^{\circ}$.

2. Mix rice and other ingredients except bacon together

3. Greased 1-quart casserole and pour mixture into it.

3. Place bacon on top and bake for 20 minutes.

Nutrition Facts (per serving): Calories $220 \sim$ fat $5 \mathrm{~g} \sim$ calories from fat $45 \sim$ sodium 470 mg total carbohydrate $30 \mathrm{~g} \sim$ fiber $3 \mathrm{~g}$ 

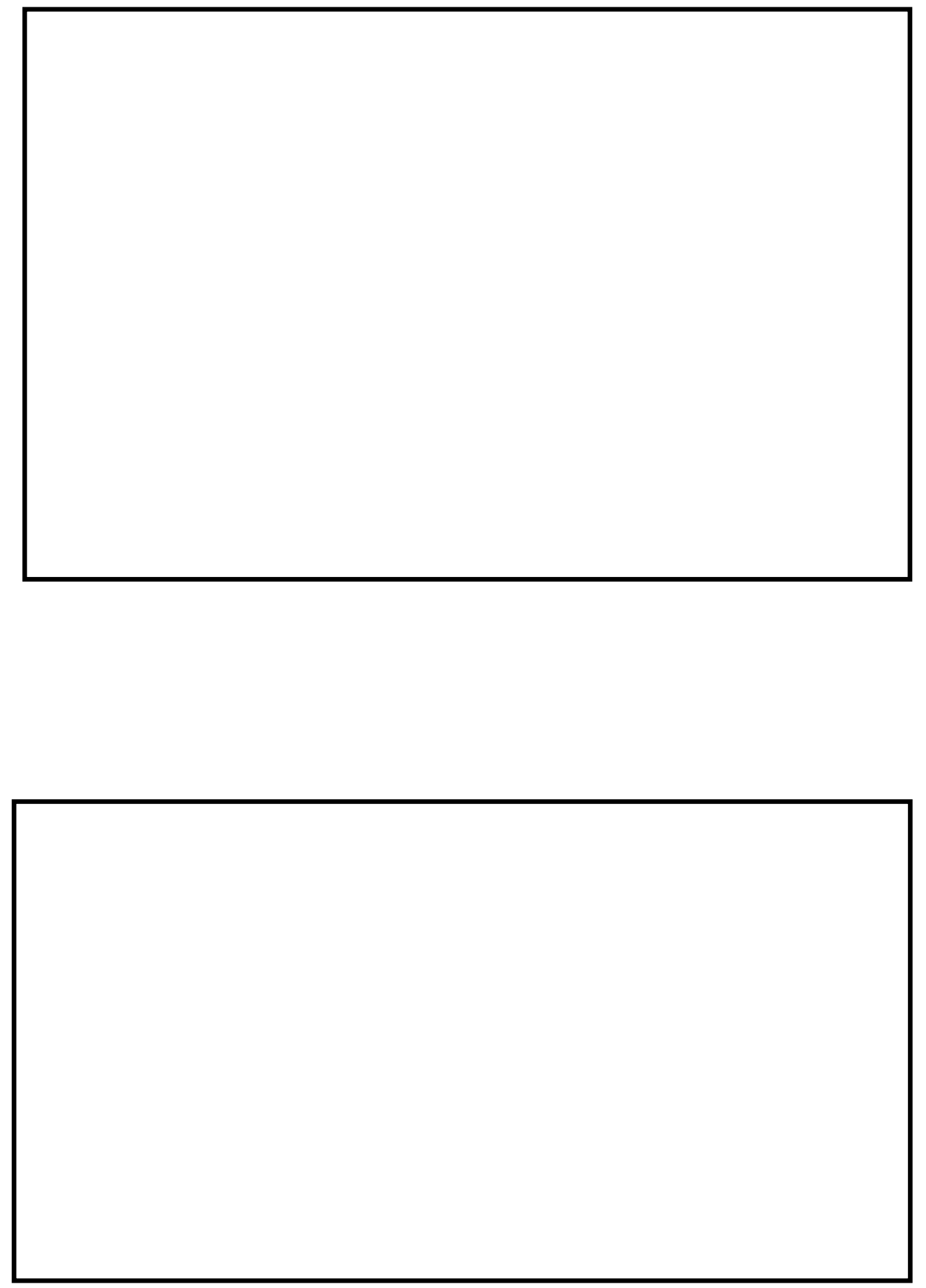

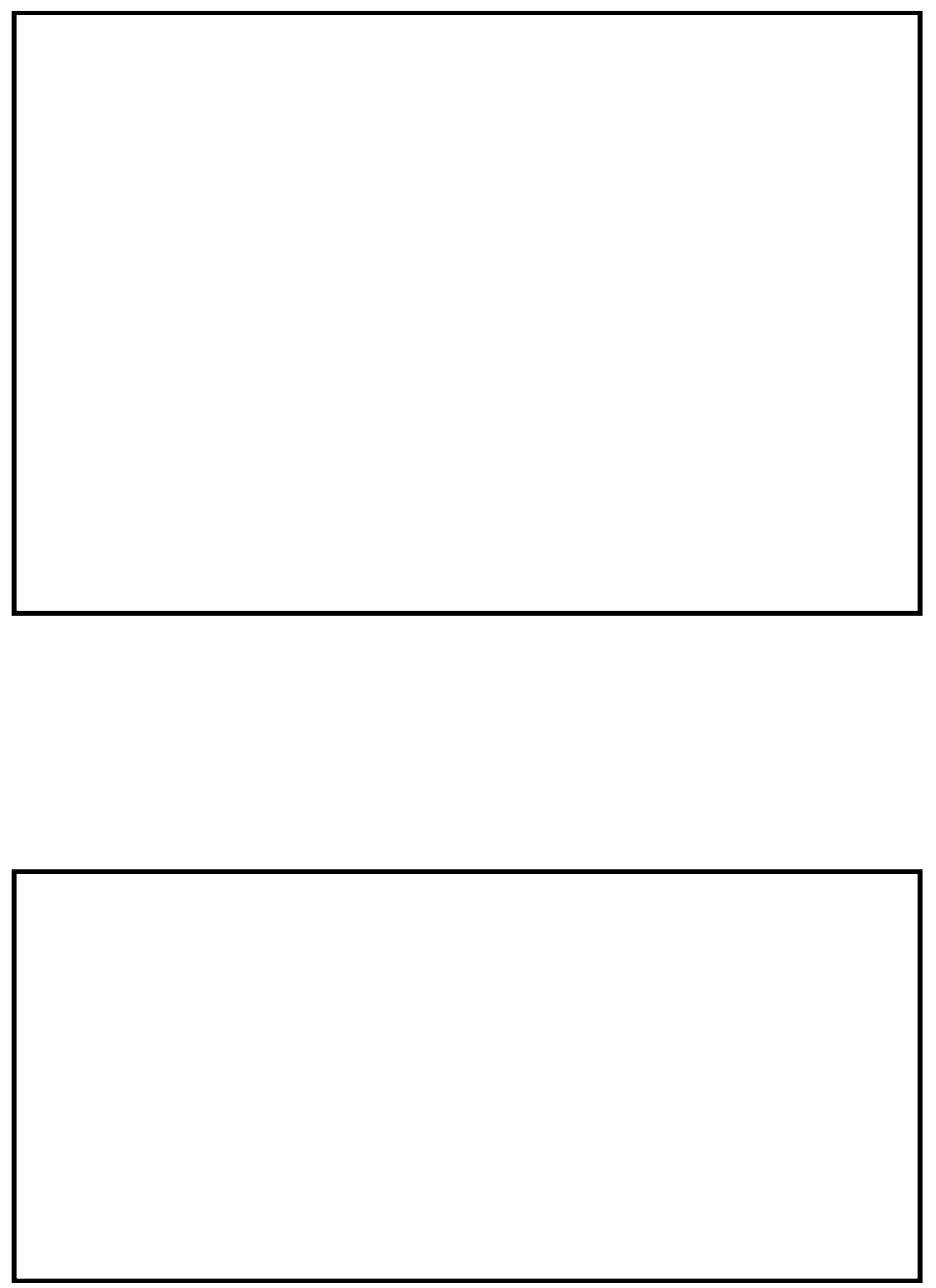

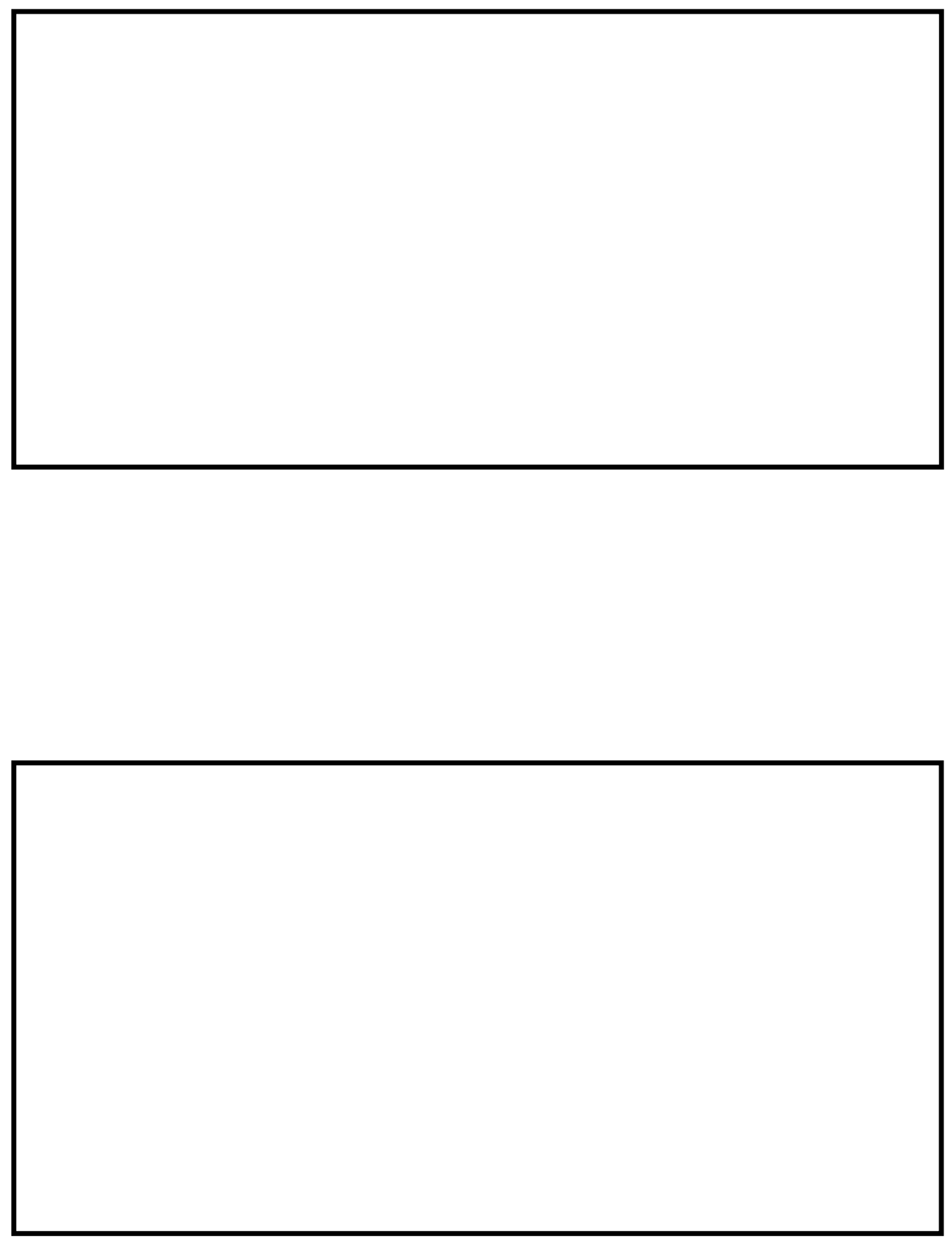

246 

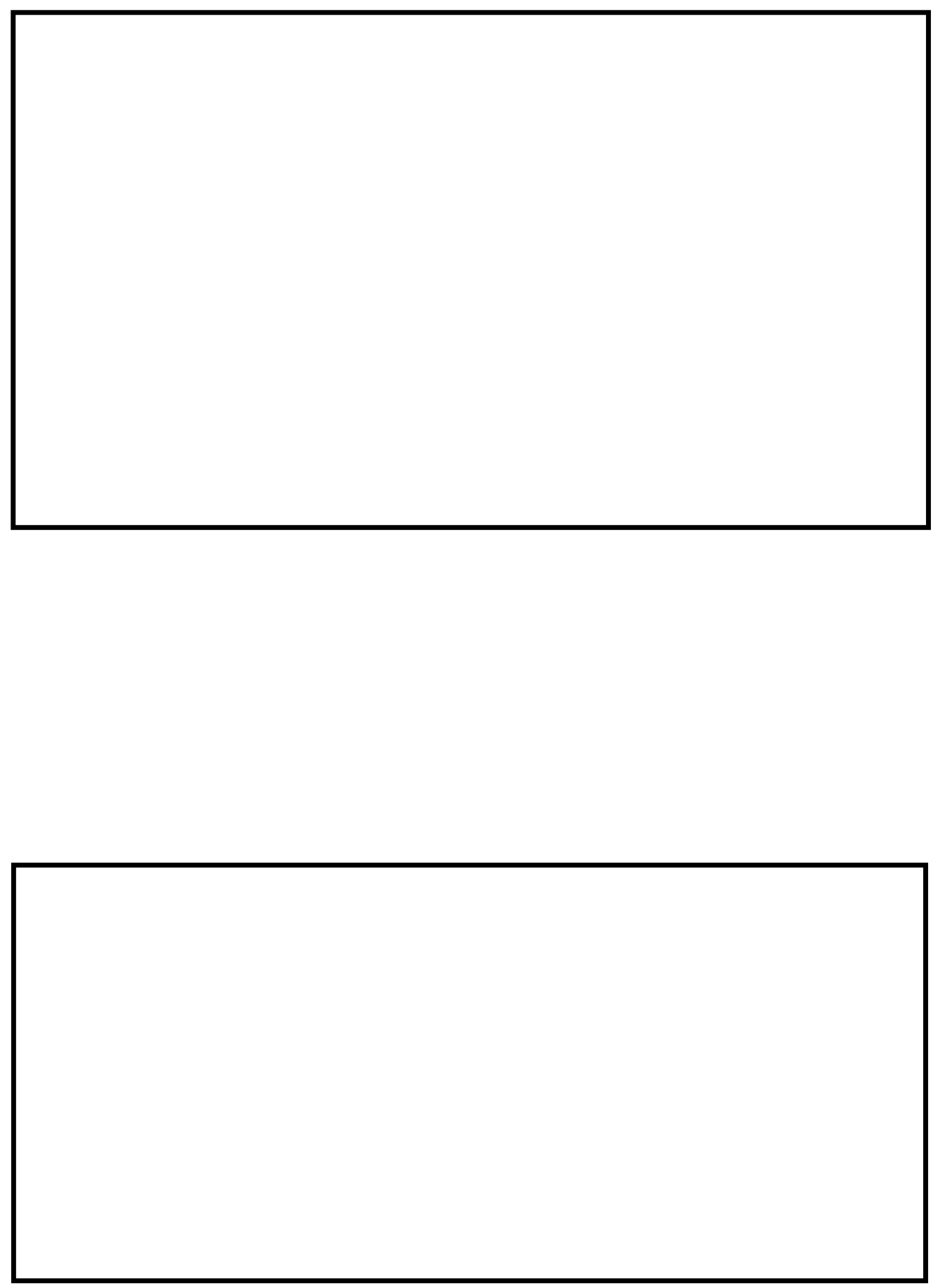

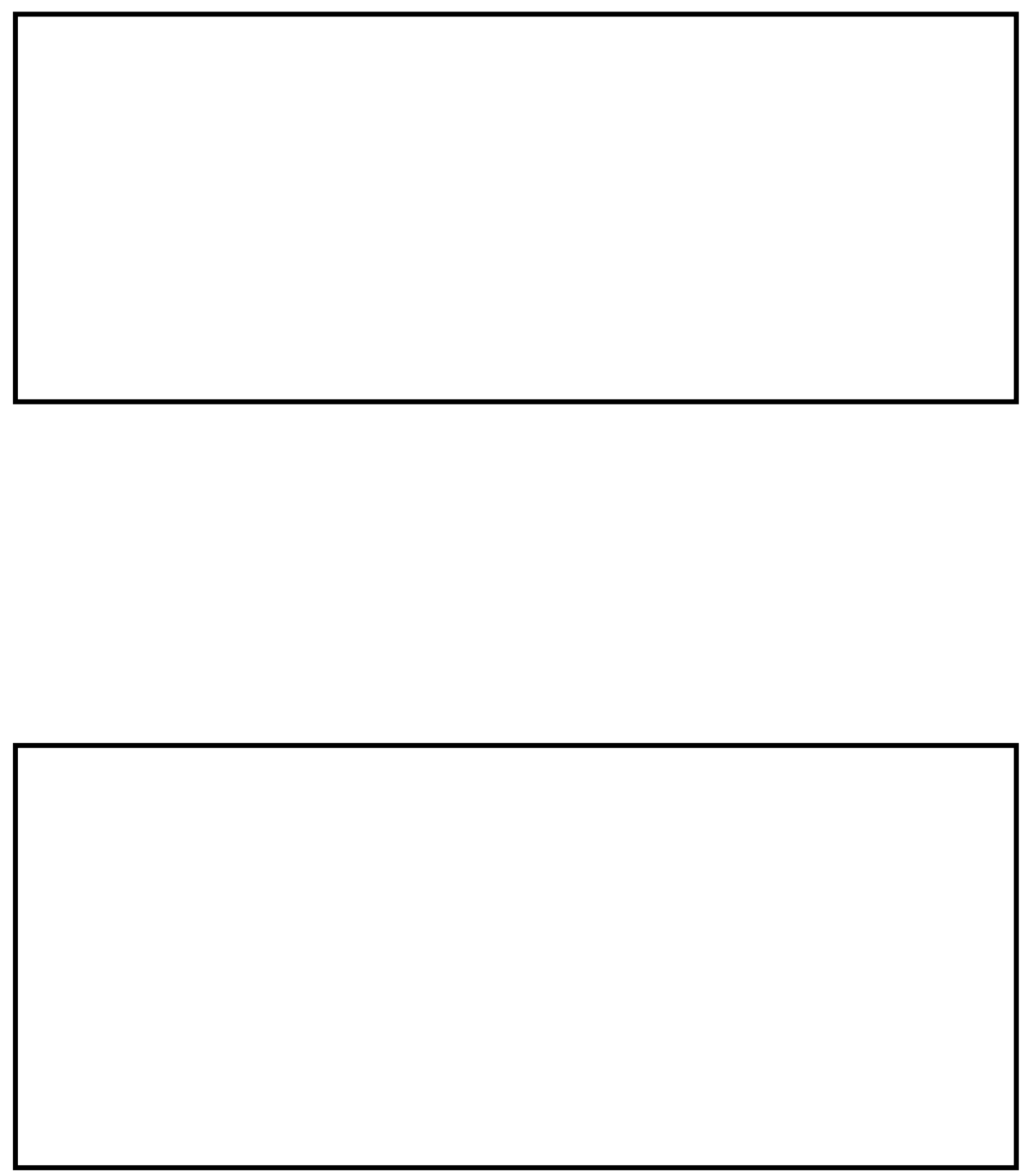

Recipes Source: University of Illinois Extension, Food Stamp Nutrition Education 


\section{C2: Make Healthful Changes to your Diet}

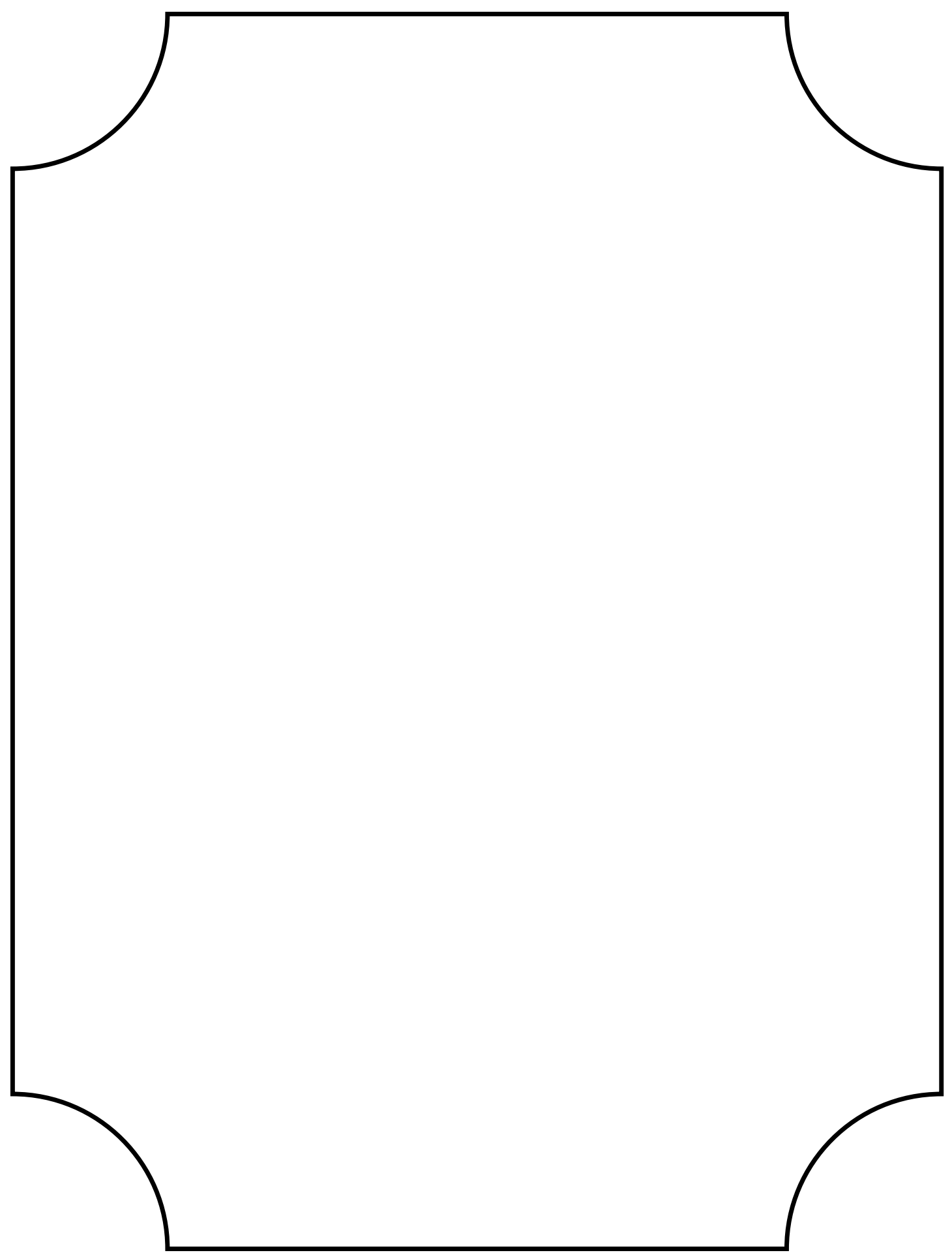

Source: University of Wisconsin Extension Nutrition Education Program 


\section{C3: MyPyramid Bingo Instructions}

\section{Supplies}

MyPyramid bingo cards (7 different cards available)

Small bathroom dispenser cups

Dried beans

MyPyramid Bingo clue cards

MyPyramid Bingo answer sheet

Prizes (e.g. healthy snacks)

\section{Instructions}

"Place dried beans in cups. Dried beans are to be used as bingo game pieces.

Distribute bingo cards and dried beans to players. Instruct them to put a game piece in the free space on their card. Tell them you will be calling out a clue for one of the foods found on their bingo card. The players need to place a game piece (dried bean) on the bingo card picture of the food described on the clue card.

The game caller must first cut out the MyPyramid Bingo clue cards then shuffle them. With the deck of cards face down, pick the top card and read the clue for a food written on the card. After the game caller reads the MyPyramid Bingo clue card, they place that card on the answer sheet on top of the food described by the clue card. To win the game, the players need to line up game pieces vertically, horizontally or diagonally on their bingo cards. When they completely fill in a line with their game pieces they must yell out loud "MyPyramid Bingo" for everyone to hear. The first person to yell out "MyPyramid Bingo" must have their answers checked before they are declared 
the winner. To check the card of a person who yells bingo ask them to tell you the name of each food found in their vertical, horizontal or diagonal line. They are a winner if the answers are in a horizontal, vertical or diagonal line and their food names correspond with the foods found on your answer card. Suggestions for prizes would be healthy snacks, MyPyramid mini-poster, etc".

Source: University of Illinois Extension, Food Stamp Nutrition Education 


\section{C4: MyPyramid Bingo Clue Cards}

\begin{tabular}{|c|c|c|c|c|}
\hline $\begin{array}{l}\text { This food belongs to the } \\
\text { fruits group. It is divided } \\
\text { into segments. }\end{array}$ & $\begin{array}{l}\text { This food belongs to } \\
\text { the milk group. Mice } \\
\text { are especially fond of } \\
\text { it. } \\
\text { CHEESE }\end{array}$ & $\begin{array}{l}\text { This food belongs to } \\
\text { the grain group. It } \\
\text { rhymes with ice. }\end{array}$ & $\begin{array}{l}\text { This food belongs to the } \\
\text { milk group. It is enjoyed } \\
\text { when poured on top of } \\
\text { your cereal. } \\
\text { MILK }\end{array}$ & $\begin{array}{l}\text { This food is needed for } \\
\text { good health but in small } \\
\text { amounts. It is not in a food } \\
\text { group but is part of the } \\
\text { MyPyramid. } \\
\text { OILS }\end{array}$ \\
\hline $\begin{array}{l}\text { This food belongs to the } \\
\text { meat \& beans group. It } \\
\text { comes from a pig. } \\
\text { HAM }\end{array}$ & $\begin{array}{l}\text { This food belongs to } \\
\text { the meat \& bean group. } \\
\text { It is often accompanied } \\
\text { by jelly. } \\
\text { PEANUT BUTTER }\end{array}$ & $\begin{array}{l}\text { This food belongs to } \\
\text { the grain group. Slice } \\
\text { it and make your } \\
\text { favorite sandwich. } \\
\text { BREAD }\end{array}$ & $\begin{array}{l}\text { This food belongs to the } \\
\text { vegetable group. It is a } \\
\text { favorite food of rabbits. } \\
\text { CARROT }\end{array}$ & $\begin{array}{l}\text { This food belongs to the } \\
\text { grain group. It comes in a } \\
\text { variety of shapes, served in } \\
\text { salads or topped with sauce. } \\
\text { PASTA }\end{array}$ \\
\hline $\begin{array}{l}\text { This food belongs to the } \\
\text { vegetable group. It grows } \\
\text { underground. It can make } \\
\text { you cry. } \\
\text { ONION }\end{array}$ & $\begin{array}{l}\text { This food belongs to } \\
\text { the fruit group. It is } \\
\text { grown in clusters and } \\
\text { monkeys love to eat it. } \\
\text { BANANA }\end{array}$ & FREE & $\begin{array}{l}\text { This food belongs to the } \\
\text { vegetable group. It is red } \\
\text { and juicy and often the } \\
\text { main ingredient in } \\
\text { sauces. } \\
\text { TOMATO }\end{array}$ & $\begin{array}{l}\text { This food belongs to the } \\
\text { meat \& bean group. It will } \\
\text { crack if dropped. }\end{array}$ \\
\hline $\begin{array}{l}\text { This food belongs to the } \\
\text { meat \& bean group. They } \\
\text { may need to be soaked } \\
\text { before cooking. } \\
\text { BEANS }\end{array}$ & $\begin{array}{l}\text { This food belongs to } \\
\text { the grain group. It is } \\
\text { commonly known as a } \\
\text { breakfast food. } \\
\text { CEREAL }\end{array}$ & $\begin{array}{l}\text { This food belongs to } \\
\text { the grain group. It is } \\
\text { shaped like a donut } \\
\text { with a hole in the } \\
\text { middle. } \\
\text { BAGEL }\end{array}$ & $\begin{array}{l}\text { This food belongs to the } \\
\text { vegetable group. It grows } \\
\text { underground and is very } \\
\text { popular french fried. } \\
\text { POTATO }\end{array}$ & $\begin{array}{l}\text { This food belongs to the milk } \\
\text { group. It comes in many } \\
\text { flavors and fruit is often } \\
\text { added. } \\
\text { YOGURT }\end{array}$ \\
\hline $\begin{array}{l}\text { This food belongs to the } \\
\text { fruits group. It is red, } \\
\text { juicy, and sweet with lots } \\
\text { of tiny seeds. It goes well } \\
\text { with shortcake. } \\
\text { STRAWBERRIES }\end{array}$ & $\begin{array}{l}\text { This food belongs to } \\
\text { the vegetable group. It } \\
\text { looks like a tree. }\end{array}$ & $\begin{array}{l}\text { This food belongs to } \\
\text { the fruit group. It } \\
\text { comes in red, yellow } \\
\text { and green colors. Hot } \\
\text { cider is made from } \\
\text { these. } \\
\text { APPLES }\end{array}$ & $\begin{array}{l}\text { This food belongs to the } \\
\text { meat \& bean group. It is } \\
\text { harvested from the ocean. }\end{array}$ & $\begin{array}{l}\text { This food belongs to the } \\
\text { vegetable group. It grows in } \\
\text { a pod. }\end{array}$ \\
\hline
\end{tabular}




\section{C5: MyPyramid Bingo Answer Sheet}

\begin{tabular}{|c|c|c|c|c|}
\hline \multirow{2}{*}{ ORANGE } & CHEESE & RICE & MILK & OILS \\
\hline HAM & $\begin{array}{c}\text { PEANUT } \\
\text { BUTTER }\end{array}$ & BREAD & CARROT & PASTA \\
\hline ONION & BANANAS & $\begin{array}{c}\text { FREE } \\
\text { SPACE }\end{array}$ & TOMATO & EGG \\
\hline BEANS & CEREAL & BAGEL & POTATO & YOGURT \\
\hline STRAWBERRIES & BROCCOLI & APPLE & TUNA & PEAS \\
\hline
\end{tabular}


MyPyramid Bingo

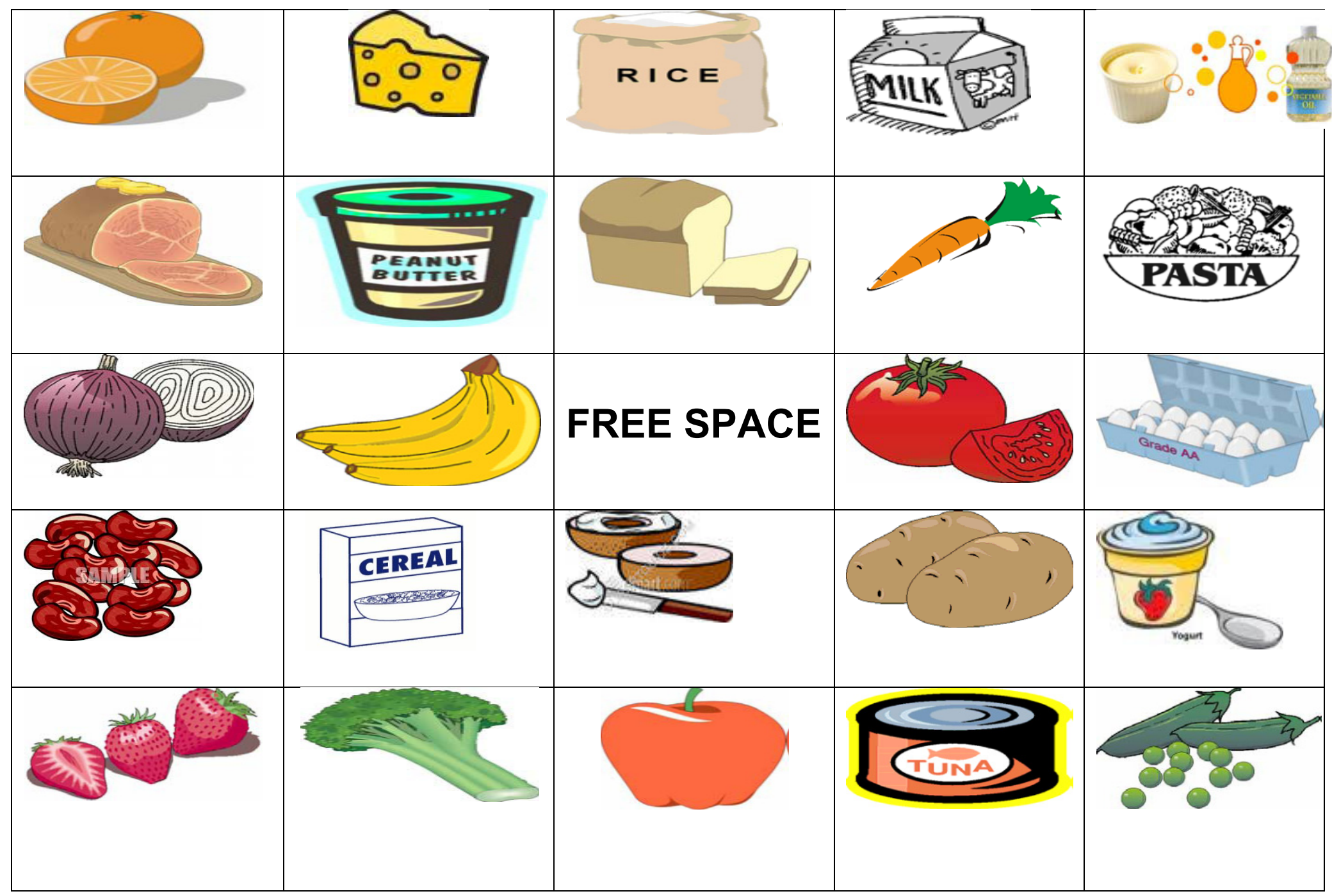


MyPyramid Bingo

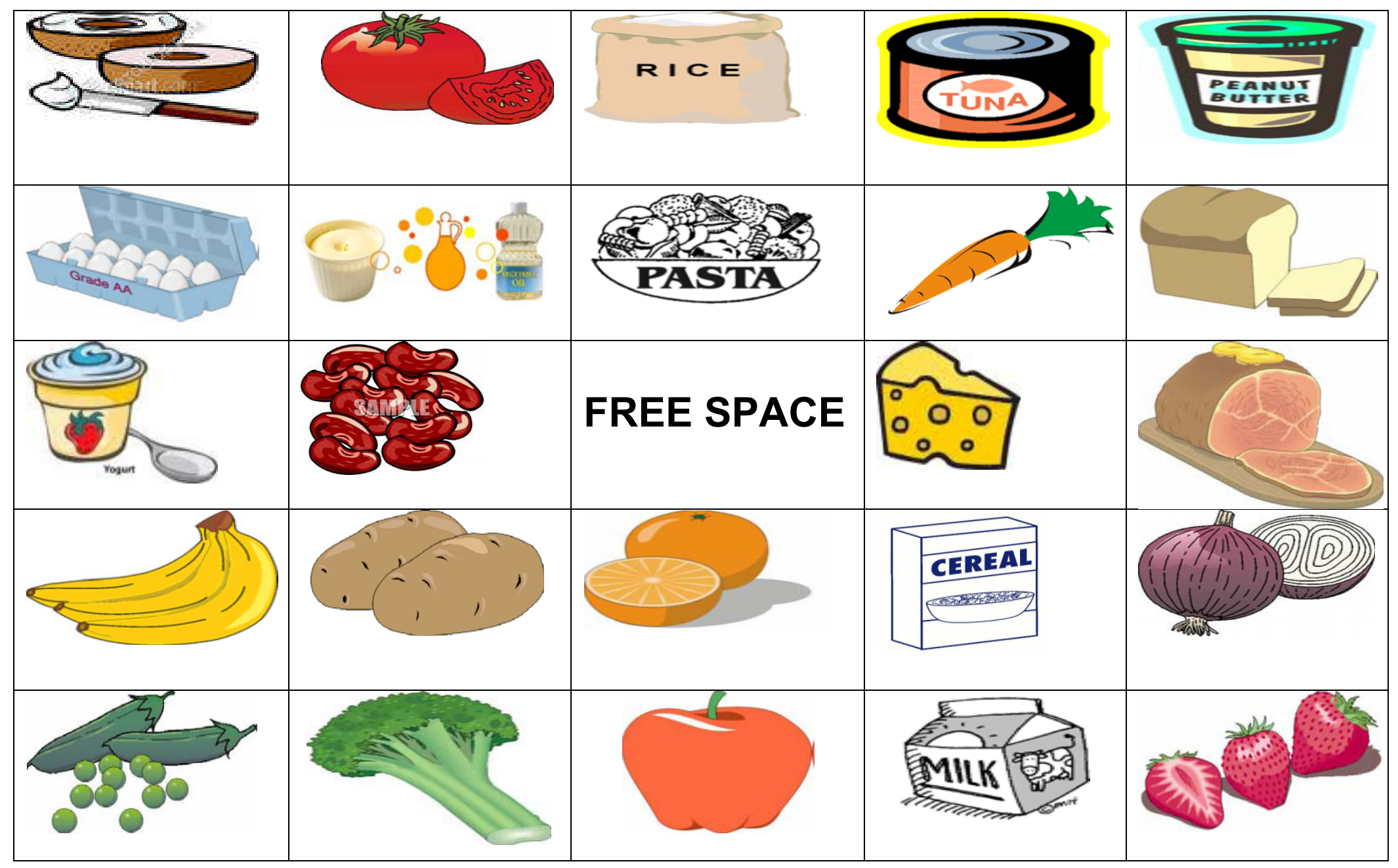


MyPyramid Bingo

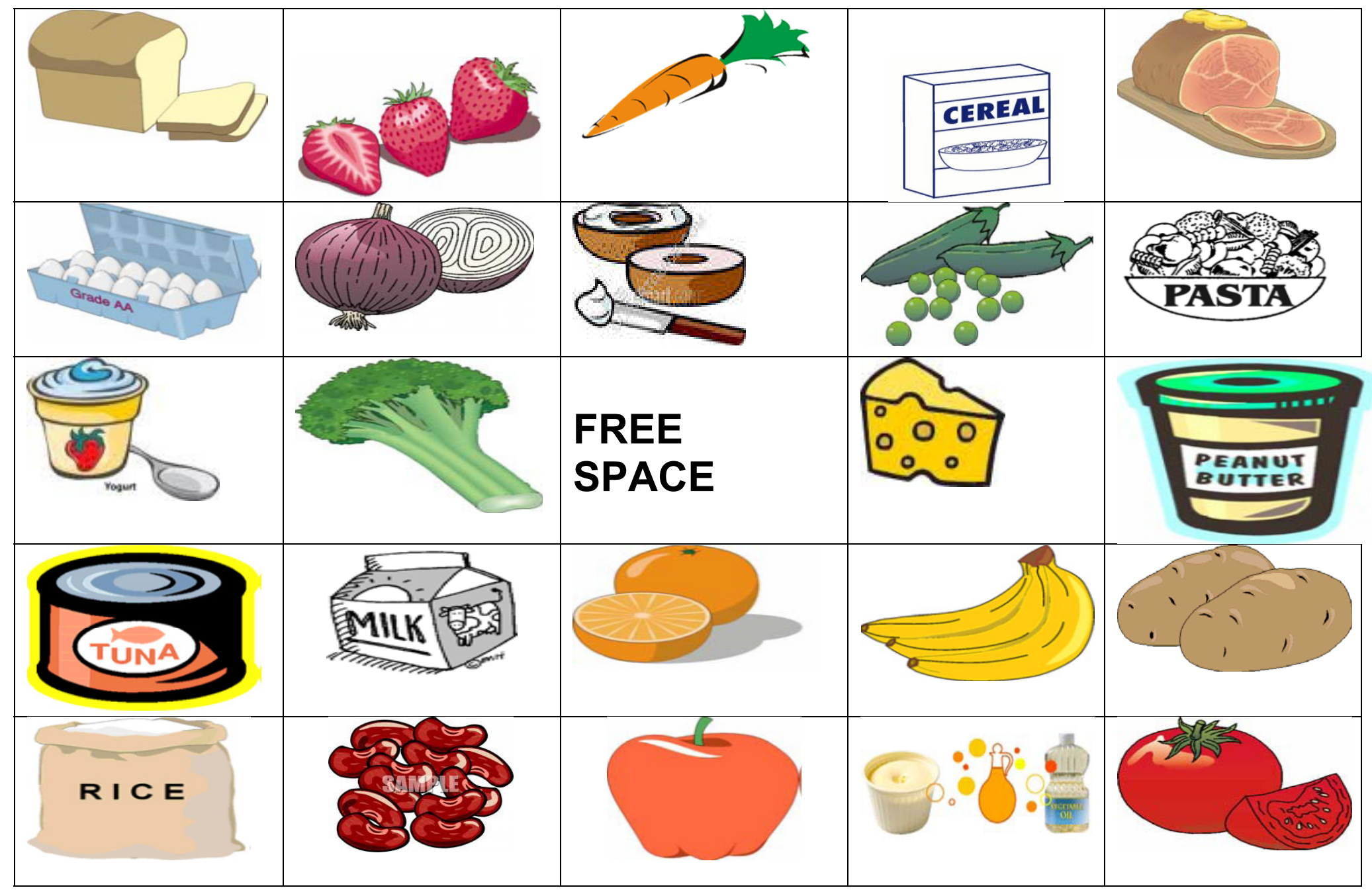




\section{MyPyramid Bingo}

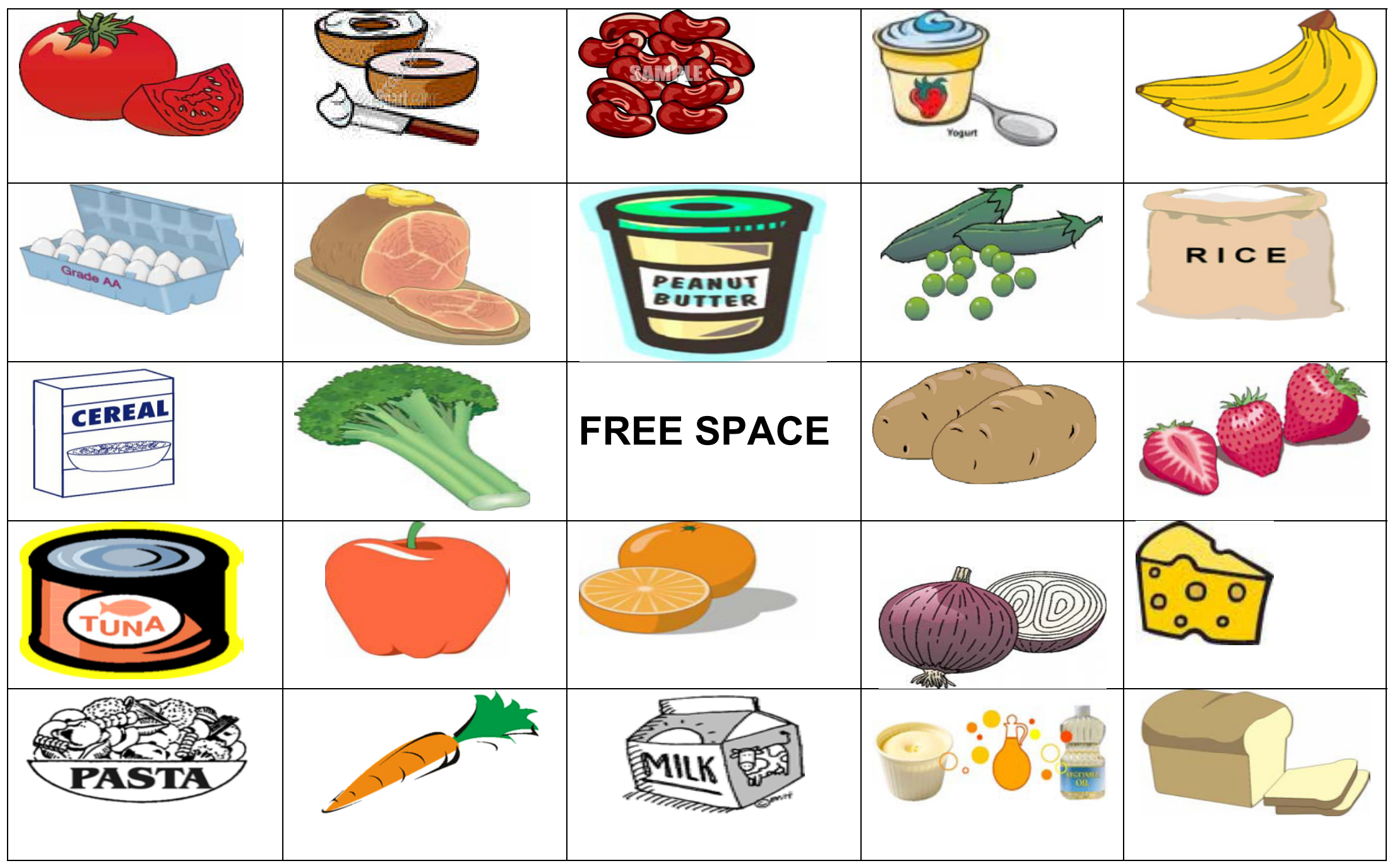


MyPyramid Bingo

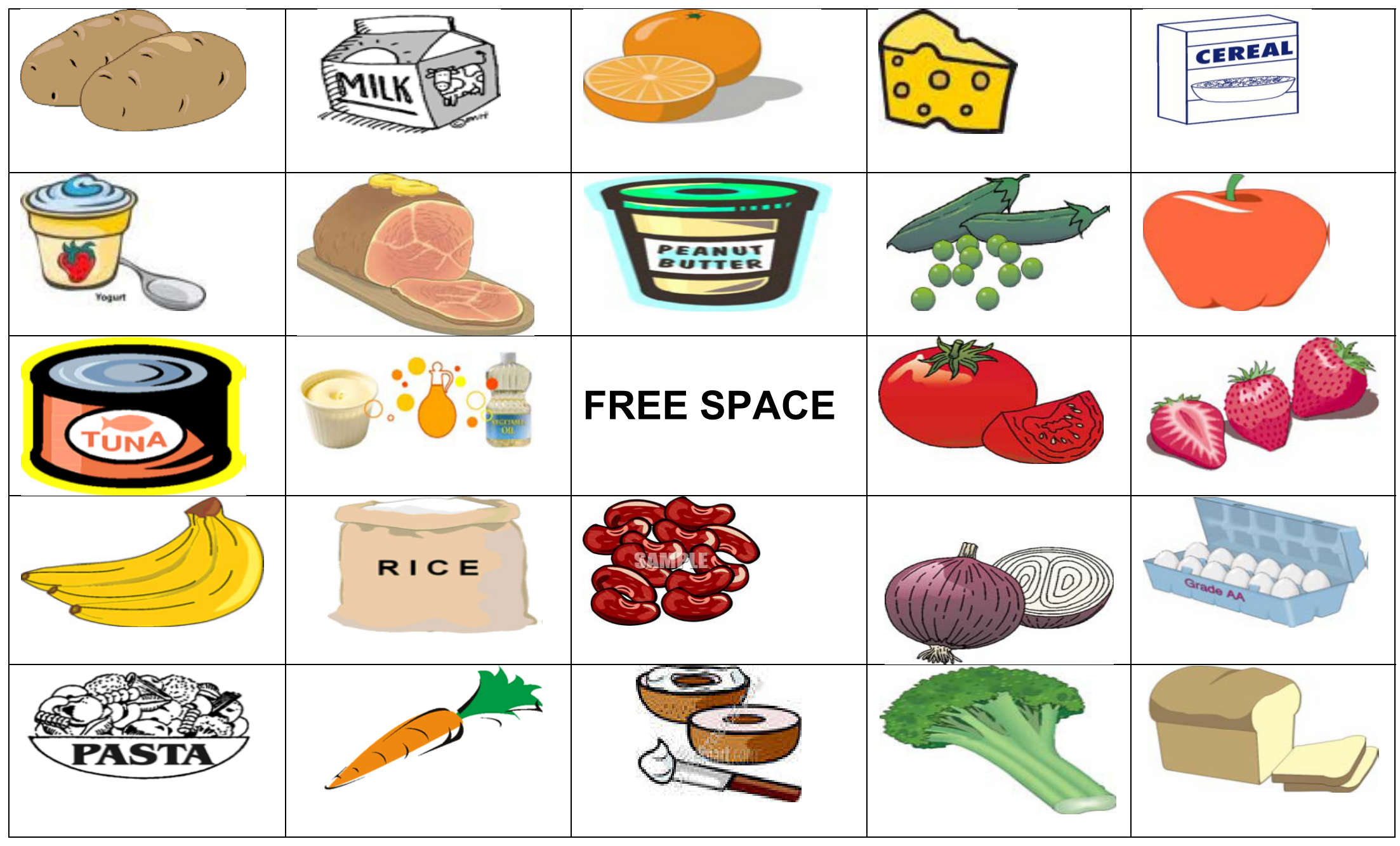




\section{D1: Cooking Meat, Poultry and Seafood Safely Handout}

- Insert the thermometer into the thickest part of the meat and keep it there for $\mathbf{1 5}$ seconds to be sure the meat is the right temperature and safe to eat.

- Beef and pork roasts need to have the correct temperature for $\mathbf{3}$ minutes.

- Clean thermometer (using paper towel soaked with a little rubbing alcohol or alcohol wipe) before and after use!
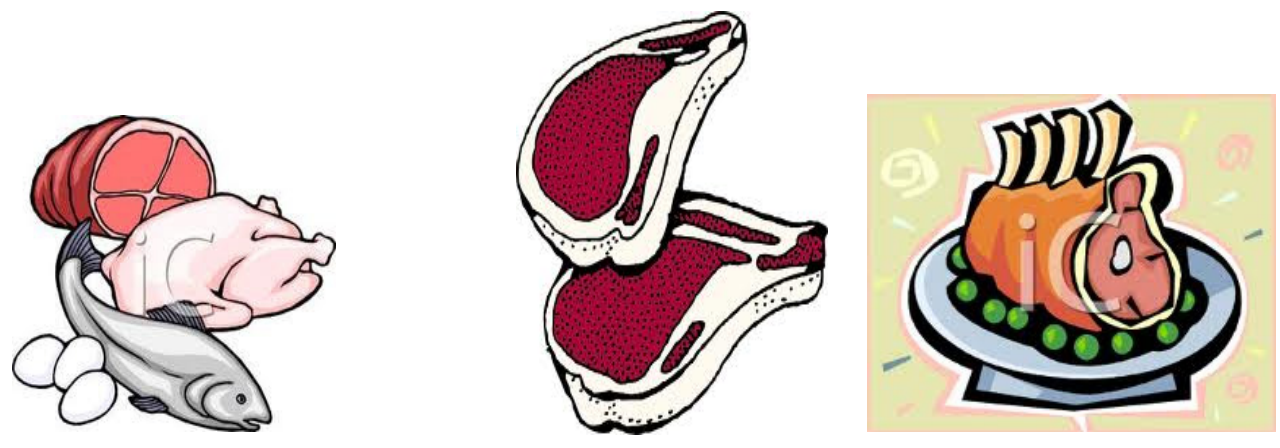

\begin{tabular}{|c|c|}
\hline Type of Meat & Temperature \\
\hline $\begin{array}{c}\text { Poultry } \\
\text { Stuffing } \\
\text { Stuffed Meats }\end{array}$ & $165^{\circ} \mathrm{F}\left(74^{\circ} \mathrm{C}\right)$ \\
\hline $\begin{array}{c}\text { Ground meats } \\
\text { Sausage }\end{array}$ & $155^{\circ} \mathrm{F}\left(68^{\circ} \mathrm{C}\right)$ \\
\hline $\begin{array}{c}\text { Beef roasts } \\
\text { Pork } \\
\text { Lamb } \\
\text { Mutton }\end{array}$ & $145^{\circ} \mathrm{F}\left(63^{\circ} \mathrm{C}\right)$ \\
\hline $\begin{array}{c}\text { Fish } \\
\text { Seafood }\end{array}$ & $145^{\circ} \mathrm{F}\left(63^{\circ} \mathrm{C}\right)$ \\
\hline
\end{tabular}

Source: Sacramento Hunger Commission Nutrition Education Manual 


\section{D2: Food Safety Tips Handout}

- Always wash hands with soap and water before eating or cooking

- Keep your hands, cooking utensils and the kitchen ( e.g. countertops) clean

- Thaw food in the refrigerator

- Keep hot foods hot and cold foods cold.

- Use a food thermometer to be sure meat is fully cooked.

- Refrigerate leftovers immediately

- Foods should not be left at room temperature for more than 2 hours.
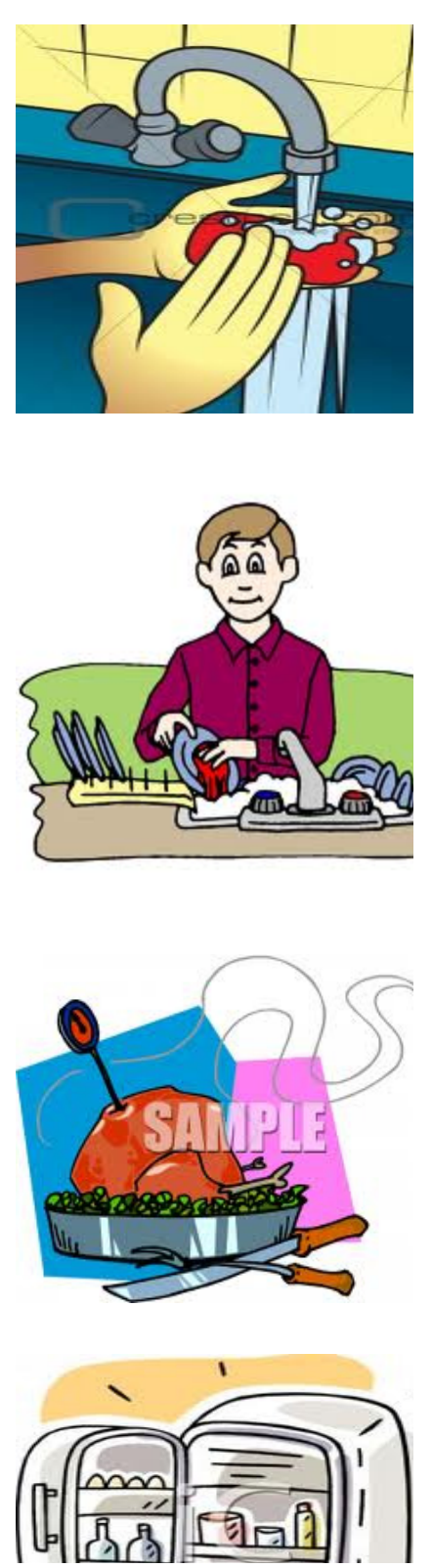

Source: University of Illinois Extension, Food Stamp Nutrition Education 


\section{D3: Food Safety Bingo Game Clues}

\section{Instructions and Clues}

"Listed below are food safety statements. Cut food safety statements into strips.

Place the strips of paper into a container. Draw these strips from the container one at a time. Read the strip and ask participants to look for that food safety fact on their bingo cards. Dried beans, buttons, etc. can be used for the bingo card game pieces.

1. Bacteria can be everywhere so always wash hands in warm, soapy water for at least 20 seconds before preparing food and after handling raw meat, poultry and fish/seafood products.

2. When unsure if the food is safe to eat, never taste it. Be on the safe side and dispose of it properly.

3. Never leave perishable food out of the refrigerator or cooler over 2 hours or longer than 1 hour in hot weather (90 degrees $\mathrm{F}$ or hotter). Bacteria can grow quickly at room temperature.

4. Never place the cooler in the trunk of the car or in the sun on warm or hot summer days. Food within the cooler should be kept cold ( 40 degree $F$ or less).

5. Never partially cook food and then wait to finish cooking it. This practice encourages the growth of bacteria by keeping the food at the temperature where bacteria multiply fastest. If you do precook meats, immediately finish cooking it.

6. Do not thaw food on the counter top at room temperature. Bacteria can multiply very quickly. The safest way to thaw foods is in the refrigerator.

7. Do not allow time for bacteria to grow. Food should remain no longer than 2 hours at room temperature and no more than 1 hour in hot weather (90 degrees $\mathrm{F}$ or above). Put leftovers in the refrigerator or cooler immediately after eating. 
8. A good sanitizing solution is 1 tablespoon unscented, liquid chlorine bleach to 1 gallon of water. Allow sanitizing solution to sit for a few minutes on the surface of the item being sanitized before washing it off.

9. To help control the growth of bacteria that may be in food, keep cold foods cold, below 40 degrees F and keep hot foods hot, above 140 degrees F.

10. Any beef can be contaminated with E. coli. A temperature of 160 degrees $F$ held for 15 seconds will kill these bacteria. Use a thermometer inserted in the middle of the meat to make sure it has been cooked enough to reach the recommended internal temperature.

11. Use clean utensils to remove cooked food from the stove or grill and place cooked food on a clean plate. Never put the cooked food back on the plate that held the raw product.

12. Do not use cutting boards that have become pitted, chipped or cracked.

Bacteria can hide in these areas and be very difficult to clean. When possible have two separate cutting boards...one for use with meat only.

13. Research shows that most of foodborne illness originates in people's homes.

14. Divide large amounts of leftovers into small shallow (2-inch or less deep) containers for quick cooling in the refrigerator.

15. Marinades are a good way to tenderize tougher cuts of meat. Be sure to marinate food in the refrigerator.

16. Although you can't see, taste or often smell harmful bacteria, they can be anywhere---in the air, in the soil, and on/in humans and animals.

17. Bacteria like to grow in warm temperatures. Warm weather is also the time people like to cook outdoors...providing ideal opportunities for foodborne illness to occur.

18. Use a separate cooler for drinks so the one containing perishable food won't be constantly opened and closed.

19. Perishable foods refrigerated at 40 degrees $\mathrm{F}$ or below will slow down the growth of most bacteria. 
20. Make sure all food preparation areas and utensils that will touch food are clean.

21. Ground beef cooked rare or medium rare is not recommended because $E$. coli bacteria present may not be destroyed. Use a food thermometer to check and make sure ground beef reaches an internal temperature of 160 degrees $F$ for 15 seconds.

22. To limit flare-ups and charred meat, remove visible fat prior to grilling.

23. Fully cooked foods like hot dogs/frankfurters and leftovers should be cooked to 165 degrees $\mathrm{F}$ or until steaming hot.

24. Do not re-use marinade that has been used for basting on raw meat, poultry or fish/seafood.

25 . The safest way to thaw food is in the refrigerator.

26. Studies show that most cases of foodborne illness could have been avoided with proper food handling.

27. After thoroughly cooking foods, they should be held above 140 degrees $F$ until serving time.

28. Using a food thermometer takes the guesswork out of determining when food is done. It can also help prevent foodborne illness, overcooking of food, and help hold foods at a safe temperature.

29. Foods thawed in the microwave can reach a temperature that encourages bacteria growth therefore it is important to finish cooking those foods immediately after thawing.

30. Leftover foods should be reheated to 165 degrees $\mathrm{F}$ or brought to a rolling boil.

31. Poultry products can contain Salmonella bacteria. By cooking poultry to 165 degrees $\mathrm{F}$, these bacteria can be destroyed.

32. To minimize the presence of bacteria, be sure the grill is clean and hot (charcoals should be grayish-white) before beginning to grill food".

Source: University of Illinois Extension, Food Stamp Nutrition Education 


\section{D4: Food Safety Bingo Answers}

(1) Wash hands before handling food

(2) When in doubt throw it out

(3) Refrigerate leftovers promptly

(4) Keep coolers in the shade

(5) Never partially cook food

(6) Never thaw food at room temperature

(7) Serve hot grilled food immediately

(8) Chlorine bleach is a good sanitizer

(9) Keep foods out of the "Danger Zone"

(10) Cook ground beef to 160 degrees $F$

(11) Use clean utensils and plates with cooked food

(12) Throw away worn cutting boards

(13) Most foodborne illness begins at home

(14) Put leftovers in small containers

(15) Marinate food in the refrigerator

(16) Bacteria can be anywhere

(17) During warm summer months the risk of foodborne illness rises

(18) Use separate coolers for beverages and food

(19) Keep cold foods cold

(20) Keep everything clean when preparing food

(21) Do not eat raw or undercooked ground beef 
(22) Before grilling, remove visible fat to limit flare-ups

(23) Fully cooked foods and leftovers should be reheated to 165 degrees F

(24) Reserve unused marinades for basting cooked food

(25) Use the refrigerator to thaw foods safely

(26) Most foodborne illness can be prevented

(27) Keep hot foods hot

(28) Use a meat thermometer

(29) Immediately cook foods thawed in the microwave

(30) Reheat foods properly

(31) Cook poultry to 165 degrees $F$

(32) Before grilling food have the grill/coals hot

Source: University of Illinois Extension, Food Stamp Nutrition Education 


\section{D5: FOOD SAFETY BINGO CARD}

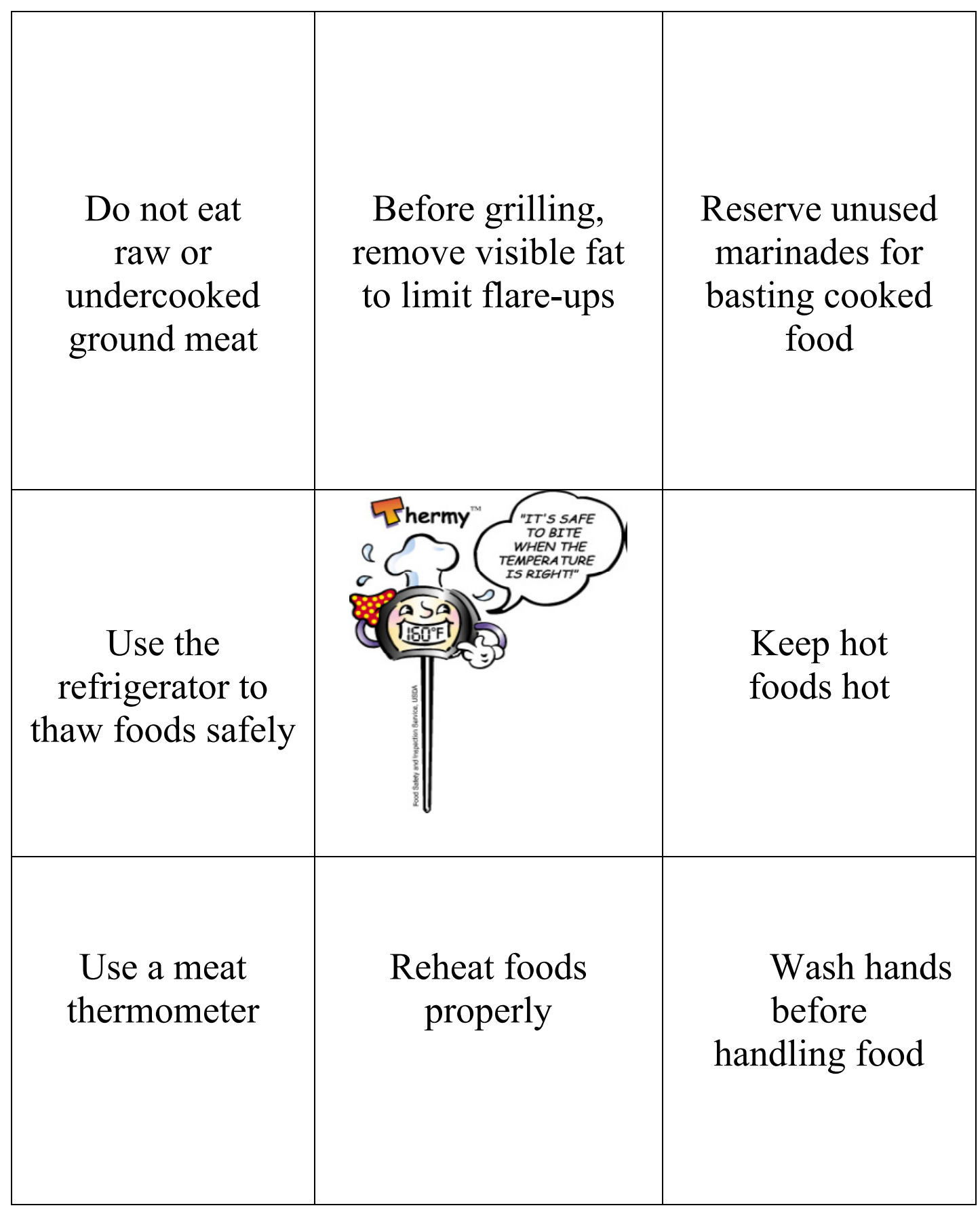

Source: University of Illinois Extension, Food Stamp Nutrition Education 


\section{FOOD SAFETY BINGO CARD}

\begin{tabular}{|c|c|c|}
\hline $\begin{array}{c}\text { Immediately cook } \\
\text { foods thawed in } \\
\text { the microwave }\end{array}$ & $\begin{array}{c}\text { Reheat foods } \\
\text { properly }\end{array}$ & $\begin{array}{c}\text { Cook poultry } \\
\text { to } 165^{\circ} \mathrm{F}\end{array}$ \\
\hline $\begin{array}{c}\text { Before grilling } \\
\text { food have the } \\
\text { grill/coals hot }\end{array}$ & \\
\hline
\end{tabular}

Source: University of Illinois Extension, Food Stamp Nutrition Education 
FOOD SAFETY BINGO CARD

\begin{tabular}{|c|c|c|}
\hline $\begin{array}{c}\text { Wash hands } \\
\text { before } \\
\text { handling food }\end{array}$ & $\begin{array}{l}\text { When in doubt } \\
\text { throw it out }\end{array}$ & $\begin{array}{l}\text { Cook poultry } \\
\text { to } 165^{\circ} \mathrm{F}\end{array}$ \\
\hline $\begin{array}{l}\text { Keep coolers } \\
\text { in the shade }\end{array}$ & & $\begin{array}{c}\text { Never partially } \\
\text { cook food }\end{array}$ \\
\hline $\begin{array}{c}\text { Never thaw food } \\
\text { at room } \\
\text { temperature }\end{array}$ & $\begin{array}{l}\text { Serve hot } \\
\text { grilled food } \\
\text { immediately }\end{array}$ & $\begin{array}{l}\text { Chlorine bleach } \\
\text { is a good sanitizer }\end{array}$ \\
\hline
\end{tabular}

Source: University of Illinois Extension, Food Stamp Nutrition Education 
FOOD SAFETY BINGO CARD

\begin{tabular}{|c|c|c|}
\hline $\begin{array}{c}\text { Refrigerate } \\
\text { leftovers } \\
\text { promptly }\end{array}$ & $\begin{array}{l}\text { Keep coolers } \\
\text { in the shade }\end{array}$ & $\begin{array}{l}\text { Never partially } \\
\text { cook food }\end{array}$ \\
\hline $\begin{array}{c}\text { Never thaw food } \\
\text { at room } \\
\text { temperature }\end{array}$ & Thermy" & $\begin{array}{l}\text { Serve hot } \\
\text { grilled food } \\
\text { immediately }\end{array}$ \\
\hline $\begin{array}{l}\text { Chlorine bleach } \\
\text { is a good sanitizer }\end{array}$ & $\begin{array}{c}\text { Keep foods } \\
\text { out of the } \\
\text { "Danger Zone" }\end{array}$ & $\begin{array}{c}\text { Cook ground beef } \\
\text { to } 160^{\circ} \mathrm{F}\end{array}$ \\
\hline
\end{tabular}

Source: University of Illinois Extension, Food Stamp Nutrition Education 


\section{FOOD SAFETY BINGO CARD}

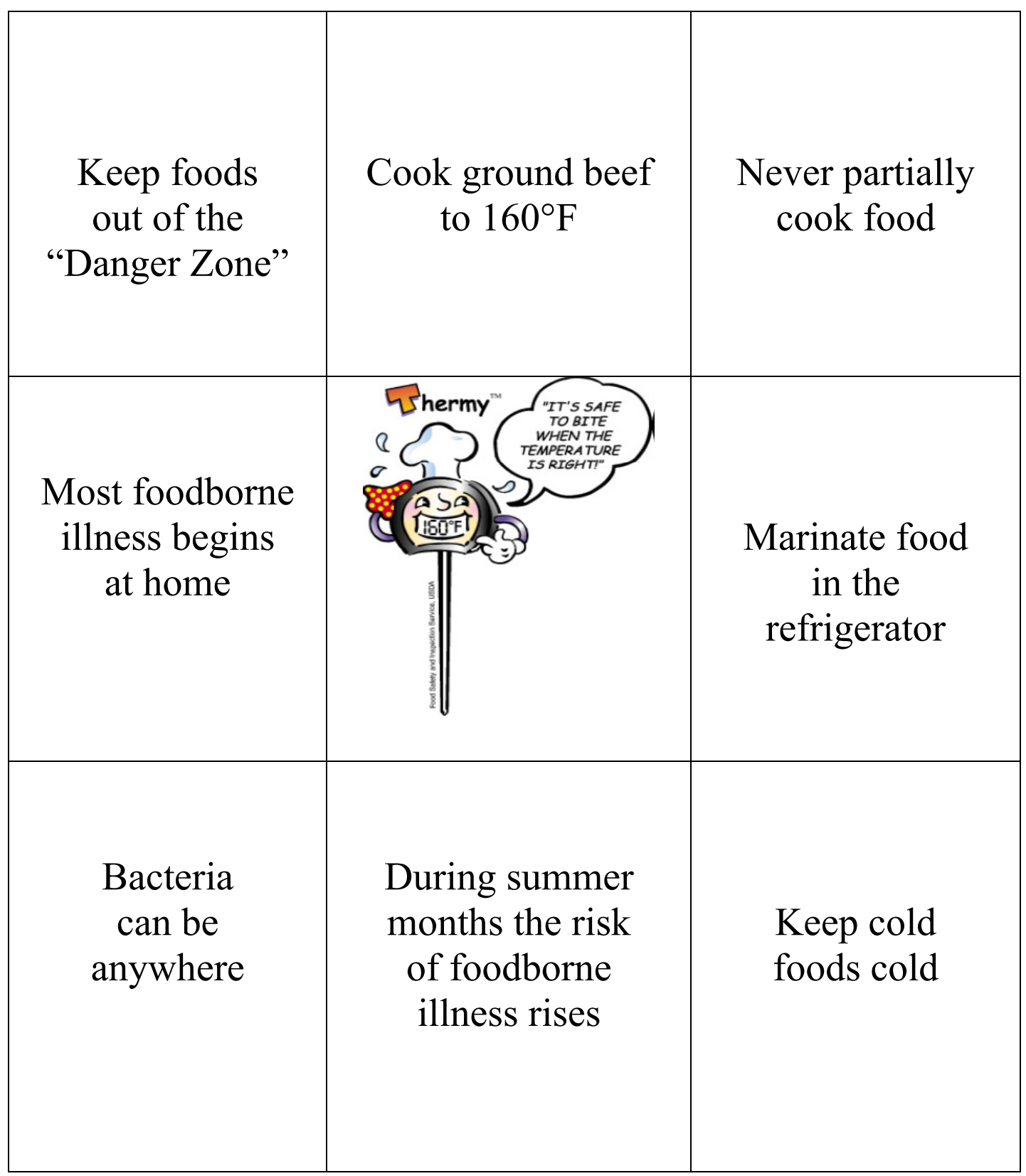

Source: University of Illinois Extension, Food Stamp Nutrition Education 
Appendix B: Consent Forms 


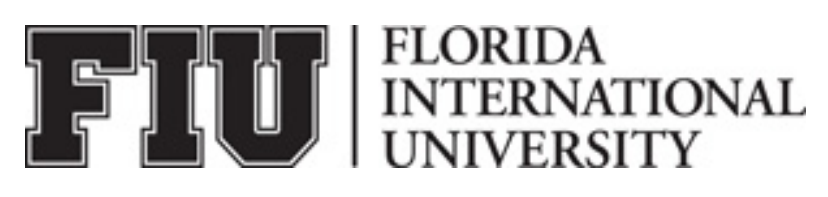

\section{ADULT CONSENT TO PARTICIPATE IN A RESEARCH STUDY OBSERVATIONAL STUDY}

\section{Participation in the Food Stamp Program by low income HIV infected Adults: \\ Effect on Nutrition and Health Outcomes}

\section{PURPOSE OF THE STUDY}

You are being asked to participate in a research study. The purpose of this study is to assess the impact of the food-stamp program on nutrition, HIV disease, perceived health and quality of life of people living with HIV who are eligible for food and nutrition programs. Additionally, the study will be used to identify nutrition concerns of people living with HIV as well as barriers to participation in the food stamp program among HIV infected eligible non-participants.

\section{NUMBER OF STUDY PARTICIPANTS}

If you decide to be in this study, you will be one of 214 people in this research study.

\section{DURATION OF THE STUDY}

Your participation will require about 45 minutes to 1 hour of your time.

\section{PROCEDURES}

If you agree to be in the study, we will ask you to do the following things: 
1. Complete study questionnaires and complete body composition measurements. The questionnaires will assess information about you, your nutrition and health status, as well as nutritional concerns.

2. Bring a copy of your current labs (not older than 3 months from the day of your initial visit)

\section{RISKS AND/OR DISCOMFORTS}

This study does not pose any substantial risk to you, since you will only be completing a questionnaire and undergoing body composition measurements. We do, however, realize that release of confidential data may occur despite all our measures to maintain confidentiality. As such, specific identification numbers will be used to code your information during collection, handling and management, to prevent identification of your data. All data collected will be protected by passwords, and access to the data will be limited to the investigators.

\section{BENEFITS}

This study will help determine the impact that the food stamp program has on the nutrition and health status of adults living with HIV. It will also help identify barriers to participation in the food assistance programs of HIV infected adults who are eligible but not participating in this type of program. The information obtained by this study will assist program administrators in identifying and targeting those who need greater outreach efforts in order to maximize Food Stamp Program participation, and improve nutritional services and benefits to people living with HIV. 


\section{ALTERNATIVES}

You always have the alternative of not participating or withdraw from the study at any time. You will be informed of any significant new finding developed during the course of the research which may affect your willingness to continue participating.

\section{CONFIDENTIALITY}

The records of this study will be kept private and will be protected to the fullest extent provided by law. Publication of results will not include any information that will make it possible to identify a participant. Research records will be stored securely and only the researcher team will have access to the records. The U.S. Department of Health and Human Services (DHHS) and/or the Food and Drug Administration (FDA) may request to review and obtain copies of your records. Your records may also be reviewed for audit purposes by authorized University staff or other agents who will be bound by the same provisions of confidentiality.

\section{COMPENSATION \& COSTS}

You will be reimbursed for your time and any other expenses with $\$ 10$.

\section{MEDICAL TREATMENT}

Routinely, FIU, its agents, or its employees do not compensate for or provide free care for human subjects in the event that any injury results from participation in a research project. If you become ill or injured as a direct result of participating in this study, contact your regular medical provider. If you have insurance, your insurance company may or may not pay for these costs. If you do not have insurance, or if your insurance company refuses to pay, you will be billed. Funds to compensate for pain, expenses, lost wages and other damages caused by injury are not routinely available. 


\section{RIGHT TO DECLINE OR WITHDRAW}

Your participation in this study is voluntary. You are free to participate in the study or withdraw your consent at any time during the study. Your withdrawal or lack of participation will not affect any benefits to which you are otherwise entitled. The investigator reserves the right to remove you without your consent at such time that they feel it is in your best interest or that of the research.

\section{RESEARCHER CONTACT INFORMATION}

If you have any questions about the purpose, procedures, or any other issues relating to this research study you may contact my advisor, Dr. Adriana Campa at 305-348-2871, or me (Irene Hatsu) at 540-797-6662, or ihats001@fiu.edu.

\section{IRB CONTACT INFORMATION}

If you would like to talk with someone about your rights of being a subject in this research study or about ethical issues with this research study you may contact the FIU Office of Research Integrity by phone at 305-348-2494 or by email at ori@fiu.edu.

\section{PARTICIPANT AGREEMENT}

I have read the information in this consent form and agree to participate in this study. I have had a chance to ask any questions I have about this study, and they have been answered for me. I understand that I am entitled to a copy of this form after it has been read and signed. 
Printed Name of Participant

Signature of Person Obtaining Consent

Date 


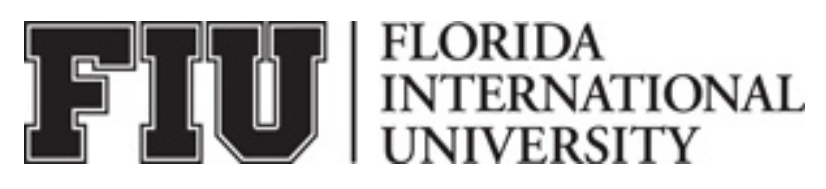

\section{ADULT CONSENT TO PARTICIPATE IN A RESEARCH STUDY INTERNEVTION STUDY}

Participation in the Supplemental Nutrition Assistance Program (SNAP) by low income HIV infected Adults: the Effect of a Nutrition Education Intervention PURPOSE OF THE STUDY

You are being asked to be in a research study for 12 months. The purpose of this study is to determine the effectiveness of a nutrition education intervention in improving nutritional status, health status and disease progression through increases in nutrition knowledge, and self-confidence in healthy dietary habits and nutrient intake among low income HIV infected adults.

\section{NUMBER OF STUDY PARTICIPANTS}

If you decide to be in this pilot study, you will be one of 60 people in this research study.

\section{DURATION OF THE STUDY}

Your participation will require 45-60 minutes of your time twice a month for two consecutive months. There will also be one 30-45 minutes assessment prior to and two such visits after intervention visits.

\section{PROCEDURES}

This study will compare 3 groups to determine the effectiveness of nutrition education in improving nutrition and health outcomes. If you agree to be in the study, we will ask you to do the following things: 
3. You will be randomly assigned to either of three groups, and asked to complete study questionnaires. The questionnaires will be administered at three time points; prior to the nutrition education, at the end of the 4 education sessions, and 3 months after the education sessions.

4. You will be required to attend nutrition education sessions twice a month for two consecutive months. In the sessions, the investigator will present you with information in 45 minutes to an hour.

5. You will be required to complete physical assessment at three time points; prior to the nutrition education, at the end of the 4 education sessions, and 3 months after the education sessions.

6. You will be required to bring your current labs (not older than 3 months from the day of the assessment) prior to the nutrition education, and 3 months after the education sessions.

\section{RISKS AND/OR DISCOMFORTS}

This proposed study does not pose any substantial risk to you since the intervention is to provide nutrition education. We do, however, realize that breach of data confidentiality is possible. As such, specific identification numbers will be used during collection, handling and management. All data collected will be encrypted and protected by passwords, and access to the data will be limited to the investigators.

\section{BENEFITS}

The benefits for participation in this study include gaining nutrition knowledge, being able to set dietary goals and increasing self confidence. The study will also support 
efforts to empower and engage low income HIV infected individuals to improve dietary practices.

\section{ALTERNATIVES}

There are no known alternatives available to you other than not taking part in this study. However, any significant new findings developed during the course of the research which may relate to your willingness to continue participation will be provided to you.

\section{CONFIDENTIALITY}

The records of this study will be kept private and will be protected to the fullest extent provided by law. In any sort of report we might publish, we will not include any information that will make it possible to identify a subject. Research records will be stored securely and only the researcher team will have access to the records. Data will be coded, de-identified, encrypted and passworded. The U.S. Department of Health and Human Services (DHHS) and/or the Food and Drug Administration (FDA) may request to review and obtain copies of your records. Your records may also be reviewed for audit purposes by authorized University or other agents who will be bound by the same provisions of confidentiality.

\section{COMPENSATION \& COSTS}

You will be reimbursed for your time and any other expenses at \$10 for the initial visit and for two subsequent assessment contacts. You will receive snacks and incentives (e.g. grocery store gift card) during each education session.

\section{MEDICAL TREATMENT}

Routinely, FIU, its agents, or its employees do not compensate for or provide free care for human subjects in the event that any injury results from participation in a research 
project. If you become ill or injured as a direct result of participating in this study, contact your regular medical provider. If you have insurance, your insurance company may or may not pay for these costs. If you do not have insurance, or if your insurance company refuses to pay, you will be billed. Funds to compensate for pain, expenses, lost wages and other damages caused by injury are not routinely available.

\section{RIGHT TO DECLINE OR WITHDRAW}

Your participation in this study is voluntary. You are free to participate in the study or withdraw your consent at any time during the study. Your withdrawal or lack of participation will not affect any benefits to which you are otherwise entitled. The investigator reserves the right to remove you without your consent at such time that they feel it is in the best interest.

\section{RESEARCHER CONTACT INFORMATION}

If you have any questions about the purpose, procedures, or any other issues relating to this research study you may contact my advisor, Dr. Adriana Campa at 305-348-2871, or me (Irene Hatsu) at ihats001@fiu.edu.

\section{IRB CONTACT INFORMATION}

If you would like to talk with someone about your rights of being a subject in this research study or about ethical issues with this research study, you may contact the FIU Office of Research Integrity by phone at 305-348-2494 or by email at ori@fiu.edu.

\section{PARTICIPANT AGREEMENT}

I have read the information in this consent form and agree to participate in this study. I have had a chance to ask any questions I have about this study, and they have been 
answered for me. I understand that I am entitled to a copy of this form after it has been read and signed.

Signature of Participant

Date

Printed Name of Participant

Signature of Person Obtaining Consent

Date 
Appendix C1: Screening Questionnaire 
1. Age: years.

2. Are you HIV positive? $\square_{1}$ Yes $\quad \square_{2}$ No

3. HIV status was determined on ___

4. Do you receive food stamps? $\square_{1}$ Yes $\quad \square_{2}$ No

4a. If yes, how many months have you received food stamps in the past 12 months?

4b. If no, I would like to screen you using the Food Stamp Program Prescreening tool to see if you qualify.

4bi. Eligible for Food Stamp; $\quad \square_{1}$ Yes $\quad \square_{2}$ No

\section{ELIGIBILITY LIST:}

If the answer to any of these conditions is NO, the participant is ineligible

\begin{tabular}{|l|l|l|}
\hline \multicolumn{1}{|c|}{ Inclusion Criteria } & YES & NO \\
\hline HIV positive & & \\
\hline Age $\geq 18$ years & & \\
\hline Participant of Food Stamp Program & & \\
\hline Eligible non-participant of Food Stamp Program & & \\
\hline Signature on consent & & \\
\hline
\end{tabular}


Appendix C2: Observational Cross-Sectional Study Questionnaire 


\section{A. Demographic Data}

For these questions, please circle your answers or write your answers in the spaces provided.

1. Gender: $\square_{1}$ Male $\square_{2}$ Female

2. Age: years.

3. Which of the following best describes your ethnic background?

$\square$ Black/African American

]$_{4}$ Hispanic American

$\square_{2}$ Asian American

$\square 3$
$\square$ Non-Hispanic White
$\square$ Other (specify):

4. In what country were you born?

$\square_{1}$ United States

$\square 2$ US Territory (Puerto Rico, Guam, Virgin Islands)

$\square_{3}$ Other country (Specify

$\square_{4}$ Unknown

5. Status: $\square_{1}$ Married $\square_{2}$ Single $\square_{3}$ Divorced/Widowed $\square_{4}$ Other

5. Please check your highest level of education.

$\square_{1}<$ High school

$\square_{3} 1-2$ years college

$\square 2$ High school or GED

$\square_{4}$ Graduated from college 6. Child Status: $\square_{1}$ Children at home $\square_{2}$ Children not at home $\square_{3}$ No Children

7. How many people live in your household?

8. Please check your highest level of education.

$\square_{1}<$ High school,

$\square$ 1-2 years college $\square 2$ High school or GED

$\square 4 \geq$ College degree

9. Work Status:

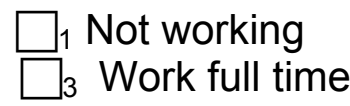

$\square_{2}$ Work Part-time, $\square_{4}$ On disability

10. What is your monthly income?

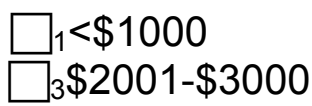

$\square_{3}$ Work full time

11. Do you live: $\square_{1}$ Alone $\quad \square_{2}$ With your family (parents, husband, children, etc) $\square_{3}$ Shelter $\square_{4}$ Street 
12. Do you smoke cigarettes?

12a. If yes how often?
$\square_{1}$ Daily
]$_{2}$ 4-6 times a week
$\square$ 2-3 times a week
$\square_{4}$ Once a week
$\square$ Less than once a month
$\square_{6}$ At least once a month but less than once a week
$\square$ Never

12b. If daily how many cigarettes per day

13. Do you use any drugs? $\square_{1}$ Yes $\square_{2}$ No

13a.If yes check all that apply: Marijuana $\square_{1}$ Cocaine $\square_{2}$ Crack $\square_{3}$ Heroin $\square_{4}$ Combination (Speedball) $\square_{5}$ Methadone $\square_{6}$ Amphetamine (Ecstasy) $\square_{7}$ Other $\square_{8}$

14. Do you drink alcohol? $\quad \square_{1}$ Yes $\square_{2}$ No

14a. If yes how often?

$\square_{1}$ Daily

$\square_{2}$ 4-6 times a week

$\square$, 2-3 times a week

$\square$ once a week

$\square$ Less than once a month

$\square_{6}$ At least once a month but less than once a week

$\square_{7}$ Never

14b. If daily how many drinks per day?

----- Beer drinks

----- Wine drinks

----- Liquor drinks

-------Total drinks

15. Do you use ART? $\square_{1}$ Yes $\quad \square_{2}$ No

15a. List of medications (1)

(2)

(3)

(4)

(5)

16. Do you take multivitamins?

16a. If yes please list them. 1)

$\square_{1}$ Yes $\square_{2}$ No 2)

3)

4)

5) 
17. Do you receive food stamps? $\square_{1}$ Yes $\square_{2}$ No

17a. If yes, how many months have you received food stamps in the past 12 months?

18. In the last 30 days, did you receive any foods to take home from community sources such as a food bank, food pantry, or other sources?

$\square_{1}$ Yes $\square_{2}$ No

19. In the past 30 days did you eat any meals at a soup kitchen, the Salvation Army, a family shelter, or another similar place? $\square_{1}$ Yes $\quad \square_{2}$ No

\section{B. Barriers}

There are many different reasons why people who qualify for food stamps do not participate. Here are some reasons that people give, as to why they would not participate in the food stamp program. Please indicate which of these is/are the reason(s) why you do not participate.

14b. If no, what are your reasons for not participating:

$\square$ Was denied

$\square_{2}$ Don't think I'm eligible

$\square$, Too hard to apply

$\square_{4}$ Worried about my citizenship status

$\square_{5}$ Didn't think about it

$\square$ 6 Didn't know about them

$\square_{7}$ Can't get to the Food Stamp Office $\square 9$ Don't need them

$\square$ 10 Don't know how to get them

$\square 11$ Don't want government help

$\square 12$ Too embarrassed to use them

$\square_{13}$ Disqualified due to misuse

$\square 14$ Refuse

$\square_{15}$ Other (describe)

$\square_{8}$ No store accepts Food Stamp in my area

\section{Sources of Nutrition Information}

Which of the following would you most likely trust as a source of nutrition or dietary information?

$\square$ Case Manager

$\square 2$ Doctor

$\square$ Dietitian

$\square 4$ Internet

$\square_{5}$ Radio $\square$ 6 Television

$\square 7$ Family and Friends

$\square$ 8 Science/Research

$\square$ O Other 


\section{Nutritional Concerns}

(I) Most HIV+ individuals have nutrition related needs. If you have any nutritional needs, we would like to what they are so a Dietitian/ Nutritionist can assist you with them.

Please check all that apply:

$\square_{1}$ I would like information on how to shop healthy

$\square_{2}$ I would like education on how to shop on a limited budget

$\square_{3}$ I would like information on how to cook healthy/ diet modification

$\square_{4}$ I would like information on strategies to overcome nutritional side effects related to HIV medication intake

$\square_{5}$ I would like education on food safety

$\square$ 6 I would like information on how to lose weight

$\square_{7}$ I would like information on how to gain weight

$\square_{8}$ I would like information on how to maintain my weight

$\square 9 \quad$ I would like information on exercise

$\square_{10}$ I would like information on how to cope with stress

$\square_{11}$ I would like information on how to cope with fatigue

$\square_{12}$ I would like education on how to read food labels

$\square_{13}$ I would like information on how to eat out healthy 


\section{(II) Dietary Habits}

\begin{tabular}{|c|c|c|c|c|c|c|}
\hline $\begin{array}{l}\text { 1) How often do you plan meals } \\
\text { ahead of time? }\end{array}$ & $\begin{array}{l}\text { Does not } \\
\text { apply }\end{array}$ & Never & Seldom & $\begin{array}{l}\text { Some- } \\
\text { times }\end{array}$ & $\begin{array}{l}\text { Most of } \\
\text { the time }\end{array}$ & $\begin{array}{l}\text { Almost } \\
\text { always }\end{array}$ \\
\hline $\begin{array}{l}\text { 2) How often do you compare } \\
\text { prices before you buy food? }\end{array}$ & $\begin{array}{l}\text { Does not } \\
\text { apply }\end{array}$ & Never & Seldom & $\begin{array}{l}\text { Some- } \\
\text { times }\end{array}$ & $\begin{array}{l}\text { Most of } \\
\text { the time }\end{array}$ & $\begin{array}{l}\text { Almost } \\
\text { always }\end{array}$ \\
\hline $\begin{array}{l}\text { 3) How often do you run out of } \\
\text { food before the end of the } \\
\text { month? }\end{array}$ & $\begin{array}{l}\text { Does not } \\
\text { apply }\end{array}$ & Never & Seldom & $\begin{array}{l}\text { Some- } \\
\text { times }\end{array}$ & $\begin{array}{l}\text { Most of } \\
\text { the time }\end{array}$ & $\begin{array}{l}\text { Almost } \\
\text { always }\end{array}$ \\
\hline $\begin{array}{l}\text { 4) How often do you shop with a } \\
\text { grocery list? }\end{array}$ & $\begin{array}{l}\text { Does not } \\
\text { apply }\end{array}$ & Never & Seldom & $\begin{array}{l}\text { Some- } \\
\text { times }\end{array}$ & $\begin{array}{l}\text { Most of } \\
\text { the time }\end{array}$ & $\begin{array}{l}\text { Almost } \\
\text { always }\end{array}$ \\
\hline $\begin{array}{l}\text { 5) This question is about meat } \\
\text { and dairy foods. How often do } \\
\text { you let these foods sit out for } \\
\text { more than two hours? }\end{array}$ & $\begin{array}{l}\text { Does not } \\
\text { apply }\end{array}$ & Never & Seldom & $\begin{array}{l}\text { Some- } \\
\text { times }\end{array}$ & $\begin{array}{l}\text { Most of } \\
\text { the time }\end{array}$ & $\begin{array}{l}\text { Almost } \\
\text { always }\end{array}$ \\
\hline $\begin{array}{l}\text { 6) How often do you thaw frozen } \\
\text { meat at room temperature? }\end{array}$ & $\begin{array}{l}\text { Does not } \\
\text { apply }\end{array}$ & Never & Seldom & $\begin{array}{l}\text { Some- } \\
\text { times }\end{array}$ & $\begin{array}{l}\text { Most of } \\
\text { the time }\end{array}$ & $\begin{array}{l}\text { Almost } \\
\text { always }\end{array}$ \\
\hline $\begin{array}{l}\text { 7) When deciding what to feed } \\
\text { your family, how often do you } \\
\text { think about healthy food } \\
\text { choices? }\end{array}$ & $\begin{array}{l}\text { Does not } \\
\text { apply }\end{array}$ & Never & Seldom & $\begin{array}{l}\text { Some- } \\
\text { times }\end{array}$ & $\begin{array}{l}\text { Most of } \\
\text { the time }\end{array}$ & $\begin{array}{l}\text { Almost } \\
\text { always }\end{array}$ \\
\hline $\begin{array}{l}\text { 8) How often have you prepared } \\
\text { foods without adding salt? }\end{array}$ & $\begin{array}{l}\text { Does not } \\
\text { apply }\end{array}$ & Never & Seldom & $\begin{array}{l}\text { Some- } \\
\text { times }\end{array}$ & $\begin{array}{l}\text { Most of } \\
\text { the time }\end{array}$ & $\begin{array}{l}\text { Almost } \\
\text { always }\end{array}$ \\
\hline $\begin{array}{l}\text { 9) How often do you use the } \\
\text { "Nutrition Facts" on the food } \\
\text { label to make food choices? }\end{array}$ & $\begin{array}{l}\text { Does not } \\
\text { apply }\end{array}$ & Never & Seldom & $\begin{array}{l}\text { Some- } \\
\text { times }\end{array}$ & $\begin{array}{l}\text { Most of } \\
\text { the time }\end{array}$ & $\begin{array}{l}\text { Almost } \\
\text { always }\end{array}$ \\
\hline $\begin{array}{l}\text { 10) How often do you choose fat } \\
\text { free or low fat milk instead of } \\
\text { whole or reduced fat milk? }\end{array}$ & $\begin{array}{l}\text { Does not } \\
\text { apply }\end{array}$ & Never & Seldom & $\begin{array}{l}\text { Some- } \\
\text { times }\end{array}$ & $\begin{array}{l}\text { Most of } \\
\text { the time }\end{array}$ & $\begin{array}{l}\text { Almost } \\
\text { always }\end{array}$ \\
\hline $\begin{array}{l}\text { 11) How often do you choose } \\
\text { whole grain bread instead of } \\
\text { white bread? }\end{array}$ & $\begin{array}{l}\text { Does not } \\
\text { apply }\end{array}$ & Never & Seldom & $\begin{array}{l}\text { Some- } \\
\text { times }\end{array}$ & $\begin{array}{l}\text { Most of } \\
\text { the time }\end{array}$ & $\begin{array}{l}\text { Almost } \\
\text { always }\end{array}$ \\
\hline $\begin{array}{l}\text { 12) Do your meals consist of a } \\
\text { variety of foods? }\end{array}$ & $\begin{array}{l}\text { Does not } \\
\text { apply }\end{array}$ & Never & Seldom & $\begin{array}{l}\text { Some- } \\
\text { times }\end{array}$ & $\begin{array}{l}\text { Most of } \\
\text { the time }\end{array}$ & $\begin{array}{l}\text { Almost } \\
\text { always }\end{array}$ \\
\hline $\begin{array}{l}\text { 13) How often do you use a meat } \\
\text { thermometer to measure the } \\
\text { doneness of meat? }\end{array}$ & $\begin{array}{l}\text { Does not } \\
\text { apply }\end{array}$ & Never & Seldom & $\begin{array}{l}\text { Some- } \\
\text { times }\end{array}$ & $\begin{array}{l}\text { Most of } \\
\text { the time }\end{array}$ & $\begin{array}{l}\text { Almost } \\
\text { always }\end{array}$ \\
\hline
\end{tabular}




\section{E. Nutrition Knowledge}

Please select the best answer to each of the following questions.

1. From the following list of foods, please select the one that is highest in fiber

$\square_{1}$ kidney beans

$\square$ 2 low-fat milk

$\square$ eggs

$\square$ yogurt

2. Which of the following may help you to lower your cholesterol level?

$\square_{1}$ low fat yogurt

$\square_{2}$ oatmeal

$\square_{3}$ scrambled eggs

$\square_{4}$ croissant sandwich

3. Which of the following have the highest content of trans fats?

$\square_{1}$ coke

]$_{2}$ doughnuts

$\square_{3}$ collard greens

$\square_{4}$ baked potatoes

4. Which of the following have the highest content of saturated fat?

$\square_{1}$ low fat cottage cheese

$\square_{2}$ cooked potatoes

$\square 3$ eggs and sausages

$\square_{4}$ raw baby carrot sticks

5. Which of the following food groups contributes most to the overall saturated fat intake in the American diet?

$\square_{1}$ fruits

$\square 2$ meats

$\square 3$ dairy

$\square_{4}$ grains

6. Which of the following have the highest content of cholesterol?

$\square$ citrus fruits

2 eggs

$\square_{3}$ low fat milk

$\square_{4}$ whole wheat flour

7. Which of the following is more likely the highest in sodium?

$\square_{1}$ low fat cottage cheese

$\square 2$ cooked potatoes

$\square 3$ rolled oats

$\square_{4}$ raw baby carrot sticks 
8. Which of the following have the highest content of added sugar?

$\square$ fruit salad

$\square 2$ potato salad

$\square$ coke

$\square_{4}$ eggs and sausages

9. Which of the following is the recommended daily number of servings of fruits for a reference $2,000 \mathrm{kcal}$ diet?

$\square_{1}$ one $\quad \square_{2}$ two $\quad \square_{3}$ three $\quad \square_{4}$ four

10. Which of the following is the recommended daily number of cups of vegetables for a reference $2,000 \mathrm{kcal}$ diet?

$\square_{1}$ one and one half $\square_{2}$ two and one half $\square_{3}$ three and one half $\square_{4}$ four and one half

11. Adequate intake of whole grains could help me to stay prevent constipation.

$\square_{1}$ True $\quad \square_{2}$ False $\square_{3}$ I do not know

12. Regular consumption of nuts such as walnuts, pecans or peanuts helps to lower cholesterol.

$\square_{1}$ True $\quad \square_{2}$ False $\quad \square_{3}$ I do not know

13. Regular intake of flax seeds helps in reducing risk for heart disease.

$\square_{1}$ True $\quad \square_{2}$ False $\square_{3}$ I do not know

14. Cakes, cookies, crackers, are high in trans fats.

$\square_{1}$ True $\quad \square_{2}$ False $\square_{3}$ I do not know

15. Trans fats may contribute to the development of a heart attack or a stroke.

$\square_{1}$ True $\quad \square_{2}$ False $\square_{3}$ I do not know

16. Olive oil is a good source of beneficial fat.

$\square_{1}$ True $\quad \square_{2}$ False $\square_{3}$ I do not know

17. Heart diseases are the number one cause of death in America.

$\square_{1}$ True $\quad \square_{2}$ False $\quad \square_{3}$ I do not know

18. Eating adequate amounts of fruits may help prevent from developing cancer.

$\square_{1}$ True $\quad \square_{2}$ False $\square_{3}$ I do not know

19. Regular intake of whole grains may help to prevent diabetes.

$\square_{1}$ True $\quad \square_{2}$ False $\square_{3}$ I do not know

20. Eating foods that are high in fiber (e.g. oats, beans, fruits) may help to reduce blood cholesterol level. $\square_{1}$ True

$\square_{2}$ False $\square_{3}$ I do not 
F. Where do you obtain your meals? Please check what applies the most $\square_{1}$ Home $\square_{2}$ Restaurant $\square_{3}$ Shelter $\square_{4}$ Fast Food $\square_{5}$ Other, please specify

Write down everything you had to eat and drink yesterday from the first thing in the morning until the last thing at night. Give as much detail as possible, more detail is better.

\begin{tabular}{|c|c|c|c|}
\hline Time or Meal & $\begin{array}{c}\text { Food or Beverage } \\
\text { Item } \\
\text { (Describe) }\end{array}$ & $\begin{array}{c}\text { How Much? } \\
\text { (Amount/size) }\end{array}$ & $\begin{array}{l}\text { How or } \\
\text { Where } \\
\text { Prepared? }\end{array}$ \\
\hline $\begin{array}{c}\text { Such as: } \\
\text { morning, mid- } \\
\text { morning, } \\
\text { lunch, } \\
\text { afternoon, } \\
\text { evening or } \\
\text { late evening }\end{array}$ & $\begin{array}{c}\text { List all foods or a } \\
\text { combination food. For } \\
\text { example, a taco could } \\
\text { be: } \\
\text { Corn tortilla } \\
\text { Ground beef } \\
\text { Lettuce } \\
\text { Tomato } \\
\text { Cheddar cheese } \\
\text { Sour cream } \\
2 \% \text { Milk }\end{array}$ & $\begin{array}{c}\text { For the taco example it } \\
\text { could be: } \\
1 \\
3 \text { oz. } \\
1 / 2 \text { cup } \\
1 / 4 \text { cup } \\
2 \text { oz. } \\
1 \text { tablespoon } \\
1 \text { cup }\end{array}$ & $\begin{array}{l}\text { Such as: } \\
\text { Baked } \\
\text { Fried } \\
\text { Fresh } \\
\text { Broiled } \\
\text { Grilled } \\
\text { Boiled } \\
\text { McDonald's }\end{array}$ \\
\hline & & & \\
\hline & & & \\
\hline & & & \\
\hline & & & \\
\hline & & & \\
\hline & & & \\
\hline & & & \\
\hline & & & \\
\hline & & & \\
\hline & & & \\
\hline & & & \\
\hline & & & \\
\hline & & & \\
\hline & & & \\
\hline & & & \\
\hline & & & \\
\hline & & & \\
\hline
\end{tabular}




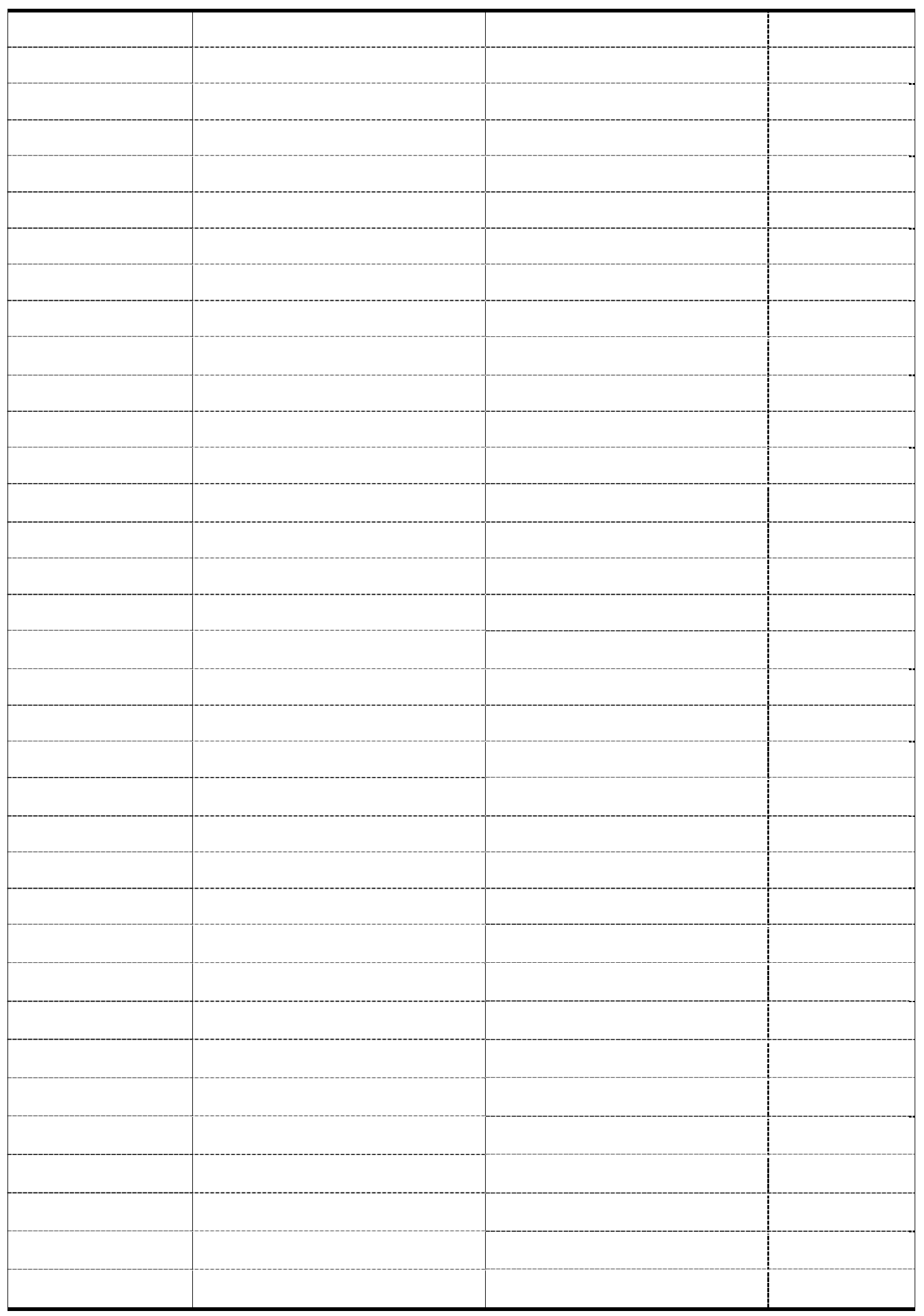


G. Food Frequency. I am now going to ask you questions about foods that you usually eat. For each food, I want to know whether you eat it (yes or no), and approximately how many times you eat it, (times per day, week, month).

\begin{tabular}{|c|c|c|}
\hline Do you eat ... & & $\begin{array}{l}\text { How often do } \\
\text { you eat? }\end{array}$ \\
\hline Fruits (excluding juices) & Yes / No & $\ldots \mathrm{d} w \mathrm{~m}$ \\
\hline $\begin{array}{l}\text { Legumes (beans, chick peas, lentils, } \\
\text { pigeon peas) }\end{array}$ & Yes / No & _ d w m \\
\hline Green leafy vegetables, lettuce & Yes / No & $\ldots \mathrm{d} w \mathrm{~m}$ \\
\hline $\begin{array}{l}\text { Milk, type of milk } 4 \% 2 \% 1 \% \text { skim Other } \\
\text { type of milk }\end{array}$ & Yes / No & $\ldots \mathrm{d} w \mathrm{~m}$ \\
\hline Cheese or yogurt & Yes / No & $\ldots \mathrm{d} w \mathrm{~m}$ \\
\hline Meats (chicken, beef, pork, ham) & Yes / No & d w m \\
\hline Fish and Shellfish & Yes / No & $\ldots \mathrm{d} w \mathrm{~m}$ \\
\hline Eggs & Yes / No & d w m \\
\hline $\begin{array}{l}\text { Pasta, breads and cereals (e.g. rice, } \\
\text { spaghetti) }\end{array}$ & Yes / No & $\ldots \mathrm{d} w \mathrm{~m}$ \\
\hline $100 \%$ fruit juice & Yes / No & $\ldots \mathrm{d} w \mathrm{~m}$ \\
\hline $\begin{array}{l}\text { Artificial drinks (e.g. sunny delight, tang, } \\
\text { kool aid) }\end{array}$ & Yes / No & $\ldots \mathrm{d} w \mathrm{~m}$ \\
\hline Regular soft drink (e.g. Pepsi, Coke) & Yes / No & d w m \\
\hline $\begin{array}{l}\text { Diet soft drinks and drinks with artificial } \\
\text { sweeteners }\end{array}$ & Yes / No & $\ldots \mathrm{d} w \mathrm{~m}$ \\
\hline Regular sweets and desserts & Yes / No & $\ldots \mathrm{dw}$ \\
\hline $\begin{array}{l}\text { Sweets and desserts with artificial } \\
\text { sweeteners }\end{array}$ & Yes / No & $\ldots \mathrm{d} w \mathrm{~m}$ \\
\hline $\begin{array}{l}\text { Snack foods (e.g., potato chips, } \\
\text { Nachos, etc) }\end{array}$ & Yes / No & $\ldots \mathrm{d} w \mathrm{~m}$ \\
\hline
\end{tabular}




\section{H. Short Form of the 12-month Food Security Scale}

These next questions are about the food eaten in your household in the last 12 months and whether you were able to afford the food you need.

1 I'm going to read you two statements that people have made about their food situation. Please tell me whether the statement was OFTEN, SOMETIMES, or NEVER true for (you/you or the other members of your household) in the last 12 months.

The first statement is, "The food that (I/we) bought just didn't last, and (I/we) didn't have money to get more." Was that often, sometimes, or never true for (you/your household) in the last 12 months?
(1) Often true
(2) Sometimes true
(3) Never true
$(\mathrm{D}, \mathrm{R})$

2 "(I/we) couldn't afford to eat balanced meals." Was that often, sometimes, or never true for (you/your household) in the last 12 months?
(1) Often true
(2) Sometimes true
(3) Never true
$(\mathrm{D}, \mathrm{R})$

3 In the last 12 months, since (date 12 months ago) did (you/you or other adults in your household) ever cut the size of your meals or skip meals because there wasn't enough money for food?
(1) Yes
(2) No (GO TO 5)
$(\mathrm{D}, \mathrm{R})(\mathrm{GO}$ TO 5$)$

4 [Ask only if \# 3 = YES] How often did this happen---almost every month, some months but not every month, or in only 1 or 2 months?
(1) Almost every month
(2) Some months but not every month
(3) Only 1 or 2 months
$(\mathrm{D}, \mathrm{R})$
(X) Question not asked because of negative or missing response to question 3

5 In the last 12 months, did you ever eat less than you felt you should because there wasn't enough money to buy food?
(1) Yes
(2) No
$(\mathrm{D}, \mathrm{R}$

6 In the last 12 months, were you ever hungry but didn't eat because you couldn't afford enough food?
(1) Yes
(2) No 


\section{MORBIDITY}

Have you experienced any of these signs and symptoms in the last month?

\begin{tabular}{|l|l|l|}
\hline \multicolumn{1}{|c|}{ Sign and Symptom } & Yes & No \\
\hline Fever & & \\
\hline Chills & & \\
\hline Fatigue & & \\
\hline Malaise & & \\
\hline Lethargy & & \\
\hline Headache & & \\
\hline Skin Lesion or Rash & & \\
\hline Visual changes & & \\
\hline Oral Lesion & & \\
\hline Abdominal Discomfort & & \\
\hline Anorexia & & \\
\hline Dysphagia & & \\
\hline Nausea & & \\
\hline Vomiting & & \\
\hline Diarrhea & & \\
\hline Constipation & & \\
\hline Rectal or Anal Lesions & & \\
\hline Changes in weight & & \\
\hline Cough & & \\
\hline Wheezing & & \\
\hline Chest pain & & \\
\hline Difficulty breathing & & \\
\hline Shortness of breath & & \\
\hline Anemia & & \\
\hline Numbness & & \\
\hline Sharp pain & & \\
\hline Loss of coordination & & \\
\hline Impaired concentration & & \\
\hline Apathy or mood changes & & \\
\hline Seizures & & \\
\hline Dysuria & & \\
\hline Genital discharge & & \\
\hline Genital lesion & & \\
\hline Myalgia & & \\
\hline Arthralgia & & \\
\hline & & \\
\hline
\end{tabular}




\section{J. MEDICATION ADHERENCE QUESTIONNIARE}

This answers you give on this form will be used to plan ways to help other people who must take pills on a difficult schedule. Please do the best you can to answer all the questions. If you do not wish to answer a question, please draw a line through it. If you do not know how to answer a question, ask your study nurse to help. Thank you for helping in this important study.

PATIENT ONLY continue here.

The next section of the questionnaire asks about your HIV study medications that you took over the last four days.

Most people with HIV have many pills to take at different times during the day. Many people find it hard to always remember their pills:

- Some people get busy and forget to carry their pills with them. such

- Some people find it hard to take their pills according to all the instructions,

as "with on every 8 hours," "with plenty of fluids" meals," or " an empty stomach,"

- Some people decide to skip doses to avoid side effects or to just not be taking

pills that day.

We need to understand how people with HIV are really doing with their pills.

Please tell us what you are actually doing. Don't worry about telling us that you don't take all your pills. We need to know what is really happening, not what you think we "want to hear"

The next section of the questionnaire asks about the study medications that you may have missed taking over the last four days. Please complete the following table by filling in the boxes below.

\section{A.IF YOU TOOK ONLY A PORTION OF A DOSE ON ONE OR MORE OF} THESE DAYS, PLEASE REPORT THE DOSE(S) AS BEING MISSED.

\begin{tabular}{|l|l|l|l|l|}
\hline \multirow{2}{*}{$\begin{array}{l}\text { Names of your } \\
\text { anti-HIV } \\
\text { medications }\end{array}$} & \multicolumn{4}{|l|}{ How many doses did you miss } \\
\hline & Yesterday & $\begin{array}{l}2 \text { days } \\
\text { ago }\end{array}$ & 3 days ago & 4 days ago \\
\hline & & & & \\
\hline & & & & \\
\hline & & & & \\
\hline & & & & \\
\hline & & & & \\
\hline & & & & \\
\hline
\end{tabular}


B. During the past 4 days, on how many days have you missed taking ail your doses?

$\square_{1}$ None $\square_{2}$ One day $\square_{3}$ Two days $\square_{4}$ Three days $\square_{5}$ Four days

C. Most ariti-HIV medications need to be taken on a schedule, such as "2 times a day" or "3 times a day" or "every 8 hours." How closely did you follow your specific schedule over the last four days?

$\square_{1}$ Never $\quad \square_{2}$ Some Of The Time $\square_{3}$ About Half Of The Time $\square_{4}$ Most Of The Time $\square_{5}$ All Of The Time

D. Do any of your anti-HIV medications have special instructions, such as "take with food" or "on an empty stomach" or "with plenty of fluids?"

$\square_{1}$ Yes $\quad \square 2$ No

If Yes, how often did you follow those special instructions over the last four days?

$\square_{1}$ Never $\square_{2}$ Some Of The Time $\square_{3}$ About Half Of The Time

$\square_{4}$ Most Of The Time

$\square_{5}$ All Of The Time

E. Some people find that they forget to take their pills on the weekend days. Did you miss any of your anti-HIV medications lasi weekend- last Saturday or Sunday?

$\square_{1}$ Yes $\quad \square_{2}$ No

F. When was the last time you missed any of your medications? Check one.

$\square_{1}$ Within the past week

$\square_{2}$ 1-2 weeks ago

$\square 3$ 2-4 weeks ago

$\square$ 1-3 months ago

$\square_{5}$ More than 3 months ago

$\square_{6}$ Never skip medications or not applicable 


\section{K. QUALITY OF LIFE INDEX}

\begin{tabular}{|c|c|}
\hline ACTIVITY & SCORE \\
\hline $\begin{array}{l}\text { Since the last visit, the patient: } \\
\text {-has been working or studying full-time, or nearly so, in usual occupation; or } \\
\text { managing own household, or participating in unpaid or voluntary activities, } \\
\text { whether retired or not. } \\
\text {-has been working or studying full-time, or nearly so, in usual occupation; or } \\
\text { managing own household, or participating in unpaid or voluntary activities; but } \\
\text { requiring major assistance or a significant reduction in hours worked or sheltered } \\
\text { situation or was on sick leave } \\
\text {-has not been working or studying in any capacity and not managing own } \\
\text { household }\end{array}$ & $\begin{array}{l}2 \\
1 \\
0\end{array}$ \\
\hline DAILY LIVING & SCORE \\
\hline $\begin{array}{l}\text { Since the last visit, the patient } \\
\text {-has been self-reliant in eating, washing, toileting, and dressing; using public } \\
\text { transport, or diving own car. } \\
\text {-has been requiring assistance (another person or special equipment) for daily } \\
\text { activities and transport, but performing light tasks. } \\
\text {-has not been managing personal care or light tasks, or not leaving own home or } \\
\text { institution at all. }\end{array}$ & $\begin{array}{l}2 \\
1 \\
0\end{array}$ \\
\hline HEALTH & SCORE \\
\hline $\begin{array}{l}\text { Since the last visit, the patient } \\
\text {-has been appearing to feel well or reporting feeling "great" most of the time. } \\
\text {-has been lacking energy or not feeling entirely "up to par" more than just } \\
\text { occasionally. } \\
\text {-has been feeling very ill or "lousy", seeming weak and washed out most of the } \\
\text { time or was unconscious }\end{array}$ & $\begin{array}{l}2 \\
1\end{array}$ \\
\hline SUPPORT & SCORE \\
\hline $\begin{array}{l}\text { Since the last visit, the patient } \\
\text {-has been having good relationships with others and receiving strong } \\
\text { support from at least one family member or friend. } \\
\text {-support received or perceived has been limited from family or friends or } \\
\text { by patient's condition. } \\
\text {-support from family and friends occurred infrequently or only when } \\
\text { absolutely necessary, or patient was unconscious. }\end{array}$ & 2 \\
\hline OUTLOOK & \\
\hline $\begin{array}{l}\text { During the last week, the patient } \\
\text {-has usually been appearing calm and positive in outlook, accepting and in control } \\
\text { of personal circumstances, including surroundings. } \\
\text {-has sometimes been troubled because not fully in control of personal } \\
\text { circumstances, or has been having periods of obvious anxiety or depression } \\
\text {-has been seriously confused or very frightened, or consistently anxious and } \\
\text { depressed or confused }\end{array}$ & 2 \\
\hline
\end{tabular}




\section{SF-36 HEALTH SURVEY \\ Your Health and Well-Being}

This survey asks for your views about your health. This information will help keep track of how you feel and how well you are able to do your usual activities. Thank you for completing this survey!

For each of the following questions, please mark an $\bigotimes$ in the one box that best describes your answer.

1. In general, would you say your health is:

\begin{tabular}{|lllll|}
\hline Excellent & Very good & Good & Fair & Poor \\
$\square_{1}$ & $\nabla$ & $\nabla$ & $\nabla$ & $\nabla$ \\
$\square_{2}$ & $\square_{3}$ & $\square_{4}$ & $\square_{5}$
\end{tabular}

2. Compared to one year ago, how would you rate your health in general now?

$\begin{array}{|ccccc|}\begin{array}{c}\text { Much better } \\ \text { now than one } \\ \text { year ago }\end{array} & \begin{array}{c}\text { Somewhat } \\ \text { better } \\ \text { now than one } \\ \text { year ago }\end{array} & \begin{array}{c}\text { About the } \\ \text { same as } \\ \text { one year ago }\end{array} & \begin{array}{c}\text { Somewhat } \\ \text { worse } \\ \text { now than one } \\ \text { year ago }\end{array} & \begin{array}{c}\text { Much worse } \\ \text { now than } \\ \text { one year ago }\end{array} \\ \square_{1} & \square_{2} & \square 3 & \square 4\end{array}$




\section{The following questions are about activities you might do during a typical day. Does your health now limit you in these activities? If so, how much?}

a Vigorous activities, such as running, lifting heavy objects, participating in strenuous sports

b Moderate activities, such as moving a table, pushing a vacuum cleaner, bowling, or playing golf

$\begin{array}{ccc}\begin{array}{c}\text { Yes, } \\ \text { limited } \\ \text { a lot }\end{array} & \begin{array}{c}\text { Yes, limited } \\ \text { a little }\end{array} & \begin{array}{c}\text { No, not } \\ \text { limited } \\ \text { at all }\end{array} \\ & & \end{array}$

c Lifting or carrying groceries

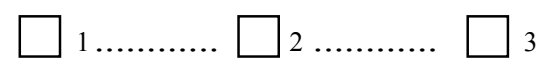

d Climbing several flights of stairs
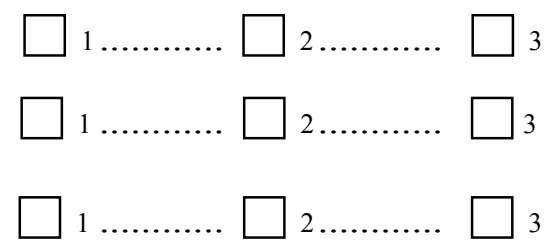

e Climbing one flight of stairs

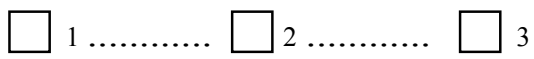

f Bending, kneeling, or stooping

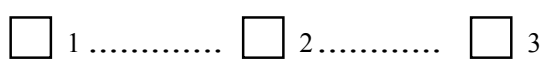

g Walking more than a mile

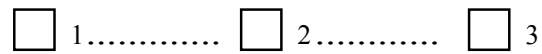

h Walking several hundred yards

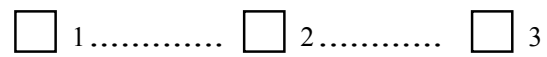

i Walking one hundred yards

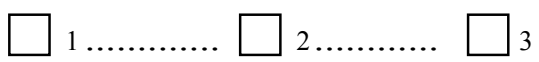

j Bathing or dressing yourself

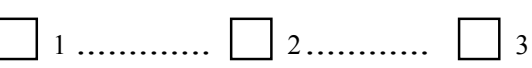


4. During the past 4 weeks, how much of the time have you had any of the following problems with your work or other regular daily activities as a result of your physical health?

a Cut down on the amount of

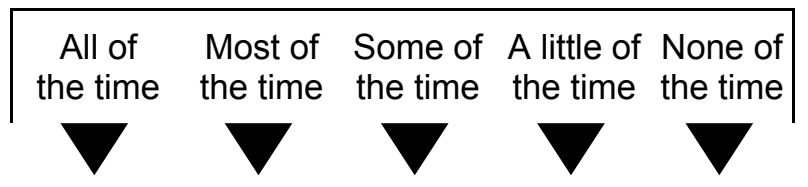
time you spent on work or

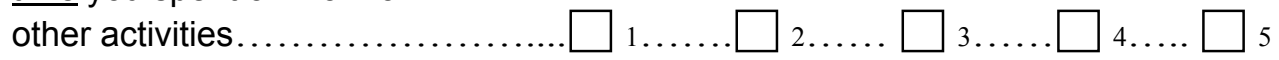

b Accomplished less than you would like.

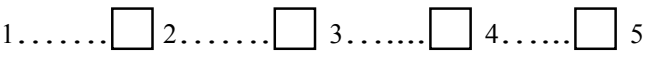

c Were limited in the kind of work or other activities. $\square_{1 \ldots \ldots} \ldots \ldots . \square 3 \ldots \ldots \square+\ldots \ldots \square \square_{5}$

d Had difficulty performing the work or other activities (for example, it took extra effort).

5. During the past 4 weeks, how much of the time have you had any of the following problems with your work or other regular daily activities as a result of any emotional problems (such as feeling depressed or anxious)?

a Cut down on the amount of

$\begin{array}{|cccc|}\begin{array}{c}\text { All of } \\ \text { the time }\end{array} & \begin{array}{c}\text { Most of } \\ \text { the time }\end{array} & \begin{array}{c}\text { Some of } \\ \text { the time little of }\end{array} \\ \text { the time }\end{array}$
time you spent on work or

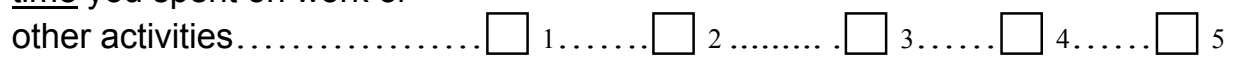

b Accomplished less than you would like. $. \square 3 \ldots \ldots \square+\ldots . . \square 5$

c Did work or other activities less carefully than usual. 
6. During the past 4 weeks, to what extent has your physical health or emotional problems interfered with your normal social activities with family, friends, neighbors, or groups?

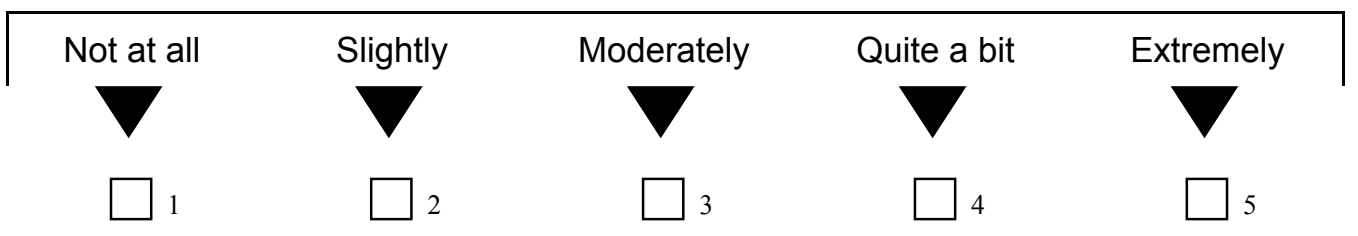

7. How much bodily pain have you had during the past 4 weeks?

\begin{tabular}{|lccccc|}
\hline None & Very mild & Mild & Moderate & Severe & Very severe \\
$\square_{1}$ & $\square_{2}$ & $\square_{3}$ & $\square_{4}$ & $\square_{5}$ & $\square_{6}$
\end{tabular}

8. During the past 4 weeks, how much did pain interfere with your normal work (including both work outside the home and housework)?

$\square_{1}^{\text {Not at all }}$


9. These questions are about how you feel and how things have been with you during the past 4 weeks. For each question, please give the one answer that comes closest to the way you have been feeling. How much of the time during the past 4 weeks...

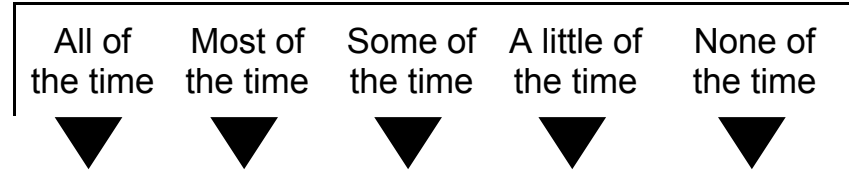
a Did you feel full of life?

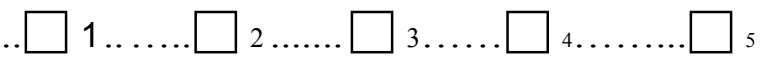

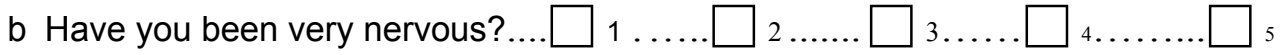
c Have you felt so down in the dumps that nothing could cheer you up?

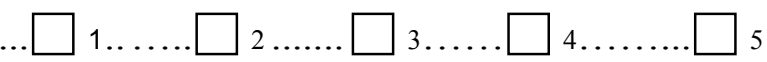
d Have you felt calm and peaceful?

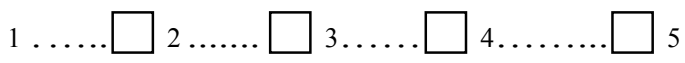
e Did you have a lot of energy?.... $\square$ 1...... $\square 2 \ldots \ldots . \square$ 3..... $\square$ 4....... $\square$ 5
f Have you felt downhearted and depressed?.
g Did you feel worn out?.............. $\square$ 1 ...... $\square 2$...... $\square \square_{3} \ldots \ldots \square$ 4........ $\square$ 5
h Have you been happy?............. $\square$ 1...... $\square 2$...... $\square \square_{3 \ldots \ldots} \square_{4 \ldots \ldots . .} \square_{5}$
i Did you feel tired?.................... $\square$ 1 ...... $\square 2 \ldots \ldots . \square{ }_{3} \ldots \ldots . \square$ 4........ $\square 5$

10. During the past 4 weeks, how much of the time has your physical health or emotional problems interfered with your social activities (like visiting with friends, relatives, etc.)?

$\begin{array}{|cccc|}\begin{array}{c}\text { All of } \\ \text { the time }\end{array} & \begin{array}{c}\text { Most of } \\ \text { the time }\end{array} & \begin{array}{l}\text { Some of } \\ \text { the time }\end{array}\end{array}$




\section{How TRUE or FALSE is each of the following statements for you?}

\begin{tabular}{|ccccc|}
\hline $\begin{array}{c}\text { Definitely } \\
\text { true }\end{array}$ & $\begin{array}{c}\text { Mostly } \\
\text { true }\end{array}$ & $\begin{array}{c}\text { Don't } \\
\text { know }\end{array}$ & $\begin{array}{c}\text { Mostly } \\
\text { false }\end{array}$ & $\begin{array}{c}\text { Definitely } \\
\text { false }\end{array}$ \\
\hline & & & &
\end{tabular}

a I seem to get sick a little

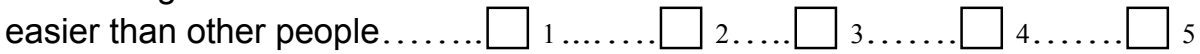

b I am as healthy as

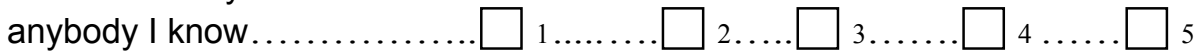

C I expect my health to

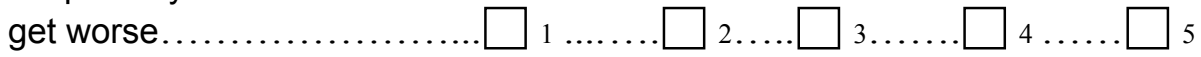

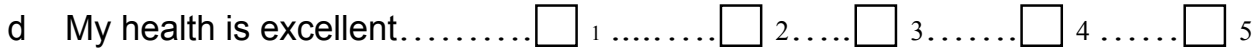


K. ANTHROPOMETRICS AND LABORATORY RESULTS

\begin{tabular}{|l|l|l|}
\hline MEASUREMENTS & RESULTS & DATE OBTAINED \\
\hline Height(ft/cm) & & \\
\hline Weight(lbs) & & \\
\hline BMI & & \\
\hline Waist & & \\
\hline Hip & & \\
\hline Waist/Hip Ratio & RESULTS & DATE OBTAINED \\
\hline TEST & & \\
\hline CD4 Cell Count & & \\
\hline Viral Load & & \\
\hline Hemoglobin & & \\
\hline Hematocrit & & \\
\hline Albumin & & \\
\hline
\end{tabular}

BODY COMPOSITION BIA RESULTS

Phase Angle

Body Capacitance

Resistance

Reactance

$\mathrm{pF}$
$\mathrm{ohm}$
$\mathrm{ohm}$

Mass Distribution

Ibs

Percent

Body Cell Mass

Extracellular Mass

Lean Body Mass

Fat Mass

Total Weight

$\mathrm{ECM} / \mathrm{BCM}$

Body Mass Index

Basal Metabolic Rate

Water Compartment

Intracellular Water

Extracellular Water

Total Body Water

TBW/Lean Body Mass

TBW/Lean Body Weight

Liters

Percent

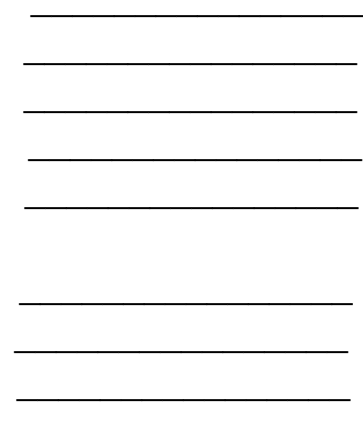


Appendix C3: Intervention Study Baseline Questionnaire 


\section{A. Demographic Data}

For these questions, please circle your answers or write your answers in the spaces provided.

1. Gender: $\square_{1}$ Male $\square_{2}$ Female

2. Age: years.

3. Which of the following best describes your ethnic background?

$\square$ Black/African American

Hispanic American

$\square 2$ Asian American

5 Native American $\square$ Non-Hispanic White $\square$ 6 Other (specify):

4. Status: $\square_{1}$ Married $\square_{2}$ Single $\square_{3}$ Divorced/Widowed $\square_{4}$ Other

5. Please check your highest level of education.

$\square_{1}<$ High school

$\square$ 3 1-2 years college

$\square_{2}$ High school or GED

$\square_{4}$ Graduated from college

6. Work Status: $\quad \square_{1}$ Not working $\square_{3}$ Work full time $\square 2$ Work Part-time, $\square_{4}$ On disability

7. What is your monthly income?

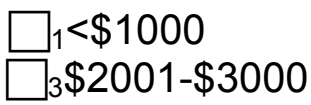
$\square_{2} \$ 1001-\$ 2000$ $\square_{4}>\$ 3001$

8. Do you live: $\square_{1}$ Alone $\quad \square_{2}$ With your family (parents, husband, children, etc) $\square_{3}$ Shelter $\square_{4}$ Street

9. Do you smoke cigarettes?

$\square_{1}$ Yes

$\square_{2}$ No

9a. If yes how often?

$\square_{1}$ Daily

$\square_{2}$ 4-6 times a week

$\square_{3}$ 2-3 times a week

$\square_{4}$ Once a week

$\square 5$ Less than once a month

$\square_{6}$ At least once a month but less than once a week

$\square_{7}$ Never

9b. If daily how many cigarettes per day

10. Do you use any drugs? $\square_{1}$ Yes $\quad \square_{2}$ No

10a.If yes please check all that apply: Marijuana $\square_{1}$ Cocaine $\square_{2}$ Crack 
$\square_{3}$ Heroin $\square_{4}$ Combination (Speedball) $\square_{5}$ Methadone

$\square_{6}$ Amphetamine (Ecstasy) $\square_{7}$ Other $\square_{8}$

11. Do you drink alcohol? $\quad \square 1$ Yes $\quad \square 2$ No

11a. If yes how often?

$\square_{1}$ Daily

$\square_{2}$ 4-6 times a week

$\square_{3}$ 2-3 times a week

$\square_{4}$ once a week

$\square$ Less than once a month

$\square$ 6 At least once a month but less than once a week

$\square_{7}$ Never

11b. If daily how many drinks per day?

----- Beer drinks

------ Wine drinks

------ Liquor drinks

Total drinks

12. Do you use ART? $\square_{1}$ Yes $\quad \square_{2}$ No

12a. List of medications (1)

(2)

(3)

(4)

(5)

13. Do you take multivitamins?

$\square_{1}$ Yes $\square_{2}$ No

13a. If yes please list them. 1)

2)

3)

4)

5)

14. Do you receive food stamps? $\quad \square_{1}$ Yes $\quad \square_{2}$ No

14a. If yes, how many months have you received food stamps in the past 12 months?

15. In the last 30 days, did you receive any foods to take home from community sources such as a food bank, food pantry, or other sources?

$\square_{1}$ Yes $\square_{2}$ No

16. In the past 30 days did you eat any meals at a soup kitchen, the Salvation Army, a family shelter, or another similar place? $\square_{1}$ Yes $\square_{2}$ No 


\section{B. Nutrition Knowledge}

Please select the best answer to each of the following questions.

1. From the following list of foods, please select the one that is highest in fiber

$\square_{1}$ kidney beans

$\square$ 2 low-fat milk

$\square_{3}$ eggs

$\square$ yogurt

2. Which of the following may help you to lower your cholesterol level?

$\square_{1}$ low fat yogurt

$\square_{2}$ oatmeal

$\square_{3}$ scrambled eggs

$\square_{4}$ croissant sandwich

3. Which of the following have the highest content of trans fats?

$\square_{1}$ coke

]$_{2}$ doughnuts

$\square_{3}$ collard greens

$\square_{4}$ baked potatoes

4. Which of the following have the highest content of saturated fat?

$\square_{1}$ low fat cottage cheese

$\square_{2}$ cooked potatoes

$\square 3$ eggs and sausages

$\square_{4}$ raw baby carrot sticks

5. Which of the following food groups contributes most to the overall saturated fat intake in the American diet?

$\square_{1}$ fruits

$\square 2$ meats

$\square 3$ dairy

$\square_{4}$ grains

6. Which of the following have the highest content of cholesterol?

$\square$ citrus fruits

2 eggs

3 low fat milk

$\square_{4}$ whole wheat flour

7. Which of the following is more likely the highest in sodium?

$\square_{1}$ low fat cottage cheese

$\square_{2}$ cooked potatoes

$\square 3$ rolled oats

$\square$ raw baby carrot sticks

8. Which of the following have the highest content of added sugar? 
$\square_{1}$ fruit salad

12 potato salad

$\square_{3}$ coke

$\square_{4}$ eggs and sausages

9. Which of the following is the recommended daily number of servings of fruits for a reference $2,000 \mathrm{kcal}$ diet?

$\square_{1}$ one $\quad \square_{2}$ two $\quad \square_{3}$ three $\quad \square_{4}$ four

10. Which of the following is the recommended daily number of cups of vegetables for a reference $2,000 \mathrm{kcal}$ diet?

$\square_{1}$ one and one half $\square_{2}$ two and one half $\square_{3}$ three and one half $\square_{4}$ four and one half

11. Adequate intake of whole grains could help me to stay prevent constipation.

$\square_{1}$ True $\quad \square_{2}$ False $\square_{3}$ I do not know

12. Regular consumption of nuts such as walnuts, pecans or peanuts helps to lower cholesterol.

$\square_{1}$ True $\quad \square_{2}$ False $\quad \square_{3}$ I do not know

13. Regular intake of flax seeds helps in reducing risk for heart disease.

$\square_{1}$ True $\quad \square_{2}$ False $\square_{3}$ I do not know

14. Cakes, cookies, crackers, are high in trans fats.

$\square_{1}$ True $\quad \square_{2}$ False $\quad \square_{3}$ I do not know

15. Trans fats may contribute to the development of a heart attack or a stroke.

$\square_{1}$ True $\quad \square_{2}$ False $\square_{3}$ I do not know

16. Olive oil is a good source of beneficial fat.

$\square_{1}$ True $\quad \square_{2}$ False $\quad \square_{3}$ I do not know

17. Heart diseases are the number one cause of death in America.

$\square_{1}$ True $\quad \square_{2}$ False $\square_{3}$ I do not know

18. Eating adequate amounts of fruits may help prevent from developing cancer.

$\square_{1}$ True $\quad \square_{2}$ False $\square_{3}$ I do not know

19. Regular intake of whole grains may help to prevent diabetes.

$\square_{1}$ True $\quad \square_{2}$ False $\quad \square_{3}$ I do not know

20. Eating foods that are high in fiber (e.g. oats, beans, fruits) may help to reduce blood cholesterol level. $\square_{1}$ True $\quad \square_{2}$ False $\quad \square_{3}$ I do not 
C. Food Frequency. I am now going to ask you questions about foods that you usually eat. For each food, I want to know whether you eat it (yes or no), and approximately how many times you eat it, (times per day, week, month).

\begin{tabular}{|c|c|c|}
\hline Do you eat & & $\begin{array}{l}\text { How often do } \\
\text { you eat? }\end{array}$ \\
\hline Fruits (excluding juices) & Yes / No & $\ldots \mathrm{d} w \mathrm{~m}$ \\
\hline $\begin{array}{l}\text { Legumes (beans, chick peas, lentils, } \\
\text { pigeon peas) }\end{array}$ & Yes / No & $\ldots \mathrm{d} \mathrm{w} \mathrm{m}$ \\
\hline Green leafy vegetables, lettuce & Yes / No & $\ldots \mathrm{d} w \mathrm{~m}$ \\
\hline $\begin{array}{l}\text { Milk, type of milk } 4 \% 2 \% 1 \% \text { skim Other } \\
\text { type of milk }\end{array}$ & Yes / No & $\ldots d w m$ \\
\hline Cheese or yogurt & Yes / No & $\ldots \mathrm{d} w \mathrm{~m}$ \\
\hline Meats (chicken, beef, pork, ham) & Yes / No & $\ldots \mathrm{d} w \mathrm{~m}$ \\
\hline Fish and Shellfish & Yes / No & $\mathrm{d} w \mathrm{~m}$ \\
\hline Eggs & Yes / No & $\ldots \mathrm{d} w \mathrm{~m}$ \\
\hline $\begin{array}{l}\text { Pasta, breads and cereals (e.g. rice, } \\
\text { spaghetti) }\end{array}$ & Yes / No & $\ldots \mathrm{d} \mathrm{w} \mathrm{m}$ \\
\hline $100 \%$ fruit juice & Yes / No & $\ldots \mathrm{d} w \mathrm{~m}$ \\
\hline $\begin{array}{l}\text { Artificial drinks (e.g. sunny delight, tang, } \\
\text { kool aid) }\end{array}$ & Yes / No & $\ldots \mathrm{d} w \mathrm{~m}$ \\
\hline Regular soft drink (e.g. Pepsi, Coke) & Yes / No & $\ldots \mathrm{d} w \mathrm{~m}$ \\
\hline $\begin{array}{l}\text { Diet soft drinks and drinks with artificial } \\
\text { sweeteners }\end{array}$ & Yes / No & $\ldots \mathrm{d} w \mathrm{~m}$ \\
\hline Regular sweets and desserts & Yes / No & $\ldots \mathrm{d} w \mathrm{~m}$ \\
\hline $\begin{array}{l}\text { Sweets and desserts with artificial } \\
\text { sweeteners }\end{array}$ & Yes / No & $\ldots \mathrm{d} w \mathrm{~m}$ \\
\hline $\begin{array}{l}\text { Snack foods (e.g., potato chips, } \\
\text { Nachos, etc) }\end{array}$ & Yes / No & $\ldots \mathrm{d} w \mathrm{~m}$ \\
\hline
\end{tabular}


D. Where do you obtain your meals? Please check what applies the most

$\square_{1}$ Home $\square_{2}$ Restaurant $\square_{3}$ Shelter $\square_{4}$ Fast Food $\square_{5}$ Other, please specify

Write down everything you had to eat and drink yesterday from the first thing in the morning until the last thing at night. Give as much detail as possible, more detail is better.

\begin{tabular}{|c|c|c|c|}
\hline Time or Meal & $\begin{array}{c}\text { Food or Beverage } \\
\text { Item } \\
\text { (Describe) }\end{array}$ & $\begin{array}{c}\text { How Much? } \\
\text { (Amount/size) }\end{array}$ & $\begin{array}{l}\text { How or } \\
\text { Where } \\
\text { Prepared? }\end{array}$ \\
\hline $\begin{array}{c}\text { Such as: } \\
\text { morning, mid- } \\
\text { morning, } \\
\text { lunch, } \\
\text { afternoon, } \\
\text { evening or } \\
\text { late evening }\end{array}$ & $\begin{array}{c}\text { List all foods or a } \\
\text { combination food. For } \\
\text { example, a taco could } \\
\text { be: } \\
\text { Corn tortilla } \\
\text { Ground beef } \\
\text { Lettuce } \\
\text { Tomato } \\
\text { Cheddar cheese } \\
\text { Sour cream } \\
2 \% \text { Milk }\end{array}$ & $\begin{array}{c}\text { For the taco example it } \\
\text { could be: } \\
1 \\
3 \text { oz. } \\
1 / 2 \text { cup } \\
1 / 4 \text { cup } \\
2 \text { oz. } \\
1 \text { tablespoon } \\
1 \text { cup }\end{array}$ & $\begin{array}{l}\text { Such as: } \\
\text { Baked } \\
\text { Fried } \\
\text { Fresh } \\
\text { Broiled } \\
\text { Grilled } \\
\text { Boiled } \\
\text { McDonald's }\end{array}$ \\
\hline & & & \\
\hline & & & \\
\hline & & & \\
\hline & & & \\
\hline & & & \\
\hline & & & \\
\hline & & & \\
\hline & & & \\
\hline & & & \\
\hline & & & \\
\hline & & & \\
\hline & & & \\
\hline & & & \\
\hline & & & \\
\hline & & & \\
\hline & & & \\
\hline & & & \\
\hline & & & \\
\hline
\end{tabular}




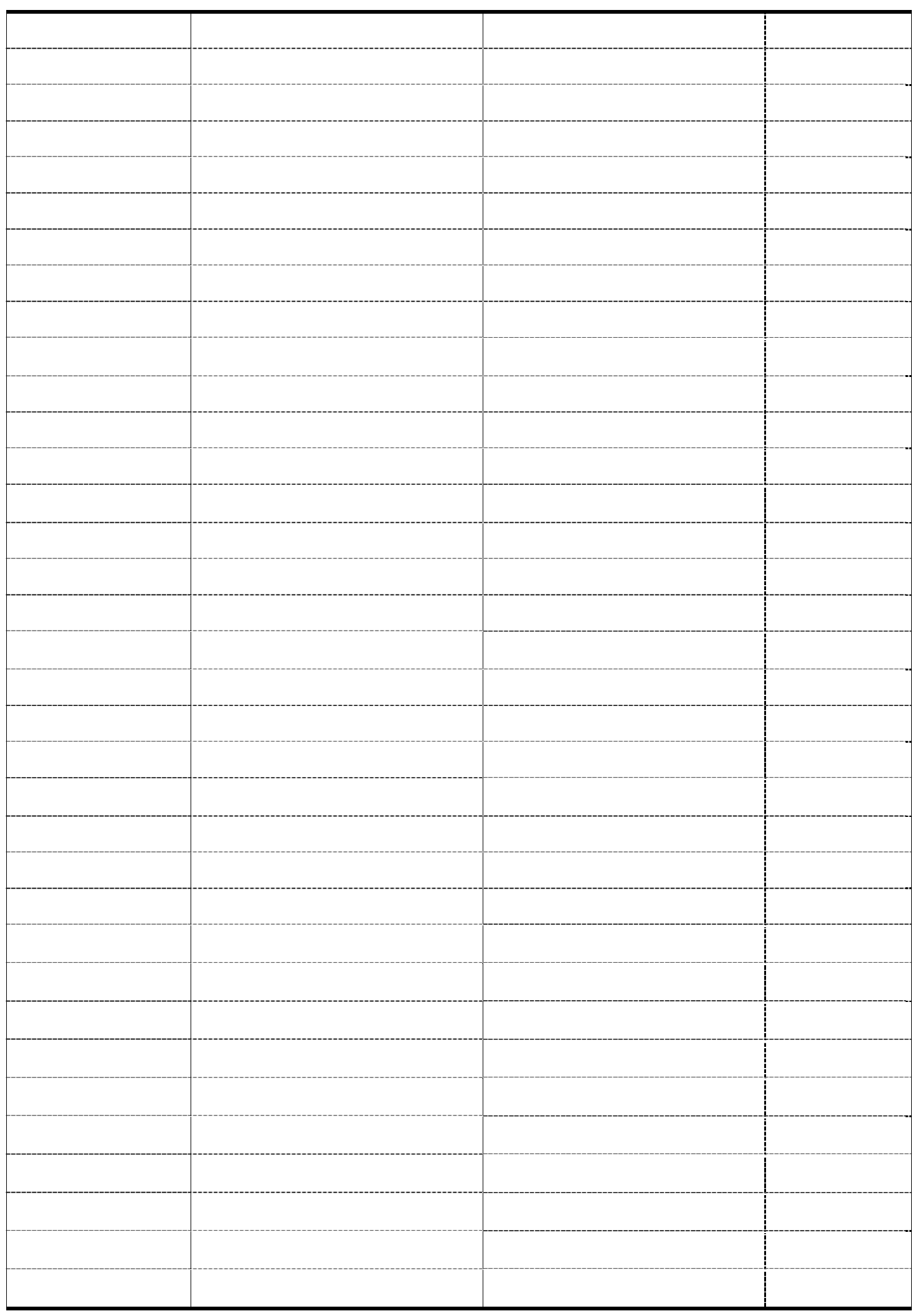




\section{E. FRUITS \& VEGETABLES: Staging}

Fruits and vegetables come in many forms: fresh, frozen, canned, dried, and $100 \%$ fruit and vegetable juices. Fruits and vegetables can be cooked or eaten raw. They can also be eaten by themselves or as part of a mixed dish such as soups or casseroles.

Use this table to help you count your fruit and vegetable servings...

COUNT AS ONE SERVING: Vegetables:

- $1 / 2$ cup of cooked or raw vegetables

- 1 cup of raw leafy greens

Fruit:

- $1 / 2$ cup or a medium sized piece of fruit

- $3 / 4$ cup of $100 \%$ fruit juice

- 1/4 cup of dried fruit

A. How many servings of fruits and vegetables do you usually eat each day? Please select one and fill in the circle.

O None (Go to Question B1)

O 1 Serving (Go to Question B1)

○ 2 Servings Days (Go to Question B1)

O 3 Servings (Go to Question B1)

O 4 Servings (Go to Question B1)

O 5 Servings (Go to Question B2)

O 6 Servings or more (Go to Question B2)

B1. Do you intend to change what you eat so you will eat at least 5 servings of fruits and vegetables every day? Please select one and fill in the circle.

$\bigcirc$ No, and I don't intend to in the next 6 months (Go to Next Page)

$\bigcirc$ Yes, and I intend to in the next 6 months (Go to Next Page)

$\bigcirc$ Yes, and I intend to in the next 30 days (Go to Next Page)

B2. You report that you have been eating 5 or more regular servings of fruits and vegetables.

For how many months have you been doing this? Please select one and fill in the circle.

$\bigcirc$ Less than 6 months

O 6 months or more 


\section{DIETARY FAT: Staging}

A. Do you regularly eat 5 or fewer servings of high fat foods every day? Please select one and fill in the circle.

No, I eat more than 5 servings of high fat foods per day (Go to Question B1)

$\bigcirc$ Yes, I eat 5 or fewer servings of high fat foods per day (Go to Question B2)

B1. Do you intend to change what you eat so you will eat 5 or fewer servings of high fat foods every day in the next 6 months? Please select one and fill in the circle.

No, and I don't intend to in the next 6 months (Go to Next Page)

Yes, and I intend to in the next 6 months (Go to Next Page)

Yes, and I intend to in the next 30 days (Go to Next Page)

B2. For how many months have you been eating 5 or fewer servings of high fat foods every day? Please select one and fill in the circle.

Less than 6 months

6 months or more 


\section{FIBER: Staging}

A. Do you eat regular servings of high fiber foods? Please select one and fill in the circle.

No (Go to Question B1)

Yes (Go to Question B2)

B1. Do you intend to change what you eat so you will eat more high fiber foods in the next 6 months? You can get this by eating high fiber cereals ( 5 grams/serving), breads ( 2 grams per serving), beans and legumes, fruits, and vegetables. Please select one and fill in the circle.

No, and I don't intend to in the next 6 months (Go to Next Page)

Yes, and I intend to in the next 6 months (Go to Next Page)

Yes, and I intend to in the next 30 days (Go to Next Page)

B2. You report that you've been eating regular servings of high fiber foods. For how many months have you been consuming this amount of fiber? Please select one and fill in the circle.

Less than 6 months

6 months or more 


\section{F. FRIUT AND VEGETABLE SELF EFFICACY}

There are many things that can get in the way of choosing to eat 5 fruits and vegetables each day Rate HOW CONFIDENT you are that you can do the following using the scale below.

\begin{tabular}{|l|l|l|l|l|l|}
\hline & $\begin{array}{l}\text { Not at All } \\
\text { Confident }\end{array}$ & $\begin{array}{l}\text { Somewhat } \\
\text { Confident }\end{array}$ & $\begin{array}{l}\text { Moderately } \\
\text { Confident }\end{array}$ & $\begin{array}{l}\text { Very } \\
\text { Confident }\end{array}$ & $\begin{array}{l}\text { Extremely } \\
\text { Confident }\end{array}$ \\
\hline $\begin{array}{l}\text { Eat } 5 \text { servings of fruits and vegetables } \\
\text { everyday? }\end{array}$ & & & & & \\
\hline $\begin{array}{l}\text { Drink } 100 \% \text { fruit juice instead of soda or fruit } \\
\text { punch? }\end{array}$ & & & & & \\
\hline $\begin{array}{l}\text { Eat fruits and vegetables for a snack instead } \\
\text { of chips or candy? }\end{array}$ & & & & & \\
\hline $\begin{array}{l}\text { Eat fruits and vegetables when eating out at } \\
\text { a restaurant? }\end{array}$ & & & & & \\
\hline $\begin{array}{l}\text { Eat fruits and vegetables when I am upset or } \\
\text { having a bad day? }\end{array}$ & & & & & \\
\hline $\begin{array}{l}\text { Eat fruits and vegetables when I am at a } \\
\text { social event? }\end{array}$ & & & & & \\
\hline
\end{tabular}




\section{DIETARY FIBER SELF-EFFICACY}

There are many things that can get in the way of choosing to eat foods high in fiber. Rate HOW CONFIDENT you are that you can do the following using the scale below

\begin{tabular}{|l|l|l|l|l|l|}
\hline & $\begin{array}{l}\text { Not at All } \\
\text { Confident }\end{array}$ & $\begin{array}{l}\text { Somewhat } \\
\text { Confident }\end{array}$ & $\begin{array}{l}\text { Moderately } \\
\text { Confident }\end{array}$ & $\begin{array}{l}\text { Very } \\
\text { Confident }\end{array}$ & $\begin{array}{l}\text { Extremely } \\
\text { Confident }\end{array}$ \\
\hline $\begin{array}{l}\text { Choose high fiber cereals over low fiber and sugary } \\
\text { cereals? }\end{array}$ & & & & & \\
\hline Avoid foods that are low in fiber? & & & & & \\
\hline $\begin{array}{l}\text { Choose high fiber foods even when you are upset and } \\
\text { having a bad day }\end{array}$ & & & & & \\
\hline $\begin{array}{l}\text { Choose high fiber snacks instead of doughnuts or } \\
\text { cookies? }\end{array}$ & & & & & \\
\hline Eat 5 servings of whole grains and beans every day? & & & & & \\
\hline $\begin{array}{l}\text { Choose selections with whole grains or beans when } \\
\text { out at a restaurant? }\end{array}$ & & & & & \\
\hline Regularly eat whole grain bread? & & & & & \\
\hline
\end{tabular}




\section{DIETARY FAT SELF-EFFICACY}

There are many things that can get in the way of choosing to eat a diet low in fat. HOW CONFIDENT are you that you can choose low fat foods in each situation?

\begin{tabular}{|l|l|l|l|l|l|}
\hline & $\begin{array}{l}\text { Not at All } \\
\text { Confident }\end{array}$ & $\begin{array}{l}\text { Somewhat } \\
\text { Confident }\end{array}$ & $\begin{array}{l}\text { Moderately } \\
\text { Confident }\end{array}$ & $\begin{array}{l}\text { Very } \\
\text { Confident }\end{array}$ & $\begin{array}{l}\text { Extremely } \\
\text { Confident }\end{array}$ \\
\hline $\begin{array}{l}\text { When others around you are eating high fat } \\
\text { foods. }\end{array}$ & & & & & \\
\hline When you are craving high fat foods. & & & & & \\
\hline When you are out at a restaurant. & & & & & \\
\hline When you are upset or having a bad day. & & & & & \\
\hline When you are at a social event. & & & & & \\
\hline
\end{tabular}


When you are grocery shopping how confident are you in your ability to? (check one answer for each food type)

\begin{tabular}{|l|c|c|c|c|}
\hline $\begin{array}{l}\text { How confident are you in your } \\
\text { ability to }\end{array}$ & $\begin{array}{c}\text { Not at all } \\
\text { confident }\end{array}$ & $\begin{array}{l}\text { Not } \\
\text { confident }\end{array}$ & $\begin{array}{c}\text { Somewhat } \\
\text { confident }\end{array}$ & $\begin{array}{c}\text { Very } \\
\text { confident }\end{array}$ \\
\hline $\begin{array}{l}\text { Select whole grain bread or } \\
\text { cereal in a grocery store? .. }\end{array}$ & $\square$ & $\square$ & $\square$ & $\square$ \\
$\begin{array}{l}\text { Select low fat dairy products } \\
\text { (e.g. yogurt) }\end{array}$ & $\square$ & $\square$ & $\square$ & $\square$ \\
$\begin{array}{l}\text { Select foods that are low in } \\
\text { sodium }\end{array}$ & $\square$ & $\square$ & $\square$ & $\square$ \\
$\begin{array}{l}\text { Select foods that are low in } \\
\text { saturated fat? }\end{array}$ & $\square$ & $\square$ & $\square$ & $\square$ \\
$\begin{array}{l}\text { Select foods that are low in } \\
\text { cholesterol? }\end{array}$ & $\square$ & $\square$ & $\square$ & $\square$ \\
Select foods high in dietary & $\square$ & $\square$ & $\square$ & $\square$ \\
fiber? & $\square$ & $\square$ & $\square$ & $\square$ \\
$\begin{array}{l}\text { Select foods that are low in or } \\
\text { free of trans fats? }\end{array}$ & & & \\
\hline
\end{tabular}




\section{G. MORBIDITY}

Have you experienced any of these signs and symptoms in the last month?

\begin{tabular}{|l|l|l|}
\hline \multicolumn{1}{|c|}{ Sign and Symptom } & Yes & No \\
\hline Fever & & \\
\hline Chills & & \\
\hline Fatigue & & \\
\hline Malaise & & \\
\hline Lethargy & & \\
\hline Headache & & \\
\hline Skin Lesion or Rash & & \\
\hline Visual changes & & \\
\hline Oral Lesion & & \\
\hline Abdominal Discomfort & & \\
\hline Anorexia & & \\
\hline Dysphagia & & \\
\hline Nausea & & \\
\hline Vomiting & & \\
\hline Diarrhea & & \\
\hline Constipation & & \\
\hline Rectal or Anal Lesions & & \\
\hline Changes in weight & & \\
\hline Cough & & \\
\hline Wheezing & & \\
\hline Chest pain & & \\
\hline Difficulty breathing & & \\
\hline Shortness of breath & & \\
\hline Anemia & & \\
\hline Numbness & & \\
\hline Sharp pain & & \\
\hline Loss of coordination & & \\
\hline Impaired concentration & & \\
\hline Apathy or mood changes & & \\
\hline Seizures & & \\
\hline Dysuria & & \\
\hline Genital discharge & & \\
\hline Genital lesion & & \\
\hline Myalgia & & \\
\hline Arthralgia & & \\
\hline
\end{tabular}




\section{H. MEDICATION ADHERENCE QUESTIONNIARE}

This answers you give on this form will be used to plan ways to help other people who must take pills on a difficult schedule. Please do the best you can to answer all the questions. If you do not wish to answer a question, please draw a line through it. If you do not know how to answer a question, ask your study nurse to help. Thank you for helping in this important study.

PATIENT ONLY continue here.

The next section of the questionnaire asks about your HIV study medications that you took over the last four days.

Most people with HIV have many pills to take at different times during the day. Many people find it hard to

always remember their pills:

- Some people get busy and forget to carry their pills with them.

- Some people find it hard to take their pills according to all the instructions, such

as "with on every 8 hours," "with plenty of fluids" meals," or " an empty stomach,"

- Some people decide to skip doses to avoid side effects or to just not be taking

pills that day.

We need to understand how people with HIV are really doing with their pills.

Please tell us what you are actually doing. Don't worry about telling us that you don't take all your pills. We need to know what is really happening, not what you think we "want to hear"

The next section of the questionnaire asks about the study medications that you may have missed taking over the last four days. Please complete the following table by filling in the boxes below.

A.IF YOU TOOK ONLY A PORTION OF A DOSE ON ONE OR MORE OF THESE DAYS, PLEASE REPORT THE DOSE(S) AS BEING MISSED.

\begin{tabular}{|l|l|l|l|l|}
\hline \multirow{2}{*}{$\begin{array}{l}\text { Names of your } \\
\text { anti-HIV } \\
\text { medications }\end{array}$} & \multicolumn{4}{|l|}{ How many doses did you miss } \\
\hline & Yesterday & $\begin{array}{l}2 \text { days } \\
\text { ago }\end{array}$ & 3 days ago & 4 days ago \\
\hline & & & & \\
\hline & & & & \\
\hline & & & & \\
\hline & & & & \\
\hline & & & & \\
\hline & & & & \\
\hline
\end{tabular}


B. During the past 4 days, on how many days have you missed taking all your doses?

$\square_{1}$ None $\square_{2}$ One day $\square_{3}$ Two days $\square_{4}$ Three days $\square_{5}$ Four days

C. Most anti-HIV medications need to be taken on a schedule, such as "2 times a day" or "3 times a day" or "every 8 hours." How closely did you follow your specific schedule over the last four days?

$\square_{1}$ Never $\quad \square_{2}$ Some Of The Time $\square_{3}$ About Half Of The Time $\square_{4}$ Most Of The Time $\square_{5}$ All Of The Time

D. Do any of your anti-HIV medications have special instructions, such as "take with food" or "on an empty stomach" or "with plenty of fluids?"

$\square_{1}$ Yes $\quad \square_{2}$ No

If Yes, how often did you follow those special instructions over the last four days?

$\square_{1}$ Never $\square_{2}$ Some Of The Time $\square_{3}$ About Half Of The Time $\square_{4}$ Most Of The Time $\square_{5}$ All Of The Time

E. Some people find that they forget to take their pills on the weekend days. Did you miss any of your anti-HIV medications last weekend- last Saturday or Sunday?

$\square_{1}$ Yes $\quad \square_{2}$ No

F. When was the last time you missed any of your medications? Check one.

$\square$ Within the past week

$\square 2$ 1-2 weeks ago

$\square 3$ 2-4 weeks ago

$\square 4$ 1-3 months ago

$\square$ $\square_{5}$ More than 3 months ago

$\square$ 6 Never skip medications or not applicable 


\section{QUALITY OF LIFE INDEX}

\begin{tabular}{|c|c|}
\hline ACTIVITY & SCORE \\
\hline $\begin{array}{l}\text { Since the last visit, the patient: } \\
\text {-has been working or studying full-time, or nearly so, in usual occupation; or } \\
\text { managing own household, or participating in unpaid or voluntary activities, } \\
\text { whether retired or not. } \\
\text {-has been working or studying full-time, or nearly so, in usual occupation; or } \\
\text { managing own household, or participating in unpaid or voluntary activities; but } \\
\text { requiring major assistance or a significant reduction in hours worked or sheltered } \\
\text { situation or was on sick leave } \\
\text {-has not been working or studying in any capacity and not managing own } \\
\text { household }\end{array}$ & $\begin{array}{l}2 \\
1 \\
0\end{array}$ \\
\hline DAILY LIVING & SCORE \\
\hline $\begin{array}{l}\text { Since the last visit, the patient } \\
\text {-has been self-reliant in eating, washing, toileting, and dressing; using public } \\
\text { transport, or diving own car. } \\
\text {-has been requiring assistance (another person or special equipment) for daily } \\
\text { activities and transport, but performing light tasks. } \\
\text {-has not been managing personal care or light tasks, or not leaving own home or } \\
\text { institution at all. }\end{array}$ & $\begin{array}{l}2 \\
1 \\
0\end{array}$ \\
\hline HEALTH & SCORE \\
\hline $\begin{array}{l}\text { Since the last visit, the patient } \\
\text {-has been appearing to feel well or reporting feeling "great" most of the time. } \\
\text {-has been lacking energy or not feeling entirely "up to par" more than just } \\
\text { occasionally. } \\
\text {-has been feeling very ill or "lousy", seeming weak and washed out most of the } \\
\text { time or was unconscious }\end{array}$ & $\begin{array}{l}2 \\
1\end{array}$ \\
\hline SUPPORT & SCORE \\
\hline $\begin{array}{l}\text { Since the last visit, the patient } \\
\text {-has been having good relationships with others and receiving strong } \\
\text { support from at least one family member or friend. } \\
\text {-support received or perceived has been limited from family or friends or } \\
\text { by patient's condition. } \\
\text {-support from family and friends occurred infrequently or only when } \\
\text { absolutely necessary, or patient was unconscious. }\end{array}$ & 2 \\
\hline OUTLOOK & \\
\hline $\begin{array}{l}\text { During the last week, the patient } \\
\text {-has usually been appearing calm and positive in outlook, accepting and in control } \\
\text { of personal circumstances, including surroundings. } \\
\text {-has sometimes been troubled because not fully in control of personal } \\
\text { circumstances, or has been having periods of obvious anxiety or depression } \\
\text {-has been seriously confused or very frightened, or consistently anxious and } \\
\text { depressed or confused }\end{array}$ & 2 \\
\hline
\end{tabular}




\section{J. SF-36 HEALTH SURVEY \\ Your Health and Well-Being}

This survey asks for your views about your health. This information will help keep track of how you feel and how well you are able to do your usual activities. Thank you for completing this survey!

For each of the following questions, please mark an $\bigotimes$ in the one box that best describes your answer.

1. In general, would you say your health is:

\begin{tabular}{|lllll|}
\hline Excellent & Very good & Good & Fair & Poor \\
$\square_{1}$ & $\nabla$ & $\nabla$ & $\nabla$ & $\nabla$ \\
$\square_{2}$ & $\square_{3}$ & $\square_{4}$ & $\square_{5}$
\end{tabular}

2. Compared to one year ago, how would you rate your health in general now?

$\begin{array}{|ccccc|}\begin{array}{c}\text { Much better } \\ \text { now than one } \\ \text { year ago }\end{array} & \begin{array}{c}\text { Somewhat } \\ \text { better } \\ \text { now than one } \\ \text { year ago }\end{array} & \begin{array}{c}\text { About the } \\ \text { same as } \\ \text { one year ago }\end{array} & \begin{array}{c}\text { Somewhat } \\ \text { worse } \\ \text { now than one } \\ \text { year ago }\end{array} & \begin{array}{c}\text { Much worse } \\ \text { now than } \\ \text { one year ago }\end{array} \\ \square_{1} & \square_{2} & \square 3 & \square 4\end{array}$




\section{The following questions are about activities you might do during a typical day. Does your health now limit you in these activities? If so, how much?}

a Vigorous activities, such as running, lifting heavy objects, participating in strenuous sports

b Moderate activities, such as moving a table, pushing a vacuum cleaner, bowling, or playing golf

$\begin{array}{ccc}\begin{array}{c}\text { Yes, } \\ \text { limited } \\ \text { a lot }\end{array} & \begin{array}{c}\text { Yes, limited } \\ \text { a little }\end{array} & \begin{array}{c}\text { No, not } \\ \text { limited } \\ \text { at all }\end{array} \\ & & \end{array}$

c Lifting or carrying groceries

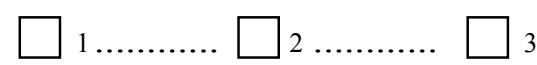

d Climbing several flights of stairs
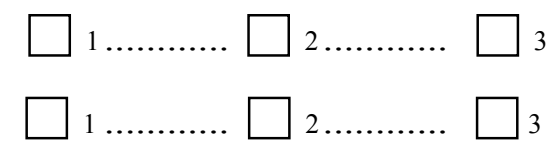

e Climbing one flight of stairs

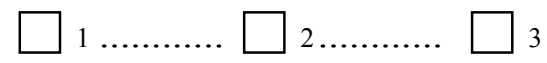

f Bending, kneeling, or stooping

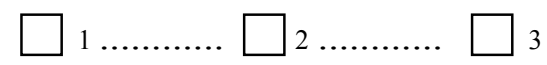

g Walking more than a mile
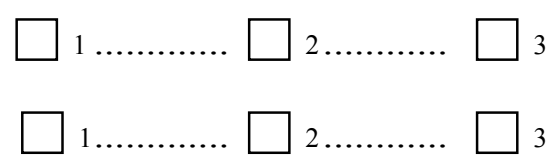

h Walking several hundred yards

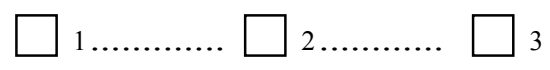

i Walking one hundred yards

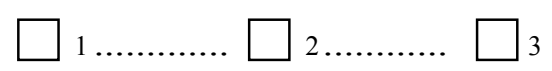

j Bathing or dressing yourself

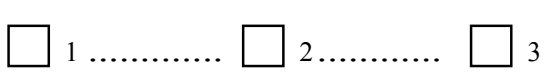


4. During the past 4 weeks, how much of the time have you had any of the following problems with your work or other regular daily activities as a result of your physical health?

a Cut down on the amount of

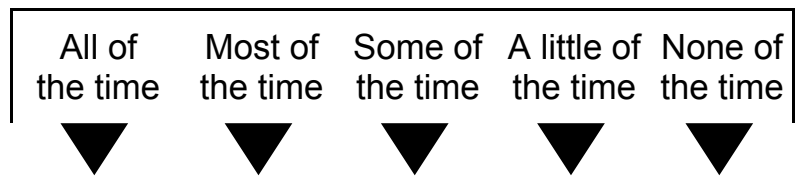
time you spent on work or

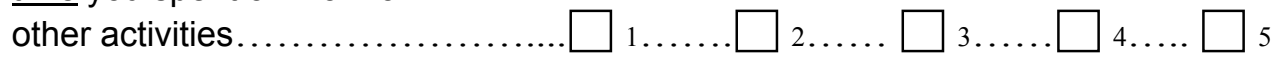

b Accomplished less than you would like.

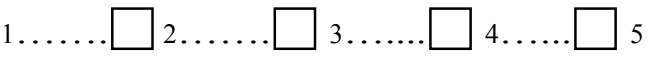

c Were limited in the kind of work or other activities. $\square_{1 \ldots \ldots} \ldots \ldots . \square 3 \ldots \ldots \square+\ldots \ldots \square \square_{5}$

d Had difficulty performing the work or other activities (for example, it took extra effort).

5. During the past 4 weeks, how much of the time have you had any of the following problems with your work or other regular daily activities as a result of any emotional problems (such as feeling depressed or anxious)?

a Cut down on the amount of

$\begin{array}{|cccc|}\begin{array}{c}\text { All of } \\ \text { the time }\end{array} & \begin{array}{c}\text { Most of } \\ \text { the time }\end{array} & \begin{array}{c}\text { Some of } \\ \text { the time little of }\end{array} \\ \text { the time }\end{array}$
time you spent on work or

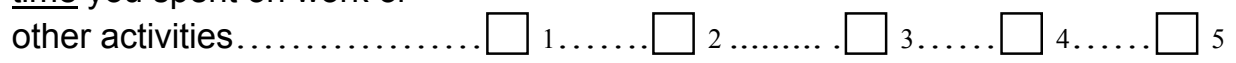

b Accomplished less than you would like. $. \square 3 \ldots \ldots \square+\ldots . . \square 5$

c Did work or other activities less carefully than usual. 
6. During the past 4 weeks, to what extent has your physical health or emotional problems interfered with your normal social activities with family, friends, neighbors, or groups?

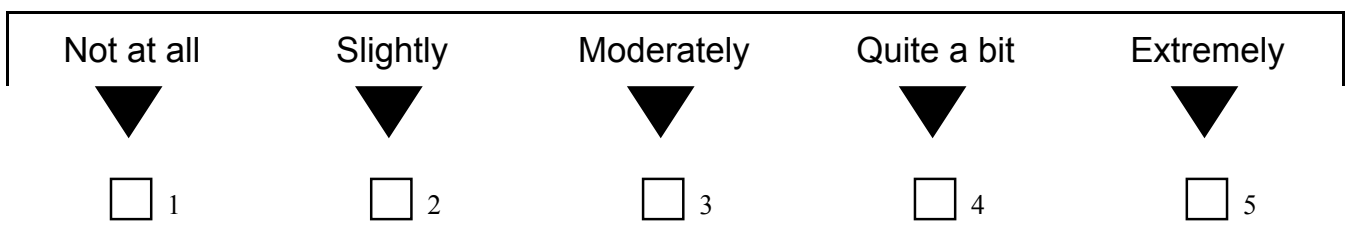

7. How much bodily pain have you had during the past 4 weeks?

\begin{tabular}{|lccccc|}
\hline None & Very mild & Mild & Moderate & Severe & Very severe \\
$\square_{1}$ & $\square_{2}$ & $\square_{3}$ & $\square_{4}$ & $\square_{5}$ & $\square_{6}$
\end{tabular}

8. During the past 4 weeks, how much did pain interfere with your normal work (including both work outside the home and housework)?

$\square_{1}^{\text {Not at all }}$


9. These questions are about how you feel and how things have been with you during the past 4 weeks. For each question, please give the one answer that comes closest to the way you have been feeling. How much of the time during the past 4 weeks...

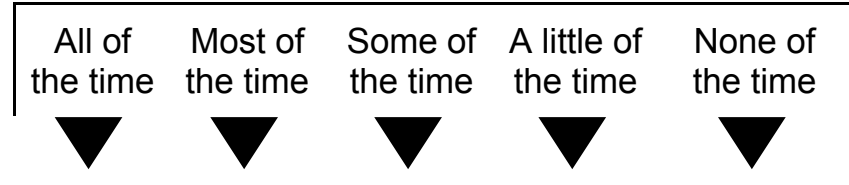
a Did you feel full of life?

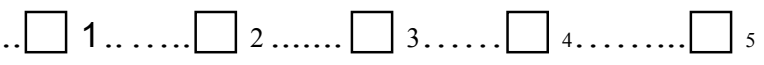

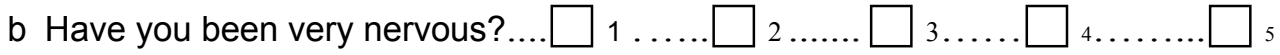
c Have you felt so down in the dumps that nothing could cheer you up?

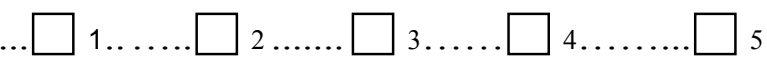
d Have you felt calm and peaceful?

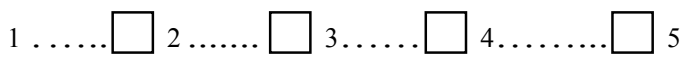
e Did you have a lot of energy?.... $\square$ 1...... $\square 2 \ldots \ldots . \square$ 3..... $\square$ 4....... $\square$ 5
f Have you felt downhearted and depressed?.
g Did you feel worn out?.............. $\square$ 1 ...... $\square 2$...... $\square \square_{3} \ldots \ldots \square$ 4........ $\square$ 5
h Have you been happy?............. $\square$ 1...... $\square 2$...... $\square \square_{3 \ldots \ldots} \square_{4 \ldots \ldots . .} \square_{5}$
i Did you feel tired?.................... $\square$ 1 ...... $\square 2 \ldots \ldots . \square{ }_{3} \ldots \ldots . \square$ 4........ $\square 5$

10. During the past 4 weeks, how much of the time has your physical health or emotional problems interfered with your social activities (like visiting with friends, relatives, etc.)?

$\begin{array}{|cccc|}\begin{array}{c}\text { All of } \\ \text { the time }\end{array} & \begin{array}{c}\text { Most of } \\ \text { the time }\end{array} & \begin{array}{l}\text { Some of } \\ \text { the time }\end{array}\end{array}$




\section{How TRUE or FALSE is each of the following statements for you?}

\begin{tabular}{|ccccc|}
\hline $\begin{array}{c}\text { Definitely } \\
\text { true }\end{array}$ & $\begin{array}{c}\text { Mostly } \\
\text { true }\end{array}$ & $\begin{array}{c}\text { Don't } \\
\text { know }\end{array}$ & $\begin{array}{c}\text { Mostly } \\
\text { false }\end{array}$ & $\begin{array}{c}\text { Definitely } \\
\text { false }\end{array}$ \\
\hline & & & &
\end{tabular}

a I seem to get sick a little

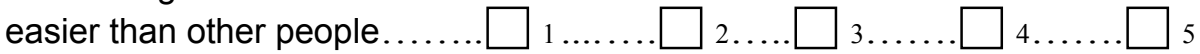

b I am as healthy as

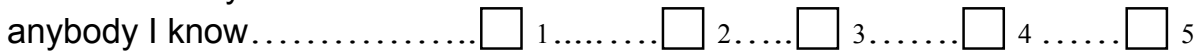

C I expect my health to

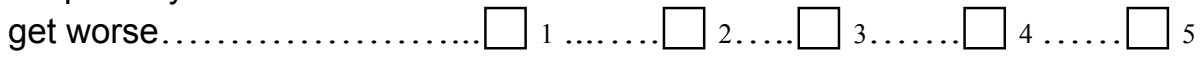

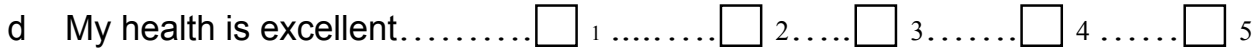




\section{K. ANTHROPOMETRICS AND LABORATORY RESULTS}

\begin{tabular}{|l|l|l|}
\hline MEASUREMENTS & RESULTS & DATE OBTAINED \\
\hline Height $(\mathrm{ft} / \mathrm{cm})$ & & \\
\hline Weight(lbs) & & \\
\hline BMI & & \\
\hline Waist & & \\
\hline Hip & & \\
\hline Waist/Hip Ratio & RESULTS & DATE OBTAINED \\
\hline TEST & & \\
\hline CD4 Cell Count & & \\
\hline Viral Load & & \\
\hline Hemoglobin & & \\
\hline Hematocrit & & \\
\hline Albumin & & \\
\hline
\end{tabular}

BODY COMPOSITION BIA RESULTS

Phase Angle

Body Capacitance

Resistance

Reactance

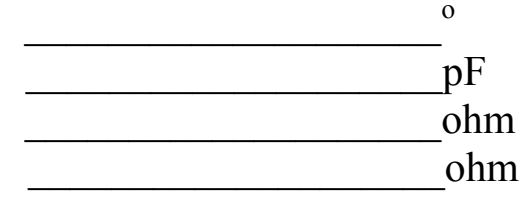

Mass Distribution

Ibs

Percent

Body Cell Mass

Extracellular Mass

Lean Body Mass

Fat Mass

Total Weight

$\mathrm{ECM} / \mathrm{BCM}$

Body Mass Index

Basal Metabolic Rate

Water Compartment

Liters

Percent

Intracellular Water

Extracellular Water

Total Body Water
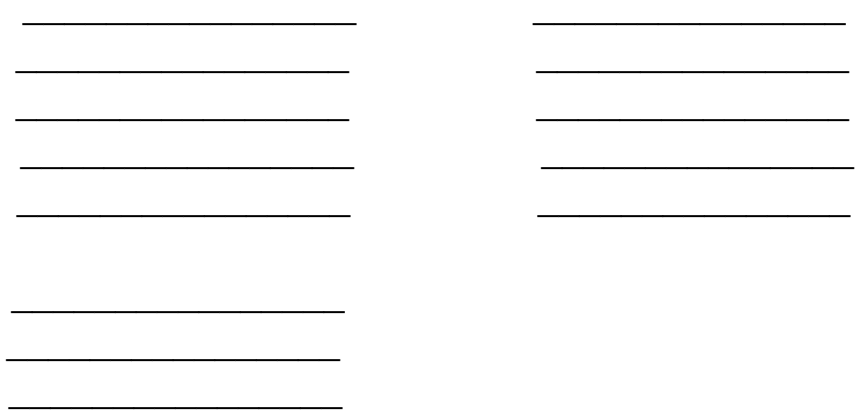

TBW/Lean Body Mass

TBW/Lean Body Weight

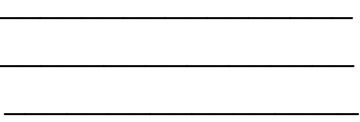

100 
Appendix C4: Intervention Study Posttest Questionnaire 


\section{A. Demographic Data}

For these questions, please circle your answers or write your answers in the spaces provided.

1. Gender: $\square_{1}$ Male $\square_{2}$ Female

2. Age: years.

3. Which of the following best describes your ethnic background?

$\square$ Black/African American

Hispanic American

$\square 2$ Asian American

5 Native American $\square$ Non-Hispanic White $\square$ 6 Other (specify):

4. Status: $\square_{1}$ Married $\square_{2}$ Single $\square_{3}$ Divorced/Widowed $\square_{4}$ Other

5. Please check your highest level of education.

$\square_{1}<$ High school

$\square$ 3 1-2 years college

$\square 2$ High school or GED

$\square_{4}$ Graduated from college

6. Work Status: $\quad \square_{1}$ Not working $\square_{3}$ Work full time $\square 2$ Work Part-time, $\square_{4}$ On disability

7. What is your monthly income?

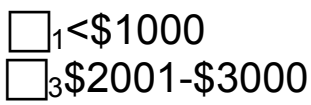
$\square_{2} \$ 1001-\$ 2000$ $\square_{4}>\$ 3001$

8. Do you live: $\square_{1}$ Alone $\quad \square_{2}$ With your family (parents, husband, children, etc) $\square_{3}$ Shelter $\square_{4}$ Street

9. Do you smoke cigarettes?

$\square_{1}$ Yes

$\square_{2}$ No

9a. If yes how often?

$\square_{1}$ Daily

$\square_{2}$ 4-6 times a week

$\square_{3}$ 2-3 times a week

$\square_{4}$ Once a week

$\square 5$ Less than once a month

$\square_{6}$ At least once a month but less than once a week

$\square_{7}$ Never

9b. If daily how many cigarettes per day

10. Do you use any drugs? $\square_{1}$ Yes $\quad \square_{2}$ No

10a.If yes please check all that apply: Marijuana $\square_{1}$ Cocaine $\square_{2}$ Crack 
$\square_{3}$ Heroin $\square_{4}$ Combination (Speedball) $\square_{5}$ Methadone

$\square_{6}$ Amphetamine (Ecstasy) $\square_{7}$ Other $\square_{8}$

11. Do you drink alcohol? $\quad \square 1$ Yes $\quad \square 2$ No

11a. If yes how often?

$\square_{1}$ Daily

$\square_{2}$ 4-6 times a week

$\square_{3}$ 2-3 times a week

$\square_{4}$ once a week

$\square$ Less than once a month

$\square$ 6 At least once a month but less than once a week

$\square_{7}$ Never

11b. If daily how many drinks per day?

----- Beer drinks

------ Wine drinks

------ Liquor drinks

Total drinks

12. Do you use ART? $\square_{1}$ Yes $\quad \square_{2}$ No

12a. List of medications (1)

(2)

(3)

(4)

(5)

13. Do you take multivitamins?

$\square_{1}$ Yes $\square_{2}$ No

13a. If yes please list them. 1)

2)

3)

4)

5)

14. Do you receive food stamps? $\quad \square_{1}$ Yes $\quad \square_{2}$ No

14a. If yes, how many months have you received food stamps in the past 12 months?

15. In the last 30 days, did you receive any foods to take home from community sources such as a food bank, food pantry, or other sources?

$\square_{1}$ Yes $\square_{2}$ No

16. In the past 30 days did you eat any meals at a soup kitchen, the Salvation Army, a family shelter, or another similar place? $\square_{1}$ Yes $\square_{2}$ No 


\section{B. Nutrition Knowledge}

Please select the best answer to each of the following questions.

1. From the following list of foods, please select the one that is highest in fiber

$\square_{1}$ kidney beans

$\square$ 2 low-fat milk

$\square_{3}$ eggs

$\square$ yogurt

2. Which of the following may help you to lower your cholesterol level?

$\square_{1}$ low fat yogurt

$\square_{2}$ oatmeal

$\square_{3}$ scrambled eggs

$\square_{4}$ croissant sandwich

3. Which of the following have the highest content of trans fats?

$\square_{1}$ coke

]$_{2}$ doughnuts

$\square_{3}$ collard greens

$\square_{4}$ baked potatoes

4. Which of the following have the highest content of saturated fat?

$\square_{1}$ low fat cottage cheese

$\square_{2}$ cooked potatoes

$\square 3$ eggs and sausages

$\square_{4}$ raw baby carrot sticks

5. Which of the following food groups contributes most to the overall saturated fat intake in the American diet?

$\square_{1}$ fruits

$\square 2$ meats

$\square 3$ dairy

$\square_{4}$ grains

6. Which of the following have the highest content of cholesterol?

$\square$ citrus fruits

2 eggs

3 low fat milk

$\square_{4}$ whole wheat flour

7. Which of the following is more likely the highest in sodium?

$\square_{1}$ low fat cottage cheese

$\square_{2}$ cooked potatoes

$\square 3$ rolled oats

$\square$ raw baby carrot sticks

8. Which of the following have the highest content of added sugar? 
$\square_{1}$ fruit salad

12 potato salad

$\square_{3}$ coke

$\square_{4}$ eggs and sausages

9. Which of the following is the recommended daily number of servings of fruits for a reference $2,000 \mathrm{kcal}$ diet?

$\square_{1}$ one $\quad \square_{2}$ two $\quad \square_{3}$ three $\quad \square_{4}$ four

10. Which of the following is the recommended daily number of cups of vegetables for a reference $2,000 \mathrm{kcal}$ diet?

$\square_{1}$ one and one half $\square_{2}$ two and one half $\square_{3}$ three and one half $\square_{4}$ four and one half

11. Adequate intake of whole grains could help me to stay prevent constipation.

$\square_{1}$ True $\quad \square_{2}$ False $\square_{3}$ I do not know

12. Regular consumption of nuts such as walnuts, pecans or peanuts helps to lower cholesterol.

$\square_{1}$ True $\quad \square_{2}$ False $\quad \square_{3}$ I do not know

13. Regular intake of flax seeds helps in reducing risk for heart disease.

$\square_{1}$ True $\quad \square_{2}$ False $\square_{3}$ I do not know

14. Cakes, cookies, crackers, are high in trans fats.

$\square_{1}$ True $\quad \square_{2}$ False $\quad \square_{3}$ I do not know

15. Trans fats may contribute to the development of a heart attack or a stroke.

$\square_{1}$ True $\quad \square_{2}$ False $\square_{3}$ I do not know

16. Olive oil is a good source of beneficial fat.

$\square_{1}$ True $\quad \square_{2}$ False $\quad \square_{3}$ I do not know

17. Heart diseases are the number one cause of death in America.

$\square_{1}$ True $\quad \square_{2}$ False $\square_{3}$ I do not know

18. Eating adequate amounts of fruits may help prevent from developing cancer.

$\square_{1}$ True $\quad \square_{2}$ False $\square_{3}$ I do not know

19. Regular intake of whole grains may help to prevent diabetes.

$\square_{1}$ True $\quad \square_{2}$ False $\quad \square_{3}$ I do not know

20. Eating foods that are high in fiber (e.g. oats, beans, fruits) may help to reduce blood cholesterol level. $\square_{1}$ True $\quad \square_{2}$ False $\quad \square_{3}$ I do not 
C. Food Frequency. I am now going to ask you questions about foods that you usually eat. For each food, I want to know whether you eat it (yes or no), and approximately how many times you eat it, (times per day, week, month).

\begin{tabular}{|c|c|c|}
\hline Do you eat ... & & $\begin{array}{l}\text { How often do } \\
\text { you eat? }\end{array}$ \\
\hline Fruits (excluding juices) & Yes / No & d w m \\
\hline $\begin{array}{l}\text { Legumes (beans, chick peas, lentils, } \\
\text { pigeon peas) }\end{array}$ & Yes / No & $\ldots \mathrm{d} w \mathrm{~m}$ \\
\hline Green leafy vegetables, lettuce & Yes / No & $\mathrm{d} w \mathrm{~m}$ \\
\hline $\begin{array}{l}\text { Milk, type of milk } 4 \% 2 \% 1 \% \text { skim Other } \\
\text { type of milk }\end{array}$ & Yes / No & $\ldots d w m$ \\
\hline Cheese or yogurt & Yes / No & d w m \\
\hline Meats (chicken, beef, pork, ham) & Yes / No & d w m \\
\hline Fish and Shellfish & Yes / No & $\ldots \mathrm{d} \mathrm{w} \mathrm{m}$ \\
\hline Eggs & Yes / No & d w m \\
\hline $\begin{array}{l}\text { Pasta, breads and cereals (e.g. rice, } \\
\text { spaghetti) }\end{array}$ & Yes / No & d \\
\hline $100 \%$ fruit juice & Yes / No & d $w \mathrm{~m}$ \\
\hline $\begin{array}{l}\text { Artificial drinks (e.g. sunny delight, tang, } \\
\text { kool aid) }\end{array}$ & Yes / No & $\ldots d w m$ \\
\hline Regular soft drink (e.g. Pepsi, Coke) & Yes / No & d w m \\
\hline $\begin{array}{l}\text { Diet soft drinks and drinks with artificial } \\
\text { sweeteners }\end{array}$ & Yes / No & $\ldots d w m$ \\
\hline Regular sweets and desserts & Yes / No & $\ldots \mathrm{d} w \mathrm{~m}$ \\
\hline $\begin{array}{l}\text { Sweets and desserts with artificial } \\
\text { sweeteners }\end{array}$ & Yes / No & $\ldots \mathrm{d} w \mathrm{~m}$ \\
\hline $\begin{array}{l}\text { Snack foods (e.g., potato chips, } \\
\text { Nachos, etc) }\end{array}$ & Yes / No & $\ldots d w m$ \\
\hline
\end{tabular}


D. Where do you obtain your meals? Please check what applies the most $\square_{1}$ Home $\square_{2}$ Restaurant $\square_{3}$ Shelter $\square_{4}$ Fast Food $\square_{5}$ Other, please specify

Write down everything you had to eat and drink yesterday from the first thing in the morning until the last thing at night. Give as much detail as possible, more detail is better.

\begin{tabular}{|c|c|c|c|}
\hline Time or Meal & $\begin{array}{c}\text { Food or Beverage } \\
\text { Item } \\
\text { (Describe) }\end{array}$ & $\begin{array}{c}\text { How Much? } \\
\text { (Amount/size) }\end{array}$ & $\begin{array}{c}\text { How or } \\
\text { Where } \\
\text { Prepared? }\end{array}$ \\
\hline $\begin{array}{l}\text { Such as: } \\
\text { morning, mid- } \\
\text { morning, } \\
\text { lunch, } \\
\text { afternoon, } \\
\text { evening or } \\
\text { late evening }\end{array}$ & $\begin{array}{c}\text { List all foods or a } \\
\text { combination food. For } \\
\text { example, a taco could } \\
\text { be: } \\
\text { Corn tortilla } \\
\text { Ground beef } \\
\text { Lettuce } \\
\text { Tomato } \\
\text { Cheddar cheese } \\
\text { Sour cream } \\
2 \% \text { Milk } \\
\end{array}$ & $\begin{array}{c}\text { For the taco example it } \\
\text { could be: } \\
1 \\
3 \text { oz. } \\
1 / 2 \text { cup } \\
1 / 4 \text { cup } \\
2 \text { oz. } \\
1 \text { tablespoon } \\
1 \text { cup }\end{array}$ & $\begin{array}{c}\text { Such as: } \\
\text { Baked } \\
\text { Fried } \\
\text { Fresh } \\
\text { Broiled } \\
\text { Grilled } \\
\text { Boiled } \\
\text { McDonald's }\end{array}$ \\
\hline & & & \\
\hline & & & \\
\hline & & & \\
\hline & & & \\
\hline & & & \\
\hline & & & \\
\hline & & & \\
\hline & & & \\
\hline & & & \\
\hline & & & \\
\hline & & & \\
\hline & & & \\
\hline & & & \\
\hline & & & \\
\hline
\end{tabular}




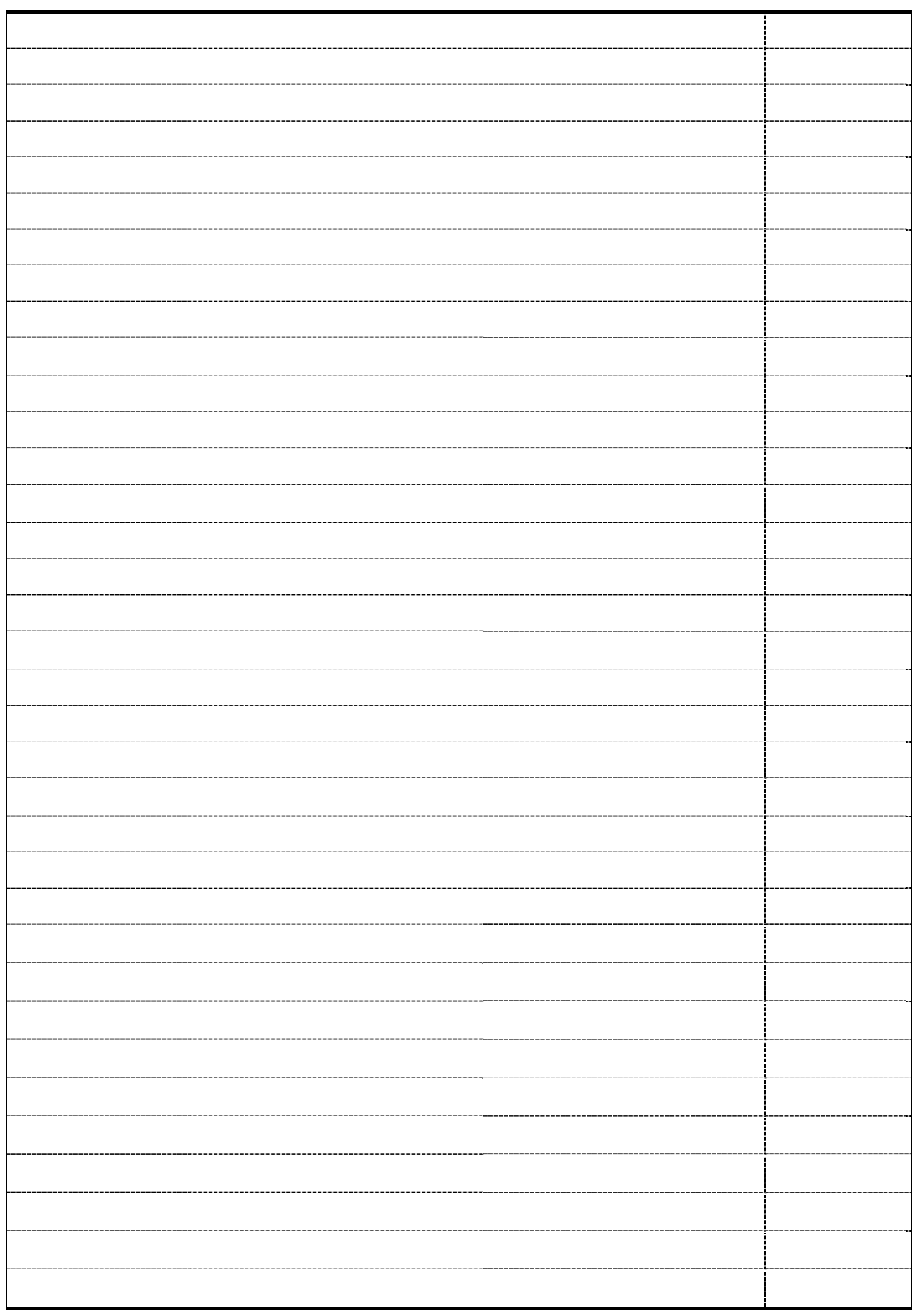




\section{E. FRUITS \& VEGETABLES: Staging}

Fruits and vegetables come in many forms: fresh, frozen, canned, dried, and $100 \%$ fruit and vegetable juices. Fruits and vegetables can be cooked or eaten raw. They can also be eaten by themselves or as part of a mixed dish such as soups or casseroles.

Use this table to help you count your fruit and vegetable servings...

COUNT AS ONE SERVING: Vegetables:

- $1 / 2$ cup of cooked or raw vegetables

- 1 cup of raw leafy greens

Fruit:

- $1 / 2$ cup or a medium sized piece of fruit

- $3 / 4$ cup of $100 \%$ fruit juice

- 1/4 cup of dried fruit

A. How many servings of fruits and vegetables do you usually eat each day? Please select one and fill in the circle.

None (Go to Question B1)

O 1 Serving (Go to Question B1)

○ 2 Servings Days (Go to Question B1)

O 3 Servings (Go to Question B1)

○ 4 Servings (Go to Question B1)

O 5 Servings (Go to Question B2)

O 6 Servings or more (Go to Question B2)

B1. Do you intend to change what you eat so you will eat at least 5 servings of fruits and vegetables every day? Please select one and fill in the circle.

No, and I don't intend to in the next 6 months (Go to Next Page)

$O$ Yes, and I intend to in the next 6 months (Go to Next Page)

O Yes, and I intend to in the next 30 days (Go to Next Page)

B2. You report that you have been eating 5 or more regular servings of fruits and vegetables.

For how many months have you been doing this? Please select one and fill in the circle.

$\bigcirc$ Less than 6 months

O 6 months or more 


\section{DIETARY FAT: Staging}

A. Do you regularly eat 5 or fewer servings of high fat foods every day? Please select one and fill in the circle.

O No, I eat more than 5 servings of high fat foods per day (Go to Question B1)

$\bigcirc$ Yes, I eat 5 or fewer servings of high fat foods per day (Go to Question B2)

B1. Do you intend to change what you eat so you will eat 5 or fewer servings of high fat foods every day in the next 6 months? Please select one and fill in the circle.

$\bigcirc$ No, and I don't intend to in the next 6 months (Go to Next Page)

Yes, and I intend to in the next 6 months (Go to Next Page)

Yes, and I intend to in the next 30 days (Go to Next Page)

B2. For how many months have you been eating 5 or fewer servings of high fat foods every day? Please select one and fill in the circle.

$\bigcirc$ Less than 6 months

O 6 months or more 


\section{FIBER: Staging}

A. Do you eat regular servings of high fiber foods? Please select one and fill in the circle.

No (Go to Question B1)

Yes (Go to Question B2)

B1. Do you intend to change what you eat so you will eat more high fiber foods in the next 6 months? You can get this by eating high fiber cereals ( 5 grams/serving), breads ( 2 grams per serving), beans and legumes, fruits, and vegetables. Please select one and fill in the circle.

No, and I don't intend to in the next 6 months (Go to Next Page)

Yes, and I intend to in the next 6 months (Go to Next Page)

$\bigcirc$ Yes, and I intend to in the next 30 days (Go to Next Page)

B2. You report that you've been eating regular servings of high fiber foods. For how many months have you been consuming this amount of fiber? Please select one and fill in the circle.

Less than 6 months

O months or more 


\section{F. FRIUT AND VEGETABLE SELF EFFICACY}

There are many things that can get in the way of choosing to eat 5 fruits and vegetables each day Rate HOW CONFIDENT you are that you can do the following using the scale below.

\begin{tabular}{|l|l|l|l|l|l|}
\hline & $\begin{array}{l}\text { Not at All } \\
\text { Confident }\end{array}$ & $\begin{array}{l}\text { Somewhat } \\
\text { Confident }\end{array}$ & $\begin{array}{l}\text { Moderately } \\
\text { Confident }\end{array}$ & $\begin{array}{l}\text { Very } \\
\text { Confident }\end{array}$ & $\begin{array}{l}\text { Extremely } \\
\text { Confident }\end{array}$ \\
\hline $\begin{array}{l}\text { Eat } 5 \text { servings of fruits and vegetables } \\
\text { everyday? }\end{array}$ & & & & & \\
\hline $\begin{array}{l}\text { Drink } 100 \% \text { fruit juice instead of soda or fruit } \\
\text { punch? }\end{array}$ & & & & & \\
\hline $\begin{array}{l}\text { Eat fruits and vegetables for a snack instead } \\
\text { of chips or candy? }\end{array}$ & & & & & \\
\hline $\begin{array}{l}\text { Eat fruits and vegetables when eating out at } \\
\text { a restaurant? }\end{array}$ & & & & & \\
\hline $\begin{array}{l}\text { Eat fruits and vegetables when I am upset or } \\
\text { having a bad day? }\end{array}$ & & & & & \\
\hline $\begin{array}{l}\text { Eat fruits and vegetables when I am at a } \\
\text { social event? }\end{array}$ & & & & & \\
\hline
\end{tabular}




\section{DIETARY FIBER SELF-EFFICACY}

There are many things that can get in the way of choosing to eat foods high in fiber. Rate HOW CONFIDENT you are that you can do the following using the scale below

\begin{tabular}{|l|l|l|l|l|l|}
\hline & $\begin{array}{l}\text { Not at All } \\
\text { Confident }\end{array}$ & $\begin{array}{l}\text { Somewhat } \\
\text { Confident }\end{array}$ & $\begin{array}{l}\text { Moderately } \\
\text { Confident }\end{array}$ & $\begin{array}{l}\text { Very } \\
\text { Confident }\end{array}$ & $\begin{array}{l}\text { Extremely } \\
\text { Confident }\end{array}$ \\
\hline $\begin{array}{l}\text { Choose high fiber cereals over low fiber and sugary } \\
\text { cereals? }\end{array}$ & & & & & \\
\hline Avoid foods that are low in fiber? & & & & & \\
\hline $\begin{array}{l}\text { Choose high fiber foods even when you are upset and } \\
\text { having a bad day }\end{array}$ & & & & & \\
\hline $\begin{array}{l}\text { Choose high fiber snacks instead of doughnuts or } \\
\text { cookies? }\end{array}$ & & & & & \\
\hline Eat 5 servings of whole grains and beans every day? & & & & & \\
\hline $\begin{array}{l}\text { Choose selections with whole grains or beans when } \\
\text { out at a restaurant? }\end{array}$ & & & & & \\
\hline Regularly eat whole grain bread? & & & & & \\
\hline $\begin{array}{l}\text { Choose foods that are high in fiber when at a social } \\
\text { event? }\end{array}$ & & & & & \\
\hline
\end{tabular}




\section{DIETARY FAT SELF EFFICACY}

There are many things that can get in the way of choosing to eat a diet low in fat. HOW CONFIDENT are you that you can choose low fat foods in each situation?

\begin{tabular}{|l|l|l|l|l|l|}
\hline & $\begin{array}{l}\text { Not at All } \\
\text { Confident }\end{array}$ & $\begin{array}{l}\text { Somewhat } \\
\text { Confident }\end{array}$ & $\begin{array}{l}\text { Moderately } \\
\text { Confident }\end{array}$ & $\begin{array}{l}\text { Very } \\
\text { Confident }\end{array}$ & $\begin{array}{l}\text { Extremely } \\
\text { Confident }\end{array}$ \\
\hline $\begin{array}{l}\text { When others around you are eating high fat } \\
\text { foods. }\end{array}$ & & & & & \\
\hline When you are craving high fat foods. & & & & & \\
\hline When you are out at a restaurant. & & & & & \\
\hline When you are upset or having a bad day. & & & & & \\
\hline When you are at a social event. & & & & & \\
\hline
\end{tabular}


When you are grocery shopping how confident are you in your ability to? (check one answer for each food type)

\begin{tabular}{|l|c|c|c|c|}
\hline $\begin{array}{l}\text { How confident are you in your } \\
\text { ability to }\end{array}$ & $\begin{array}{c}\text { Not at all } \\
\text { confident }\end{array}$ & $\begin{array}{c}\text { Not } \\
\text { confident }\end{array}$ & $\begin{array}{c}\text { Somewhat } \\
\text { confident }\end{array}$ & $\begin{array}{c}\text { Very } \\
\text { confident }\end{array}$ \\
\hline $\begin{array}{l}\text { Select whole grain bread or } \\
\text { cereal in a grocery store? .. }\end{array}$ & $\square$ & $\square$ & $\square$ & $\square$ \\
$\begin{array}{l}\text { Select low fat dairy products } \\
\text { (e.g. yogurt) }\end{array}$ & $\square$ & $\square$ & $\square$ & $\square$ \\
$\begin{array}{l}\text { Select foods that are low in } \\
\text { sodium }\end{array}$ & $\square$ & $\square$ & $\square$ & $\square$ \\
$\begin{array}{l}\text { Select foods that are low in } \\
\text { saturated fat? }\end{array}$ & $\square$ & $\square$ & $\square$ & $\square$ \\
$\begin{array}{l}\text { Select foods that are low in } \\
\text { cholesterol? } \\
\text { Select foods high in dietary } \\
\text { fiber? }\end{array}$ & $\square$ & $\square$ & $\square$ & $\square$ \\
$\begin{array}{l}\text { Select foods that are low in or } \\
\text { free of trans fats? }\end{array}$ & $\square$ & $\square$ & $\square$ & $\square$ \\
\hline
\end{tabular}




\section{G. MORBIDITY}

Have you experienced any of these signs and symptoms in the last month?

\begin{tabular}{|c|c|c|}
\hline Sign and Symptom & Yes & No \\
\hline \multicolumn{3}{|l|}{ Fever } \\
\hline \multicolumn{3}{|l|}{ Chills } \\
\hline \multicolumn{3}{|l|}{ Fatigue } \\
\hline \multicolumn{3}{|l|}{ Malaise } \\
\hline \multicolumn{3}{|l|}{ Lethargy } \\
\hline \multicolumn{3}{|l|}{ Headache } \\
\hline \multicolumn{3}{|l|}{ Skin Lesion or Rash } \\
\hline \multicolumn{3}{|l|}{ Visual changes } \\
\hline \multicolumn{3}{|l|}{ Oral Lesion } \\
\hline \multicolumn{3}{|l|}{ Abdominal Discomfort } \\
\hline \multicolumn{3}{|l|}{ Anorexia } \\
\hline \multicolumn{3}{|l|}{ Dysphagia } \\
\hline \multicolumn{3}{|l|}{ Nausea } \\
\hline \multicolumn{3}{|l|}{ Vomiting } \\
\hline \multicolumn{3}{|l|}{ Diarrhea } \\
\hline \multicolumn{3}{|l|}{ Constipation } \\
\hline \multicolumn{3}{|l|}{ Rectal or Anal Lesions } \\
\hline \multicolumn{3}{|l|}{ Changes in weight } \\
\hline \multicolumn{3}{|l|}{ Cough } \\
\hline \multicolumn{3}{|l|}{ Wheezing } \\
\hline \multicolumn{3}{|l|}{ Chest pain } \\
\hline \multicolumn{3}{|l|}{ Difficulty breathing } \\
\hline \multicolumn{3}{|l|}{ Shortness of breath } \\
\hline \multicolumn{3}{|l|}{ Anemia } \\
\hline \multicolumn{3}{|l|}{ Numbness } \\
\hline \multicolumn{3}{|l|}{ Sharp pain } \\
\hline \multicolumn{3}{|l|}{ Loss of coordination } \\
\hline \multicolumn{3}{|l|}{ Impaired concentration } \\
\hline \multicolumn{3}{|l|}{ Apathy or mood changes } \\
\hline \multicolumn{3}{|l|}{ Seizures } \\
\hline Dysuria & & \\
\hline Genital discharge & & \\
\hline Genital lesion & & \\
\hline Myalgia & & \\
\hline Arthralgia & & \\
\hline
\end{tabular}




\section{H. MEDICATION ADHERENCE QUESTIONNIARE}

This answers you give on this form will be used to plan ways to help other people who must take pills on a difficult schedule. Please do the best you can to answer all the questions. If you do not wish to answer a question, please draw a line through it. If you do not know how to answer a question, ask your study nurse to help. Thank you for helping in this important study.

PATIENT ONLY continue here.

The next section of the questionnaire asks about your HIV study medications that you took over the last four days.

Most people with HIV have many pills to take at different times during the day.

Many people find it hard to

always remember their pills:

- Some people get busy and forget to carry their pills with them. such

- Some people find it hard to take their pills according to all the instructions, stomach,"

as "with on every 8 hours," "with plenty of fluids" meals," or " an empty

- Some people decide to skip doses to avoid side effects or to just not be taking

pills that day.

We need to understand how people with HIV are really doing with their pills.

Please tell us what you are actually doing. Don't worry about telling us that you don't take all your pills. We need to know what is really happening, not what you think we "want to hear"

The next section of the questionnaire asks about the study medications that you may have missed taking over the last four days. Please complete the following table by filling in the boxes below.

A.IF YOU TOOK ONLY A PORTION OF A DOSE ON ONE OR MORE OF THESE DAYS, PLEASE REPORT THE DOSE(S) AS BEING MISSED.

\begin{tabular}{|l|l|l|l|l|}
\hline \multirow{2}{*}{$\begin{array}{l}\text { Names of your } \\
\text { anti-HIV } \\
\text { medications }\end{array}$} & \multicolumn{4}{|l|}{ How many doses did you miss } \\
\hline & Yesterday & $\begin{array}{l}2 \text { days } \\
\text { ago }\end{array}$ & 3 days ago & 4 days ago \\
\hline & & & & \\
\hline & & & & \\
\hline & & & & \\
\hline & & & & \\
\hline & & & & \\
\hline & & & & \\
\hline
\end{tabular}


B. During the past 4 days, on how many days have you missed taking all your doses?

$\square_{1}$ None $\square_{2}$ One day $\square_{3}$ Two days $\square_{4}$ Three days $\square_{5}$ Four days

C. Most anti-HIV medications need to be taken on a schedule, such as "2 times a day" or "3 times a day" or "every 8 hours." How closely did you follow your specific schedule over the last four days?

$\square_{1}$ Never $\quad \square_{2}$ Some Of The Time $\square_{3}$ About Half Of The Time $\square_{4}$ Most Of The Time $\square$ A All Of The Time

D. Do any of your anti-HIV medications have special instructions, such as "take with food" or "on an empty stomach" or "with plenty of fluids?"

$\square_{1}$ Yes $\quad \square 2$ No

If Yes, how often did you follow those special instructions over the last four days?

$\square_{1}$ Never $\square_{2}$ Some Of The Time $\square_{3}$ About Half Of The Time

$\square_{4}$ Most Of The Time

$\square$ All Of The Time

E. Some people find that they forget to take their pills on the weekend days. Did you miss any of your anti-HIV medications last weekend- last Saturday or Sunday?

$\square_{1}$ Yes $\quad \square_{2}$ No

F. When was the last time you missed any of your medications? Check one.

$\square_{1}$ Within the past week

$\square 2$ 1-2 weeks ago

$\square 3$ 2-4 weeks ago

$\square_{4}$ 1-3 months ago

$\square$. More than 3 months ago

$\square$ 6 Never skip medications or not applicable 


\section{QUALITY OF LIFE INDEX}

\begin{tabular}{|c|c|}
\hline ACTIVITY & SCORE \\
\hline $\begin{array}{l}\text { Since the last visit, the patient: } \\
\text {-has been working or studying full-time, or nearly so, in usual occupation; or } \\
\text { managing own household, or participating in unpaid or voluntary activities, } \\
\text { whether retired or not. } \\
\text {-has been working or studying full-time, or nearly so, in usual occupation; or } \\
\text { managing own household, or participating in unpaid or voluntary activities; but } \\
\text { requiring major assistance or a significant reduction in hours worked or sheltered } \\
\text { situation or was on sick leave } \\
\text {-has not been working or studying in any capacity and not managing own } \\
\text { household }\end{array}$ & $\begin{array}{l}2 \\
1 \\
0\end{array}$ \\
\hline DAILY LIVING & SCORE \\
\hline $\begin{array}{l}\text { Since the last visit, the patient } \\
\text {-has been self-reliant in eating, washing, toileting, and dressing; using public } \\
\text { transport, or diving own car. } \\
\text {-has been requiring assistance (another person or special equipment) for daily } \\
\text { activities and transport, but performing light tasks. } \\
\text {-has not been managing personal care or light tasks, or not leaving own home or } \\
\text { institution at all. }\end{array}$ & $\begin{array}{l}2 \\
1 \\
0\end{array}$ \\
\hline HEALTH & SCORE \\
\hline $\begin{array}{l}\text { Since the last visit, the patient } \\
\text {-has been appearing to feel well or reporting feeling "great" most of the time. } \\
\text {-has been lacking energy or not feeling entirely "up to par" more than just } \\
\text { occasionally. } \\
\text {-has been feeling very ill or "lousy", seeming weak and washed out most of the } \\
\text { time or was unconscious }\end{array}$ & $\begin{array}{l}2 \\
1\end{array}$ \\
\hline SUPPORT & SCORE \\
\hline $\begin{array}{l}\text { Since the last visit, the patient } \\
\text {-has been having good relationships with others and receiving strong } \\
\text { support from at least one family member or friend. } \\
\text {-support received or perceived has been limited from family or friends or } \\
\text { by patient's condition. } \\
\text {-support from family and friends occurred infrequently or only when } \\
\text { absolutely necessary, or patient was unconscious. }\end{array}$ & 2 \\
\hline \multicolumn{2}{|l|}{ OUTLOOK } \\
\hline $\begin{array}{l}\text { During the last week, the patient } \\
\text {-has usually been appearing calm and positive in outlook, accepting and in control } \\
\text { of personal circumstances, including surroundings. } \\
\text {-has sometimes been troubled because not fully in control of personal } \\
\text { circumstances, or has been having periods of obvious anxiety or depression } \\
\text {-has been seriously confused or very frightened, or consistently anxious and } \\
\text { depressed or confused }\end{array}$ & 2 \\
\hline
\end{tabular}




\section{J. SF-36 HEALTH SURVEY \\ Your Health and Well-Being}

This survey asks for your views about your health. This information will help keep track of how you feel and how well you are able to do your usual activities. Thank you for completing this survey!

For each of the following questions, please mark an $\bigotimes$ in the one box that best describes your answer.

1. In general, would you say your health is:

\begin{tabular}{|lllll|}
\hline Excellent & Very good & Good & Fair & Poor \\
$\square_{1}$ & $\square_{2}$ & $\square_{3}$ & $\square_{4}$ & $\square_{5}$
\end{tabular}

2. Compared to one year ago, how would you rate your health in general now?

$\begin{array}{|ccccc|}\begin{array}{c}\text { Much better } \\ \text { now than one } \\ \text { year ago }\end{array} & \begin{array}{c}\text { Somewhat } \\ \text { better } \\ \text { now than one } \\ \text { year ago }\end{array} & \begin{array}{c}\text { About the } \\ \text { same as } \\ \text { one year ago }\end{array} & \begin{array}{c}\text { Somewhat } \\ \text { worse } \\ \text { now than one } \\ \text { year ago }\end{array} & \begin{array}{c}\text { Much worse } \\ \text { now than } \\ \text { one year ago }\end{array} \\ \square 1 & \square 2 & \square 3 & \square 4 & \square 5\end{array}$




\section{The following questions are about activities you might do during a typical day. Does your health now limit you in these activities? If so, how much?}

a Vigorous activities, such as running, lifting heavy objects, participating in strenuous sports

b Moderate activities, such as moving a table, pushing a vacuum cleaner, bowling, or playing golf

$\begin{array}{ccc}\begin{array}{c}\text { Yes, } \\ \text { limited } \\ \text { a lot }\end{array} & \begin{array}{c}\text { Yes, limited } \\ \text { a little }\end{array} & \begin{array}{c}\text { No, not } \\ \text { limited } \\ \text { at all }\end{array} \\ & & \end{array}$

c Lifting or carrying groceries

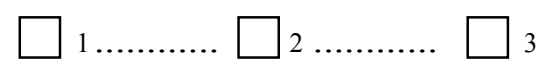

d Climbing several flights of stairs
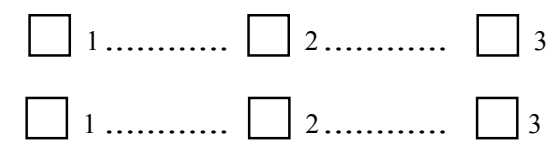

e Climbing one flight of stairs

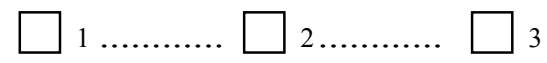

f Bending, kneeling, or stooping

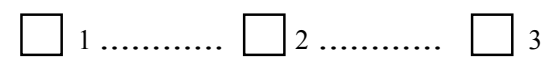

g Walking more than a mile
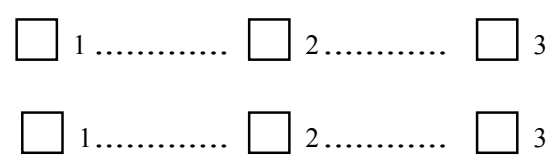

h Walking several hundred yards

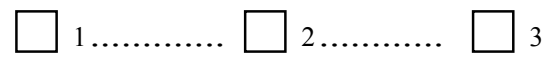

i Walking one hundred yards

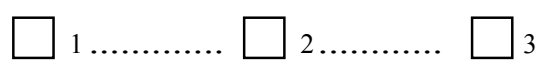

j Bathing or dressing yourself

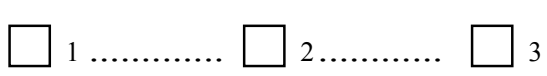


4. During the past 4 weeks, how much of the time have you had any of the following problems with your work or other regular daily activities as a result of your physical health?

a Cut down on the amount of

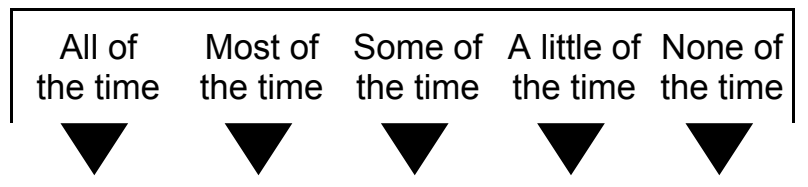
time you spent on work or

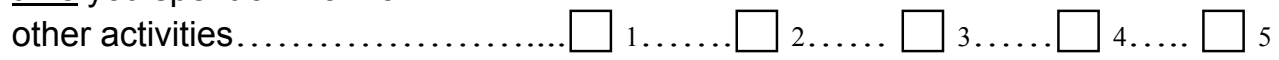

b Accomplished less than you would like.

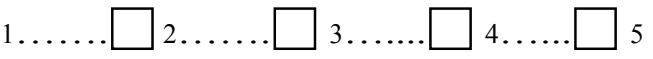

c Were limited in the kind of work or other activities. $1 \ldots \ldots . \square 2 \ldots \ldots . \square 3 \ldots \ldots \square+\ldots \ldots \square$

d Had difficulty performing the work or other activities (for example, it took extra effort).

5. During the past 4 weeks, how much of the time have you had any of the following problems with your work or other regular daily activities as a result of any emotional problems (such as feeling depressed or anxious)?

a Cut down on the amount of

$\begin{array}{cccc}\begin{array}{c}\text { All of } \\ \text { the time }\end{array} & \begin{array}{c}\text { Most of } \\ \text { the time }\end{array} & \begin{array}{c}\text { Some of } \\ \text { the time }\end{array} & \begin{array}{c}\text { Alttle of } \\ \text { the time }\end{array}\end{array}$
time you spent on work or

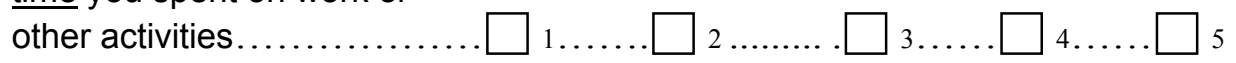

b Accomplished less than you would like. $. \square 3 \ldots \ldots \square+\ldots . . \square 5$

c Did work or other activities less carefully than usual. 
6. During the past 4 weeks, to what extent has your physical health or emotional problems interfered with your normal social activities with family, friends, neighbors, or groups?

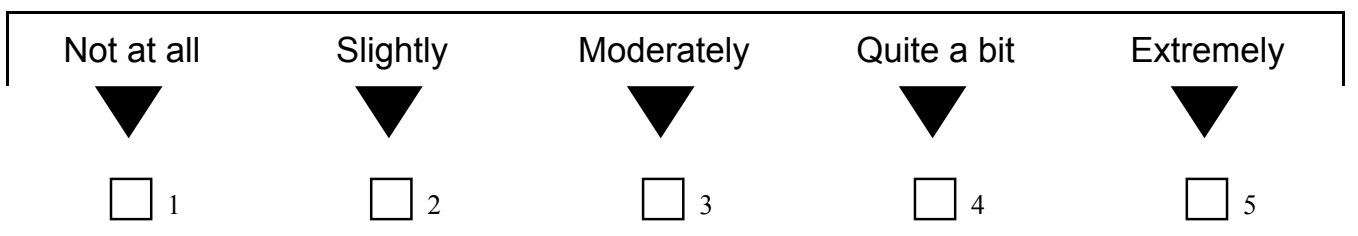

7. How much bodily pain have you had during the past 4 weeks?

\begin{tabular}{|lccccc|}
\hline None & Very mild & Mild & Moderate & Severe & Very severe \\
$\square_{1}$ & $\square_{2}$ & $\square_{3}$ & $\square_{4}$ & $\square_{5}$ & $\square_{6}$
\end{tabular}

8. During the past 4 weeks, how much did pain interfere with your normal work (including both work outside the home and housework)?

$\square_{1}^{\text {Not at all }}$


9. These questions are about how you feel and how things have been with you during the past 4 weeks. For each question, please give the one answer that comes closest to the way you have been feeling. How much of the time during the past 4 weeks...

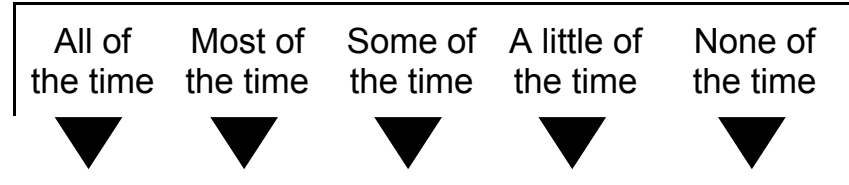
a Did you feel full of life?

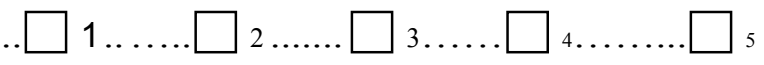

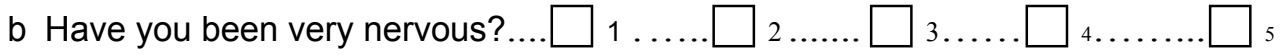
c Have you felt so down in the dumps that nothing could cheer you up?

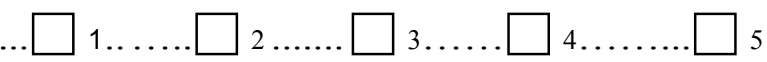
d Have you felt calm and peaceful?

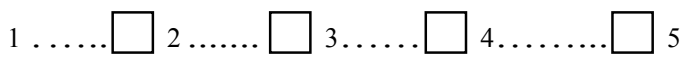
e Did you have a lot of energy?.... $\square$ 1...... $\square 2 \ldots \ldots . \square$ 3..... $\square$ 4....... $\square$ 5
f Have you felt downhearted and depressed?.
g Did you feel worn out?.............. $\square$ 1 ...... $\square 2$...... $\square \square_{3} \ldots \ldots \square$ 4........ $\square$ 5
h Have you been happy?............. $\square$ 1...... $\square 2$...... $\square \square_{3 \ldots \ldots} \square_{4 \ldots \ldots . .} \square_{5}$
i Did you feel tired?.................... $\square$ 1 ...... $\square 2 \ldots \ldots . \square{ }_{3} \ldots \ldots . \square$ 4........ $\square 5$

10. During the past 4 weeks, how much of the time has your physical health or emotional problems interfered with your social activities (like visiting with friends, relatives, etc.)?

$\begin{array}{|cccc|}\begin{array}{c}\text { All of } \\ \text { the time }\end{array} & \begin{array}{c}\text { Most of } \\ \text { the time }\end{array} & \begin{array}{l}\text { Some of } \\ \text { the time }\end{array}\end{array}$




\section{How TRUE or FALSE is each of the following statements for you?}

\begin{tabular}{|ccccc|}
\hline $\begin{array}{c}\text { Definitely } \\
\text { true }\end{array}$ & $\begin{array}{c}\text { Mostly } \\
\text { true }\end{array}$ & $\begin{array}{c}\text { Don't } \\
\text { know }\end{array}$ & $\begin{array}{c}\text { Mostly } \\
\text { false }\end{array}$ & $\begin{array}{c}\text { Definitely } \\
\text { false }\end{array}$ \\
\hline & & & &
\end{tabular}

a I seem to get sick a little

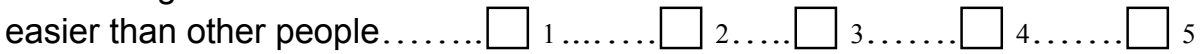

b I am as healthy as

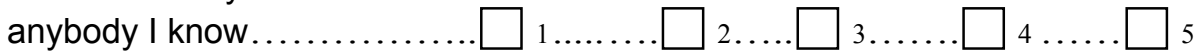

C I expect my health to

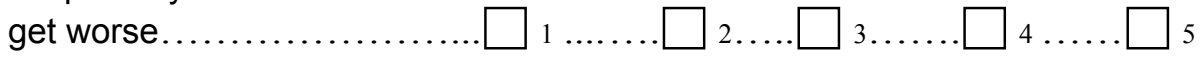

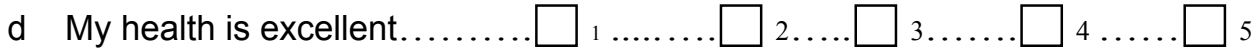


K. ANTHROPOMETRICS AND LABORATORY RESULTS

\begin{tabular}{|l|l|l|}
\hline MEASUREMENTS & RESULTS & DATE OBTAINED \\
\hline Height(ft/cm) & & \\
\hline Weight(lbs) & & \\
\hline BMI & & \\
\hline Waist & & \\
\hline Hip & & \\
\hline Waist/Hip Ratio & RESULTS & DATE OBTAINED \\
\hline TEST & & \\
\hline CD4 Cell Count & & \\
\hline Viral Load & & \\
\hline Hemoglobin & & \\
\hline Hematocrit & & \\
\hline Albumin & & \\
\hline
\end{tabular}

BODY COMPOSITION BIA RESULTS

Phase Angle

Body Capacitance

Resistance

Reactance

$\mathrm{pF}$
$\mathrm{ohm}$
$\mathrm{ohm}$

Mass Distribution

Ibs

Percent

Body Cell Mass

Extracellular Mass

Lean Body Mass

Fat Mass

Total Weight

\section{$\mathrm{ECM} / \mathrm{BCM}$}

Body Mass Index

Basal Metabolic Rate

Water Compartment

Intracellular Water

Extracellular Water

Total Body Water

TBW/Lean Body Mass

TBW/Lean Body Weight

Liters

Percent

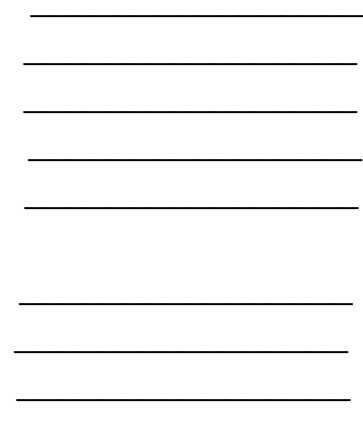


Appendix C5: Intervention Study 3-Months Follow-up Questionnaire 


\section{A. Demographic Data}

For these questions, please circle your answers or write your answers in the spaces provided.

1. Gender: $\square_{1}$ Male $\square_{2}$ Female

2. Age: years.

3. Which of the following best describes your ethnic background?

$\square$ Black/African American

Hispanic American

$\square 2$ Asian American

5 Native American $\square$ Non-Hispanic White $\square$ 6 Other (specify):

4. Status: $\square_{1}$ Married $\square_{2}$ Single $\square_{3}$ Divorced/Widowed $\square_{4}$ Other

5. Please check your highest level of education.

$\square_{1}<$ High school

$\square$ 3 1-2 years college

$\square 2$ High school or GED

$\square_{4}$ Graduated from college

6. Work Status: $\quad \square_{1}$ Not working $\square_{3}$ Work full time $\square 2$ Work Part-time, $\square_{4}$ On disability

7. What is your monthly income?

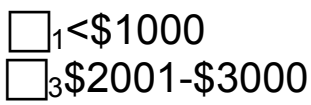
$\square_{2} \$ 1001-\$ 2000$ $\square_{4}>\$ 3001$

8. Do you live: $\square_{1}$ Alone $\quad \square_{2}$ With your family (parents, husband, children, etc) $\square_{3}$ Shelter $\square_{4}$ Street

9. Do you smoke cigarettes?

$\square_{1}$ Yes

$\square_{2}$ No

9a. If yes how often?

$\square_{1}$ Daily

$\square_{2}$ 4-6 times a week

$\square_{3}$ 2-3 times a week

$\square_{4}$ Once a week

$\square 5$ Less than once a month

$\square_{6}$ At least once a month but less than once a week

$\square_{7}$ Never

9b. If daily how many cigarettes per day

10. Do you use any drugs? $\square_{1}$ Yes $\quad \square_{2}$ No

10a.If yes please check all that apply: Marijuana $\square_{1}$ Cocaine $\square_{2}$ Crack 
$\square_{3}$ Heroin $\square_{4}$ Combination (Speedball) $\square_{5}$ Methadone

Amphetamine (Ecstasy) $\square_{7}$ Other $\square$ 8

11. Do you drink alcohol? $\quad \square 1$ Yes $\quad \square 2$ No

11a. If yes how often?

$\square_{1}$ Daily

$\square_{2}$ 4-6 times a week

$\square_{3}$ 2-3 times a week

$\square_{4}$ once a week

$\square$ Less than once a month

$\square$ 6 At least once a month but less than once a week

$\square_{7}$ Never

11b. If daily how many drinks per day?

----- Beer drinks

------ Wine drinks

------ Liquor drinks

Total drinks

12. Do you use ART? $\square_{1}$ Yes $\quad \square_{2}$ No

12a. List of medications (1)

(2)

(3)

(4)

(5)

13. Do you take multivitamins?

$\square_{1}$ Yes $\square_{2}$ No

13a. If yes please list them. 1)

2)

3)

4)

5)

14. Do you receive food stamps? $\quad \square_{1}$ Yes $\quad \square 2$ No

14a. If yes, how many months have you received food stamps in the past 12 months?

15. In the last 30 days, did you receive any foods to take home from community sources such as a food bank, food pantry, or other sources?

$\square_{1}$ Yes $\square_{2}$ No

16. In the past 30 days did you eat any meals at a soup kitchen, the Salvation Army, a family shelter, or another similar place? $\square_{1}$ Yes $\square_{2}$ No 


\section{B. Nutrition Knowledge}

Please select the best answer to each of the following questions.

1. From the following list of foods, please select the one that is highest in fiber

$\square_{1}$ kidney beans

$\square$ 2 low-fat milk

$\square_{3}$ eggs

$\square$ yogurt

2. Which of the following may help you to lower your cholesterol level?

$\square_{1}$ low fat yogurt

$\square_{2}$ oatmeal

$\square_{3}$ scrambled eggs

$\square_{4}$ croissant sandwich

3. Which of the following have the highest content of trans fats?

$\square_{1}$ coke

]$_{2}$ doughnuts

$\square_{3}$ collard greens

$\square_{4}$ baked potatoes

4. Which of the following have the highest content of saturated fat?

$\square_{1}$ low fat cottage cheese

$\square_{2}$ cooked potatoes

$\square 3$ eggs and sausages

$\square_{4}$ raw baby carrot sticks

5. Which of the following food groups contributes most to the overall saturated fat intake in the American diet?

$\square_{1}$ fruits

$\square 2$ meats

$\square 3$ dairy

$\square_{4}$ grains

6. Which of the following have the highest content of cholesterol?

$\square$ citrus fruits

2 eggs

3 low fat milk

$\square_{4}$ whole wheat flour

7. Which of the following is more likely the highest in sodium?

$\square_{1}$ low fat cottage cheese

$\square_{2}$ cooked potatoes

$\square 3$ rolled oats

$\square$ raw baby carrot sticks

8. Which of the following have the highest content of added sugar? 
$\square_{1}$ fruit salad

12 potato salad

$\square_{3}$ coke

$\square_{4}$ eggs and sausages

9. Which of the following is the recommended daily number of servings of fruits for a reference $2,000 \mathrm{kcal}$ diet?

$\square_{1}$ one $\quad \square_{2}$ two $\quad \square_{3}$ three $\quad \square_{4}$ four

10. Which of the following is the recommended daily number of cups of vegetables for a reference $2,000 \mathrm{kcal}$ diet?

$\square_{1}$ one and one half $\square_{2}$ two and one half $\square_{3}$ three and one half $\square_{4}$ four and one half

11. Adequate intake of whole grains could help me to stay prevent constipation.

$\square_{1}$ True $\quad \square_{2}$ False $\square_{3}$ I do not know

12. Regular consumption of nuts such as walnuts, pecans or peanuts helps to lower cholesterol.

$\square_{1}$ True $\quad \square_{2}$ False $\quad \square_{3}$ I do not know

13. Regular intake of flax seeds helps in reducing risk for heart disease.

$\square_{1}$ True $\quad \square_{2}$ False $\square_{3}$ I do not know

14. Cakes, cookies, crackers, are high in trans fats.

$\square_{1}$ True $\quad \square_{2}$ False $\quad \square_{3}$ I do not know

15. Trans fats may contribute to the development of a heart attack or a stroke.

$\square_{1}$ True $\quad \square_{2}$ False $\square_{3}$ I do not know

16. Olive oil is a good source of beneficial fat.

$\square_{1}$ True $\quad \square_{2}$ False $\quad \square_{3}$ I do not know

17. Heart diseases are the number one cause of death in America.

$\square_{1}$ True $\quad \square_{2}$ False $\square_{3}$ I do not know

18. Eating adequate amounts of fruits may help prevent from developing cancer.

$\square_{1}$ True $\quad \square_{2}$ False $\square_{3}$ I do not know

19. Regular intake of whole grains may help to prevent diabetes.

$\square_{1}$ True $\quad \square_{2}$ False $\quad \square_{3}$ I do not know

20. Eating foods that are high in fiber (e.g. oats, beans, fruits) may help to reduce blood cholesterol level. $\square_{1}$ True $\quad \square_{2}$ False $\quad \square_{3}$ I do not 
C. Food Frequency. I am now going to ask you questions about foods that you usually eat. For each food, I want to know whether you eat it (yes or no), and approximately how many times you eat it, (times per day, week, month).

\begin{tabular}{|c|c|c|}
\hline Do you eat ... & & $\begin{array}{l}\text { How often do } \\
\text { you eat? }\end{array}$ \\
\hline Fruits (excluding juices) & Yes / No & $d w m$ \\
\hline $\begin{array}{l}\text { Legumes (beans, chick peas, lentils, } \\
\text { pigeon peas) }\end{array}$ & Yes / No & $\ldots \mathrm{d} w \mathrm{~m}$ \\
\hline Green leafy vegetables, lettuce & Yes / No & $\mathrm{d} w \mathrm{~m}$ \\
\hline $\begin{array}{l}\text { Milk, type of milk } 4 \% 2 \% 1 \% \text { skim Other } \\
\text { type of milk }\end{array}$ & Yes / No & $\ldots \mathrm{d} w \mathrm{~m}$ \\
\hline Cheese or yogurt & Yes / No & d w m \\
\hline Meats (chicken, beef, pork, ham) & Yes / No & $\ldots \mathrm{dw}$ \\
\hline Fish and Shellfish & Yes / No & $\ldots \mathrm{d} w \mathrm{~m}$ \\
\hline Eggs & Yes / No & $\ldots \mathrm{dw}$ \\
\hline $\begin{array}{l}\text { Pasta, breads and cereals (e.g. rice, } \\
\text { spaghetti) }\end{array}$ & Yes / No & $\ldots \mathrm{d} w \mathrm{~m}$ \\
\hline $100 \%$ fruit juice & Yes / No & d w m \\
\hline $\begin{array}{l}\text { Artificial drinks (e.g. sunny delight, tang, } \\
\text { kool aid) }\end{array}$ & Yes / No & $\ldots \mathrm{d} w \mathrm{~m}$ \\
\hline Regular soft drink (e.g. Pepsi, Coke) & Yes / No & $\ldots \mathrm{dw}$ \\
\hline $\begin{array}{l}\text { Diet soft drinks and drinks with artificial } \\
\text { sweeteners }\end{array}$ & Yes / No & $\ldots \mathrm{d} w \mathrm{~m}$ \\
\hline Regular sweets and desserts & Yes / No & d w m \\
\hline $\begin{array}{l}\text { Sweets and desserts with artificial } \\
\text { sweeteners }\end{array}$ & Yes / No & $\ldots \mathrm{d} w \mathrm{~m}$ \\
\hline $\begin{array}{l}\text { Snack foods (e.g., potato chips, } \\
\text { Nachos, etc) }\end{array}$ & Yes / No & $\ldots \mathrm{d} w \mathrm{~m}$ \\
\hline
\end{tabular}


D. Where do you obtain your meals? Please check what applies the most $\square_{1}$ Home $\square_{2}$ Restaurant $\square_{3}$ Shelter $\square_{4}$ Fast Food $\square_{5}$ Other, please specify

Write down everything you had to eat and drink yesterday from the first thing in the morning until the last thing at night. Give as much detail as possible, more detail is better.

\begin{tabular}{|c|c|c|c|}
\hline Time or Meal & $\begin{array}{c}\text { Food or Beverage } \\
\text { Item } \\
\text { (Describe) }\end{array}$ & $\begin{array}{c}\text { How Much? } \\
\text { (Amount/size) }\end{array}$ & $\begin{array}{c}\text { How or } \\
\text { Where } \\
\text { Prepared? }\end{array}$ \\
\hline $\begin{array}{l}\text { Such as: } \\
\text { morning, mid- } \\
\text { morning, } \\
\text { lunch, } \\
\text { afternoon, } \\
\text { evening or } \\
\text { late evening }\end{array}$ & $\begin{array}{c}\text { List all foods or a } \\
\text { combination food. For } \\
\text { example, a taco could } \\
\text { be: } \\
\text { Corn tortilla } \\
\text { Ground beef } \\
\text { Lettuce } \\
\text { Tomato } \\
\text { Cheddar cheese } \\
\text { Sour cream } \\
2 \% \text { Milk } \\
\end{array}$ & $\begin{array}{c}\text { For the taco example it } \\
\text { could be: } \\
1 \\
3 \text { oz. } \\
1 / 2 \text { cup } \\
1 / 4 \text { cup } \\
2 \text { oz. } \\
1 \text { tablespoon } \\
1 \text { cup }\end{array}$ & $\begin{array}{c}\text { Such as: } \\
\text { Baked } \\
\text { Fried } \\
\text { Fresh } \\
\text { Broiled } \\
\text { Grilled } \\
\text { Boiled } \\
\text { McDonald's }\end{array}$ \\
\hline & & & \\
\hline & & & \\
\hline & & & \\
\hline & & & \\
\hline & & & \\
\hline & & & \\
\hline & & & \\
\hline & & & \\
\hline & & & \\
\hline & & & \\
\hline & & & \\
\hline & & & \\
\hline & & & \\
\hline & & & \\
\hline
\end{tabular}




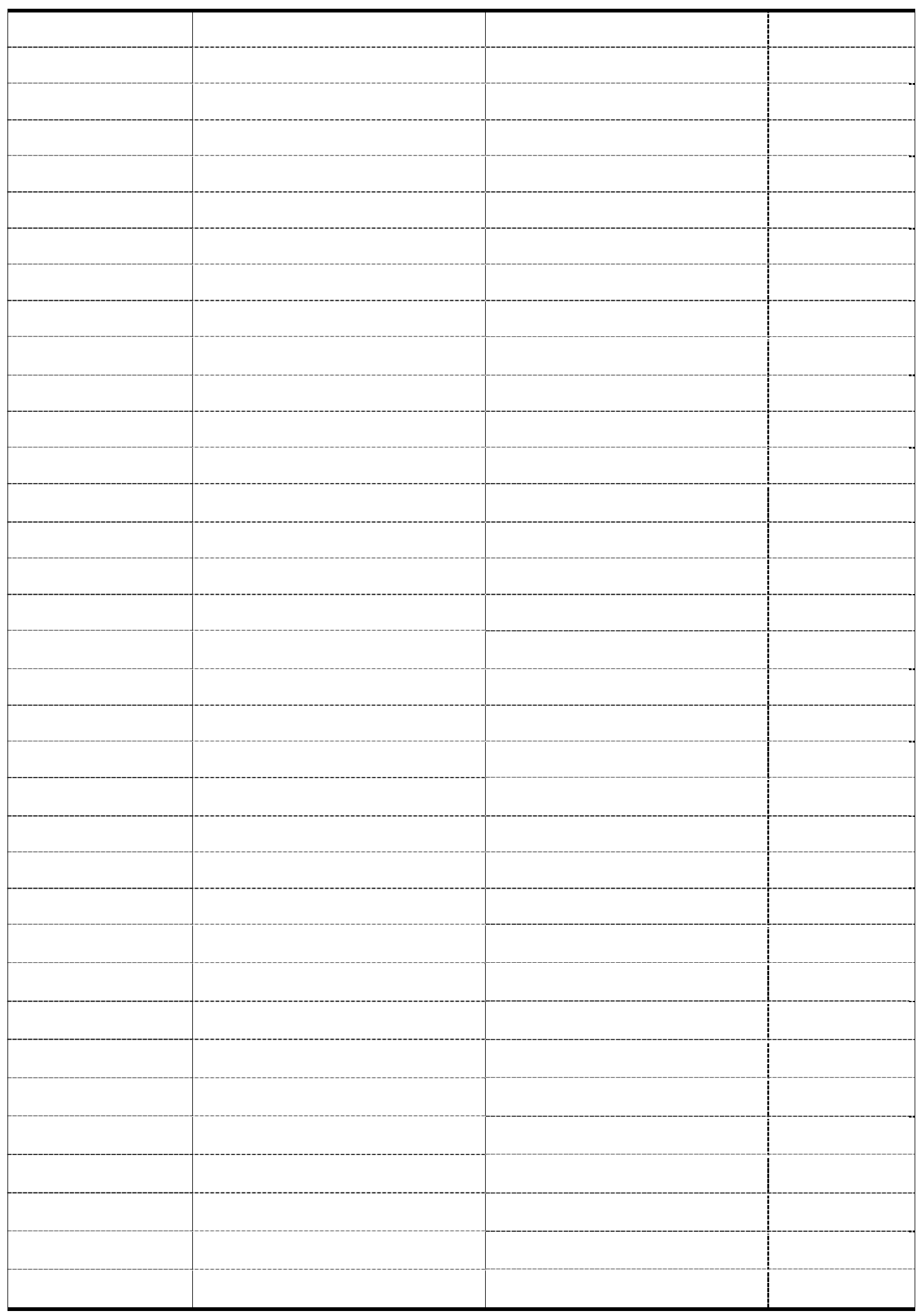




\section{E. FRUITS \& VEGETABLES: Staging}

Fruits and vegetables come in many forms: fresh, frozen, canned, dried, and $100 \%$ fruit and vegetable juices. Fruits and vegetables can be cooked or eaten raw. They can also be eaten by themselves or as part of a mixed dish such as soups or casseroles.

Use this table to help you count your fruit and vegetable servings...

COUNT AS ONE SERVING: Vegetables:

- $1 / 2$ cup of cooked or raw vegetables

- 1 cup of raw leafy greens

Fruit:

- $1 / 2$ cup or a medium sized piece of fruit

- $3 / 4$ cup of $100 \%$ fruit juice

- 1/4 cup of dried fruit

A. How many servings of fruits and vegetables do you usually eat each day? Please select one and fill in the circle.

None (Go to Question B1)

O 1 Serving (Go to Question B1)

○ 2 Servings Days (Go to Question B1)

O 3 Servings (Go to Question B1)

O 4 Servings (Go to Question B1)

O 5 Servings (Go to Question B2)

○ 6 Servings or more (Go to Question B2)

B1. Do you intend to change what you eat so you will eat at least 5 servings of fruits and vegetables every day? Please select one and fill in the circle.

No, and I don't intend to in the next 6 months (Go to Next Page)

Y Yes, and I intend to in the next 6 months (Go to Next Page)

$\bigcirc$ Yes, and I intend to in the next 30 days (Go to Next Page)

B2. You report that you have been eating 5 or more regular servings of fruits and vegetables.

For how many months have you been doing this? Please select one and fill in the circle.

$\bigcirc$ Less than 6 months

6 months or more 


\section{DIETARY FAT: Staging}

A. Do you regularly eat 5 or fewer servings of high fat foods every day? Please select one and fill in the circle.

No, I eat more than 5 servings of high fat foods per day (Go to Question B1)

$\bigcirc$ Yes, I eat 5 or fewer servings of high fat foods per day (Go to Question B2)

B1. Do you intend to change what you eat so you will eat 5 or fewer servings of high fat foods every day in the next 6 months? Please select one and fill in the circle.

No, and I don't intend to in the next 6 months (Go to Next Page)

Yes, and I intend to in the next 6 months (Go to Next Page)

Yes, and I intend to in the next 30 days (Go to Next Page)

B2. For how many months have you been eating 5 or fewer servings of high fat foods every day? Please select one and fill in the circle.

Less than 6 months

6 months or more 


\section{FIBER: Staging}

A. Do you eat regular servings of high fiber foods? Please select one and fill in the circle.

No (Go to Question B1)

Yes (Go to Question B2)

B1. Do you intend to change what you eat so you will eat more high fiber foods in the next 6 months? You can get this by eating high fiber cereals ( 5 grams/serving), breads ( 2 grams per serving), beans and legumes, fruits, and vegetables. Please select one and fill in the circle.

No, and I don't intend to in the next 6 months (Go to Next Page)

Yes, and I intend to in the next 6 months (Go to Next Page)

Yes, and I intend to in the next 30 days (Go to Next Page)

B2. You report that you've been eating regular servings of high fiber foods. For how many months have you been consuming this amount of fiber? Please select one and fill in the circle.

Less than 6 months

6 months or more 


\section{F. FRIUT AND VEGETABLE SELF EFFICACY}

There are many things that can get in the way of choosing to eat 5 fruits and vegetables each day Rate HOW CONFIDENT you are that you can do the following using the scale below.

\begin{tabular}{|l|l|l|l|l|l|}
\hline & $\begin{array}{l}\text { Not at All } \\
\text { Confident }\end{array}$ & $\begin{array}{l}\text { Somewhat } \\
\text { Confident }\end{array}$ & $\begin{array}{l}\text { Moderately } \\
\text { Confident }\end{array}$ & $\begin{array}{l}\text { Very } \\
\text { Confident }\end{array}$ & $\begin{array}{l}\text { Extremely } \\
\text { Confident }\end{array}$ \\
\hline $\begin{array}{l}\text { Eat } 5 \text { servings of fruits and vegetables } \\
\text { everyday? }\end{array}$ & & & & & \\
\hline $\begin{array}{l}\text { Drink } 100 \% \text { fruit juice instead of soda or fruit } \\
\text { punch? }\end{array}$ & & & & & \\
\hline $\begin{array}{l}\text { Eat fruits and vegetables for a snack instead } \\
\text { of chips or candy? }\end{array}$ & & & & & \\
\hline $\begin{array}{l}\text { Eat fruits and vegetables when eating out at } \\
\text { a restaurant? }\end{array}$ & & & & & \\
\hline $\begin{array}{l}\text { Eat fruits and vegetables when I am upset or } \\
\text { having a bad day? }\end{array}$ & & & & & \\
\hline $\begin{array}{l}\text { Eat fruits and vegetables when I am at a } \\
\text { social event? }\end{array}$ & & & & & \\
\hline
\end{tabular}




\section{DIETARY FIBER SELF-EFFICACY}

There are many things that can get in the way of choosing to eat foods high in fiber. Rate HOW CONFIDENT you are that you can do the following using the scale below

\begin{tabular}{|c|c|c|c|c|c|}
\hline & $\begin{array}{l}\text { Not at All } \\
\text { Confident }\end{array}$ & $\begin{array}{l}\text { Somewhat } \\
\text { Confident }\end{array}$ & $\begin{array}{l}\text { Moderately } \\
\text { Confident }\end{array}$ & $\begin{array}{l}\text { Very } \\
\text { Confident }\end{array}$ & $\begin{array}{l}\text { Extremely } \\
\text { Confident }\end{array}$ \\
\hline \multicolumn{6}{|l|}{$\begin{array}{l}\text { Choose high fiber cereals over low fiber and sugary } \\
\text { cereals? }\end{array}$} \\
\hline \multicolumn{6}{|l|}{ Avoid foods that are low in fiber? } \\
\hline \multicolumn{6}{|l|}{$\begin{array}{l}\text { Choose high fiber foods even when you are upset and } \\
\text { having a bad day }\end{array}$} \\
\hline \multicolumn{6}{|l|}{$\begin{array}{l}\text { Choose high fiber snacks instead of doughnuts or } \\
\text { cookies? }\end{array}$} \\
\hline \multicolumn{6}{|l|}{ Eat 5 servings of whole grains and beans every day? } \\
\hline \multicolumn{6}{|l|}{$\begin{array}{l}\text { Choose selections with whole grains or beans when } \\
\text { out at a restaurant? }\end{array}$} \\
\hline \multicolumn{6}{|l|}{ Regularly eat whole grain bread? } \\
\hline $\begin{array}{l}\text { Choose foods that are high in fiber when at a social } \\
\text { event? }\end{array}$ & & & & & \\
\hline
\end{tabular}




\section{DIETARY FAT SELF EFFICACY}

There are many things that can get in the way of choosing to eat a diet low in fat. HOW CONFIDENT are you that you can choose low fat foods in each situation?

\begin{tabular}{|l|l|l|l|l|l|}
\hline & $\begin{array}{l}\text { Not at All } \\
\text { Confident }\end{array}$ & $\begin{array}{l}\text { Somewhat } \\
\text { Confident }\end{array}$ & $\begin{array}{l}\text { Moderately } \\
\text { Confident }\end{array}$ & $\begin{array}{l}\text { Very } \\
\text { Confident }\end{array}$ & $\begin{array}{l}\text { Extremely } \\
\text { Confident }\end{array}$ \\
\hline $\begin{array}{l}\text { When others around you are eating high fat } \\
\text { foods. }\end{array}$ & & & & & \\
\hline When you are craving high fat foods. & & & & & \\
\hline When you are out at a restaurant. & & & & & \\
\hline When you are upset or having a bad day. & & & & & \\
\hline When you are at a social event. & & & & & \\
\hline
\end{tabular}


When you are grocery shopping how confident are you in your ability to? (check one answer for each food type)

\begin{tabular}{|l|c|c|c|c|}
\hline $\begin{array}{l}\text { How confident are you in your } \\
\text { ability to }\end{array}$ & $\begin{array}{c}\text { Not at all } \\
\text { confident }\end{array}$ & $\begin{array}{c}\text { Not } \\
\text { confident }\end{array}$ & $\begin{array}{c}\text { Somewhat } \\
\text { confident }\end{array}$ & $\begin{array}{c}\text { Very } \\
\text { confident }\end{array}$ \\
\hline $\begin{array}{l}\text { Select whole grain bread or } \\
\text { cereal in a grocery store? .. }\end{array}$ & $\square$ & $\square$ & $\square$ & $\square$ \\
$\begin{array}{l}\text { Select low fat dairy products } \\
\text { (e.g. yogurt) }\end{array}$ & $\square$ & $\square$ & $\square$ & $\square$ \\
$\begin{array}{l}\text { Select foods that are low in } \\
\text { sodium }\end{array}$ & $\square$ & $\square$ & $\square$ & $\square$ \\
$\begin{array}{l}\text { Select foods that are low in } \\
\text { saturated fat? }\end{array}$ & $\square$ & $\square$ & $\square$ & $\square$ \\
$\begin{array}{l}\text { Select foods that are low in } \\
\text { cholesterol? } \\
\text { Select foods high in dietary } \\
\text { fiber? }\end{array}$ & $\square$ & $\square$ & $\square$ & $\square$ \\
$\begin{array}{l}\text { Select foods that are low in or } \\
\text { free of trans fats? }\end{array}$ & $\square$ & $\square$ & $\square$ & $\square$ \\
\hline
\end{tabular}




\section{G. MORBIDITY}

Have you experienced any of these signs and symptoms in the last month?

\begin{tabular}{|l|l|l|}
\hline \multicolumn{1}{|c|}{ Sign and Symptom } & Yes & No \\
\hline Fever & & \\
\hline Chills & & \\
\hline Fatigue & & \\
\hline Malaise & & \\
\hline Lethargy & & \\
\hline Headache & & \\
\hline Skin Lesion or Rash & & \\
\hline Visual changes & & \\
\hline Oral Lesion & & \\
\hline Abdominal Discomfort & & \\
\hline Anorexia & & \\
\hline Dysphagia & & \\
\hline Nausea & & \\
\hline Vomiting & & \\
\hline Diarrhea & & \\
\hline Constipation & & \\
\hline Rectal or Anal Lesions & & \\
\hline Changes in weight & & \\
\hline Cough & & \\
\hline Wheezing & & \\
\hline Chest pain & & \\
\hline Difficulty breathing & & \\
\hline Shortness of breath & & \\
\hline Anemia & & \\
\hline Numbness & & \\
\hline Sharp pain & & \\
\hline Loss of coordination & & \\
\hline Impaired concentration & & \\
\hline Apathy or mood changes & & \\
\hline Seizures & & \\
\hline Dysuria & & \\
\hline Genital discharge & & \\
\hline Genital lesion & & \\
\hline Myalgia & & \\
\hline Arthralgia & & \\
\hline
\end{tabular}

H. 


\section{MEDICATION ADHERENCE QUESTIONNIARE}

This answers you give on this form will be used to plan ways to help other people who must take pills on a difficult schedule. Please do the best you can to answer all the questions. If you do not wish to answer a question, please draw a line through it. If you do not know how to answer a question, ask your study nurse to help. Thank you for helping in this important study.

PATIENT ONLY continue here.

The next section of the questionnaire asks about your HIV study medications that you took over the last four days.

Most people with HIV have many pills to take at different times during the day.

Many people find it hard to

always remember their pills:

- Some people get busy and forget to carry their pills with them. such

- Some people find it hard to take their pills according to all the instructions, stomach,"

as "with on every 8 hours," "with plenty of fluids" meals," or " an empty

- Some people decide to skip doses to avoid side effects or to just not be taking

pills that day.

We need to understand how people with HIV are really doing with their pills.

Please tell us what you are actually doing. Don't worry about telling us that you don't take all your pills. We need to know what is really happening, not what you think we "want to hear"

The next section of the questionnaire asks about the study medications that you may have missed taking over the last four days. Please complete the following table by filling in the boxes below.

A.IF YOU TOOK ONLY A PORTION OF A DOSE ON ONE OR MORE OF THESE DAYS, PLEASE REPORT THE DOSE(S) AS BEING MISSED.

\begin{tabular}{|l|l|l|l|l|}
\hline \multirow{2}{*}{$\begin{array}{l}\text { Names of your } \\
\text { anti-HIV } \\
\text { medications }\end{array}$} & \multicolumn{4}{|l|}{ How many doses did you miss } \\
\hline & Yesterday & $\begin{array}{l}2 \text { days } \\
\text { ago }\end{array}$ & 3 days ago & 4 days ago \\
\hline & & & & \\
\hline & & & & \\
\hline & & & & \\
\hline & & & & \\
\hline & & & & \\
\hline & & & & \\
\hline
\end{tabular}


B. During the past 4 days, on how many days have you missed taking all your doses?

$\square_{1}$ None $\square_{2}$ One day $\square_{3}$ Two days $\square_{4}$ Three days $\square_{5}$ Four days

C. Most anti-HIV medications need to be taken on a schedule, such as "2 times a day" or "3 times a day" or "every 8 hours." How closely did you follow your specific schedule over the last four days?

$\square_{1}$ Never $\quad \square_{2}$ Some Of The Time $\square_{3}$ About Half Of The Time $\square_{4}$ Most Of The Time $\square$ A All Of The Time

D. Do any of your anti-HIV medications have special instructions, such as "take with food" or "on an empty stomach" or "with plenty of fluids?"

$\square_{1}$ Yes $\quad \square 2$ No

If Yes, how often did you follow those special instructions over the last four days?

$\square_{1}$ Never $\square_{2}$ Some Of The Time $\square_{3}$ About Half Of The Time

$\square_{4}$ Most Of The Time

$\square$ All Of The Time

E. Some people find that they forget to take their pills on the weekend days. Did you miss any of your anti-HIV medications last weekend- last Saturday or Sunday?

$\square_{1}$ Yes $\quad \square_{2}$ No

F. When was the last time you missed any of your medications? Check one.

$\square_{1}$ Within the past week

$\square 2$ 1-2 weeks ago

$\square 3$ 2-4 weeks ago

$\square_{4}$ 1-3 months ago

$\square$. More than 3 months ago

$\square_{6}$ Never skip medications or not applicable 


\section{QUALITY OF LIFE INDEX}

\begin{tabular}{|c|c|}
\hline ACTIVITY & SCORE \\
\hline $\begin{array}{l}\text { Since the last visit, the patient: } \\
\text {-has been working or studying full-time, or nearly so, in usual occupation; or } \\
\text { managing own household, or participating in unpaid or voluntary activities, } \\
\text { whether retired or not. } \\
\text {-has been working or studying full-time, or nearly so, in usual occupation; or } \\
\text { managing own household, or participating in unpaid or voluntary activities; but } \\
\text { requiring major assistance or a significant reduction in hours worked or sheltered } \\
\text { situation or was on sick leave } \\
\text {-has not been working or studying in any capacity and not managing own } \\
\text { household }\end{array}$ & $\begin{array}{l}2 \\
1 \\
0\end{array}$ \\
\hline DAILY LIVING & SCORE \\
\hline $\begin{array}{l}\text { Since the last visit, the patient } \\
\text {-has been self-reliant in eating, washing, toileting, and dressing; using public } \\
\text { transport, or diving own car. } \\
\text {-has been requiring assistance (another person or special equipment) for daily } \\
\text { activities and transport, but performing light tasks. } \\
\text {-has not been managing personal care or light tasks, or not leaving own home or } \\
\text { institution at all. }\end{array}$ & $\begin{array}{l}2 \\
1 \\
0\end{array}$ \\
\hline HEALTH & SCORE \\
\hline $\begin{array}{l}\text { Since the last visit, the patient } \\
\text {-has been appearing to feel well or reporting feeling "great" most of the time. } \\
\text {-has been lacking energy or not feeling entirely "up to par" more than just } \\
\text { occasionally. } \\
\text {-has been feeling very ill or "lousy", seeming weak and washed out most of the } \\
\text { time or was unconscious }\end{array}$ & $\begin{array}{l}2 \\
1\end{array}$ \\
\hline SUPPORT & SCORE \\
\hline $\begin{array}{l}\text { Since the last visit, the patient } \\
\text {-has been having good relationships with others and receiving strong } \\
\text { support from at least one family member or friend. } \\
\text {-support received or perceived has been limited from family or friends or } \\
\text { by patient's condition. } \\
\text {-support from family and friends occurred infrequently or only when } \\
\text { absolutely necessary, or patient was unconscious. }\end{array}$ & 2 \\
\hline \multicolumn{2}{|l|}{ OUTLOOK } \\
\hline $\begin{array}{l}\text { During the last week, the patient } \\
\text {-has usually been appearing calm and positive in outlook, accepting and in control } \\
\text { of personal circumstances, including surroundings. } \\
\text {-has sometimes been troubled because not fully in control of personal } \\
\text { circumstances, or has been having periods of obvious anxiety or depression } \\
\text {-has been seriously confused or very frightened, or consistently anxious and } \\
\text { depressed or confused }\end{array}$ & 2 \\
\hline
\end{tabular}




\section{J. SF-36 HEALTH SURVEY \\ Your Health and Well-Being}

This survey asks for your views about your health. This information will help keep track of how you feel and how well you are able to do your usual activities. Thank you for completing this survey!

For each of the following questions, please mark an $\bigotimes$ in the one box that best describes your answer.

1. In general, would you say your health is:

\begin{tabular}{|lllll|}
\hline Excellent & Very good & Good & Fair & Poor \\
$\square_{1}$ & $\square_{2}$ & $\square_{3}$ & $\square_{4}$ & $\square_{5}$
\end{tabular}

2. Compared to one year ago, how would you rate your health in general now?

$\begin{array}{|ccccc|}\begin{array}{c}\text { Much better } \\ \text { now than one } \\ \text { year ago }\end{array} & \begin{array}{c}\text { Somewhat } \\ \text { better } \\ \text { now than one } \\ \text { year ago }\end{array} & \begin{array}{c}\text { About the } \\ \text { same as } \\ \text { one year ago }\end{array} & \begin{array}{c}\text { Somewhat } \\ \text { worse } \\ \text { now than one } \\ \text { year ago }\end{array} & \begin{array}{c}\text { Much worse } \\ \text { now than } \\ \text { one year ago }\end{array} \\ \square 1 & \square 2 & \square 3 & \square 4 & \square 5\end{array}$




\section{The following questions are about activities you might do during a typical day. Does your health now limit you in these activities? If so, how much?}

a Vigorous activities, such as running, lifting heavy objects, participating in strenuous sports

b Moderate activities, such as moving a table, pushing a vacuum cleaner, bowling, or playing golf

$\begin{array}{ccc}\begin{array}{c}\text { Yes, } \\ \text { limited } \\ \text { a lot }\end{array} & \begin{array}{c}\text { Yes, limited } \\ \text { a little }\end{array} & \begin{array}{c}\text { No, not } \\ \text { limited } \\ \text { at all }\end{array} \\ & & \end{array}$

c Lifting or carrying groceries

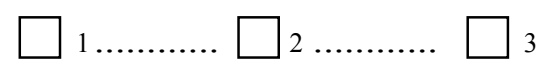

d Climbing several flights of stairs
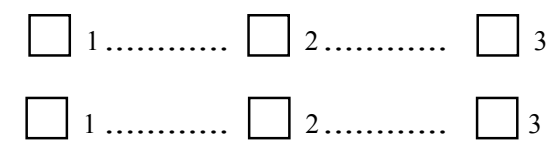

e Climbing one flight of stairs

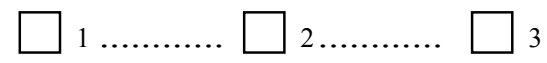

f Bending, kneeling, or stooping

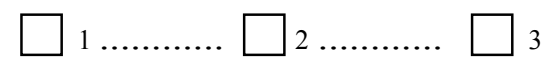

g Walking more than a mile
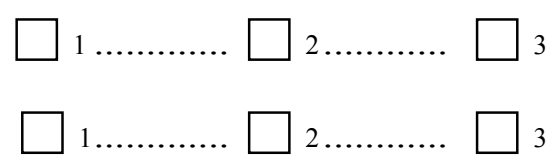

h Walking several hundred yards

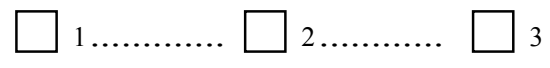

i Walking one hundred yards

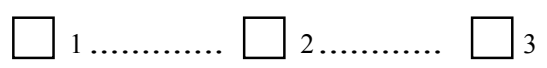

j Bathing or dressing yourself 
4. During the past 4 weeks, how much of the time have you had any of the following problems with your work or other regular daily activities as a result of your physical health?

a Cut down on the amount of

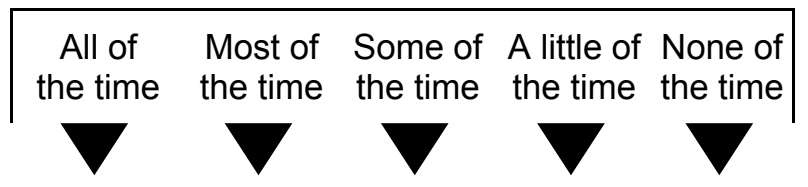
time you spent on work or

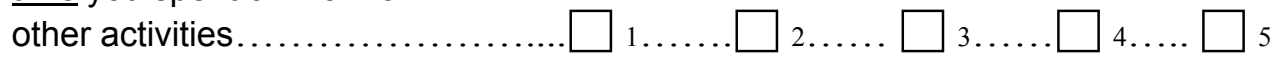

b Accomplished less than you would like.

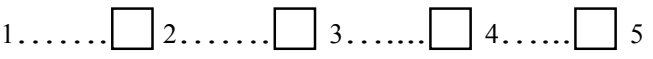

c Were limited in the kind of work or other activities. $1 \ldots \ldots . \square 2 \ldots \ldots . \square 3 \ldots \ldots \square+\ldots \ldots \square$

d Had difficulty performing the work or other activities (for example, it took extra effort).

5. During the past 4 weeks, how much of the time have you had any of the following problems with your work or other regular daily activities as a result of any emotional problems (such as feeling depressed or anxious)?

a Cut down on the amount of

$\begin{array}{cccc}\begin{array}{c}\text { All of } \\ \text { the time }\end{array} & \begin{array}{c}\text { Most of } \\ \text { the time }\end{array} & \begin{array}{c}\text { Some of } \\ \text { the time }\end{array} & \begin{array}{c}\text { Alttle of } \\ \text { the time }\end{array}\end{array}$
time you spent on work or

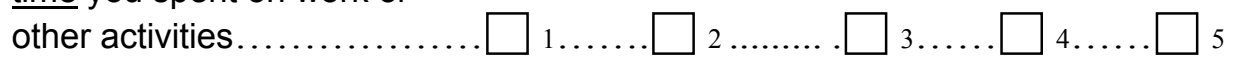

b Accomplished less than you would like. $. \square 3 \ldots \ldots \square+\ldots . . \square 5$

c Did work or other activities less carefully than usual. 
6. During the past 4 weeks, to what extent has your physical health or emotional problems interfered with your normal social activities with family, friends, neighbors, or groups?

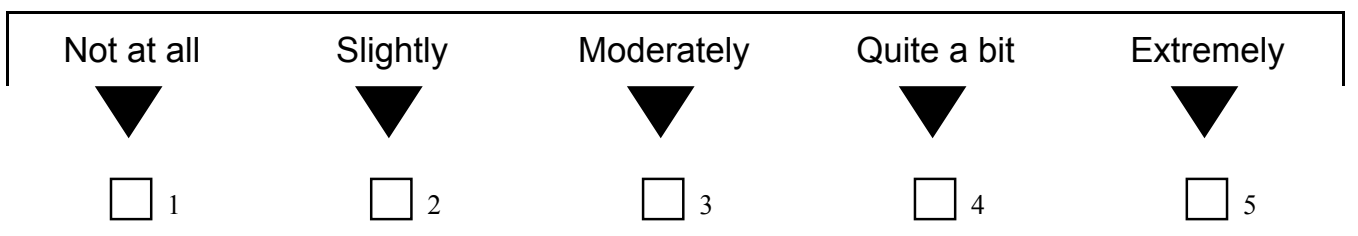

7. How much bodily pain have you had during the past 4 weeks?

\begin{tabular}{|lccccc|}
\hline None & Very mild & Mild & Moderate & Severe & Very severe \\
$\square_{1}$ & $\square_{2}$ & $\square_{3}$ & $\square_{4}$ & $\square_{5}$ & $\square_{6}$
\end{tabular}

8. During the past 4 weeks, how much did pain interfere with your normal work (including both work outside the home and housework)?

$\square_{1}^{\text {Not at all }}$


9. These questions are about how you feel and how things have been with you during the past 4 weeks. For each question, please give the one answer that comes closest to the way you have been feeling. How much of the time during the past 4 weeks...

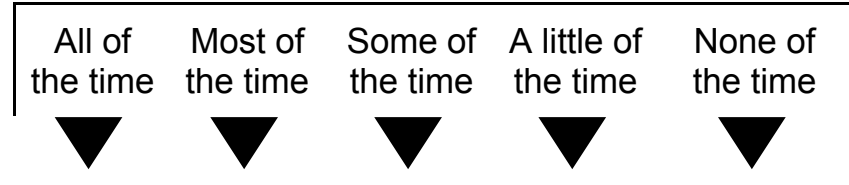
a Did you feel full of life?

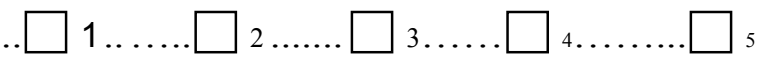

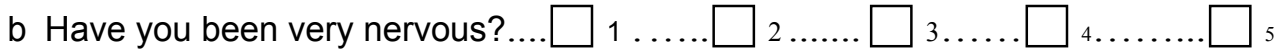
c Have you felt so down in the dumps that nothing could cheer you up?

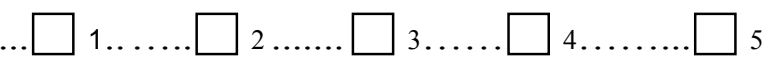
d Have you felt calm and peaceful?

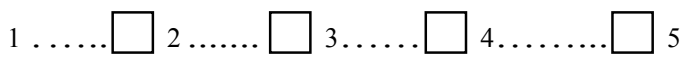
e Did you have a lot of energy?.... $\square$ 1...... $\square 2 \ldots \ldots . \square$ 3..... $\square$ 4....... $\square$ 5
f Have you felt downhearted and depressed?.
g Did you feel worn out?.............. $\square$ 1 ...... $\square 2$...... $\square \square_{3} \ldots \ldots \square$ 4........ $\square$ 5
h Have you been happy?............. $\square$ 1...... $\square 2$...... $\square \square_{3 \ldots \ldots} \square_{4 \ldots \ldots . .} \square_{5}$
i Did you feel tired?.................... $\square$ 1 ...... $\square 2 \ldots \ldots . \square{ }_{3} \ldots \ldots . \square$ 4........ $\square 5$

10. During the past 4 weeks, how much of the time has your physical health or emotional problems interfered with your social activities (like visiting with friends, relatives, etc.)?

$\begin{array}{|cccc|}\begin{array}{c}\text { All of } \\ \text { the time }\end{array} & \begin{array}{c}\text { Most of } \\ \text { the time }\end{array} & \begin{array}{l}\text { Some of } \\ \text { the time }\end{array}\end{array}$




\section{How TRUE or FALSE is each of the following statements for you?}

\begin{tabular}{|ccccc|}
\hline $\begin{array}{c}\text { Definitely } \\
\text { true }\end{array}$ & $\begin{array}{c}\text { Mostly } \\
\text { true }\end{array}$ & $\begin{array}{c}\text { Don't } \\
\text { know }\end{array}$ & $\begin{array}{c}\text { Mostly } \\
\text { false }\end{array}$ & $\begin{array}{c}\text { Definitely } \\
\text { false }\end{array}$ \\
\hline & & & &
\end{tabular}

a I seem to get sick a little

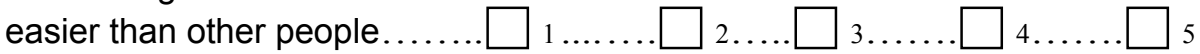

b I am as healthy as

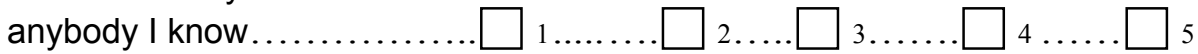

C I expect my health to

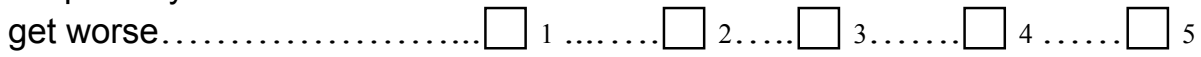

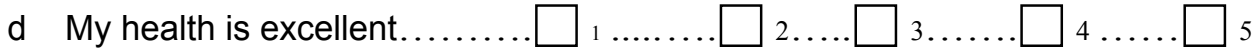




\section{K. ANTHROPOMETRICS AND LABORATORY RESULTS}

\begin{tabular}{|l|l|l|}
\hline MEASUREMENTS & RESULTS & DATE OBTAINED \\
\hline Height $(\mathrm{ft} / \mathrm{cm})$ & & \\
\hline Weight(lbs) & & \\
\hline BMI & & \\
\hline Waist & & \\
\hline Hip & & \\
\hline Waist/Hip Ratio & RESULTS & DATE OBTAINED \\
\hline TEST & & \\
\hline CD4 Cell Count & & \\
\hline Viral Load & & \\
\hline Hemoglobin & & \\
\hline Hematocrit & & \\
\hline Albumin & & \\
\hline
\end{tabular}

\section{BODY COMPOSITION BIA RESULTS}

Phase Angle

Body Capacitance

Resistance

Reactance

Mass Distribution

Body Cell Mass

Extracellular Mass

Lean Body Mass

Fat Mass

Total Weight

$\mathrm{ECM} / \mathrm{BCM}$

Body Mass Index

Basal Metabolic Rate

Water Compartment

Intracellular Water

Extracellular Water

Total Body Water

TBW/Lean Body Mass

TBW/Lean Body Weight

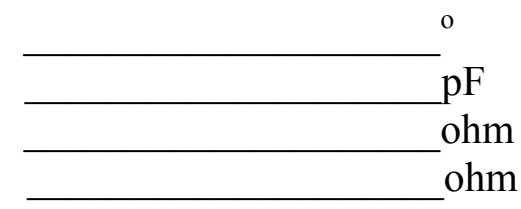

Ibs

Percent
Percent

100 
VITA

\section{IRENE E. HATSU}

2004

B.Sc., Zoology

University of Ghana

Accra, Ghana

2004-2005

Teaching Assistant

Zoology Department, University of Ghana Accra, Ghana

2005-2007

MS., Foods and Nutrition

University of Georgia

Athens, Georgia

$2005-2007$

Graduate Teaching and Research Assistant University of Georgia

Athens, Georgia

2007-2008

Public Health Nutritionist (WIC)

Georgia District 2 Public Health

Gainesville, Georgia

2008-2013

Graduate Teaching and Research Assistant Florida International University

Miami, Florida 